\title{
5 »Was lebst Du? «: Narrative der Ankunft und Integration
}

\subsection{Kultur als Ressource und die Ankunft in der Mehrheitsgesellschaft}

\begin{abstract}
Die Sprachlosigkeit und Distanz, die es in unserem Land lange zwischen der einheimischen Bevölkerung und den so genannten Gastarbeitern und ihren in Deutschland geborenen Kindern gegeben hat, ist überwunden. Ihre Eltern kamen meist in übervollen Zügen aus ihrer Heimat hier in Deutschland an. Heute, in diesem besonderen, der Kultur gewidmeten Bahnhofsgebäude können wir sagen: Sie sind bei uns, sie sind in unserer Mitte angekommen. In der neuen Heimat. Und gehören dazu. ${ }^{1}$
\end{abstract}

Mit diesen Worten schließt der damalige Innenminister Wolfgang Schäuble am 25. Juni 2009 seine Eröffnungsrede zur letzten Plenarsitzung der ersten Phase der Deutschen Islam Konferenz (DIK) im Museum Hamburger Bahnhof Berlin. Man könnte Schäubles Rekurs auf den Zug und das damit verbundene Narrativ der Ankunft auch so verstehen, dass die türkischen Migranten der ersten und zweiten Generation nach einer 50-jährigen Fahrt nun als deutsche Muslime aus dem Zug gestiegen sind. Ich selbst habe die Kapitel der vorliegenden Kulturgeschichte der Migration in der Bundesrepublik jeweils mit einer Zugfahrt und unterschiedlichen Formen der Begegnung beginnen lassen. Allerdings könnte man meinen, dass die Südländer und Gastarbeiter der 1960er und 1970er Jahre, die Türken der 1980er Jahre, die >Kanaken` der 1990er Jahre trotz aller Bewegungen, selbstbewussten Auftretens und Grenzüberschreitungen bis heute gerade nicht angekommen sind. Man könnte weiter argumentieren, dass erst eine Politik von ganz oben Integration wirklich gelingen ließe. Und tatsächlich mahnt der ehemalige Bundespräsident Johannes Rau in seiner vielbeachteten »Berliner Rede« anlässlich der Ausstellung Heimat im Haus der Kulturen der Welt neun Jahre vor Schäubles Befund, dass man die Integration nicht dem "Zufall überlassen darf «. ${ }^{2}$ Beide Reden stehen hinsichtlich Ort und Praxis in

1 SchäUble, Wolfgang (2009): Rede von Bundesminister Dr. Wolfgang Schäuble zur Eröffnung der 4. Plenarsitzung der Deutschen Islam Konferenz (DIK) am 25. Juni 2009 in Berlin. In: http:// www.deutsche-islam-konferenz.de/SharedDocs/Anlagen/DIK/DE/Downloads/Sonstiges/schaeuble-plenum4.pdf?_blob=publicationFile (07.02.2018).

2 RAU, Johannes (2000): »Ohne Angst und ohne Träumereien. Gemeinsam in Deutschland leben«. In: Berliner Rede 2000 von Bundespräsident Johannes Rau, Haus der Kulturen der Welt, Berlin, 12. Mai 2000, http://www.bundespraesident.de/SharedDocs/Reden/DE/Johannes-Rau/ Reden/2000/05/20000512_Rede2.html (19.09.2018). 
einem kulturellen Zusammenhang, worauf die Redner selbst verweisen und sich damit verorten. Daher geht es in beiden Reden nicht einfach um kulturelle Veranstaltungen. Vielmehr ist Kultur hier rhetorisch wie praktisch der Ausgangspunkt für die »schlichte Tatsache«, dass »Menschen unterschiedlicher Herkunft und Kultur in unserem Land zusammenleben « und die Integration nun »aktiv und systematisch " gefördert werden muss. ${ }^{3}$

Dazu passt, dass während der rot-grünen Regierung (1998-2005) unter Bundeskanzler Gerhard Schröder eine Änderung im Staatsangehörigkeitsrecht in Kraft tritt, die es den Kindern der Gastarbeiter ermöglicht, bis zum Ende ihres 21. Lebensjahrs beide Staatsbürgerschaften zu haben. ${ }^{4}$ Diese neue Regelung gilt ab 2001 und nur für Kinder, die ab 2000 in Deutschland geboren wurden. Bis Ende 2000 haben ausländische Kinder (Nicht-EU-Bürger), die seit über 8 Jahren in der Bundesrepublik leben und das zehnte Lebensjahr noch nicht vollendet haben, noch die Möglichkeit, den deutschen Pass zusätzlich zu ihrem ausländischen zu erhalten. ${ }^{5}$ Trotz der bestehenden Optionspflicht, sich mit Vollendung des 21. Lebensjahres für eine Nationalität $\mathrm{zu}$ entscheiden, verabschiedet das deutsche Recht damit die Denizenship. »Die Bürgerschaft lenkt den Blick jenseits des Rechts auf die gesellschaftlichen Selbstverständigungsdiskurse, die ausgeklammert zu haben ein zentrales Kennzeichen der rechtlichen Gleichstellung der Denizenship-Epoche gewesen war. ${ }^{6}$ Damit löst sich die deutsche Gesellschaft "von ihrem tradierten Verständnis, Zugehörigkeit zu und Integration in die politische Gemeinschaft von primordialen Bindungen abhängig zu machen «. ${ }^{7}$ Neben dieser Gesetzesänderung aus dem Jahr 2000 wird im Sommer 2004 im Bundestag das Zuwanderungsgesetz verabschiedet, das am 1. Januar 2005 in Kraft tritt. ${ }^{8}$

\section{Ebd.}

4 Siehe hierzu: § 29 [Wahl zwischen deutscher und ausländischer Staatsangehörigkeit bei Volljährigkeit] im Staatsangehörigkeitsgesetz (StAG), in: Ausländerrecht (2015), München: dtv, S. 534. 5 Ebd., § 40 b [Einbürgerung ausländischer Kinder], S. 539.

6 Tнум, Daniel (2018): „Vom `Fremdenrecht « über die `Denizenship` zur 〉Bürgerschaft`. Gewandeltes Selbstverständnis im deutschen Migrationsrecht«. In: Der Staat, 57 (2018), Berlin: Duncker \& Humblot, S. 77-117, S. 100.

7 EDER, Klaus/Rauer, Valentin/Schmidtke, Oliver (2004): Die Einhegung des Anderen. Türkische, polnische und russlanddeutsche Einwanderer in Deutschland, Wiesbaden: VS Verlag für Sozialwissenschaften, S. 13.

8 Leider ist in Zeitungsartikeln und anderen Texten zu diesem Gesetz nicht selten die Rede von einem »Einwanderungsgesetz«, wofür weder seine Bezeichnung »Zuwanderungsgesetz« noch seine inhaltliche Definition spricht. Siehe hierzu für viele: ŞENOCAK, Zafer (2011): Deutschsein. Eine Aufklärungsschrift, Hamburg: Edition Körber Stiftung, S. 36. Das Zuwanderungsgesetz steuert per definitionem die Zuwanderung, motiviert aber Nicht-EU-Bürger nicht zur Einwanderung in die Bundesrepublik. Im Zentrum des Gesetzes steht die Verpflichtung zu Sprach- und Integrationskursen, die sich vornehmlich auf die bereits vollzogene Migration nach Deutschland 
2006 folgen Integrationsgipfel und DIK. ${ }^{9}$ Entgegen Schäubles Erzählung hat die vorliegende Kulturgeschichte gezeigt, dass in allen hier beschriebenen und kulturanalytisch aufbereiteten Dekaden weder von einer Sprachlosigkeit noch ausschließlich von Desintegration die Rede sein kann. Unter ganz spezifischen Bedingungen war in jeder Phase möglich, Migration nach Deutschland und ihre Folgen zu thematisieren. In jedem Abschnitt gab es auf bestimmte Art und Weise ein Weitersprechen, ein Erzählen der Migration und Integration, Artikulationen einer informellen Geschichte der Migration und ihrer Folgen in der Bundesrepublik. Die Grundlagen des Erzählens wandeln sich mit den topografischen, körperlichen und zwischenmenschlichen Veränderungen von »Deutschen « und »Türken« seit den 1960ern bis heute. In allen Dekaden haben die filmischen und literarischen Erzählungen eine Analyse von Konflikten ermöglicht. Darüber hinaus waren alle bisher dargestellten Phasen von einer gestörten Kommunikation zwischen Innen und Außen bestimmt. Bereits die Analyse von Zaimoğlus Antwort auf die Frage, warum er Schriftsteller geworden sei, hat uns am Ausgang der vorliegenden Kulturgeschichte gezeigt, dass nicht klar ist, wer draußen zuhört und was dieses Draußen als Ort genau ist.

Schäuble greift zwar als Grundlage und Ziel der Islam Konferenz erneut den Aspekt des Zuhörens auf. Die Bedingung für die DIK liegt für ihn jedoch nicht in einem passiven Zuhören oder einem irritierten, aber wohlmeinenden Aufhorchen wie in den 1990ern. Es geht jetzt vielmehr darum, eine gemeinsame »Kultur des Zuhörens« zu entwickeln, wie er prononciert festhält; es ist also weder hermeneutisch wie in den 1980ern noch existenziell wie in den 1990ern konnotiert, sondern verlangt eine öffentliche und zugleich alltägliche Praxis. Denn eine weitere Bedingung zu Beginn der DIK ist es, sich endlich "gemeinsam an einen Tisch zu setzen und [...] zu sprechen ${ }^{10}{ }^{10} \mathrm{Nur}$, wie spricht man mit jemandem, der faktisch schon lange da ist, aber symbolisch erst jetzt wirklich angekommen ist und aufgenommen wird? ${ }^{11}$ So gleicht beispielsweise

seit den 1950er Jahren konzentrieren - etwa Sprach- und Integrationskurse für nachziehende Ehegatten und für Imame aus der Türkei.

9 Siehe zu Integrationsgipfel 2006: DER SPIEGEL (2006): »Integrationsgipfel. `Ein fast historisches Ereignisı«. In: DER SPIEGEL, http://www.spiegel.de/politik/deutschland/integrationsgipfel-ein-fast-historisches-ereignis-a-426823.html (19.09.2018). Siehe zu Islamkonferenz 2006 http://www.deutsche-islam-konferenz.de/DIK/DE/DIK/1UeberDIK/DIK06-09/dik06-09-node. html (19.09.2018).

10 SCHÄUBLE, Wolfgang (2006): »Muslime in Deutschland«. In: FRANKFURTER ALLGEMEINE ZEITUNG, 27.09.2006.

11 Der Religionssoziologe Levent Tezcan hat an der DIK teilgenommen. Obwohl die Sitzordnung am Tisch nicht vorgegeben war, habe sich eine solche schnell etabliert. Mitglieder der islamischen Verbände wie ZM, IRD, DITIB und VIKZ saßen als Verhandlungspartner »exakt gegenüber 
für Zafer Şenocak der Einwanderungsprozess in Deutschland, auf den die Integrationspolitik in den 2000er Jahren endlich reagiert, einem »Einschleichen « in dieses Land. ${ }^{12}$ Wenn das Zuhören um einen Tisch ergänzt wird, ist das nicht banal. Im Gegensatz zu den 1990ern sitzt man in Film und Literatur der 2000er Jahre sehr häufig gemeinsam am Tisch, um zu reden oder zu essen. Das Spektrum reicht dabei von Streit bis zu Feierlichkeiten. Damit aus dieser Geschichte des »Einschleichens « am Ende eine Geschichte der Integration oder Desintegration wird, stellen viele Filme, literarische und publizistische Texte dar, wie Türken in Deutschland leben, was sie kochen, wie sie Deutsch sprechen, ihrem Beruf nachgehen, wie sie kulturelle Marker einsetzen und sich an Gesetze halten. Insgesamt spielen Dinge, Orte und der bewusste Einsatz kultureller Marker eine wesentliche Rolle in der Verhandlung von Migration; also ganz anders als noch in den 1990er Jahren.

Im Jahr 2000 plädiert Johannes Rau dafür, sich »ohne Angst und Träumereien « einzugestehen, dass die Bundesrepublik ein Einwanderungsland sei. ${ }^{13}$ Was heißt das - vor allem hinsichtlich des bisherigen Umgangs von Deutschen, Deutsch-Türken und Türken mit Migration? Für Klaus Bade und Rainer Münz heißt das, dass sich nun »im Ansatz eine positive Migrationsdiskussion « abzeichnen müsse, die sie ihrerseits für die Bundesrepublik aktuell auch feststellen. Sie machen aber zugleich darauf aufmerksam, dass diese neue positive Wendung mit einer neuen ökonomischen und demografischen Bedarfslage in der Bundesrepublik einhergeht und zusammenhängt. Eindrücklich zeigt sich diese Konstellation etwa in den Ergebnissen der Süssmuth-Zuwanderungskommission von 2001, die die Fachkräftezuwanderung als alternativlos für den deutschen Arbeitsmarkt erklärte. ${ }^{14}$ Tatsächlich fehlen Ende der 1990er Jahre und Anfang der 2000er auf-

der Diskussionsleitung aus dem Innenministerium und dem BAMF«. Die anderen Teilnehmer hätten sich hingegen verteilt. Siehe hierzu: TEzCAN, Levent (2012): »Das strittige Kollektiv im Kontext eines Repräsentationsregimes «. In: Die Integrationsdebatte zwischen Assimilation und Diversität. Grenzziehungen in Theorie, Kunst und Gesellschaft, hg. v. Özkan Ezli, Andreas Langenohl, Valentin Rauer, Claudia Marion Voigtmann, Bielefeld: transcript, S. 159-188, hier S. 182. 12 ŞENOCAK (2011): S. 125. Ich selbst habe mich 2010 einbürgern lassen und dafür die türkische Staatsbürgerschaft aufgegeben. Obwohl ich in Deutschland geboren wurde und immer hier gelebt habe, bekam ich bei den Fragen im Ausländeramt der Stadt Bielefeld das Gefühl, mich in dieses Land eingeschlichen zu haben. Denn ich musste trotz Abitur, Hochschulstudium und Promotion im Fach Germanistik an der Universität Tübingen die mittlere Reife nachweisen, um nicht die erforderlichen Sprach- und Landeskundetests absolvieren zu müssen. Glücklicherweise hatten meine Eltern dieses Dokument aufbewahrt.

13 RAU (2000).

14 Siehe hierzu: Der SPIEgEL (2001): „Süssmuth-Kommission: Pläne für 50.000 Einwanderer pro Jahr. Die von der Bundesregierung eingesetzte Zuwanderungskommission empfiehlt Medienberichten zufolge die Aufnahme von 50.000 ausländischen Arbeitskräften pro Jahr. Und das soll 
grund des rasanten Technologiewandels besonders im IT-Bereich Arbeitskräfte. Die Bundesregierung unter Gerhard Schröder reagiert darauf mit der »Greencard«-Initiative für IT-Fachkräfte. ${ }^{15}$

Bevölkerungsrückgang sowie »demografische Alterung" der deutschen Gesellschaft sind zu Beginn der 2000er Jahre drängende Probleme. In Szenarien zur Entwicklung des Arbeitskräftepotentials in Deutschland konstatiert Bernd Hof, dass ohne die Zuwanderung in die Bundesrepublik die Einwohnerzahlen schon seit 1972 rückläufig wären. Die Bundesrepublik sei einwanderungserfahren. »Aber sie muss sich vom alten Gastarbeiterkonzept nach dem Prinzip des Kommens und Gehens abwenden und sich klar und entschieden dem Konzept des Neubürgers mit konkreten Bleibe-Angeboten zuwenden. ${ }^{16}$ Gegen diese Umwertungsvorschläge und die Initiativen der rot-grünen Bundesregierung setzt der CDU-Politiker Jürgen Rüttgers im Wahlkampf in Nordrhein-Westfalen im Frühling 2000 seinen Wahlspruch »Kinder statt Inder «. ${ }^{17}$ Einsetzen müsse, so der Migrationsreport aus demselben Jahr, eine »diskursive Entstörung und pragmatische Normalisierung des Verhältnisses von Politik zu den Themen von Migration und Integration«, die den "gesellschaftlichen Tatsachen Rechnung tragen «. ${ }^{18}$ Zwei Jahre später hält der Bundespräsident im zweiten Band des Migrationsreports fest, dass es »immer gut ist, wenn Tatsachen anerkannt werden und wenn ideologisch begründende Vorurteile nicht mehr den Blick auf die Wirklichkeit verstellen ${ }^{19}{ }^{19}$ Und er schließt seinen Text mit den Worten, dass die Wissenschaftler selber am besten wüssten, »daß Migration und Integration letzten Endes eine Sache alltäglicher Praxis sind ${ }^{20}$

nur der Anfang sein«. In: DER SPIEGEL, 29.06.2001, http://www.spiegel.de/politik/deutschland/ suessmuth-kommission-plaene-fuer-50-000-einwanderer-pro-jahr-a-142315.html (05.09.2018).

15 Astheimer, Sven (2010): »Geburtsstunde der Greencard. Als Einwanderung wieder als Gewinn galt«. In: FRANKFURTER ALLGEMEINE ZEITUNG, 01.03.2010, http://www.faz.net/aktuell/technik-motor/cebit-2010/geburtsstunde-der-greencard-als-einwanderung-wieder-als-gewinn-galt-1941918.html (25.03.2018).

16 Hof, Bernd (2001): »Szenarien zur Entwicklung des Arbeitskräftepotentials in Deutschland«. In: Aus Politik und Zeitgeschichte, B 8/2001, S. 20-30, hier S. 26.

17 DER SPIEgEL (2000): » $/$ Kinder statt Inder . Rüttgers verteidigt verbalen Ausrutscher «. In: DER SPIEGEL, 09.03.2000, http://www.spiegel.de/politik/deutschland/kinder-statt-inder-ruettgersverteidigt-verbalen-ausrutscher-a-68369.html (25.03.2018).

18 BADE, Klaus J./MüNZ, Rainer (2000): »Migration und Integration. Herausforderungen für Deutschland«. In: Migrationsreport 2000. Fakten - Analysen - Perspektiven, hg. v. dens., Frankfurt a. M.: Campus, S. 7-23, hier S. 19.

19 RAU, Johannes (2002): »Geleitwort«. In: Migrationsreport 2002. Fakten - Analysen - Perspektiven, hg. v. Klaus J. Bade, Rainer Münz, Frankfurt a. M.: Campus, S. 7-9, hier S. 7.

20 Ebd., S. 8. 
Für den Politik- und Sozialwissenschaftler Bertold Löffler ersetzt zu Beginn der 2000er Jahre das wirtschaftliche Sachzwangargument die These von der »Unvermeidbarkeit der multikulturellen Gesellschaft« der 1990er Jahre, wie letztere auch Bade, Cohn-Bendit, Habermas und Taylor publizistisch und wissenschaftlich formulierten. ${ }^{21}$ In Literatur und Film standen Artikulationen von >Kanaken ‘ oder Individuen im Vordergrund, oder der für Özdamar und Şenocak erforderliche Traum, die »negative Hermeneutik«, um die Wirklichkeit gegen die Ablehnung der Folgen der Migration in den westlichen Mehrheitsgesellschaften darzustellen. Nun sind es - das gilt, wie wir sehen werden, für Theorie, Literatur und Film in den 2000er Jahren gleichermaßen - Verhaltensweisen und Lebensstile. Die Wende führt vom Narrativ »Wie lebt es sich in Deiner Haut?«, das dem Surrealen und Imaginären freien Lauf ließ, die es möglich machten Wut und Ungeduld der 1990er Jahre zu verarbeiten, zur Frage »Was lebst Du?«, die den konkreten und realen Alltag in den Blick nimmt. Selbst in anspruchsvollen und komplexen Romanen wie Der Pavillon von Zafer Şenocak von 2009 nähert sich der Traum dem Alltag des Protagonisten, ohne diesen wie noch in den 1990er Jahren zu verfremden: Seit der Musikstudent Hamit Ende der 1950er Jahre aus der Türkei nach Deutschland gekommen war, hatte sich seine »Beziehung zu Träumen geändert«. Beim Aufwachen »erinnerte er sich an manche Schauplätze, die er im Traum gesehen hatte, und die Träume gingen mit dem Ort, an dem er lebte, eine engere Verbindung ein. Es war, als ob die Träume ihr Aroma verloren hätten. Sie waren nun nicht länger ein Teil des Reichs der Phantasie, sondern ein Teil des Lebens «. ${ }^{22}$ Diese neue Konstellation von Traum und Wirklichkeit erlaubt es Şenocaks Akteuren, sich zu verorten. Selbst wenn sie sich nur als »Stäubchen« begreifen, können sie sich mit ihren Praktiken in Deutschland oder der Türkei als »Teil einer bestimmten Gegend begreifen«, beispielsweise im Englischen Garten in München oder in einem Pavillon in Istanbul. ${ }^{23}$ Es geht in dieser Reihenfolge um Orte, um das Auftreten und darum, wofür bestimmte Handlungen stehen. In öffentlicher Debatte, Film, Literatur und Theorie rückt so auf besondere Weise eine realistische Darstellung der Gegenwart in den Vordergrund, selbst wenn sie sich, wie in den bekannten Romanen Leyla, Die Tochter des Schmieds und Der Pavillon von Feridun Zaimoğlu, Selim Özdoğan und Zafer Şenocak auf die Zeit vor der Arbeitsmigration in der Türkei konzentrieren. Zaimoğlu hat mehrere Monate in einem türkischen Dorf verbracht, bevor er seinen Roman Leyla schrieb. Er wollte den Ort, das soziale Gefüge und den Ton der Sprechweisen der Frauen studieren. ${ }^{24}$ Der Musikstudent Hamit sammelt hingegen, weil er ein unglaublich gutes

21 Siehe hierzu: LöFfLER, Bertold (2010): Integration in Deutschland, München: Oldenbourg, S. 189. 22 ŞENocaK, Zafer (2009): Der Pavillon, Berlin: Dağyeli, S. 39.

23 Ebd., S. 31 u. S. 57.

24 Siehe hierzu: EzLI (2006): S. 70. 
Gehör hat, Töne von lebendigen wie leblosen Dingen wie Kühlschränken oder Ventilatoren. In den 1990er Jahren kämpfen unterschiedliche Vorstellungen gegeneinander. Nun rückt die Frage der Darstellung als Vertretung in den Vordergrund.

Wie in Schäubles Rede prominent festgehalten, enden auch die Romane mit der Ankunft ihrer Protagonistinnen in der Bundesrepublik Deutschland. In Der Pavillon kommt Hamit in München, aber auch in Istanbul im Alltag an. Wichtig ist ihm, dass er kleine Ereignisse ebenso sehr wertschätzt wie die großen. Denn »wenn Du nicht imstande bist bei großen Geschehnissen eine Distanz zu dir selbst herzustellen, kannst du nicht verstehen, was sich um dich herum abspielt «. ${ }^{25}$ Es sind ebenfalls Orte und Dinge, die die Protagonisten in Fatih Akıns Film AUf DER ANDEREN SEITE von 2006 als Angekommene ausweisen. ${ }^{26}$ In den Romanen Mein Name ist Revolution von Imran Ayata und Der Mond ist unsere Sonne von Nuran David Calış - beide von 2011 - werden Zugehörigkeitsfragen ebenfalls über Orte und soziale Bindungen geklärt. ${ }^{27}$ In Hatice Akyüns Roman Hans mit scharfer Soße von 2005, dem deutsch-türkischen Bestseller der 2000er Jahre, sind es die Industriehochöfen von Duisburg, ihre »vielen, steilen Türme und der weiße Rauch, der in den Himmel« steigt, die in der Ich-Erzählerin nach dem alljährlich obligatorischen Türkeiurlaub mit der Familie Heimatgefühle auslösen. ${ }^{28}$ Auf das Kapitel »Reise in die Türkei« folgt »Duisburg, ich hänge an Dir «. ${ }^{29}$ Aber auch Necla Kelek erwähnt mehrmals in ihrer Autobiografie Die fremde Braut (2005), dem deutsch-türkischen Sachbuchbestseller der 2000er Jahre, dass sie nun in Deutschland angekommen sei, weil sie sich von der repressiven türkisch-islamischen Kultur emanzipiert habe. ${ }^{30}$ Diese Emanzipation wünscht sie auch den »türkischen Importbräuten«, die aus Zwang oder arrangiert von türkischen Familien nach Deutschland gelotst werden, um dort regelrecht als Haushaltssklavinnen zu arbeiten. ${ }^{31}$ Doch im Vordergrund ihres sehr bekannten, viel prämierten und zugleich sehr umstrittenen Buches steht ihre eigene Biografie. Die unterdrückte türkische Frau wünscht sie sich nicht einfach rebellisch, selbstbewusst und mitunter irrational wie in den 1990er Jahren, sondern vielmehr als eine Frau, deren Lebensstil mit dem modernen deutschen Leben kompatibel ist. Letzteres schließt ein selbstbewusstes und rebellisches Auftreten nicht aus, doch geht es Necla Kelek nicht um einen Bruch, sondern letztlich

25 ŞENOCAK (2009): S. 57.

26 Siehe hierzu: AkIn, Fatih (2006/2007): Auf der anderen Seite, Spielfilm, Deutschland.

27 Siehe: Ayata, Imran (2011): Mein Name ist Revolution, Berlin: Verbrecher. CALIş, Nuran David (2011): Der Mond ist unsere Sonne, Frankfurt a. M.: Fischer.

28 AкYÜN, Hatice (2005): Hans mit scharfer Soße, München: Goldmann, S. 60.

29 Ebd., S. 69.

30 KeLEK, Necla (2005): Die fremde Braut, Köln: Kiepenheuer \& Witsch, S. 281. Siehe hierzu auch: ebd., S. 25, 65 u. 184.

31 Siehe hierzu: ebd., S. 11 u. 244. 
um ein Leben, das die freiheitliche Verfassung der Bundesrepublik verteidigt und sichtbar macht. ${ }^{32}$ Gebrochen werden soll aber das patriarchalische unterdrückerische System, das im privaten Raum in der Bundesrepublik entstanden ist. Freiheit und Repression gehören nun gleichermaßen zu Deutschland. So ist Kelek selber auch nicht mit ihren Eltern in den 1960er Jahren in der Bundesrepublik angekommen, sondern erst, nachdem sie sich aus »unterdrückerischen« türkischen Verhältnissen in Deutschland emanzipiert hat. Wie in Schäubles Zug-Narrativ findet das Ankommen nicht in den 1960ern statt, sondern knapp 50 Jahre später unter postmigrantischen Bedingungen. Identität und Zugehörigkeit sind rein öffentliche Angelegenheiten geworden.

Die besondere Verbindung von Anfang und Ende, von Innen und Außen materialisiert sich zwei Jahre nach Schäubles Rede eindrücklich: Im Spätherbst 2011 fährt anlässlich des Festakts zu »50 Jahre türkische Gastarbeitermigration nach Deutschland« ein Sonderzug von Istanbul nach München; an Bord: Migranten der ersten Generation und Politiker. ${ }^{33}$ In der zeitnah entstandenen, bekannten und erfolgreichen Familienkomödie AlmanYa. Willkommen IN DEUTSChland der Şamdereli-Schwestern spielt die Ankunft des Gastarbeiters Hüseyin 1964 in der Bundesrepublik ebenfalls eine besondere Rolle. Er hatte, wie wir noch sehen werden, dem einmillionsten Gastarbeiter Armando Rodriguez de Sá den Vortritt bei der Registrierung gelassen. ${ }^{34}$ Im Unterschied zu KuRz UND SCHMERzLOs und GEgen die WAND kommt in Akıns Film Auf DER ANDEREN SeITE von 2007 der Protagonist Nejat im Laufe des Films an der türkischen Schwarzmeerküste an. Retrospektiv konstatiert Akın, dass mit dem Film AUf DER ANDEREN SEITE die Suche seiner Figuren zu einem Ende gekommen sei. Jetzt laufen sie nicht mehr weg, sondern verteidigen wie im zwei Jahre später entstandenen Film SouL KITCHEN, was ihnen in der Bundesrepublik gehört und wozu sie gehören. ${ }^{35}$ In SouL KITCHEN

32 Kelek leitet die erste Taschenbuchausgabe von Die fremde Braut mit der Ermordung der Deutsch-Türkin Hatun Sürücü durch ihren Bruder am 7. Februar 2005 ein. Sie habe »wie eine Deutsche leben « wollen, stellt Kelek gleich zu Beginn ihres Buches fest. Und dieser Umstand sei ihr zum »Verhängnis« geworden. Die Schüsse hätten nicht nur Hatun Sürücü gegolten, sondern mit Fokus auf ihre Lebensweise auch der deutschen Gesellschaft. Siehe hierzu: KelEK (2005): S. 9-11.

33 Siehe hierzu: BILDzeitung (2011): Sonderzug aus Istanbul erinnert an 50 Jahre Migration, 26.10.2011. Siehe auch: TAZ (2011): Sonderzug aus Istanbul. Vor 50 Jahren begann die Einwanderung türkischer Gastarbeiter nach Deutschland, 27.10.2011. Von dort ist auch Bekir Yıldız 1962 aufgebrochen, wie er es in seinem Roman Türkler Almanyada beschreibt. Siehe hierzu: YILdIz, Bekir (1966): Türkler Almanyada, Istanbul: Selbstverlag, S. 7.

34 Siehe hierzu: ŞAMDERELI (2011).

35 AKIn, Fatih/Borcholte, Andreas (2009): »Ich hatte Bock zu lachen«. In: DER SPIEGEL, 23.12.2009, http://www.spiegel.de/kultur/kino/soul-kitchen-regisseur-fatih-akin-ich-hatte-bockzu-lachen-a-668682.html (27.03.2018). 
geht es um ein Restaurant im Hamburger Gängeviertel. Tatsächlich beginnt dieser Film auch damit, wie der Protagonist Zinos Kazantsakis mit einem kleinen Transporter angefahren kommt und sein Restaurant eröffnet, in dem der Film auch endet. ${ }^{36}$ In Kemal Kurts Jugendroman Die Sonnentrinker von 2002 kehren beide Motive aus den genannten Filmen wieder. Der deutsch-türkische Jugendliche Hakan aus dem Berliner Wedding sucht wie Nejat in Auf DER ANDEREN SEITE ab der Mitte des Romans am Tag des Zuckerfestes seinen Vater in Berlin, der einen Abend davor nicht nach Hause zurückgekehrt ist. Gegen Ende des Romans findet er seinen Vater. Der Roman endet damit, dass sie zu Hause in der Wohnung zum Festessen ankommen. ${ }^{37}$ Hakan und seine Freunde haben den großen Wunsch, ein Kulturcafé im Berliner Wedding zu eröffnen. Hakan ist in Berlin unterwegs, um anzukommen. Sein Vater hingegen ist unterwegs, um »nirgendwo sein zu müssen «. ${ }^{38}$ Hakan sieht zu, »wie sein Vater läuft, bis der Akku leer ist «. ${ }^{39}$

Ähnlich aktiv ist der deutsch-türkische Protagonist in Yadé Karas 2004 mit dem Deutschen Buchpreis prämierten Roman Selam Berlin. ${ }^{40}$ Auch er will ankommen. Der Roman beginnt mit dem Mauerfall 1989, den der Protagonist mit seinen Eltern in Istanbul im Fernsehen verfolgt. Er war in Berlin aufgewachsen und geht nun wieder dorthin zurück. Auch in dieser Erzählung gibt es ein Ankommen am Ende des Romans. ${ }^{41}$ Die Protagonistin in Emine Sevgi Özdamars drittem Roman Seltsame Sterne starren zur Erde von 2004 kommt am Ende des Romans im Unterschied zu Das Leben ist eine Karawanserei (1992) und Die Brücke vom Goldenen Horn (1998) mit dem Zug an - im Zentrum der europäischen Kultur, in Paris. Zuvor hatte sie an der Volksbühne bei Benno Besson, der sie am Ende des Romans als Assistentin mit nach Paris nimmt, in Ostberlin gearbeitet und zwischen 1974 und 1976 abwechselnd in West- und Ostberlin gewohnt. Özdamars Romane der 1990er Jahre enden dagegen jeweils mit dem Beginn einer Zugfahrt. ${ }^{42}$ Erzählerisch unterscheidet sich dieser dritte Roman ebenfalls grundlegend von den beiden ersten aus den 1990er Jahren. Es geht nicht mehr um ein

36 AKIN, Fatih (2009): Soul Kitchen, Spielfilm, Deutschland.

37 Auch Akins Film beginnt mit dem muslimischen Opferfest.

38 KURT, Kemal (2002): Die Sonnentrinker, Frankfurt a. M.: Baumhaus, S. 30.

39 Ebd., S. 84. In Abdellatif Kechiches mehrfach prämierten französischen Spielfilm LE GRAINE ET LE MULET (dt. Couscous MIT Fisch) von 2007 ist ebenfalls in der Mitte des Films sehr lange ein Vater und Gastarbeiter der ersten Generation in Frankreich ohne Ziel zu Fuß unterwegs, bis er körperlich nicht mehr kann. Siehe hierzu: Kechiche, Abdellatif (2007): Couscous mit Fisch, Spielfilm, Frankreich.

40 KARA, Yade (2004): Selam Berlin, Zürich: Diogenes, S. 381.

41 Ebd.

42 Siehe hierzu: ÖzDAmar, Emine Sevgi (1992): Das Leben ist eine Karawanserei, Köln: Kiepenheuer \& Witsch, S. 380; dies. (1998): Die Brücke vom Goldenen Horn, Köln: Kiepenheuer \& Witsch, S. 330. 
Wohnen auf der Straße, sondern um das Wohnen in vier Wänden und um den beruflichen Ein- und Aufstieg im Theater. Selbst wenn sich die Ich-Erzählerin in Seltsame Sterne starren zur Erde im Laufe des Romans in den Amerikaner Steve verliebt, der sie heiraten und mit nach Amerika nehmen möchte, bleibt sie Benno Besson und der Arbeit im Theater treu. ${ }^{43}$ An die Stelle surrealistischer Ästhetik tritt wieder eine realistische Beschreibung des Zusammenlebens und Arbeitens in Berlin. Dieser neuen Koordination im Raum liegt ein zentraler Wandel in den Erzählungen zugrunde. Denn im Unterscheid zu den Erzählungen aus den 1990er Jahren ist die Schwelle, nach Bhabha der Ort der Hybridität, in den 2000er Jahren kein behaglicher Ort mehr. Eindrücklich finden wir diesen Zustand in Nuran David Caliş’ Roman Der Mond ist unsere Sonne beschrieben: Von spät nachts bis in den frühen Morgen bietet Alen als Türsteher in einer Bielefelder Disko jedem die Stirn. "21 Stufen runter in den Club, vor der ersten Stufe stehe ich, Alen, ich bin nicht drinnen und nicht draußen, mein Arsch zeigt nach innen, meine Stirn nach außen. ${ }^{44}$ In diesem unbehaglichen Schwellenzustand befindet sich Alen jedoch nicht nur bei der Ausübung seines Berufs; er fühlt sich auch generell als in ihm verhaftet. ${ }^{45}$ Auch Sprachen miteinander zu vermischen, steht nun für ein Unbehagen, nicht mehr für Weltverbundenheit. 2010 schreibt Zafer Şenocak:

Der Niedergang in einer Gesellschaft beginnt mit der Verwahrlosung der Sprache. Wenn ich heute auf den Straßen oder in der U-Bahn Jugendliche höre, die Deutsch, Arabisch, Türkisch miteinander vermischen, keiner der Sprachen wirklich zuhörend, keiner zugehörig, fühle ich eine tiefe Verletzung in mir. [...] Diese zerstückelten Sprachen sind für mich der Ausdruck einer Unbehaustheit. ${ }^{46}$

In Nurkan Erpulats vielbesprochenem und sehr erfolgreichem Theaterstück Verrücktes Blut, ebenfalls von 2010, zeugt die Kanak Sprak auch nicht mehr von der Gestaltung hybrider Identität und Existenz, sondern vielmehr von andauernder Beleidigung und Verletzung. ${ }^{47}$ Die Sprache selbst hat nichts mehr $\mathrm{zu}$ tun mit künstlerischem Ausdruck und Selbstpositionierung. Verrücktes Blut spielt in einer Klasse aus Schülern mit türkischem, arabischem und kurdischem Migrationshintergrund. Im Fazit dieses Kapitels werde ich ausführlich auf das Stück zu sprechen kommen. Zunächst will ich skizzieren, inwiefern die Debatten und

43 ÖZDAMAR, Emine Sevgi (2003): Selstsame Sterne starren zur Erde, Köln: Kiepenheuer \& Witsch, S. 180.

44 Caliş (2011): S. 30.

45 Ebd., S. 146, 185 u. 193.

46 ŞENOCAK (2011): S. 19.

47 ERPulat, Nurkan/Hillje, Jens (2012): Verrücktes Blut, Berlin: Theater Edition. 
theoretischen Reflexionen zu Migration und ihren Folgen sich im Unterschied zu den 1990er Jahren verändert haben.

»Zusammenleben« ist ein zentraler Begriff in den Debatten der 2000er Jahre. Er ist von Beginn an mit einer neuen Frage nach Öffentlichkeit, Zugehörigkeit und Identifikation verbunden. Ausgangspunkt ist die Änderung des Staatsbürgerschaftsrechts, der Übergang vom ius sanguinis (Abstammungsprinzip) zum ius soli (Geburtsortprinzip). Sie lockerte den Zusammenhang zwischen Ethnie und Staatsbürgerschaft und zielte mehr auf die »Übereinstimmung von Staatsvolk und Bevölkerung « ab. ${ }^{48}$ Türken der zweiten und dritten Generation konnten jetzt, wie oben bereits dargelegt, offiziell für eine bestimmte Zeit formell Deutsche und Türken zugleich sein. Begleitet wurde dieser Übergang in der Bundesrepublik mit der ersten Leitkultur-Debatte, die der CDU-Politiker Friedrich Merz im Herbst 2000 entfachte. In seinem Beitrag in Die Welt »Einwanderung und Identität. Zur Diskussion um die sfreiheitliche deutsche Leitkultur«" geht es ihm vor allem um die Regeln des Zusammenlebens in Deutschland: »Ich habe diese Regeln als die >freiheitliche deutsche Leitkultur bezeichnet $«{ }^{49}$ Mit dem Adjektiv »deutsch» stellt Merz sich dem Multikulturalismus der 1980er und 1990er Jahre entgegen. Aber selbst bekannte Kritiker dieser Leitkulturdebatte, wie der Rechtswissenschaftler Ulrich Preuss, sehen Anfang der 2000er Jahre »Multikulti« nur noch als Illusion an. So konstatiert Preuss in Die Zeit vom 31. Mai 2001, dass »wir [...] die durch Zuwanderung bereits entstandene, gewissermaßen bloß sinnlich-physische Anwesenheit der Fremden in den Tatbestand ihrer Zugehörigkeit zu unserer Gesellschaft verwandeln [müssen] «. ${ }^{50}$ Linken und Liberalen hält Preuss vor, dass die Einbürgerung keineswegs die alleinige Lösung sein könne. Das Hauptproblem im Multikulturalismus sei vielmehr gewesen, das hatte auch Frank-Olaf Radtke Anfang der 1990er Jahre festgestellt, ${ }^{51}$ dass die Kultur der Anderen zwar anerkannt wurde, doch alle besonderen Merkmale wie Herkunft, Religion, Hautfarbe, Sprache, Sitten und Gebräuche, »die in dem abstrakten Menschen erst das kon-

48 Rita SÜSSMUth ET AL. (2011): »Zuwanderung gestalten. Integration fördern. Bericht der Unabhängigen Kommission `Zuwanderung «. In: Transit Deutschland. Debatten zu Nation und Migration, hg. v. Deniz Göktürk u. a., Konstanz: Konstanz University Press, S. 250-252, hier S. 252. Siehe hierzu auch: EDER, Klaus/RAUER, Valentin/SchmidTKE, Oliver (2004): Die Einhegung des Anderen. Türkische, polnische und russlanddeutsche Einwanderer in Deutschland, Wiesbaden: VS Verlag, S. 13.

49 Merz, Friedrich (2000): »Einwanderung und Identität«. In: Die Welt, 25.10.2000, https:// www.welt.de/print-welt/article540438/Einwanderung-und-Identitaet.html (09.03.2018).

50 PREuss, Ulrich K. (2011): »Multikulti ist nur eine Illusion«. In: Transit Deutschland, S. 480484, hier S. 480, Hervorhebung im Original.

51 RADTKE, Frank-Olaf (1998): »Lob der Gleich-Gültigkeit. Die Konstruktion des Fremden im Diskurs des Multikulturalismus«. In: Das Eigene und das Fremde. Neuer Rassismus in der Alten Welt?, hg. v. Ulrich Bielefeld, Hamburg: Hamburger Edition, S. 79-98, hier S. 92. 
krete Individuum erkennen lassen, [...] aus der öffentlichen Sphäre ferngehalten und in den privaten Bereich verbannt « werden mussten. ${ }^{52}$ Dabei sei der befreiende Impuls verdrängt worden, der in der »Entdeckung der eigenen ethnischen Besonderheit liegen kann«. So ist nach Preuss eine Einwanderungspolitik, "die auf menschenrechtlich-universalistischen Prinzipien ruht, zwiespältig«.53 Bemerkenswert ist, dass Preuss die Kultur des Anderen nicht über den Verweis oder über die Anrufung eines universellen Menschseins ableitet, sondern explizit auf das Besondere und Spezifische zu sprechen kommt: Sexualität, Religion oder Hautfarbe. In der bereits erwähnten, großangelegten Studie wird Religion ebenfalls als eine »identitätskonstitutive Ressource« für den Alltag in der Bundesrepublik begriffen. ${ }^{54}$

Auf diese konkrete, praxeologische Ebene bezieht sich auch Talal Asad in seiner bekannten Schrift Formations of the Secular. Christianity, Islam, Modernity von 2003, in der die Folgen der Migration besonders in Europa eine wichtige Rolle spielen. Dabei geht er davon aus, dass heute der Übergang oder die Entwicklung vom Religiösen zum Säkularen, vom Traditionellen zum Modernen, nicht mehr möglich sei. In Europa, so Asad, leben zwar Muslime. Sie gehören aber nicht zu Europa, sind also inkludiert und exkludiert zugleich. ${ }^{55}$ Dieses Paradox der Integration gilt vor allem in den 1990er Jahren und wird von der Mehrheitsgesell-

52 Ebd., S. 482.

53 Preuss (2011): S. 482.

54 Siehe hierzu: Boss-NÜNnING, Ursula/KaRAKaşoğLu, Yasemin (2004): Viele Welten leben. Lebenslagen von Mädchen und jungen Frauen mit griechischem, italienischem, jugoslawischem, türkischemund Aussiedlerhintergrund, https://www.bmfsfj.de/blob/84598/2094d4132e371423945367fdf3d967f3/viele-welten-lang-data.pdf (16.03.2018), S. 483-486. Interessanterweise kommt Necla Kelek in ihrer Dissertation ebenfalls zu diesem Befund, der doch demjenigen in Die fremde Braut widerspricht. In Islam und Alltag. Islamische Religiosität und ihre Bedeutung in der Lebenswelt von Schülerinnen und Schülern türkischer Herkunft zeigt Kelek auf, dass die muslimische Religiosität kein Integrationshindernis darstelle. Im Gegenteil passen die Schüler ihre religiösen Bedürfnisse differenziert, individuell und pragmatisch an die deutschen Lebensumstände an. Sie beschreibt sie als »Experten ihrer Lebenswelt«. Siehe hierzu: KeLEK, Necla (2002): Islam und Alltag. Islamische Religiosität und ihre Bedeutung in der Lebenswelt von Schülerinnen und Schülern türkischer Herkunft, Münster: Waxmann, S. 94. Zwei Jahre später beschreibt Kelek in Die fremde Braut, die zuvor als selbstbewusst im öffentlichen Raum charakterisierten Muslime, nun als an die muslimische Umma überangepasste Akteure, die Innen und Außen nicht mehr in einen schonenden und praktikablen Ausgleich bringen. Das Kopftuch ist kein Integrationsmedium mehr, das deutschen Alltag und Religion in einen Zusammenhang bringt, sondern stellt nun in der Schule eindeutig ein Integrationshindernis dar. Die Ressource der Integration ist nun nicht mehr die individuelle Übersetzung der Religion in den Alltag, sondern die Kompatibilität der Praktiken mit dem deutschen Grundgesetz. Siehe hierz: KeLEK (2005): S. $258 f$.

55 Asad, Talal (2017): Die Ordnung des Säkularen. Christentum, Islam, Moderne, Konstanz: Konstanz University Press, S. 203. 
schaft insofern ignoriert, weil sie Europa nach Asad als einen homogenen und allgemeinen Raum denkt. ${ }^{56}$ Doch die europäische Öffentlichkeit ist, wie die amerikanische, entgegen jedem Homogenitätsnarrativ ein komplexer Raum, der sich aus den Praktiken der Vielfalt ergibt. ${ }^{57}$

Eine Reaktion auf diesen gesellschaftspolitischen Wandel besteht auch in der Gründung der Deutschen Islam Konferenz, in deren Zusammenhang Wolfgang Schäuble festhielt, dass der Islam ein Teil von Deutschland sei und er sich auf der Grundlage des Grundgesetzes als Werteordnung deutsche Muslime wünsche. ${ }^{58}$ Vier Jahre später wiederholt der damalige Bundespräsident Christian Wulff in seiner Rede am Tag der Deutschen Einheit, dass der Islam »inzwischen « auch zu Deutschland gehöre. ${ }^{59}$ Die Reaktion darauf ist gespalten. Neben der Zustimmung muslimischer Verbände und Einrichtungen kommt viel Kritik besonders aus CDU und CSU. Der Tenor der Kritik lautet, dass die Muslime zwar zu Deutschland gehörten, aber nicht der Islam. Im Kern geht es hier um Werte: »Unsere Werteordnung, zu der auch die Religionsfreiheit gehört, müssen wir erhalten. Der Islam kann diese Werteordnung nicht bestimmen«, meint Volker Kauder fünf Tage nach Wulffs Rede. ${ }^{60}$ Nicht als Kritik oder als Reaktion, sondern als Befund hält der neue Innen- und Heimatminister Horst Seehofer im Jahr 2018 fest, dass der Islam nicht zu Deutschland gehöre, aber die »bei uns lebenden Muslime gehören selbstverständlich zu Deutschland «. ${ }^{61}$ Bundeskanzlerin Angela Merkel entgegnete, dass mit den Muslimen auch ihre Religion zu Deutschland gehöre. In all diesen Fällen geht es um Zugehörigkeitsfragen, die in den 1990er Jahren weder von deutscher noch von türkischer Seite auf diese Weise verhandelt wurden. ${ }^{62}$ Bereits an dieser Debatte wird deutlich, dass in den

56 Siehe hierzu: WeHLER, Hans-Ulrich (2002): »Das Türkenproblem«. In: DIE ZEIT, 12.09.2002, http://www.zeit.de/2002/38/200238_tuerkei.contra.xml (27.03.2018).

57 Ebd., S. 220-222.

58 Die Welt (2006): »Schäuble: Islam in Teil Deutschlands«. In: Die Welt, https://www.welt.de/ politik/article156022/Schaeuble-Islam-ist-Teil-Deutschlands.html (16.03.2018).

59 WulfF, Christian (2010): „Vielfalt schätzen. Zusammenhalt fördern«. In: http://www.bundespraesident.de/SharedDocs/Reden/DE/Christian-Wulff/Reden/2010/10/20101003_Rede.html (27.03.2018).

60 DeR SPIEgEL (2010): »Kritik an Wulffs Islam-Thesen. Unionsfraktionschef Kauder legt nach«. In: DER SPIEGEL, http://www.spiegel.de/politik/deutschland/kritik-an-wulffs-islam-thesenunionsfraktionschef-kauder-legt-nach-a-722155.html (16.03.2018).

61 Frankfurter Allgemeine Zeitung (2018): „Seehofer: >Der Islam gehört nicht zu Deutschland««. In: FRANKFURTER ALLGEMEINE ZEITUNG, http://www.faz.net/aktuell/politik/inland/ horst-seehofer-islam-gehoert-doch-nicht-zu-deutschland-15496891.html (16.03.2018).

62 Wolfgang Schäuble selbst hat als Bundestagspräsident am 18. März 2018 in einem Interview seine Aussage, dass der Islam ein Teil Deutschlands sei, erneut bekräftigt. Siehe hierzu: WolfGANG SCHÄUBLE IM GESPRÄCH MIT STEPHAN DETJEN (2018): »Bundestagspräsident Wolfgang Schäuble. ,Wir fangen ja jetzt erst mit dem Normalbetrieb an««. In: Kulturfragen - Deutschlandfunk, 18.03.2018. 
2000er Jahren eine Verschiebung stattgefunden hat. Das Private, die kulturelle Eigenart, ist vom allgemeinen Öffentlichen nicht mehr zu trennen.

Auch Jürgen Habermas revidiert seinen Zugang zu politischer und kultureller Integration sowie zur Verknüpfung von Öffentlichkeit und Einwanderungsgesellschaft aus den 1990er Jahren. Wie viele andere Studien aus dieser Zeit begreift auch er Religion als eine sinnstiftende Ressource für den öffentlichen Raum. ${ }^{63}$ Entgegen seiner früheren Trennung von politischer und kultureller Integration hält er in Dialektik der Säkularisierung nun fest, dass die muslimischen Einwanderer nicht gegen »ihre Religion, sondern nur mit ihr in eine westliche Gesellschaft integriert werden« könnten. ${ }^{64}$ Mit Blick auf aktuelle europäische Integrationspolitiken stellt er außerdem einen bestimmten staatlichen Denk- und Konstitutionsfehler in der langen Geschichte der europäischen Säkularisierung und Modernisierung fest: Religion als Partizipations- und Sinnstifter aus dem öffentlich-politischen Raum ausgeschlossen zu haben. ${ }^{65}$

Den Anfang nahm dieser Ausschluss nach Habermas mit den Konfliktschlichtungen nach den europäischen Konfessionskriegen im 16. und 17. Jahrhundert, in denen Staatsgewalt $\mathrm{zu}$ »weltanschaulich neutralem « Handeln genötigt war. Die streitenden Parteien mussten entwaffnet und ein Arrangement für ein friedliches Zusammenleben der verfeindeten Konfessionen musste gefunden werden, so dass die Regierung das prekäre Nebeneinander beobachten konnte. Daraus folgte nach Habermas, dass in »der Gesellschaft sich die gegnerischen Subkulturen dann so einnisten [konnten], dass sie füreinander Fremde blieben $"{ }^{66}$ Diese Lebensweise überdauerte auch die grundlegend säkularistische Neuordnung des Staates in Europa im späten 18. Jahrhundert und hat mitunter dazu geführt, dass die katholische Kirche sich »bekanntlich erst mit dem zweiten Vaticanum im Jahre $1965 \mathrm{zu}$ Liberalismus und Demokratie bekannt hat «. ${ }^{67}$

Dieses Nebeneinander und das »Einnisten-lassen« zeige sich auch im »falsch verstandenen« Multikulturalismus der 1980er und 1990er Jahre, in dem man von einer »Inkommensurabilität` von Weltbildern, Diskursen oder Begriffsschemata« ausgegangen sei. ${ }^{68}$ Für eine erfolgreiche Integrationspolitik sei ein anderes Verhältnis von demokratischem Staat, Zivilgesellschaft und subkultureller Eigenstän-

63 Siehe hierzu: Boss-NÜNNING/KARAKAŞoğLU (2004).

64 HABERMAS, Jürgen (2008): »Die Dialektik der Säkularisierung«: In: Blätter für deutsche und internationale Politik, Einzelheft 04/2008, S. 33-46, S. 41.

65 Dasselbe kritisiert auch Asad. Er kommt dazu besonders in Auseinandersetzung mit Charles Taylors Definition von säkular-liberal bestimmten Gesellschaften. Siehe hierzu: AsAD, Talal (2017): Die Ordnungen des Säkularen. Christentum, Islam, Moderne, Konstanz: Konstanz University Press, S. 11.

66 HABERMAS (2008): S. 39, Hervorhebung im Original.

67 Ebd., S. 44.

68 Ebd., S. 42. 
digkeit nötig. Dafür müssten die »Kulturen ihre individuellen Mitglieder aus der Umklammerung entlassen, damit diese sich in der Zielgesellschaft gegenseitig als [...] Träger und Mitglieder desselben politischen Gemeinwesens anerkennen können $«{ }^{69}$ Es geht also um eine Bindung von Staats- und Gesellschaftsbürger, die den alteingesessenen Deutschen und muslimischen Zuwanderern erlaubt, das Verhältnis von Glauben und Wissen selbst zu interpretieren, was in der Folge »ein selbstreflexiv aufgeklärtes Miteinander möglich macht «. ${ }^{70}$ Habermas hofft darauf, dass eine erweiterte Selbstreflexion die Strukturen von Parallelgesellschaften aufzubrechen vermag. Diese Selbstreflexion sei jedoch in einer postsäkularen Zeit ohne Religion nicht mehr zu denken. Für Talal Asad steckt in diesem Umstand eine »unaufgelöste Spannung«. Er fragt: »Wie kann Respekt gegenüber Individuen sichergestellt und zugleich begünstigt werden, dass Zustände herrschen, in denen kollektive >Lebensweisen ` aufrechterhalten werden können? « ${ }^{71}$ Wie Habermas geht es Asad dabei nicht mehr um Fragen der Anerkennung, »nicht bloß darum, dass man die Möglichkeit haben sollte, sich als Angehöriger einer Gruppe zu erkennen $\mathrm{zu}$ geben und von anderen in dieser Zugehörigkeit bestärkt und geachtet zu werden «. ${ }^{72}$ Denn im öffentlichen Raum haben wir es mit den Praktiken als »verkörperte Erinnerungen « zu tun, »die sich zu Traditionen verdichtet haben«. Im Kern geht es nicht mehr darum, wie Identitäten ausgehandelt und anerkannt werden, sondern darum, "was erforderlich dafür ist, dass bestimmte Lebensweisen kontinuierlich, kooperativ und unbefangen gelebt werden können.$^{73}$ Nicht Kulturen als Einheiten interessieren Asad, sondern vielmehr die Produktion von Kategorien »des Säkularen und des Religiösen, die vorgeben, wie modernes Leben sich zu gestalten hat, und die zugleich nicht-moderne Völker dazu herausfordern, ihre Eignung für ein solches Leben abzuschätzen ${ }^{74}{ }^{74}$ Das ist etwas anderes als die Vorstellung einer Entwicklung aus einem traditionellen Leben in ein modernes hinein. Man fragt vielmehr, wozu man mit seinem gelebten Leben gehört und wie aus dieser Verortung heraus kulturelle Kompromisse und Kompatibilitäten entstehen können. Bedingung dafür ist nach Asad, dass die Muslime sich in Europa verorten können.

Diese neue Ordnungspolitik verbindet privaten und öffentlichen Raum und setzt sie zugleich in ein neues Verhältnis. Wenn beispielsweise politische und kulturelle Integration über die Modi der Anerkennung und des kulturellen Überlebens in den 1990er Jahren getrennt voneinander behandelt wurden, werden sie nun über

69 Ebd., S. 39.

70 Ebd., S. 46.

$71 \operatorname{ASAD}(2017):$ S. 219.

72 AsAD (2017): S. 219, Hervorhebung im Original.

73 Ebd.

74 Ebd. S. 22. 
die Praktiken, also über Integration und Kultur, aufs Engste zusammengeführt. Dieser Wandel hat besonders im Kontext der Deutschen Islam Konferenz zu gewissen politischen Verengungen geführt. Der bereits zitierte Levent Tezcan hält fest, dass die DIK in ihren Effekten tatsächlich insofern performativ gewesen sei, als ihr Ziel die Fabrikation des kritischen und aufgeklärten Muslims gewesen sei. Personen sowie Gruppen, »die sich nie über die Religion definierten, [mussten] sich auf den Diskurs >Dialog mit Muslimen` einlassen«. Individualisten hätten keine Islamkonferenz veranstaltet. »Ihr Glaube zielt nicht auf Repräsentation: sie pflegen eine Version von Islam, die eben ohne Repräsentation auskommt. “ ${ }^{75}$ Gerhard Schröders integrationspolitischer Imperativ von 2000, »Verfassung achten, die Gesetze befolgen und die Landessprache beherrschen «, genügt hier nicht mehr. ${ }^{76}$ Die DIK und die Debatten nach dem 11. September 2001 rücken neben den sozialdemokratisch geprägten wohlfahrtstaatlichen Diskursen über Ausländerintegration den von der CDU geführten Islam-Diskurs in den Vordergrund.

Auch auf der Objektseite dieser Diskurse lässt sich eine Verschiebung beobachten. Nicht der Gastarbeiter oder Ausländer zwischen den Stühlen, dem man noch mit ökonomischen und pädagogischen Mitteln zur Integration verhelfen konnte, sondern der Muslim mit einer spezifischen Lebensform ist der Gegenstand politischer Sorge. ${ }^{77}$

Dabei geht es darum, die »Berechenbarkeit, Kompatibilität einer Bevölkerungsgruppe und ihrer Wertorientierungen ${ }^{78}$ sicherzustellen. Dass es kulturell grundsätzlich inkompatible Ebenen geben könnte, wie im Multikulturalismus behauptet, steht hier nicht zur Debatte. Denn Ziel des Diskurses ist es, »die friedlichen Muslime als Gegner des islamistischen Extremismus zu gewinnen «. ${ }^{79}$ Diese spezifische Form der Integrationspolitik macht der Religionssoziologe Bryan S. Turner zu Beginn und Mitte der 2000er Jahre für den westeuropäischen Raum insgesamt aus. Den Islam teilt er dabei auf in upgrading (»moderate Muslims«) und enclaving Islam (»extremist Muslims«). Den kritischen und kompatiblen Islam gilt es zu fördern, den potentiell fundamentalistischen und extremistischen über Präventionsmaßnahmen zu fixieren und einzuschließen. ${ }^{80}$ In dieser staatspolitischen Richtung hält Tibi im Sommer 2002 im Tagesspiegel bereits fest, dass seit dem

75 TEZCAN (2012): S. 183.

76 LÖFFLER (2011): S. 182.

77 Tezcan, Levent (2012a): Das muslimische Subjekt. Verfangen im Dialog der Deutschen Islam Konferenz, Konstanz: Konstanz University Press, S. 163f.

78 Ebd., S. 165.

79 Ebd., S. 167.

80 Siehe hierzu: TuRnER, Bryan S. (2007): »Managing Religions. State Responses to religious Diversity«. In: Content Islam, 2007/1, S. 123-137. 
11. September 2001 eines feststehen würde: »dass das Erlernen der Sprache allein noch kein Indikator für eine gelungene Integration ist«. Muhammad Ata sprach perfekt Deutsch. ${ }^{81}$ Gegen eine solche Politik der Durchleuchtung und die »fieberhafte Suche des Westens nach dem ıgemäßigten Muslim« « wendet sich Amartya Sen in seiner bekannten und vielzitierten Publikation Die Identitätsfalle. Man verwechsele in dieser Angelegenheit die »Mäßigung in den politischen Anschauungen « mit der »Gemäßigtheit« des religiösen Glaubens. Denn jemand »kann einen starken - islamischen oder anderen - religiösen Glauben und zugleich eine tolerante politische Einstellung haben ${ }^{82}$ Diese Gleichberechtigung von Inkompatiblem steht in den 2000er Jahren nicht mehr zur Disposition. Ein ordnungsund verfassungsnahes Leben geht auch mit toleranten Positionierungen einher.

Daher geht auch der Kulturbegriff in den 2000er Jahren über die integrationspolitische Ebene hinaus. Kultur wird zu einem allgemeinen Beobachtungsschema von Praktiken. Kulturwissenschaftlich vertritt diese Position Dirk Baecker in seiner bekannten Publikation Wozu Kultur? von 2003. An die Stelle der interkulturellen Kompetenz, die hilft, auf Vorurteilen basierende Asymmetrien abzubauen und ein Verstehen oder ein Anerkennen des Anderen zu entwickeln, setzt er auf die kulturelle Kompetenz, mit der alle möglichen Praktiken und Verhaltensweisen verglichen werden könnten. ${ }^{83}$ Baecker will ein Beobachtungsverfahren entwickeln, das Kultur nicht anhand von Herkunft und Gesetzen beschreibt, sondern als einen Möglichkeitsraum, durch den sie von der Ankunft her gedacht wird. Diese Idee findet sich auch in politischen, literarischen und filmischen Erzählungen der Migration der Zeit. ${ }^{84}$ Allen geht es darum, unterschiedliche

81 TiBI, Bassam (2002): „Zwischen den Welten. Wir müssen den hier praktizierten Islam verwestlichen, so wie Deutschland nach 1945 verwestlicht worden ist«. In: Transit Deutschland, S. 303-307, hier S. 305. Auch Zafer Şenocak begreift die Funktion der Sprache Mitte der 2000er anders als noch in den 1990er Jahren. Die Übersetzung diente beispielsweise in Gefährliche Verwandtschaft dazu, mit literarischen Mitteln Inkompatibilität herzustellen; Şenocak wollte mit dem öffentlich machen der Herstellung von Inkompatibilität zeigen, dass es an sich keine Trennung der Kulturen gibt. Am 20. Juli 2005 schreibt er hingegen in Die Welt, dass antipodisch zueinander stehende Welten eine »übersetzende Kraft« bräuchten. Der Zweck der Übersetzung liege dabei »nicht in der Nivellierung von Unterschieden, wohl aber im Transfer von unterschiedlichen Deutungen«. Jede Übersetzung ist für Şenocak nun »eine Deutung, die Beleuchtung eines Begriffs aus unterschiedlichen Perspektiven. Wenn die Leuchtkraft abnimmt, bleibt vieles im Dunkeln. Aus dem Dunklen wachsen Ängste und Aggressionen.« Siehe hierzu: ŞEnocaK, Zafer (2005): »Die Hilflosigkeit des religiösen Dialogs«. In: Die Welt, https://www.welt.de/print-welt/ article683574/Die-Hilflosigkeit-des-religioesen-Dialogs.html (09.03.2018).

82 SEN, Amartya (2007): Die Identitätsfalle. Warum es keinen Krieg der Kulturen gibt, München: Beck, S. 31.

83 Siehe hierzu: BAECKER, Dirk (2003): Wozu Kultur?, Berlin: Kadmos.

84 Siehe hierzu: Ebd., S. 31. 
Praktiken zu vergleichen. Das heißt aber auch, dass sich der Möglichkeitsraum von Kultur zuvorderst aus neuen Praktiken und nicht aus neuen Sprechweisen oder neuen Verstehenszusammenhängen ergibt. Die Sichtbarkeit im öffentlichen Raum ist ausschlaggebend..$^{85}$

Für die bekannten Soziologen und Ethnologen Andreas Wimmer und Rogers Brubaker stehen ethnische Gruppenbezeichnungen und Identitätsbestimmungen ebenfalls am Ende von sozialen Prozessen, nicht an deren Anfang. »Kultur« begreift Wimmer weder als "Setzung" noch als einen "anonymen Diskurs" oder einen »Kontraktersatz«. ${ }^{86}$ Einem klassischen und postmodernen Kulturbegriff entgegengesetzt, mit dem sich intrakulturelle Varianzen analytisch nicht beschreiben ließen, definiert Wimmer 2005 Kultur als »einen offenen und instabilen Prozeß des Aushandelns von Bedeutungen, der im Falle einer Kompromissbildung zur Abschließung sozialer Gruppen führt«. ${ }^{87}$ Wie Asad geht auch Wimmer von der im Akteur verinnerlichten Kultur aus. Er bedient sich für seine Theorie der Grenzziehungen eines modifizierten Habitusbegriffs, der »zwischen einer Theorie zweckrationalen Handelns und dem Modell normativ-kultureller Prägung vermitteln« soll. ${ }^{88} \mathrm{Am}$ Ende des Prozesses zwischen Innen und Außen, zwischen Prägung, Interessen und den Prägungen und Interessen des Anderen

85 Der Historiker und Kulturwissenschaftler Jörn Rüsen möchte zur selben Zeit wie Dirk Baecker einen Zugang zu Geschichte und Erinnerung entwickeln, der »den Sinn der Geschichte von einer Zukunft her erschließt«. Der Weg zur Geschichte als kulturelle Orientierungsressource setze zunächst »schlicht und einfach durch Erzählen« ein, durch das Sichtbarwerden dessen, was geschehen sei. Der »vor Augen gerückte Schrecken muß als Erfahrung so durchgearbeitet werden, daß er zur Handlungsmotivation für sein Gegenteil wird, d. h. sich als Schubkraft für Sinnbildung auswirkt«. Bedingung für diese Arbeit an der Vergangenheit ist für Rüsen, dass die historische Analyse im Gegensatz zur traditionellen Geschichtsforschung auf die Zukunft ausgerichtet ist und nicht auf Herkunft und Ursprünge. RÜSEN, Jörn (2002): Kann gestern besser werden? Essays zum Bedenken der Geschichte, Berlin: Kadmos, S. 20; S. 42 u. S. 44. Tatsächlich spielt die Geschichte der Migration in den filmischen und literarischen Erzählungen der 2000er Jahre, vor allem als soziales Gedächtnis, eine herausragende Rolle, wie noch zu zeigen sein wird. »Soziales Gedächtnis« ist nach Aleida Assmann abhängig von Interaktionen und Erinnerung der Akteure, die es weitergeben. »Mit dem Tode der lebendigen Träger löst sich ein soziales Gedächtnis immer wieder auf.« Von dieser Form des Gedächtnisses unterscheidet Assmann das kollektive Gedächtnis, das sich in der Regel durch staatstragende Rituale konstituiert und historische Ereignisse lediglich aus einer einzigen und spezifisch interessierten Perspektive wahrnimmt. Im Unterschied zum sozialen Gedächtnis erlaubt es keine Mehrdeutigkeit der Ereignisse und »reduziert sie auf mythische Archetypen«. Siehe hierzu: AssmanN, Aleida (2007): Geschichte im Gedächtnis. Von der individuellen Erfahrung zur öffentlichen Inszenierung, München: Beck, S. 19.

86 Wimmer, Andreas (2005): Kultur als Prozess. Zur Dynamik des Aushandelns von Bedeutungen, Wiesbaden: Verlag für Sozialwissenschaften, S. 13.

87 Ebd., S. 32.

88 Ebd., S. 34. 
steht bei Wimmer ein »kultureller Kompromiss«, auf den erst der Akt der sozialen Schließung folgt und mit ihm die ethnische Selbstbeschreibung. Dieser Form kultureller Verhandlungen durch Interaktionen gehen historische Transformationen und Diffusionen kultureller Ordnung voraus. Der »Strukturzyklus« von Prägung, Aushandlung und Kompromiss gelangt $\mathrm{zu}$ seinem Höhepunkt, wenn dieser Prozess ein »Maximum an Gestaltungskraft und Ausdifferenzierung erreicht«. Da aber Kultur Prozess bleibt, mündet dieser Zustand dann wieder in »eine Phase konfliktiver Auseinandersetzungen, welche wiederum den Boden für einen neuformulierten und rekonstruierten kulturellen Kompromiß bereiten «. ${ }^{89}$

Der am Ende genannte Verweis auf den »Boden« fällt nicht zufällig, denn nach Wimmer ist für einen gelingenden Aushandlungsprozess ein »neues Verhältnis zur Territorialität« nötig. Individuen können auch einzeln auf »Wanderschaft« gehen, schreibt Wimmer weiter, »weil sie eine reflexive Distanz zu den eigenen kulturellen Prägungen [einnehmen] und diese kreativ neu zu interpretieren vermögen ${ }^{90}{ }^{90}$ Dies bezeichnet Wimmer als »Pragmatik der kulturellen Produktion«. Diese Koordination im Raum und auf Territorien ist in Filmen und literarischen Texten jener Zeit ebenfalls konstitutiv. Wir werden noch sehen, welch besondere Bedeutung Landschaften, Orte, Straßen und Dinge in Relation mit kulturellen Markern in den Erzählungen einnehmen. Anders als in den 1990ern wissen wir als Zuschauer und Leser fast immer, wohin die Akteure gehen und aus welchem Grund. Dieses Wissen rahmt die erzählten Geschehnisse. Die Erzählungen entwickeln zwar eine reflexive Distanz zu kulturellen Markern, doch ohne diese, wie in den 1990er Jahren, in Frage zu stellen oder zu unterlaufen. ${ }^{91}$ Die Perspektive ist vielmehr vom Umgang mit kulturellen Unterscheidungsmerkmalen bestimmt.

Wie Andreas Wimmer schlägt auch Rogers Brubaker vor, ethnische Gruppenbezeichnungen als Ergebnisse sozialer Prozesse zu verstehen. Die »machtvolle Kristallisation des Gruppengefühls« resultiere aus einer »Praxis der Verdinglichung «. ${ }^{92}$ So könnten Ethnizität, Rasse oder Nation »nicht auf wesenhafte Gruppen oder Gebilde bezogen« werden. Auch hier sind es "praktische Kategorien, situatives Handeln, kulturelle Redensarten, kognitive Schemata, diskursive Deutungsmuster, organisatorische Routine, institutionelle Formen, politische Projekte und zufällige Ereignisse«, die bestimmen, was Ethnizität und Kultur sind. Brubaker geht so weit zu behaupten, dass Ethnizität bereits Kognition sei,

89 Ebd., S. 47.

90 Ebd., S. 48.

91 Siehe hierzu: EzLI, Özkan (2006): »Von der Identitätskrise zu einer ethnografischen Poetik. Migration in der deutsch-türkischen Literatur«. In: Literatur und Migration, Sonderband edition text+kritik, München, S. 61-73.

92 Ebd., S. 21. 
also die Wahrnehmung, das Sehen von etwas. Nach Brubaker lässt sich aus dieser Perspektive zeigen, wie identitätspolitische $\mathrm{Zu}$ - und Selbstbeschreibungen konstruiert werden - statt im Sinne einer postmodernen Logik einfach zu behaupten, dass sie konstruiert sind.$^{93}$ Für ihn ist wichtig zu beobachten, nicht wie Gruppen funktionieren, sondern wie mit Kategorien umgegangen und gearbeitet wird. Oft würden Kategorien mit Gruppen verwechselt und dabei der Alltagskontext vernachlässigt. »Deshalb ist es wichtig, um zu begreifen, wie Ethnizität funktioniert, [...] nicht mit den >Rumänen >rumänisch « und sungarisch`als Kategorien«, die immer im Verwendungszusammenhang auftauchen, nicht nur sprachlich, sondern auch praktisch. ${ }^{94}$ Kategorien brauchen nach Brubaker »Biotope mit Artenschutz, in denen sie überleben und gedeihen können «. ${ }^{95}$ Ähnlich wie Asad und Wimmer geht es auch in dieser Theorie um neue Verhältnisse: zur Territorialität, zur Praxis und zum Gebrauch der Marker, die kulturelle und politische Integration zusammenführen, und um eine neue Sichtbarkeit von Kultur.

Nach Amartya Sen darf es nicht mehr ausschließlich darum gehen, hybride Identitäten anzuerkennen; wichtig sei die Art und Weise des Umgangs mit einer Vielzahl von Identitäten. Denn die Akteure sind mehr als hybride Identitäten: Sie sind Mitglieder einer Vielzahl von Gruppen über die »Staatsangehörigkeit, Wohnort, geografische Herkunft, Geschlecht, Klassenzugehörigkeit, politische Ansichten, Beruf, Arbeit, Eßgewohnheiten, sportliche Interessen, Musikgeschmack, soziale Engagements usw. «. ${ }^{96}$ Trotz der Vielfalt dieser Zugehörigkeiten gilt nach Sen: «Wenn man als Araber oder Muslim wahrgenommen wird, muß man immer noch entscheiden, welche Bedeutung man dieser Identität im Vergleich $\mathrm{zu}$ den anderen Kategorien beimißt, denen man ebenfalls angehört. “ ${ }^{97}$ Kultur oder die Entdeckung kultureller Eigenheiten ist für Sen keine Schicksals-, sondern eine Entscheidungsfrage. ${ }^{98}$ Entscheidungen beruhen dabei nicht immer auf der freien Wahl zwischen Positionen, sondern darauf, dass trotz einer belasteten Position oder Identität, wie Muslim zu sein, "Wahlmöglichkeiten « bestehen. ${ }^{99}$ Im Sinne der Verhandlung bei Wimmer verlangt die Wahl also nicht, »daß wir aus dem Nichts irgendwohin springen, aber sie kann dazu führen, daß wir uns

93 Ebd., S. 32.

94 Ebd., S. 37.

95 Ebd., S. 44. Siehe hierzu auch: EDER u. a. (2004): S. 15.

96 SEN (2006): S. 20.

97 Ebd., S. 22.

98 Ebd., S. 53. Siehe hierzu auch: GRAY, John (2002): Two Faces of Liberalism, New York: New Press, S. 121.

99 SEN (2006): S. 49. 
von einer Stelle zur anderen bewegen «. ${ }^{100}$ Für diese Bewegungen, die andere sind als in den 1990er Jahren - dort ging es vor allem darum, zunächst eine Position überhaupt zu finden, muss nun eine Ordnung sichtbar gemacht, müssen Straßen benannt und Orte bestimmt werden. Ihr Medium ist in den 2000er Jahren das Verhandeln von Werten und ihre darauffolgende Bewahrung.

Steven Vertovec stellt die Diversität ebenfalls in einen Verortungszusammenhang. Wie viele andere verabschiedet er sich wissenschaftlich vom Begriff des Multikulturalismus »because of its >catch all and confusing quality «. ${ }^{101}$ Die Abkehr hat aber noch weitere Gründe: In den Debatten, die auf den 11. September 2001, auf den Mord an Theo van Gogh, die Anschläge in Madrid und London, auf die Straßenschlachten 2005 in den Banlieues in Paris und auf den Karikaturenstreit folgen, wird der Multikulturalismus der 1990er Jahre als zentrale Ursache für diese Konflikte gesehen. Er habe, wie in Habermas' Interpretation, die Gruppen voneinander getrennt statt sie zusammenzuführen. Das Konzept lehne gemeinsame Werte $\mathrm{ab}$, verleugne Probleme, unterstütze respektlose, beleidigende und unerhörte Praktiken und sei letztendlich der »heaven for terrorists «. ${ }^{102}$ In diesem Zusammenhang konstatiert der Soziologe Christian Joppke, dass in den Einwanderungsländern Großbritannien, den Niederlanden und Australien ein Übergang vom Multikulturalismus $\mathrm{zu}$ »civic integration « eingesetzt habe. ${ }^{103}$ Man spreche sich nun für einen neuen Realismus (»new realism«) aus. Dessen Grundlage sei Kultur als Diversität; Besonderheiten und Spezifika rücken in den Vordergrund.

Dass Fragen der Integration zunehmend kulturell codiert werden, zeigt sich in England beispielsweise am Übergang von der »social cohesion« zur »community cohesion «, die als neue Maxime der Integrationspolitik firmiert. ${ }^{104}$ Der Begriff »diversity« wird beispielsweise im Strategiepapier Improving Opportunities, Strengthening Society der britischen Regierung von 2005 auf 54 Seiten 34 Mal genannt; im Nationalen Integrationsplan der deutschen Bundesregierung von 2007 lesen wir »Diversität« auf 202 Seiten 84 Mal. ${ }^{105}$ Diese politischen Maßnahmen verdeutlichen wie die öffentlichen Debatten der 2000er Jahre insgesamt, wie sehr die Folgen der Migration in den europäischen Einwanderungsländern, und besonders in Deutschland, über den Begriff der Diversität bzw. Vielfalt mit der

100 Ebd.

101 Vertovec, Steven/Wessendorf, Susanne (2010): »Introduction. Assessing the backlash against multiculturalism in Europe«. In: The Multiculturalism Backlash. European Discourses, Policies, and Practices, London: Routledge, S. 1-31, hier S. 14.

102 Ebd., S. 13.

103 Joppke, Christian (2004): "The retreat of multiculturalism in the liberal state: theory and policy«. In: The British Journal of Sociology, 2004 Volume 55 Issue 2, S. 239-257, S. 243.

104 Ebd., S. 18.

105 Ebd., S. 18. 
Integration verknüpft, ja fast unlösbar mit ihr verschränkt werden. Wenn in den 1990er Jahren mit den Thesen und Annahmen des Multikulturalismus Integration weder auf die Herstellung einer kulturellen Homogenität zielen, noch andere kulturell bedingte Prägungen ausschließen durfte, ist der Zusammenhang von Vielfalt und Integration nach dem 11. September ein anderer.

Das Ziel dieses politischen Umdenkens ist eine Präventionspolitik, die vor den Gefahren des islamistischen Terrorismus schützen soll. Im Zentrum steht dabei der Gedanke, dass es nicht einfach ausreicht, sich zum Grundgesetz zu bekennen, sondern es gilt, dieses sichtbar zu leben. Säkulare und kritische Muslime fordern dies selbst ein. Im Zusammenhang der DIK konstatieren die Aleviten, dass sie nicht nur rechtstreu seien, "sondern auf dem Boden der demokratisch-freiheitlichen Grundordnung « stünden. Diese Verbindung von Innen, Außen, Praxis und dem Boden, auf dem man steht, veranschaulicht den Zusammenhang von Integration und den Folgen der Migration in den 2000er Jahren. Folglich setzen die genannten Theorien zur Diversität (Vertovec, Asad, Wimmer) auf Praktiken. Die Zeit sei gekommen, so Vertovec, »to re-valuate [...] the nature of contemporary diversity «. ${ }^{106}$ Dazu gehöre der komplexe Zusammenhang zwischen Integration und Transnationalismus; und zugleich, dass »new immigrants clearly are getting on with developing a new life, livelihood, social ties and political interests in their places of settlement $« .{ }^{107}$ Auf der Basis dieser Bindung zwischen Transnationalismus, und Aneignung und des sich am Ort der Ankunft orientierenden Lebens, erfindet Vertovec den Begriff der Superdiversität: »Social cohesion and national identity can coexist with valuing diversity in the public sphere, as well as offering programmes to recognise and support cultural traditions, and institutional structures to provide ethnic minority community representation - all without reference to the M-word «. ${ }^{108}$

Der Integrationstheoretiker Hartmut Esser, der sie bis dahin durchweg vernachlässigte, greift ab Mitte der 2000er Jahre ebenfalls auf die Kategorie der Kultur zurück. Vorher hatte es für ihn nur zwei Enden des Assimilationsprozesses gegeben: entweder die Assimilation als Aufstieg in die Mittelschichten der Aufnahmegesellschaft oder die ethnische Schichtung als dauerhafter Abstieg und als »Mobilitätsfalle«. Nun spricht er von »selektiver Akkulturation «. ${ }^{109}$ Damit

106 Vertovec, Steven (2010): »Towards Postmulticulturalism? Changing Communities, conditions and contexts of diversity«. In: International Social Science Journal, Volume 61, Issue 199, March 2010, S. 83-95, hier S. 86.

107 Ebd., S. 90.

108 Ebd., S. 94.

109 ESSER, Hartmut (2008): »Assimilation, ethnische Schichtung oder selektive Akkulturation? Neuere Theorien der Eingliederung von Migranten und das Modell der intergenerationalen Inte- 
sei »unter Nutzung und Beibehaltung der ethnischen Ressourcen und Identitäten ohne Aufgabe der ethnischen Identität« ein sozialer Aufstieg möglich. ${ }^{110}$ Sozialer Aufstieg und »eine starke ethnische Einbettung und Orientierung « widersprechen sich also nicht mehr. ${ }^{111}$ Eine herausragende Rolle spielt dabei für Esser der Übergang von einem »boundary crossing «, wie es die klassische Assimilationstheorie auszeichnete, $\mathrm{zu}$ einem »boundary blurring«, das den veränderten Gebrauch kultureller Marker oder den Prozess ihrer Auflösung genauer beschreibbar macht. ${ }^{112}$ Letzteres kann etwa dazu führen, dass sich die kulturelle Auffälligkeit (,Salienz') auf andere Gruppen verlagert, wie sich beispielsweise am kritischen und aufgeklärten Islam zeigt. Um diese Prozesse und die Mechanismen hinter diesen Vorgängen präzise beschreiben und dadurch womöglich wieder eine allgemeine Theorie der Integration entwickeln zu können, schlägt Esser vor, den Weg einer »intergenerationalen Integration « zu gehen, d. h. sich genauer die Familiengeschichten im Kontext der Folgen der Migration anzusehen. ${ }^{113}$ Spannenderweise spielt das Thema der Familie als intergenerationale Konstellation im Unterschied zu den 1990er Jahren in allen literarischen und filmischen Erzählungen der 2000er Jahre eine zentrale Rolle. ${ }^{114}$ Esser geht es, das sei abschließend festgehalten, nicht um die logische Entwicklung einer modernen und ausdiffe-

gration«. In: Kölner Zeitschrift für für Soziologie und Sozialpsychologie, Heft Sonderheft, S. 81-107, hier S. 82.

110 Ebd.

111 Ebd., S. 103.

112 Ebd., S. 86.

113 Diesen intergenerationalen Zugang hält auch Andreas Wimmer für vielversprechend, um die Verschiebung kultureller Grenzziehungen als Ergebnisse und nicht als Enden zu begreifen. »Das bestmögliche Forschungsdesign wäre wohl eine Panelstudie, die Immigranten aus demselben Herkunftsland (oder -dorf/-region) über mehrere Dekaden, idealerweise Generationen hinweg verfolgt." Siehe hierzu: Wimmer, Andreas (2008): "Ethnische Grenzziehungen in der Immigrationsgesellschaft. Jenseits des Herderschen Commonsense«. In: Kölner Zeitschrift für für Soziologie und Sozialpsychologie, Special Issue 48, S. 57-80, hier S. 74.

114 Auch publizistische und dokumentarische Arbeiten nehmen die erste Generation und das Verhältnis zwischen erster und zweiter Generation eingehend in den Blick. Siehe hierzu: AKIN, Fatih (2000): Wir haben vergessen zurückzukehren, Dokumentarfilm, Deutschland, Bayrischer Rundfunk. VetTer, Marcus Attila (2005/06): MeIn VATER DER TÜrKe, Dokumentarfilm, Deutschland, SWR. BADEMSoy, Aysun (2005): Am Rande der Städte, Dokumentarfilm, Deutschland; Priessner, Martina (2010): Wir sitzen im Süden, Dokumentarfilm, Deutschland. Cil, Hasan (2003): Anfänge einer Epoche. Bir Dönemin Başlangçlar, Berlin: Hans Schiler. SpoHN, Margret (2002): Türkische Männer in Deutschland. Familie und Identität. Migranten der ersten Generation erzählen ihre Geschichte, Bielefeld: transcript. RICHTER, Michael (2004): gekommen und geblieben. Deutsch-türkische Lebensgeschichten, Hamburg: Edition Koerber Stiftung. GodDAR, Jeannette/HunEKe, Dorte (2011): Auf Zeit. Für immer. Zuwanderer aus der Türkei erinnern sich, Köln: Kiepenheuer \& Witsch. 
renzierten Gesellschaft oder die rationale Anpassung an ein Mehrheitssystem. ${ }^{115}$ Auch wenn er in seiner theoretischen Neuausrichtung am Assimilationsbegriff festhält, geht er wie die anderen Wissenschaftler der Zeit von der Alltagspraxis aus. Nicht mehr ein System gibt die sozialen Gesetzmäßigkeiten vor, sondern nun sind es »die Gesetzmäßigkeiten des situationsorientierten Handelns der menschlichen Akteure ${ }^{116}$

Diese Spannung zwischen dem Wunsch, eine allgemeine soziale Theorie zu entwerfen, und der situationsbezogenen Alltagspraxis resultiert aus der Vielfalt, die sich in den vergangenen 50 Jahren in der Bundesrepublik entwickelt hat und die nun als allgemeines Faktum angenommen wird. Dieser allgemeine Befund ist mit einem gesellschaftlichen Stillstand gekoppelt, der eine Projektion der Entwicklung auf ein bestimmtes Ziel sehr erschwert, ja fast unmöglich macht. Vielfalt wirkt dadurch wie eine neue Art und Weise der Homogenisierung. Denn aus dem Besonderen soll nun das Allgemeine entworfen werden. Dass damit zugleich ein schwacher Gesellschaftsbegriff verbunden ist, zeigt sich auch an den Überlegungen von Nina Glick-Schiller. Die Transnationalismusforscherin führt etwa den Begriff der incorporation ein. Damit will sie, wie Hartmut Esser, »analytisch die eher kleinteiligen Verbindungen zwischen Personen, Netzwerken und Institutionen, die alltäglich $\mathrm{zu}$ beobachten sind «, erschließen. ${ }^{117}$ Auch in der aktuellen »reflexiven Wende der Migrationsforschung« steht nicht mehr die Kultur einer ethnischen Gruppe im Mittelpunkt. Es geht vielmehr darum, »die Konstruktion sozialer Realität als Zusammenspiel von sozialer Praxis und kulturellen Wissensbeständen zu rekonstruieren«. Denn die Gesellschaft lässt sich nicht mehr mit Adjektiven wie » >integriert`, ১zentriert` und ১homogen` beschreiben, eher als >fragmentiert`, >dezentriert $\iota$ und >differenziert « ${ }^{118}$

Die theoretischen Texte, die im Umfeld des Begriffs »Postmigration« Ende der 2000er Jahre entstehen, konstatieren eine Differenz zwischen der öffentlichen Semantik von Migration und Integration in der Bundesrepublik und der All-

115 Siehe hierzu: EssER, Hartmut (1980): Aspekte der Wanderungssoziologie. Assimilation und Integration von Wanderern, ethnischen Gruppen und Minderheiten - eine handlungstheoretische Analyse, Darmstadt: Luchterhand.

116 ESSER (2008): S. 104.

117 Glick Schiller, Nina/Basch, Linda/Blanc-Szanton, Cristina (2014): »Transnationalismus. Ein neuer analytischer Rahmen zum Verständnis von Migration«. In: Transkulturalität. Klassische Texte, hg. v. Andreas Langenohl, Ralph Poole und Manfred Weinberg, Bielefeld: transcript, S. 139-154, S. 144.

118 Nieswand, Boris/Drotвoнm, Heike (2014): »Einleitung. Die reflexive Wende in der Migrationsforschung «. In: Kultur, Gesellschaft, Migration. Die reflexive Wende in der Migrationsforschung, Heidelberg: Springer, S. 1-37, S. 13. Dieser Zugang wird als »methodologischer Kulturalismus« beschrieben. Seine Analysemittel sind die der narrativen Deskription und der Praxeologie. 
tagspraxis der Akteure mit Zuwanderungsgeschichte und Migrationshintergrund. Besonders nach der Sarrazin-Debatte weist man darauf immer wieder hin. ${ }^{119}$ Wie in der Publikation zur »reflexiven Wende in der Migrationsforschung « steht die produktive Krise der Unterscheidung Ausländer/Einheimischer, des Gesellschafts- und zugleich Kulturbegriffs, den die Migrationsforschung bisher selbst geprägt und auch mitbestimmt hat, im Vordergrund. ${ }^{120}$ Auch Theoretiker der Postmigration wollen folglich die Migrationsforschung aus ihrer bisherigen Sonderrolle herauslösen und sie als Gesellschaftsanalyse etablieren. Damit hängt erneut ein schwacher Gesellschaftsbegriff zusammen. So begreift etwa Regina Römhild Migration vielmehr als Perspektive und nicht mehr als Gegenstand ${ }^{\mathbf{1 2 1}}$ - ähnlich wie der oben genannte Brubaker Ethnizität nicht mehr als Gegenstand, sondern als Kognition begreift. Auch Postmigration bezieht sich demnach auf Zwischenräume, »in denen weltweite Querverbindungen zusammenlaufen und sich zu Alltagskontexten verdichten «. ${ }^{122}$ Dieser Zugang zur Migration bestimmt auch die große Ausstellung Projekt Migration, die anlässlich von 50 Jahren Arbeitsmigration nach Deutschland im Jahr 2005 in Köln stattfand. Die Kuratoren und Herausgeber des voluminösen Begleitkatalogs haben vor, den »nationalen Blick umzukehren «. Denn nach ihrer Ansicht »gebraucht« die Nation den Anderen, »um sich selbst ins Zentrum zu setzen«. Dieser Einsatz sei die Grundlage der »Erzählung von der Mehrheit und ihren Minderheiten«. Es ist die Form »des Nationalstaats: die geschlossene Container-Gesellschaft, in der die Herkunft über Zugehörigkeit und Partizipation entscheidet«. Die Ausstellung und das Buch Projekt Migration stehen folglich für »den Versuch, zu einer neuen Einschätzung und Bewertung zu kommen: den nationalen Blick umzukehren und Migration selbst als eine zentrale Kraft gesellschaftlicher Veränderung sichtbar zu machen «. ${ }^{123}$

119 Thilo Sarrazin arbeitet in seiner aufsehenerregenden Publikation Deutschland schafft sich $a b$ aus dem Jahr 2010 mit den Mitteln der Entortung und Verortung im Kontext der Migration. Das siebte Kapitel in seinem Buch, das sich ausschließlich um Einwanderung dreht, beginnt er mit den Worten, dass der Mensch ein »territorial orientiertes Wesen« sei. Doch gerade die Muslime, die bedingt durch Migration seit 50 Jahren in Deutschland leben, scheinen keinen Ort zu haben. Siehe hierzu: EzLI (2010).

120 Nieswand/Drothboнm (2014): S. 3.

121 Siehe hierzu: YILDIZ, Erol (2014): »Postmigrantische Perspektiven«. In: Nach der Migration. Postmigrantische Perspektiven jenseits der Parallelgesellschaft, hg. v. Erol Yıldız, Marc Hill, Bielefeld: transcript, S. 19-48.

122 Ebd., S. 24.

123 Frangenberg, Frank (2005): Projekt Migration. Ausstellungskatalog des »Projektes Migration« im Kölnischen Kunstverein vom 29. September bis 15. Januar 2006, Köln: Dumont, S. 16. Der Zeit-Autor Ulrich Deuter hält fest: wo die "gedanklichen und migrationsfreundlichen Positionen« der Autoren im Buch »denkbar« seien, sei die Ausstellung, »wo sie Geschichte dokumentiert, ordentlich, wo sie künstlerischen Standpunkten Raum gibt, hingegen oft mut- und einfallslos«. 
Dies stellt einen wesentlichen Unterschied dar zum Weltverbundenheitsgefühl der 1990er Jahre. In Akıns und Arslans Filmen, in Zaimoğlus Kanak Sprak und Özdamars surrealer Poetik hängen Bruce-Lee-Plakate an der Wand, und der Konsum dieser und anderer Filme, der Bruch mit der Sprache und mit den Bildern führten zu der Vorstellung, dass man mit der Welt verbunden sei. In den 2000er Jahren wird diese Globalisierung vorausgesetzt und in den nun eigentlich wichtigen Beobachtungsgegenstand, in den Alltag, in die Praktiken zurückgeführt. Die Welt stand in den 1990er Jahren für neue Räume; in den 2000ern wird sie im Alltag verortet. An die Stelle des Raumes tritt also der Ort, der nicht unbedingt bindet oder neue Bewegungen freisetzt, sondern zunächst einmal nach der Ordnung fragt. Dazu passt, dass postmigrantische Forscher verlangen, dass die Zahl der Beschäftigten im Öffentlichen Dienst, der Journalisten, Räte deutscher Städte und Beschäftigter in Führungspositionen deutscher Stiftungen mit Migrationshintergrund steigen muss, wenn sich im System der Bundesrepublik die Bevölkerung spiegeln soll. ${ }^{124}$ Dies hat in den 1990er Jahren kaum ein Befürworter des Multikulturalismus verlangt. Aber auch das Ziel der Akteure in Film und Lite-

Zum Gesamteindruck der Ausstellung resümiert er: »Fotografien von Türken im öffentlichen und im privaten Raum (Candida Höfer, Brigitte Kraemer) von Tauschwirtschaft auf Berliner Polenmärkten (Wolfgang Tillmans) sind ästhetisch hochwertige Produkte, verblassen jedoch auf nicht verdiente Weise angesichts des realen Lebens in der Migrationsgesellschaft direkt draußen vor der Tür - es hätten viel mehr sein müssen, um das fremde Leben mit den Mitteln der Fotokunst zu nobilitieren, aus der `Schwemmeく Individuen zu machen«. Siehe hierzu: DeUTER, Ulrich (2005): »Das Projekt Migration in Köln«. In: DIE ZEIT, 05.11.2005. Siehe auch: http://www. kulturwest.de/kulturpolitik/detailseite/artikel/transit-europa/ (19.09.2018). Eine ähnliche Kritik an der Ausstellung findet sich in: WoLBeRT, Barbara (2010): ")Studio of Realism`. On the need for Art in Exhibitions on Migration History«. In: Forum: Qualitative Social Research. Sozialfoschung, http://www.qualitative-research.net/index.php/fqs/article/view/1483/2996 (19.09.2018). Bemerkenswert ist im Zusammenhang des Ausstellens von Migration und ihrer Geschichte in der Bundesrepublik, dass in Kadir Sözens Film ZEIT DER WüNSCHE von 2004 der Protagonist, ein Gastarbeiter der ersten Stunde in der Bundesrepublik, erst in einer Zeche arbeitet, dann Fotograf wird und in der Erzählung des zweiteiligen Fernsehfilms zwei Ausstellungen zur türkischen Migration nach Deutschland realisiert. Siehe hierzu: Sözen (2004). Doch im Unterschied zu den »echten« Dokumentaristen der Migration wie Candida Höfer, Brigitte Kramer, Wolfgang Tillmanns und Vlassis Caniaris macht Sözens Fotograf vorwiegend Portraitaufnahmen. Bei den ersteren Fotografen stehen die Einwanderer der ersten Stunde in Interaktionszusammenhängen oder es werden die Dinge, die sie gebraucht haben und brauchen, abgelichtet. Siehe hierzu: SöZEN (2004). Siehe auch: CANIARIS, Vlassis (1974): Gastarbeiter - Fremdarbeiter, Berlin: Neue Gesellschaft für Bildende Kunst Realismusstudio. Siehe hierzu auch die Fotografien von türkischen Gastarbeitern in: HöFER, Candida (2013): Düsseldorf, Düsseldorf: Richter.

124 Siehe hierzu: Foroutan, Naika (2015): »Die postmigrantische Gesellschaft«. In: Bundeszentrale für politische Bildung, 20.04.2015, http://www.bpb.de/gesellschaft/migration/kurzdossiers/205190/die-postmigrantische-gesellschaft (27.03.2018). 
ratur war nicht, sozialstrukturell aufzusteigen oder einen Aufstieg zu projezieren, sondern sich auszudrücken, $\mathrm{zu}$ behaupten und zu positionieren.

Mit der Perspektive der Postmigration wird bis heute nicht zwischen Raum (Möglichkeit) und Ort (Ordnung) unterschieden. So werden die drei zentralen Aspekte der Postmigration nebeneinandergestellt, ohne ihre spezifischen Konstellationen zu berücksichtigen. Diese Aspekte sind nach Erol Yildız erstens die Notwendigkeit einer »Neuerzählung der Geschichte der Gastarbeiter«, zweitens die Aufarbeitung der unterschiedlichen Gegenstrategien der Nachfolgegenerationen gegen hegemoniale Bezeichnungspraktiken und drittens der soziale Aufstieg, der »auf eigene Rechnung« als Selbstständige oder über »transnationale Umwege« erfolgt sei. ${ }^{125}$ Wie diese sehr unterschiedlichen kulturellen und ökonomischen Konstellationen zusammenhängen, warum und wie sie aufeinander folgen, bleibt leider unerwähnt und wird an keiner Stelle erläutert. Die Klammer, die bei Yıldız, aber auch bei Paul Mecheril alles zusammenhält, ist Bhabhas postkoloniale Theorie, in der »Brüche, Diskontinuitäten und Umwege eher den Regelfall darstellen als die Ausnahme und als Potential deklariert werden. ${ }^{126}$ Geht man davon für alle drei genannten Aspekte aus, dann versteht man »Selbstethnisierung« als eine Reaktion auf hegemoniale Benennungspraktiken. Zugleich ließen sich damit erfahrene Diskriminierungen verarbeiten, denen »Selbstethnisierungen « eine Gestalt zu geben vermögen. ${ }^{127}$ Das Besondere an der Selbstethnisierung hier ist, dass die ethische Zugehörigkeit nicht von außen zugeschrieben oder von einer Gruppe oder Elite vorherbestimmt und vorgeschrieben wird. Sie entsteht im bewussten Einsatz kultureller Marker zur Selbstpositionierung in spannungsgeladenen Interaktionen. In der Essaysammlung Eure Heimat ist unser Albtraum hält die Dramatikerin Sasha Marianna Salzmann in ihrem Beitrag Sichtbar programmatisch fest, dass der »einzige Weg, der verhindert, dass das, was man ist, gegen einen verwendet wird «, das Sprechen über sich sei, »bevor es andere tun«. ${ }^{128}$

Im Spielfilm MEINE VERRÜCKTE TÜRKISCHE HOCHZEIT von 2007 wird die türkische Protagonistin Aylin von zwei deutschen Autorinnen, eine hat ein Buch mit dem Titel Happy Single veröffentlicht und die andere schreibt aktuell ein Buch zu Ehrenmorden und Zwangsehen in Berlin Kreuzberg, auf einer öffentlichen Veranstaltung gefragt, warum sich die türkischen Frauen das alles überhaupt gefal-

125 YILDIZ, Erol (2014): »Postmigrantische Perspektiven«. In: Nach der Migration. Postmigrantische Perspektiven jenseits der Parallelgesellschaft, hg. v. Erol Yıldız und Marc Hill, Bielefeld: transcript, S. 19-48, S. 22.

126 YiLDIZ (2014): S. 30.

127 Ebd., S. 31.

128 Salzmann, Sasha Marianna (2019): »Sichtbar«. In: Eure Heimat ist unser Albtraum, Berlin: Ullstein, S. 13-26, S. 13. 
len ließen. Aylin selbst trägt kein Kopftuch, betet nicht, spricht perfekt deutsch, studiert Jura, lässt sich auch nicht zur Ehe zwingen und ist mit einem Deutschen zusammen. Sie kann also unmöglich die Adressatin der Fragen der deutschen Frauen sein. Dennoch erwidert sie wütend in einem beleidigten und zugleich ironischen Ton, dass sie zwar kein »happy Single«, aber dafür ein »happy Muslim» sei. Fast tweetartig hilft ihr hier der kulturelle Distinktionsmarker, nicht eine den sozialen Tatsachen aber ihren Gefühlen entsprechende Gegenposition einzunehmen. Auch Almanya. Willkommen in Deutschland, Selam Berlin und Das Geheimnis meiner türkischen Großmutter sind von einer solchen Mischung aus Wut und Ironie gekennzeichnet. Vor diesem Hintergrund wird klar, dass der Begriff der Postmigration die Funktion einer Kampfvokabel einnimmt. Mit ihm werden insbesondere Menschen mit Migrationshintergrund aber ohne eigene Migrationserfahrung angesprochen. ${ }^{129}$ Der Kampf und Umgang mit Diskriminierungen unterscheidet sich dabei von denen der 1990er Jahre. Wenn man damals in einem Akt der Antidiskriminierung jegliche ethnische Zuschreibung, ob deutsch oder türkisch, in Frage stellte, gehört die Ethnie nun wesentlich zum Kampfeinsatz dazu. ${ }^{130}$ Erst vor dem Hintergrund dieses Wandels von Raum zu Ort, von Ironie zu Ernst und Wut lässt sich begreifen, warum eine der bekanntesten Fürsprecherinnen der Postmigration, Naika Foroutan, im Jahr 2018 davon spricht, dass wir " unser Land « gegen die neue rechte Gefahr verteidigen müssten. ${ }^{131}$ Auch wenn es nicht gleich zu setzen ist, war eine solche Rhetorik in den 1980er Jahren noch den konservativen Monokulturalisten vorbehalten.

So zeigt bereits der Unterschied in der Bearbeitung von Diskriminierungen zwischen den 1990ern und seit den 2000ern, dass die Geschichte der Diskriminierung in der Bundesrepublik weitaus komplizierter ist, als die Verkürzung auf die Negativerfahrungen mit einem postkolonialen Vokabular suggeriert. Arbeit, kulturelle Selbstbehauptung und sozialstruktureller Aufstieg können schon für sich genommen in ihren jeweiligen historischen und sozialpolitischen Konstellationen nicht so behandelt werden. Denn es gibt nicht nur eine narrative und biografische Differenz zwischen den Sätzen »Wir wollten alle Amerikaner werden«, »Wie lebt es sich als Türke in Deutschland«, »Wie lebt es sich in Deiner Haut?»

129 Foroutan, Naika (2010): »Neue Deutsche, Postmigranten und Bindungsidentitäten. Wer gehört zum neuen Deutschland?«. In: Bundeszentrale für politische Bildung, 08.11.2010, http:// www.bpb.de/apuz/32367/neue-deutsche-postmigranten-und-bindungs-identitaeten-wer-gehoert-zum-neuen-deutschland?p=all (zuletzt 07.02.2019).

130 Holtz, Stefan (2007): »Bonusmaterial zu ১Meine verrückte türkische Hochzeit««. In: Meine verrückte türkische Hochzeit, DVD, Münster: Tubine Medien.

131 Foroutan, Naika (2018): „Es ist unser Land. Verteidigen wir es gemeinsam«. In: Der Tagesspiegel, 22.07.2018, https://www.tagesspiegel.de/politik/migrationsforscherin-naika-foroutan-es-ist-unser-land-verteidigen-wir-es-gemeinsam/22830476.html (19.09.2018). 
und »Was lebst Du?«. Paradoxerweise führt der Fokus auf den Bruch, auf das Dezentrierte, der alle Aspekte der Postmigration anscheinend zusammenführt, nicht zu einer Gesellschaft, die sie alle rahmt, sondern zur Konstitution einander entgegengesetzter Gruppen.

Shermin Langhoff, von 2008 bis 2013 künstlerische Leiterin des von ihr so genannten "postmigrantischen Theaters« im Ballhaus Naunynstraße und seit 2013 Intendantin des Maxim-Gorki-Theaters, befand, dass in jeder gebrochenen Biografie Potential stecke. Wer den Bruch als Potential begreift ${ }^{132}$, ökonomisiert ihn und bewegt sich zugleich weg von einer allgemeinen gesellschaftlichen Rahmung. Da stellt sich die Frage, was mit »ungebrochenen« Biografien gemeint ist? Und wann ist eine biografische Zäsur überhaupt ein Bruch? Wenn man den Eltern nicht genügen kann, weil sie schon als Professoren, Manager oder Ärzte sozialstrukturell ganz oben stehen oder wenn man eigentlich nur gewinnen kann, weil die Eltern seit jeher in Schicht- oder Reinigungsarbeit ihr Leben fristen? In den filmischen und literarischen Erzählungen der 2000er Jahre dient der Bruch keineswegs der Verarbeitung von Migration und ihren Folgen. Vielmehr haben wir es mit einem übersetzten und kompatibel gewordenen Bruch zu tun. Brüche sind Teil des neuen Marktes und der neuen Möglichkeiten. In den Erzählungen der 2000er Jahre sind es Praktiken, also Lebensweisen und Verhalten, die eine bindende und integrative Funktion erfüllen. Dass Praktiken, Zusammenleben und Alltag verstärkt in den Blick von Debatten, Theorien, Film und Literatur rücken, hängt mit dem bereits genannten Wandel vom Raum zum Ort zusammen.

Räume entstehen nach Michel de Certeau mit dem Gehen der Akteure. Räume bestimmen sich daher durch »Richtungsvektoren«, über Verweise und aus »Geschwindigkeitsgrößen«. Diese mobile Anlage mit der Verweiskraft des Raums lässt es zu, dass zwei unterschiedliche Dinge an ein und derselben Stelle sein können. Ein plastisches Beispiel hierfür ist, wie Sibel in Fatih Akıns Film GEGEN DIE Wand auf die Frage des Deutschen Nico, ob sie jetzt zusammen seien oder nicht, in einer einzelnen Sequenz als »moderne Deutsche« und als »traditionelle Türkin« reagieren und somit auch die ganze Spannung deutsch-türkischer Bindung entladen kann. Oder dass Bildikid in Atamans Film türkischer Macho und zugleich schwul ist. Gegen diese sowohl-als-auch-Struktur des Raums ist nach Certeau der Ort eine «momentane Konstellation von festen Punkten«. Im Unterschied zum Raum geht die Entstehung von Orten vom Sehen einer Ordnung aus, die in der Regel eine »aufgezwungene Ordnung « ist; ${ }^{133}$ eine Ordnung, »nach

132 Aus: YILDIZ, Erol (2019): »Postmigrantische Lebensentwürfe jenseits der Parallelgesellschaft«. In: Migration bewegt und bildet. Kontrapunktische Betrachtungen, hg. Alexandra Böttcher, Marc Hill und andere, Innsbruck: Innsbruck University Press, 13-28, S. 22.

133 Ebd., S. 352. 
der Elemente in Koexistenzbeziehungen aufgeteilt werden «. ${ }^{134}$ Nach dieser ist es nicht mehr möglich, »daß sich zwei Dinge an derselben Stelle befinden «. ${ }^{135}$ Die Ordnung eines Ortes lässt auch nicht mehr offen, ob Erol aus Arslans GESCHWISTER nun aus patriotischen Gefühlen oder aufgrund seiner Schulden den Militärdienst in der Türkei antritt. Gerade in diesem Zusammenschluss von Inkompatiblem, der im eigenen Körper verortet war, lag der universale und politische Anspruch des Leitsatzes »Wie lebt es dich in Deiner Haut?«. In solch einer Konstellation konnte die Anrufung des Menschseins überzeugen. Doch an diese Stelle rückt nun die Frage, was man lebt und wofür das steht, was man tut. Schon dies führt dazu, dass Orten und Verortungen besondere Funktionen zukommen. Für Bhabha steht allerdings die Konzeption des Ortes diametral zum postkolonialen Zwischenraum. Dort, wo dieser Zwischenraum auf eine gemeinsame Gegenwart verweist, trennt der Ort die Akteure durch Fragen nach Zugehörigkeit und Besitz voneinander, unterscheidet sie dann beispielsweise in moderne und nichtmoderne Akteure. ${ }^{136}$ Wir werden sehen, dass eine Bhabha'sche Analyse und Abwertung des Sichtbarmachens von Orten nicht mehr ausreichen, wenn Unterscheidungen wie modern und traditionell analytisch kaum noch greifen. Ein weiterer Grund liegt darin, dass Orte auch verräumlicht, in Bewegung gebracht werden können, wenn durch und mit ihnen gehandelt wird. Wir werden sehen, dass sich in den 2000er Jahren die Politik als System und das Politische als Feld genau auf dieser Achse bewegen: mit und an den Orten wird etwas gemacht bzw. werden Orte unsichtbar gehalten, mit dem politischen Ziel, die potentiellen Gefährder von den ungefährlichen, den kritischen, Muslimen unterscheiden zu können. Letztlich dominiert das politische System bis heute die Frage, wie man es durch die Kultur mit der Kultur hält, wie man mit den kulturellen und identitätspolitischen Markern umgeht. Anders formuliert interessiert nicht, was die Muslime an ihren Orten (den Moscheen) machen, sondern was sie dort sagen. Dabei wird übersehen, dass Predigt und Alltagspraxis in einem Gotteshaus diametral zueinanderstehen können, dass sozusagen auch nicht unbedingt streng religiöse oder gar nicht religiöse Menschen aus sozialer Gewohnheit in die Moschee gehen; die Verbindung solcher Inkompatibilitäten steht hier nicht mehr zur Disposition. Wer in die Moschee geht, ist religiös. Im Blick steht die sichtbare öffentliche Identität. Einige Filme und Texte nehmen diese Perspektive ein, andere stellen sie in Frage.

Film und Literatur wollen kein globales Weltverbundenheitsgefühl mehr darstellen, sondern fragen vielmehr danach, ob Kultur über bestimmte Formen verhandelbar ist oder nicht. In Züli Aladağs WUT ist sie beispielsweise nicht verhan-

134 Ebd., S. 347

135 Ebd.

136 Внавна (2000), S. 219 u. 248. 
delbar. Die titelgebende Wut des deutsch-türkischen Protagonisten Can auf den Wohlstand einer deutschen Familie und sein Empfinden, er werde immer noch als der kleine Türke gesehen, führt in dieser Erzählung zur Katastrophe. ${ }^{137}$ Dabei tritt Can keineswegs als Opfer auf, sondern fühlt sich von anderen diskriminiert, die ihn tatsächlich gar nicht diskriminieren. Sein Auftritt ist im Unterschied zu dem der >Kanaken` in den 1990ern frei von Ironie. So hält auch der deutsch-türkische Regisseur des Films fest, dass er zwar die Wut seines jungen deutsch-türkischen Protagonisten im Film verstehe, seine eigenen Wertvorstellungen aber mit denen des deutschen Vaters identisch seien. ${ }^{138}$ Der Regisseur ist tolerant und bewegt sich in derselben Ordnung wie die dargestellte deutsche Familie; er teilt deren Werte. Frei von Ironie und Komik sind auch die zeitnah entstandenen Filme ChiKo. WenN Du DER Beste SEIN WILlST, MUSST Du RESPEKT KRIEGEN. WENN DU RESPEKT KRIEGEN WILLST, DARFST DU KEINEM RESPEKT ZEIGEN! (2008) von Özgür Yildirım und KNALLHART (2005) von Detlef Buck; ganz anders also noch KuRZ und SCHMERzlos, AuslandstourneE, APRILKINDER und GEgen die WAND.

Umgekehrt erleben Ethno-Comedy und Multikulti-Komödien im Film in den 2000er Jahren einen besonderen Boom. Integrationspolitisch werden sie zum beliebten Verhandlungsraum. Denn im Komischen können im Unterschied zum Tragischen »Ambivalenzen und einander widersprechende Vorstellungen vereint werden «. ${ }^{139}$ Hinzu kommt, dass Komik sehr gut mit dem politischen Bedürfnis nach Ordnung der 2000er Jahre zusammenpasst, also kompatibel ist. Denn nach Peter Berger macht Komik den »Widerspruch zwischen Ordnung und Unordnung « verhandel- und verortbar und »insofern zwischen dem Menschen, der stets nach Ordnung sucht, und den unordentlichen Realitäten der empirischen Welt «. ${ }^{140}$ Für den Komik-Theoretiker Uwe Wirth bewegt sich Komik nicht außer-

137 Tatsächlich wurde der Film Aladağs äußerst kontrovers diskutiert und löste nach starken Protesten von Jugendschützern eine Debatte aus. Die ARD reagierte auf diesen öffentlichen Unmut, indem sie den Sendetermin des Films in den späten Abend verschob. Siehe hierzu: DER SPIEGEL (2006): „Umstrittener TV-Film. ARD zeigt >Wut`später«. In: DER SPIEGEL, 22.09.2006, http://www.spiegel.de/kultur/gesellschaft/umstrittener-tv-film-ard-zeigt-wut-spaetera-438700.html (zuletzt 07.02.2019). Siehe hierzu: LuLEy, Peter (2010): »Wut ‘ aus dem Migrantenmilieu«. In: Die Süddeutsche, 19.05.2010, https://www.sueddeutsche.de/kultur/ard-verlegt-thrillerwut-aus-dem-migrantenmilieu-1.897372 (zuletzt 07.02.2019).

138 Siehe hierzu: ALADAĞ, Züli (2007): »Interview mit Züli Aladağ«. In: ders.: Wut, Spielfilm, DVD, Hamburg: Mondo Entertainment. Feridun Zaimoğlu, Ayşe Polat und Yüksel Yavuz haben sich hingegen in ihren Produktionen der 1990er Jahre sehr wohl mit ihren Protagonisten identifiziert.

139 Kotthoff, Helga/JASHARI, Shpresa/KLINGEnBERG, Darja (2013): Komik (in) der Migrationsgesellschaft, Konstanz: UVK, S. 17. Siehe hierzu auch: EzLI, Özkan/GöKTürK, Deniz/WIRTH, Uwe (2019): Komik der Integration. Grenzpraktiken und Identifikationen des Sozialen, Bielefeld: Aisthesis. 140 BERgER, Peter (1998): Erlösendes Lachen. Das Komische in der menschlichen Erfahrung, Berlin: De Gruyter, S. 43. 
halb gesellschaftlicher Grenzen: „Genau genommen entsteht Komik nur dann, wenn unausgesprochene Regeln - also implizit vorausgesetzte - Regeln verletzt werden. [...] Somit macht Komik die implizit vorausgesetzten Rahmen und Regeln spürbar und damit in ihrer Wirksamkeit überhaupt erst erkennbar «. ${ }^{141}$ Der weiterhin anhaltende Boom der Ethno-Comedy zeigt, dass dieser Bereich auch ökonomisch eine besondere Verhandlungsform kultureller Marker darstellt. Wenn in Filmen und Texten der 1990er Jahre Dramatisches und Komisches wie in Das Leben ist eine Karawanserei, Abschaum, Die Prärie, KuRz Und SCHMERzLOS, LOLA und BILDIKID, GeSCHWISTER und ICH CHEF, Du TuRNSCHUH zusammengehören, gehen diese beiden Formen künstlerischer Aushandlung in den 2000er Jahre in der Regel getrennte Wege. Inwiefern diese Trennung mit Orten und Verortungen, mit der Unterscheidung von Ordnung und Unordnung zusammenhängt, werden die nachfolgenden Analysen zeigen.

Die in den 2000er Jahren immer wieder kehrenden spezifischen Orte, die durch Straßennamen, Moscheen, durch Wohnungen, Geschäfte bis hin zu Schulen markiert werden, verweisen auf eine Globalisierung, die nicht mehr jenseits verortet und nur vorgestellt wird, sondern im konkreten Alltag stattfindet. Dass diese Perspektiven von Ordnung und Rahmung in Film und Literatur auch in enger sozialstruktureller Verbindung stehen, zeigen schon die Berufe der jeweiligen Protagonisten: Sie sind Polizisten, Radiomoderatoren, Ärzte, Studenten, Selbstständige oder Filmemacher, die für sozialen Aufstieg und bestimmte Positionen in der Gesellschaft stehen. Vergleichbare Aufstiegsgeschichten erzählen Mitte der 2000er Jahre auch der Dokumentarfilm GANZ oBEN von Neco Celik und die Publikationen Zehn für Deutschland. Gespräche mit türkeistämmigen Abgeordneten, Mitten in Deutschland. Deutsch-Türkische Erfolgsgeschichten. Der nun folgende Überblick über die filmischen, literarischen und dokumentarischen Werke von 2000 bis $2011 \mathrm{zu}$ den Folgen der Migration wird einen Einblick gewähren, wie darin Orte und Verortungen eingesetzt werden. Sie sind der Rahmen, innerhalb dessen sich die Praktiken und die kulturelle Authentizität der Akteure analysieren und sehen lassen. Zudem zeigen sie, dass Kultur einen Einsatz von Symbolen und Markern darstellt, die nicht von außen einbrechen und dabei maßgeblich die Handlungen der Akteure deterministisch bestimmen. Ebenso wenig stellen sie über Weltverbundenheit Monokulturalität in Frage. In den 2000er Jahren, im Jahrzehnt der Integration, sind kulturelle Marker oder Kategorien, wie Türkisch-Sein, Teil der Akteure und treten mit ihnen von innen nach außen. Dabei geht es nicht mehr um ein »Eingewurzelt-sein«

141 WiRTH, Uwe (2019): »Komik der Integration, Komik der Nicht-Integration«. In: Komik der Integration. Grenzpraktiken der Gemeinschaft, hg. v. Özkan Ezli, Deniz Göktürk, Uwe Wirth, Bielefeld: Aisthesis, S. 19-43, hier S. 25. 
auf Straßen, sondern um eines in Kontexten, Landschaften, genau beschriebenen Stadtteilen und letztlich der Verbindung von öffentlichen und privaten Räumen.

\subsection{Ankommen in filmischen und literarischen Erzählungen}

Kadir Sözen produzierte im Jahr 2004 den zweiteiligen Fernsehfilm ZEIT DER WÜNscHE. Das Drehbuch schrieb Tevfik Başer, Regie führte Rolf Schübel. In der ersten Einstellung sehen wir in Nahaufnahme ein Ölgemälde eines Dorfes. Die Kamera schwenkt nach links auf einen Baum im Gemälde, der auf den ersten Teil des Films »Der Wunschbaum« verweist. Die Kamera bewegt sich über den Rahmen des Bildes und die Wand, an der es hängt, bis wir erkennen, dass wir uns im Flur einer Wohnung befinden. Die Kamera bewegt sich weiter vorbei an einem Wecker (es ist 7:29 Uhr morgens), einem Familienfoto und filmt über eine Türschwelle eine attraktive Frau, die gerade das Frühstück zubereitet und in akzentfreiem Deutsch ihre Kinder Hasan und Mine mahnt, sich zu beeilen, da der Schulbus bald fahre. Sie frühstücken schnell gemeinsam am Tisch, gehen danach gemeinsam durch das Treppenhaus auf die Straße, und die Mutter gibt den Kindern noch ihr Pausenbrot mit. Am bayrischen Akzent des Busfahrers und der Zielhaltestelle des Buses erkennen wir, dass die Sequenz in München spielt. ${ }^{142}$

Am Ende dieser Einstiegssequenz des Films wird ihr Ehemann Yaşar auf seine Frau, die Protagonistin und Ich-Erzählerin des Films, mit einer Pistole schießen. Von der Pistole ihres Mannes getroffen wird Melike auf der Straße liegend aus dem Off beginnen, ihre Geschichte zu erzählen. ${ }^{143}$ Diese beginnt in einem türkischen Dorf in den 1960er Jahren, das auf dem eingangs gezeigten Ölgemälde zu sehen war. So wird gewissermaßen aus Fiktion, Bild und Vorstellung Realität. Im Mittelpunkt steht die sich unglücklich entwickelnde Liebesgeschichte zwischen Melike und Mustafa, das Leben und die Ausbreitung des »Deutschlandfiebers« im Dorf. Der zweite Teil des Films spielt in der Bundesrepublik und zeigt neben den Beziehungen Melikes zu Mustafa und Yaşar das Leben der Gastarbeiterinnen und Gastarbeiter. Zugleich wird anhand von Mustafas Freund Kadir ein Wandel im Leben der türkischen Gastarbei-

142 Siehe hierzu: ScHüBEL (2004).

143 Auch Necla Kelek beginnt die Taschenbuchausgabe ihres Buchs Die fremde Braut mit der Beschreibung der Ermordung einer Deutsch-Türkin. Hatun Sürücü wurde am 7. Februar 2005 von ihrem Bruder nach einem Streit auf dem Weg zur Bushaltestelle an der Tempelhofer Oberlandstraße erschossen. Vor Gericht gab die Familie an, dass Hatuns Lebensweise die Ehre der Familie verletzt habe. Zur Tat bekannte sich der jüngste Bruder, der minderjährig war. Siehe hierzu: KeleK (2005): S. 9. Im Unterschied zu Kadir Sözen erzählt Necla Kelek nicht die Geschichte der Ermordeten, sondern ihre eigene. Sie ist wie Hatun Sürücü eine Türkin, die sich für die deutsche Lebensweise entschieden hat. 
ter gegen Ende der 1970er Jahre in der Bundesrepublik skizziert. Mustafa und Kadir hatten beide als erste das Dorf in Richtung Deutschland verlassen. Der Schluss des Films wird mit der zuvor beschriebenen Einstiegssequenz des Films eingeleitet. ${ }^{144}$ Am Ende erfahren wir, dass Melike, die Erzählerin der Geschichte, auf der Straße in München stirbt und dass die beiden Freunde, Mustafa und Kadir, die sich in Deutschland voneinander entfremdet hatten, wieder als Freunde zusammenkommen. Ersterer ist ein anerkannter Künstler geworden, letzterer ein erzkonservativer Muslim mit einem Krämerladen. Die Erzählerin schließt auch mit den Worten den Film, dass wenn ihr Tod einen Sinn gehabt hat, dann den, dass alte Freunde wieder zusammengekommen sind. ${ }^{145}$ Daher ist die im ersten Teil des Films dargestellte Form des Dorflebens in der Türkei nicht die tatsächliche Grundlage für die Tötung der Erzählerin. Obwohl dem Mord an der Erzählerin in Deutschland die Beschreibung des Dorflebens in der Türkei vorausgeht, hat die Tat weder mit ihrem Lebenswandel noch mit der Ehrenrettung ihres Mannes Yaşar zu tun, wie es noch in den wissenschaftlichen, filmischen und literarischen Erzählungen der 1980er Jahre gewesen wäre. Yaşar begeht den Mord aus egoistischen Motiven und niederen Instinkten. ${ }^{146}$ Noch im türkischen Dorf ist ihm zuvor auf unlautere Weise gelungen, Melikes Ehemann zu werden: Er hat die Liebesbriefe Mustafas aus Deutschland an Melike abgefangen und Melikes Briefe umgekehrt nicht nach Deutschland versenden lassen. ${ }^{147}$ So steht im Zentrum des Films nicht die Darstellung und Erklärung des Phänomens des Ehrenmords als ein von oben befohlene Tat, sondern vielmehr die Frage, wie sich bedingt durch Migration unterschiedlich entwickelte Lebensweisen in einen gesellschaftlichen Lebenszusammenhang gebracht werden können. Diese Klarheit der Erzählung ist auch ein Resultat ihrer Rahmenerzählung.

Eine derartig erzählerische Rahmenstruktur von Anfang und Ende der Erzählung finden wir auch in Fatih Akıns Film Auf DER ANDEREN SEITE. Dort beginnt der Film ebenfalls mit einer ruhigen, malerisch wirkenden Einstellung. Auch hier bewegt sich zunächst niemand. Wie in ZEIT DER WÜNSCHE gibt es einen deutschen und einen türkischen Teil des Films. Am Anfang sehen wir einen malerischen Ort in der Türkei, eine einstöckige weiße Hütte im Sonnenschein. Die Kamera schwenkt nach rechts, bis sie an den Zapfsäulen an einer Tankstelle

144 Siehe hierzu: SCHÜвEL (2004).

145 Siehe hierzu: ebd.

146 ScнüBEL, Ralf (2004): Zeit der Wünsche, Spielfilm, Deutschland.

147 Yaşar ist Inhaber des einzigen Krämerladens im Dorf, in dem er auch die angekommene Post an die Dorfbewohner verteilt und zu versendende an die türkische Post übergibt. Siehe hierzu: SöZEN (2004). 
mit der Aufschrift »Petrol« anhält. ${ }^{148}$ Wir hören dabei leise türkische Musik aus einem Radio. Entgegengesetzt zur Kamera-Bewegung fährt nun von rechts ein Auto an die Zapfsäule ins Bild. Einer der Protagonisten des Films, Nejat, steigt aus, wünscht Tankwart und Besitzer der Tankstelle ein schönes muslimisches Opferfest, lässt tanken, holt sich etwas zu essen, führt ein kurzes Gespräch mit dem Besitzer der Tankstelle und fährt weiter. ${ }^{149}$ Im Gegensatz zu Sözens Film wird Türkisch gesprochen, das deutsch untertitelt ist. Wie in ZEIT DER WüNSCHE gibt es keine Vermischung der Sprachen in der Weise, dass man beim Sprechen zwischen beiden hin- und herwechseln würde. Entweder wird Deutsch, Türkisch oder Englisch gesprochen. Wie in ZEIT DER WüNSCHE scheint auch in diesem Film oft die Sonne. Bei Ausblendungen werden die Titel der Teile des Films eingeblendet. Als etwa Nejat kurz nach dem Tanken durch einen Tunnel fährt, erscheint der Schriftzug »Yeters Tod« im Bild. In der nächsten Einstellung wird in Bremen der zweite Protagonist eingeführt. Ali ist ein Gastarbeiter der ersten Stunde und beobachtet an einem sonnigen Tag auf dem Weg ins Bordell eine 1. Mai-Demo. Er ist also nicht wie Niyazi über dreißig Jahre zuvor unterwegs zur Nachtschicht in eine Fabrik, während seine deutsche Nachbarin im kalten Bett keinen Schlaf findet. ${ }^{150}$ Nach dem Sex wird Ali die türkeistämmige Prostituierte Yeter darum bitten, für Geld mit ihm zusammen zu leben. Sie willigt ein. Später sehen wir, wie Ali sie im Streit unbeabsichtigt totschlägt. ${ }^{151}$

Während das anfangs gezeigte orientalische Postkartenidyll aus GEGEN DIE WAND mit dem grellen Scheinwerferlicht aus Die Fabrik in Hamburg kontrastiert wurde, entsprechen sich in lichtdramaturgischer Hinsicht die ersten Einstellungen in Auf DER ANDEREN SEITE in der Türkei und in Deutschland, sie sind gewissermaßen kompatibel. Wie die Einstiegssequenz in ZEIT DER WÜNSCHE werden wir die Tankstelle in AUf DER ANDEREN SEITE gegen Ende des Films als Ort der Motivbündelung erneut zu sehen bekommen. Außerdem sehen wir eine türkische Version der 1.-Mai-Demo in Istanbul. ${ }^{152}$ Während Gehen und Sprechen Leitkategorien der filmischen und literarischen Erzählungen der 1990er Jahre

148 Siehe hierzu: GöKTÜRK, Deniz (2010): »Mobilität und Stillstand im Weltkino digital«. In: Kultur als Ereignis. Fatih Akms Auf der anderen Seite als transkulturelle Narration, hg. v. Özkan Ezli, Bielefeld: transcript, S. 15-46, hier S. 19. Siehe auch: GüNELI, Berna (2014): »The Sound of Fatih Akın's Cinema. Polyphony and the Aesthetics of Heterogeneity in The Edge of Heaven«. In: German Studies Review, Volume 37, Number 2, May 2014, S. 337-356.

149 Siehe hierzu: Akin, Fatih (2007): Auf der anderen Seite, Spielfilm, Deutschland.

150 Siehe hierzu: ÖREN, Aras (1973): Was will Niyazi in der Naunynstraße, Berlin: Rotbuch, S. 9. 151 Siehe hierzu: AkIN, Fatih (2007).

152 Ebd. In Deniz Göktürks Analyse der Einstiegssequenz dient der Aspekt der Verortung der Beschreibung der digitalen Revolution im DVD-Bereich, die die Rezeption von Filmen wie AuF DER ANDEREN SEITE bestimme. Siehe hierzu: GöKTÜRK (2010). 
waren, geht es nun um Entscheiden, Handeln und vor allem um das Sehen: das Sehen geografischer, topografischer, stereotyper und ethischer Ordnungen, die durch lebensgeschichtlich bestimmte Kontexte zwischen Ähnlichkeit und Differenz pendeln. ${ }^{153}$ Wie bei Römhild und Brubaker sind Migration und Ethnizität keine eindeutig bestimmbaren Untersuchungsgegenstände, sondern Fragen der Perspektive und Kognition. Eindrücklich zeigt sich diese Verschiebung auch in den mehrfach prämierten und sehr erfolgreichen Filmen DIE FREMDE (2010) und Almanya. Willkommen in Deutschland (2011). Die Ich-Erzählerin aus Emine Sevgi Özdamars Erzählband Der Hof im Spiegel (2001) bewegt sich ebenfalls weniger als in den früheren Romanen. Die meiste Zeit beschreibt sie beim Telefonat mit ihrer Mutter oder beim morgendlichen Aufstehen, wie sie in ihrem großen Spiegel, ohne selbst gesehen zu werden und ohne sich selbst zu sehen, sieht, was im Hof des Mehrparteienhauses und in den Wohnungen der Nachbarn passiert: »Wenn ich aufwachte, schaute ich nicht vom Balkon aus auf den Hof, sondern schaute in den Spiegel. Ich kochte Kaffee oder schrieb oder putzte und konnte immer wieder den Hof und meine Nachbarn in meinen Zimmern sehen. «154

Dieser Verschiebung der Perspektive begegnen wir auch in Feridun Zaimoğlus Erzählband Zwölf Gramm Glück von 2004. Gleich in der ersten von zwölf Erzählungen nimmt der Ich-Erzähler einen Platz ein, der ihm ein distanziertes Sehen ermöglicht. Er beobachtet aus seinem »Krähennest«, seiner Wohnung, eine »eskalierende Situation«, eine Demonstration einer linken Gruppierung in Kiel. ${ }^{155}$ Er selbst möchte sich nicht mehr an Auseinandersetzungen auf Straßen beteiligen, ihm reicht »die Zimmerwärme und die Schreibmaschine im Rücken «. ${ }^{156}$ Von dort aus kann er genau beobachten, wie in der »Hauptstraße«, oder »zwischen der Julius- und Eifflerstraße [...] eine Yuppiesanierung « sich breit gemacht hat. Etwas, das »jedem linkskulturellen Milieu blüht: auf der rechten Straßenseite wechseln sich Fischrestaurants, portugiesische Stehcafes, Goldschmuckläden und Nostalgiemöbelmärkte ab«. ${ }^{157}$

153 Siehe hierzu: ELSÄSSER, Thomas (2011): „Vom Tod als Experiment im Leben zum Kino der ethischen Handlungsmacht. Fatih Akın und die >Ethische Wende«. In: Kino in Bewegung. Perspektiven des deutschen Gegenwartsfilms, hg. v. Thomas Schick, Tobias Ebbrecht, Wiesbaden: Springer, S. 61-62. Siehe auch: TezCAN, Levent (2010): »Der Tod diesseits von Kultur. Wie Fatih Akın in `Auf der anderen Seite` den großen Kulturdialog umgeht «. In: Kultur als Ereignis, S. 45-70. 154 Özdamar, Emine Sevgi (2001): Der Hof im Spiegel, Köln: Kiepenheuer \& Witsch, S. 28.

155 ZAIMoĞLU, Feridun (2004): „Fünf klopfende Herzen, wenn die Liebe springt«. In: ders: Zwölf Gramm Glück, Köln: Kiepenheuer \& Witsch, S. 11-32, hier S. 20.

156 Ebd.

157 Ebd., S. 13. Dieser Übergang von der Straße in die Wohnung und der damit einhergehenden präziseren Beschreibung der Umgebung vor Ort dokumentiert auch der Dokumentarfilm von Susan Tratz: Feridun ZaimoĞLu. Mein Leben (2010). Siehe hierzu: Tratz/ZaimoĞLu (2010). 
Vergleichbar präzise beschreibt Zaimoğlu in »Häute« aus demselben Band das Leben in einem archaisch wirkenden Dorf. ${ }^{158}$ Wie der Protagonist in Akıns Film spricht auch hier der Ich-Erzähler die Sprache der Dorfbewohner, doch seine langen Haare und sein Verhalten weisen ihn als jemanden aus, der nicht zum Dorf gehört. ${ }^{159}$ Aus der ersten Erzählung wissen wir bereits, dass er eigentlich in Kiel lebt. Und wie die bereits genannten beiden Filme ist auch der Erzählband Zwölf Gramm Glück in territorialer Hinsicht in zwei Hälften geteilt: Sieben der zwölf Erzählungen spielen unter dem Obertitel »Diesseits« in Deutschland; die anderen fünf »Jenseits « in der Türkei. ${ }^{160}$ Der Theaterregisseur Nuran David Caliş schreibt seinen autobiografisch grundierten Roman Der Mond ist unsere Sonne (2011) ebenfalls aus einer bestimmten Perspektive, die mit einer identitätspolitischen Erkenntnis einhergeht. Der Protagonist des Romans Alen hat einen armenisch-türkisch-jüdischen Hintergrund und wurde in Bielefeld geboren. Er ist mit seinem Onkel im Osten der Türkei auf der Suche nach ihrer Herkunft. Zu Beginn des Romans sitzt er auf einem Felsvorsprung und blickt auf den Berg Ararat. Er erkennt, dass sein Vater vielleicht hierher gehört, er selbst aber nicht. Der Ort, an dem für ihn alles anfing, liegt $5000 \mathrm{~km}$ vom Ararat entfernt im Stadtteil Baumheide in Bielefeld. ${ }^{161}$

Hasan, der Protagonist in Yadé Karas mit dem Deutschen Buchpreis prämierten Roman Selam Berlin (2004), nimmt ebenfalls zu Beginn der Erzählung in topografischer wie kultureller Hinsicht eine bestimmte Position ein. Mit seinen Eltern sieht er im Fernsehen in Istanbul, wie im Jahr 1989 die Berliner Mauer fällt. Er sieht, wie plötzlich »Straßen, Plätze und Orte« seiner Kindheit »im Interesse des Weltgeschehens « stehen. ${ }^{162}$ Sein erster Impuls - »Kanake her, Almanci hin« - ist, nach Berlin zurückzukehren, wo er aufgewachsen ist. ${ }^{163}$ Bisher war alles transit in seinem Leben, »das sollte sich aber ändern «. ${ }^{164}$ Sehen und zu wissen, wohin man gehört, fallen hier zusammen. In Berlin angekommen, möchte er aus seinem Leben etwas machen und setzt seinen türkischen Hintergrund ein, um in der Filmbranche als Schauspieler arbeiten zu können. Auch wenn er sich explizit als Berliner begreift und dort Abitur gemacht hat, spielt er in einem Film einen dealenden >Kanaken`. Den Türken zu türken, ist hier Teil der Berufsfin-

158 Siehe hierzu: ZAImoĞLU, Feridun (2004): »Häute«. In: ders.: Zwölf Gramm Glück, S. 105-121. 2003 wurde diese Erzählung mit dem Ingeborg-Bachmann-Preis ausgezeichnet.

159 Eine ähnliche Beobachtung hält Deniz Göktürk für den Protagonisten Nejat in AUF DER ANDEREN SEITE fest. Siehe hierzu: GöKTÜRK (2010): S. 20.

160 Siehe hierzu: ZAIMoĞLU, Feridun (2004): Zwölf Gramm Glück, Köln: Kiepenheuer \& Witsch.

161 CaLIş, Nuran David (2011): Der Mond ist unsere Sonne, Frankfurt a. M.: Fischer, S. 5-11.

162 KARA, Yade (2004): Selam Berlin, Zürich: Diogenes, S. 9.

163 Ebd., S. 5.

164 Ebd., S. 17. 
dung, die in Karas Roman zugleich für die Selbstfindung, für ein Ankommen in Deutschland steht. ${ }^{165}$ Die Stadt Berlin beschreibt Hasan detailliert von Straße zu Straße, Haltestelle zu Haltestelle. Diese immer wieder stattfindenden Verortungen in Selam Berlin weisen Hasan als kundigen Berliner aus, der zu der Stadt gehört, in der er lebt, sie kennt und in ihr seinen Platz sucht. Mit Letzterem ist vor allem seine Berufssuche gemeint, für die Hasan seinen türkischen Hintergrund bewusst einsetzt. Ähnlich präzise wie in Selam Berlin werden Stadtteile und Orte in Mein Name ist Revolution (2011) von Imran Ayata und im bereits erwähnten Der Mond ist unsere Sonne beschrieben. Bei Calış steht das Viertel Baumheide im Vordergrund; ein Bielefelder Stadtteil, der eigentlich weder physisch noch emotional ein Ankommen in der Stadt und in der Gesellschaft ermöglicht. Denn

wie soll einer, der in Baumheide gelandet ist, seinen Beitrag leisten, überhaupt, was soll der Beitrag von jemandem sein, der nicht hier ankommen darf, und wie soll einer seinen Beitrag leisten, wenn es nur eine Buslinie gibt, die die Siedlung mit dem Zentrum verbindet, ein Bus, der nur zweimal in der Stunde fährt, und um 20 Uhr ist Schluss, und der Bus kostet 4 Euro hin und zurück, und das ist die Hälfte des dir am Tag zur Verfügung stehenden Budgets bei dem momentanen Hartz-IV-Satz. ${ }^{166}$

Alen möchte aber ankommen, und er wird sich dafür »die Haut abziehen, wenn sie sich nicht von alleine lösen will«. Seine Mutter und seine Freunde werden ihn nicht mehr verstehen, aber dafür wird er ankommen. „Dann werde ich endlich dabei sein und dazugehören. Nicht am Rand sein. Nicht mehr außen vor sein.« Nicht wie sein Onkel, der neben ihm am Ararat »auf seiner Heimat-Scheiße hängengeblieben ist . $^{167}$

Kemal Kurts Jugendroman Sonnentrinker, sein letzter Prosatext, beginnt ebenfalls mit Platzierung und Orientierung. Der erste Satz definiert, was Glück heißt: wenn die Bruchstücke des Lebens an ihre Plätze fallen und ein Ganzes ergeben. Dabei bleibt »kein Teilchen übrig, kein Zwischenraum wird verschenkt. Alles passt zusammen«, ist kompatibel. ${ }^{168}$ Anschließend wird der Protagonist Hakan von seinen Freunden per Handy zu einem bestimmten Ort manövriert. Dabei können wir als Leser anhand der Straßennamen genau mitverfolgen, wie Hakan sich durch den

165 In der Komödie SüPERSEKS mimt der deutsch-türkische Protagonist Elviz einen »Prolltürken«, um bei einer attraktiven Frau anzukommen, die einen türkischen Vater, der ein erfolgreicher Arzt ist, und eine deutsche Mutter hat. Er hat nämlich erfahren, dass sie ihren Vater mit einem »Prolltürken« schockieren will, der eine gute deutsche Partie für sie im Auge hat. Siehe hierzu: WACKER, Torsten (2004): Süperseks, Hamburg: Magnolia Filmproduktion GmbH.

166 CALIŞ (2011) S. 120f.

167 Ebd., S. 16.

168 KuRT, Kemal (2002): Die Sonnentrinker, Berlin: Altberliner Verlag, S. 7. 
Berliner Wedding bewegt und wo er ankommt. ${ }^{169}$ Mit einem Ankommen an einem bestimmten Ort, der Wohnung seiner türkischen Familie, endet auch der Roman. ${ }^{170}$ Dazwischen suchen die Familienmitglieder Kneipen, Moscheen und öffentliche Plätze ab, um Hakans Vater zu finden, der am Tag des muslimischen Opferfestes verschwunden ist. ${ }^{171}$ In der erzählten Zeit des Romans fällt der erste Tag des muslimischen Opferfestes mit dem christlichen Heiligen Abend zusammen. Wie in AuF DER ANDEREN SEITE rahmen Ort und Religion die Erzählung, und die Sonne scheint häufig. Stadt-, Ortsbeschreibungen, Lichtverhältnisse und der Einsatz kultureller Marker sind in den Texten und Filmen der 2000er Jahre einander sehr ähnlich.

In Detlef Bucks intensivem Film KNALlHaRT von 2005, in dem es um den Zusammenprall der Kulturen in Berlin-Neukölln geht, ist der Zusammenhang von Ort und Erzählung ebenfalls konstitutiv. Die Erzählung beginnt an einem spezifischen Ort. Im Vorspann ohne Titelei sehen wir einen etwas aufgelösten blonden Jungen, der unterwegs ist auf einem Fußweg zwischen zwei stark befahrenen Berliner Straßen. Im Unterschied zu den Filmen der 1990er Jahre sehen wir in der nächsten Einstellung, dass seine Bewegung ein klares Ziel hat, die Polizeistation in Berlin-Neukölln. Er betritt das Gebäude und wartet, bis der Kommissar eintrifft. Sie duzen einander, kennen sich also bereits. Der Kommissar sieht Blut an den weißen Turnschuhen des Jungen und verlangt von ihm, alles zu erzählen, von Anfang an. ${ }^{172}$ Nicht nur der Polizist braucht die Erzählung. Wir als Zuschauer brauchen sie ebenfalls, um zu erfahren und einordnen zu können, was passiert ist.

Auch in Züli Aladağs mehrfach prämierten und zugleich äußerst kontrovers diskutierten Film WuT spielt ein bestimmter Ort am Anfang und am Ende eine herausragende Rolle. Am Anfang kommt der deutsche Protagonist Felix ohne Schuhe aus der Schule nach Hause. Die Barfüßigkeit steht hier nicht für die existenzielle Disposition der Akteure wie in Ayhan Salars Kurzfilm ToTENTRAUM von 1994, indem ein türkischer Gastarbeiter barfuß nachts aus einem Zugwaggon aussteigt. ${ }^{173}$ Can, sein Mitschüler und zugleich türkischer Protagonist im Film, hat Felix die Schuhe abgenommen. Sein Vater erfährt daraufhin, dass sein Sohn schon länger von Can »abgezogen « wird. ${ }^{174}$ Im Laufe des Films wird Can Felix und seine wohlhabenden Eltern immer mehr terrorisieren, dabei wird ihr luxuriöses Haus eine konstitutive Rolle spielen, wo der Film auch tragisch enden wird. ${ }^{175}$

169 Siehe hierzu: Ebd., S. 14-21.

170 Ebd., S. 221.

171 Ebd., S. 89-202.

172 Siehe hierzu: Buck, Detlef (2005): Knallhart, Spielfilm, Deutschland.

173 Siehe hierzu: http://www.salarfilm.de/salarfilm/films.html (20.09.2018).

174 AlADAĞ, Züli (2005): Wut, TV-Spielfilm, Köln: Colonia Media Filmproduktions GmbH. 175 Ebd. 
Felix' Vater und Can fechten in Aladağs Film einen territorialen Kampf aus. Im Laufe des Films dringen sie wechselseitig immer stärker in die Territorien des anderen ein, bis am Ende als Austragungsort des Konflikts nur noch das Haus der reichen deutschen Familie übrig bleibt, wo der deutsche Vater seine universalistischen von den 68ern und von der Aufklärung geprägten Werte mit der Tötung Cans verrät. ${ }^{176}$ Auch in Necla Keleks Autobiografie sind die Orte als Verweise auf eine Ordnung konstitutiv: zum einen das türkische Dorf mit seinen rückständigen Regeln, aber auch die Moschee in Hamburg, in der sie ihre Interviewpartner immer wieder trifft. Interessanterweise hat auch sie ihren Text in einen türkischen und einen deutschen Bereich aufgeteilt, die zusammengeführt und ineinander verschränkt werden. Zaimoǧlus wichtiger Roman Leyla beginnt ebenfalls mit der Verortung der Familie in einem Haus in einem türkischen Dorf. Die Protagonistin und Erzählerin ist Tochter einer armenischen Mutter und eines tscherkessischen Vaters. Am Abend erwarten alle mit großer Furcht den tyrannischen Vater, der nach der Arbeit die Familie terrorisiert. Leyla lernt, selbstbewusst mit dieser Situation umzugehen und migriert am Ende des Romans nach Deutschland. ${ }^{177}$

Eine vergleichbare Verschränkung der Territorien bestimmt auch den erfolgreichen Film DiE FREMdE von Feo Aladağ. Er beginnt in der Peripherie Istanbuls, in der die neue türkische Familie der eingeheirateten Deutsch-Türkin Umay lebt. Da sie es mit ihrem gewalttätigen Ehemann und seiner unterdrückerischen Familie nicht mehr aushält, flieht sie mit dem gemeinsamen Kind zurück nach Deutschland zu ihren Eltern. Aus Sorge vor dem Gerede der anderen Türken in der deutschen Nachbarschaft fliegt Vater Kader ratsuchend in ein türkisches Dorf. ${ }^{178}$ Er besucht dort, ein ebenfalls malerisch wirkendes Dorf, ein bestimmtes Haus, indem ein Mann auf einem Divan schläft. An diesem Ort wird nicht geredet. ${ }^{179}$ Wie in ZEIT DER WüNSCHE steht am Ende des Films ein Mord, der als Ergebnis eines sehr schwierigen Aushandlungsprozesses gezeigt wird. Im Unterschied zu Sözens Film sind es hier nicht egoistische oder niedere Instinkte, die zur Tat führen, sondern der soziale Druck der türkischen Community in Berlin.

Die besondere Bedeutung spezifischer Orte, von Sichtbarkeit, Ordnungen und dem selbstgewählten Einsatz kultureller Marker finden wir auch in den

176 Siehe hierzu: Prager, Brad (2012): » Only the Wounded Honour Fightsı. Züli Aladağs Rage and the Drama of the Turkish German Perspective«. In: Turkish German Cinema in the New Millennium. Sites, Sounds, and Screens, hg. v. Sabine Hake, Barbara Mennel, New York: Berghahn Books, S. 109-122.

177 Siehe hierzu: ZaimoğLu, Feridun (2006): Leyla, Köln: Kiepenheuer \& Witsch, S. 9 f.

178 AladaĞ, Feo (2010): Die Fremde, Berlin: Independent Artists Filmproduktion.

179 Siehe hierzu: Gramling, David (2012): »The Oblivion of Influence. Mythical Realism in Feo Aladağs When we leave«. In: Turkish German Cinema in the New Millennium. Sites, Sound, and Screens, hg. v. Sabine Hake, Barbara Mennel, New York: Berghahn Books, S. 32-43. 
Culture-Clash-Komödien, die in den 2000er Jahren eine besondere Konjunktur erfahren. Anno Sauls Kевав Connection von 2005 beginnt mit einem Werbefilm für einen Dönerimbiss im Hamburger Schanzenviertel, wo am Ende des Films die Protagonisten Ibo und Titzi heiraten. ${ }^{180}$ Das Drehbuch zu diesem Film verfasste Fatih Akın. In Torsten Wackers SüPERSEKS von 2004 muss der Protagonist Elviz seine Schulden bei seinem Onkel Cengiz zurückzahlen, der andernfalls das Haus seiner Mutter Gülbahar (gespielt von Emine Sevgi Özdamar) in der Türkei abreißen und dort einen riesigen Hotelkomplex errichten will. Elviz kommt auf die Idee, eine Sexhotline für Türken einzurichten. So etwas gibt es in Deutschland nämlich noch nicht. ${ }^{181}$ Und auch wenn der Deutsch-Türke Elviz als Rufnamen einen bekannten amerikanischen Namen trägt, verweist nichts an und um ihn herum auf den amerikanischen Musiker. Vielmehr mimt er den >Kanaken oder halbsprachigen Türken, wenn es die Situation erfordert. In dem mehrfach prämierten Film MEINE VERRÜCKTE TÜRKISCHE HOCHZEIT von 2006, der sich an die äußerst erfolgreiche amerikanisch-griechische Komödie MY BIG FAT GREEK WEDDING (2002) anlehnt, steht am Anfang ein Plattenladen, in dem am Ende die besagte Hochzeit stattfindet. ${ }^{182}$ Durch die Aneignung bestimmter Praktiken wird sich der deutsche Protagonist Götz im Laufe des Films zu einem türkischen Mann entwickeln. Indem Ort und Perspektive an die Stelle des Subjekts rücken, verschiebt sich der Fokus von der Artikulation und Bewegung der Akteure auf ihre Lebensweisen; darauf, welchen Platz sie einnehmen und was sie in und mit ihrer Umgebung machen.

Wir werden noch sehen, dass Praktiken den Ausschlag für Integration oder Desintegration geben. Genau in dieser Wende von der Artikulation zur Praxis, vom Gehen zum Sehen, wie ich sie für den Übergang von den 1990ern zu den 2000ern feststelle, liegt auch der besondere Reiz, Komödien zu wählen, um Konflikte und ihre Verhandlungen zu thematisieren. Denn die Komödie setzt nach Robert Pfaller eine »einfache, ernüchternde Position des Materialismus voraus: Sie anerkennt die grundlegende Dezentrierung der Individuen, die sich mit Notwendigkeit immer für Subjekte, für Zentren halten $« .{ }^{183}$ Doch gilt diese Dezentrierung keineswegs allein für die Culture-Clash-Komödien. Sie gilt für die meisten Filme und Texte der Zeit: Zeit der Wünsche, Wut, Auf Der Anderen Seite, Die Fremde, Almanya. WillKommen In DeUTSCHLAND, MEINE VERRÜCKTE TÜRKISCHE HOCHZEIT, Zwölf Gramm Glück, Selam. Berlin, Seltsame Sterne starren zur Erde, Mein Name ist Revolution, Der Mond ist unsere Sonne und Leyla. All diese Werke haben

180 SAUl, Anno (2004): Kebab Connection, Spielfilm, Deutschland.

181 WACKER, Torsten (2004): Süperseks, Spielfilm, Deutschland.

$182 \operatorname{Holtz}$ (2007).

183 Pfaller, Robert (2015): Wofür es sich zu leben lohnt, Frankfurt a. M.: Fischer, S. 72. 
Preise bekommen. Bei MeIne verrückTE tüRKISche HochzeIT, der 2007 den Grimme-Preis erhielt, war das auschlaggebende Argument, dass es dieser Multikulti-Komödie gelungen sei, alle möglichen Klischees über türkische Familien zusammenzubringen und gekonnt mit ihnen umzugehen. Vor allem die Figur des Vaters habe das Ernste der Thematik ins überspitzt Komische überführt. ${ }^{184}$

Besondere Aufmerksamkeit und Popularität erlangte die Serie TüRKISCH FÜR ANFÄNGER, indem Orte auch eine herausragende Funktion einnehmen. So gibt es in den 52 Folgen der 3 Staffeln von TÜRKISCH FÜR ANFÄNGER des Drehbuchautors Bora Dağtekin kaum eine Sequenz, die nicht mit einem establishing shot einsetzt; eine Aufnahme, die bestimmt, worin das Folgende stattfindet, und die in den 1990er Jahren kaum vorkam. Besonders Szenen im gemeinsamen Wohnhaus, das die Familien Öztürk und Schneider zu Beginn der Serie in Berlin-Neukölln beziehen, werden immer mit establishing shots eingeführt. Das gilt auch für fast jede Sequenz in der Schule, die mit einer Außenaufnahme des Gebäudes eingeleitet wird. ${ }^{185}$ Dadurch konzentriert sich die Beobachtung auf die Handlungen der Akteure. In der Diktion der Serie heißt das aber auch, dass durch diese Verortungen jedes soziale und kulturelle Problem gelöst werden kann. Beispielsweise teilen sich die Töchter von Doris und Metin, Lena und Yağmur, in TÜRKISCH FÜR ANFÄNGER ungewollt ein großes Zimmer. Lena begreift und inszeniert sich selbst als aufgeklärtes, emanzipiertes und cooles Mädchen, Yağmur hingegen nimmt die Regeln ihrer Religion sehr ernst. Wie der Umgang mit diesen Inkompatibilitäten hier und an anderen Stellen der Serie gelöst, d. h. kompatibel gemacht wird, das trotz der Differenz der Lebensweisen und Konflikte über den gemeinsamen Alltag im Haus ein Zusammenlebenwollen entsteht, ist eine Verhandlungsform, die in den 2000er Jahren zur Disposition steht. Ihre Grundlage ist, dass trotz aller Befindlichkeiten die Akteure ihre Gefühle und den Einsatz der kulturellen Marker unter Kontrolle haben.

In Sinan Akkuş' Komödie EvET, ICH wILL! ist es ein Hochhaus in Berlin, das immer wieder fotografiert wird. Darin leben Türken, Kurden, Deutsche, Alt-Achtundsechziger und Homosexuelle. Berlin ist hier die multikulturelle Hauptstadt, in deren Zentrum das Zusammenleben und das Zusammenkommen der genannten Gruppen stehen. Doch geht es keineswegs um die Gruppen selbst, vielmehr um ihre einzelnen Akteure, um ihre grenzüberschreitende Liebe und besonders um ihren Umgang mit und beherrschbaren Einsatz von kulturellen Markern und

184 Siehe hierzu: GRIMmE PreIS (2007): »Meine verrückte türkische Hochzeit (ProSieben)«. In: Grimme Preis, http://www.grimme-preis.de/archiv/2007/preistraeger/p/d/meine-verrueckte-tuerkische-hochzeit-prosieben/ (29.03.2018).

185 DAĞTEKIN, Bora (2006-2009): Türkisch für Anfänger 1, 2 \& 3, TV-Serie, Deutschland, Universum Film $\mathrm{GmbH}$. 
Erwartungen. Vielfalt ist hier Programm, ihr Konfliktpotential löst sich durch besondere Umgangsweisen auf. ${ }^{186}$ Ähnliches gilt für ALMANYA. WILLKOMMEN IN DEUTSCHLAND. In dieser Tragikomödie leben intergenerational alle Familienmitglieder in dem Haus, das Großvater Hüseyin, der einmillionen und erster Gastarbeiter in der Bundesrepublik, kurz nachdem er seine Familie in Deutschland zusammengeführt hat, gekauft hat. Auch hier wird das Haus mit einem establishing shot eingeführt, bevor sich alle Mitglieder zum Mittagessen bei Hüseyin und seiner Frau Fatma einfinden. ${ }^{187}$

In TÜRKISCH FÜR ANFäNgER, EvET, ICH WILl! und in AlmANYA ist der Zuschauer durchweg im Bilde darüber, wo etwas stattfindet. Äußerst prominent sind Tischsequenzen. ${ }^{188}$ Damit setzt auch die Erzählung in der Erzählung im Film der Şamdereli-Schwestern ein, die den Ausgang zur Frage bildet, ob man Türke oder Deutscher sei, zur gemeinsamen Reise in die Türkei, zu einem Haus, das der Vater gekauft hat. Es ist nach dem deutschen Haus, das zweite, das Hüseyin 40 Jahre später kauft. Der Hauptgrund für diesen Kauf ist nicht wie in den 1980er Jahren die Rückkehr in eine Heimat, sondern vielmehr eine gemeinsame letzte Reise der ganzen Familie in die Türkei. Auf dieser Reise wird wie in Akkuşs Film die Vielfalt innerhalb der Familie verhandelt. Auf der Reise stirbt auch der Protagonist Hüseyin. Das Haus in der Türkei stellt sich am Ende als ein Ort heraus, an dem noch gebaut werden muss. Zurück bleibt der Sohn, der in Deutschland arbeitslos ist und nun das Haus bauen will. Alle anderen Familienmitglieder kehren in die Bundesrepublik zurück, ob aus beruflichen Gründen oder heimatlichen Gefühlen, bleibt unklar. Der Film endet jedenfalls mit dem Auftritt von Hüseyins Enkel Cem, der eine Rede bei den Feierlichkeiten zum 50-jährigen Jubiläum der türkischen Gastarbeitermigration nach Deutschland in Berlin hält. Anfangs war Hüseyin selbst mit einem Schreiben der deutschen Kanzlerin zu den Feierlichkeiten der Bundesregierung »Deutschland sagt Danke« als Redner eingeladen. ${ }^{189}$

186 AKKUŞ, Sinan (2008): Evet, ich will!, Spielfilm, Deutschland.

187 ŞAMDERELI, Yasemin (2011): Almanya. Willkommen in Deutschland, Spielfilm, Deutschland. 188 Siehe hierzu auch: Holtz (2007); AladAĞ (2010); AkIN (2007). Der amerikanische Literaturwissenschaftler David Gramling macht ebenfalls auf die zentrale und konstitutive Bedeutung von Tischsequenzen beim Essen, miteinander Sprechen und Schweigen in Feo Aladağs Film DiE FREMDE aufmerksam. Siehe hierzu: GRAMLIng, David (2012): »The Oblivion of Influence: Mythical Realism in Feo Aladağ's When We Leave«. In: Turkish German Cinema in the New Millennium. Sites, Sounds, and Screens, New York: Berghahn, S. 32-43, S. 37.

189 Ebd. Am 1. Oktober 2008 würdigte die Bundeskanzlerin Angela Merkel unter dem Motto »Deutschland sagt Danke« die Aufbauleistung der ehemaligen Gastarbeiter für die Bundesrepublik. Eingeladen waren in das Bundeskanzleramt 200 Arbeitnehmerinnen und Arbeitnehmer der ersten Generation von Gast- und Vertragsarbeitern. Siehe hierzu: https://www.bundesregierung.de/Content/DE/Artikel/IB/Artikel/Geschichte/2008-09-23-deutschland-sagt-danke.html (01.05.2018). 
In den 2000er Jahren boomte nicht nur die Ethno-Comedy, sondern auch die Programme deutsch-türkischer Comedians, die bis heute erfolgreich sind: Kaya Yanar, Bülent Ceylan, Murat Topal, Fatih Cevikkollu, Django Asül und Serdar Somuncu. Auch bei ihnen stehen Orte und Verortungen im Zentrum des Geschehens. Beispielsweise gehören zu den ersten Sketchen, die Kaya Yanar in seiner Fernsehsendung Was guckst Du? (2001-2005) zeigt, Aufnahmen in bestimmten Lokalitäten, die auch als solche markiert werden: das türkische Barbiergeschäft in Berlin-Neukölln, türkische Brotfabriken in Köln oder Export- und Importgeschäfte in anderen deutschen Städten. ${ }^{190}$ Alle diese Sequenzen setzen mit establishing shots ein. Später und darauf bauend entwickelt Yanar seine bekannten Figuren: Hakan, den >Kanaken`, Ranjid, den Inder mit seiner Kuh, Franceso, Ylldırım, Olga, Mr. Sirtaki, Dr. Achmed Rashad und Peter von Frusta, die über sein Fernsehprogramm WAS GUCKST DU?! in den 2000er Jahren bekannt werden.

190 YANAR, Kaya (2004): Best of »Was guckst Du!?«, Hamburg: WVG Medien GmbH. Dieser Zugang ist auch in der Familienserie DIE ÖzDAGs aus dem Jahre 2007 des WDR bestimmend. Es handelt sich dabei um eine türkische Familie in Köln-Mühlheim, die mittlerweile in der dritten Generation eine Konditorei betreibt. Diese »wahre Familienserie«, wie ihre Schöpferin, die Journalistin Ute Diehl sie nennt, skizziert mehr durch Nah- als durch halbtotale und totale Aufnahmen den »hektischen und lauten Alltag« der Großfamilie Özdağ, die aus 14 Personen besteht. Siehe hierzu: WeBER, Martin (2007): »Die ganz normale Familie Özdag«. In: Kölner Stadt-Anzeiger, https:// www.ksta.de/kultur/tv-tipp-die-ganz-normale-familie-oezdag-4700102 (13.04.2018). In der sehr gelungenen Dokumentation Berlin - ECKe BundesPlatz: Der YILMAZ-Clan von 2008 wird der berufliche und gesellschaftliche Aufstieg einer türkischen Familie von den 1990er Jahren bis Mitte der 2000er Jahre geschildert. Als einfache Putzkräfte fangen die Yılmaz-Brüder in den 1990er Jahren an und gründen in den 2000er Jahren ein eigenes Reinigungsunternehmen. Inzwischen leben 25 Mitglieder der Familie in Berlin. Auch hier ist die Verbindung von Arbeit in Form eines beruflichen Aufstiegs mit dem Alltag und Orten der Arbeit und des Wohnens konstitutiv - ebenso wie die Bedeutung der Ökonomie. Konstitutiv im Sinne, dass die Familie mit ihrer Arbeit, ihrer Aufstiegsgeschichte von den 1990ern bis heute und ihr Alltagsleben zu Berlin, Ecke Bundesplatz gehören. Diese Konstellation zeigt sich auch im Dokumentarfilm Ganz OBEN von Neco Celik. Siehe hierzu: UlRICH, Hans-Georg (2009): Berlin - Ecke Bundesplatz. Der Yllmaz-Clan, Dokumentation, Deutschland, WDR; CeliK, Neco (2007): Ganz oben. Türkisch. Deutsch. Erfolgreich, Dokumentarfilm, Deutschland, AVE Gesellschaft für Fernsehproduktion. Eindrücklich zeigt sich der berufliche Aufstiegsgedanke in krimineller Form in Özgür Yıldırıms Film CHIKo von 2008. In diesem Gangsterdrama in einem Hamburger Arbeiterviertel möchte Chiko als Drogendealer aufsteigen. Als Orientierung dient ihm sein Leitsatz, der auch der Untertitel des Films ist: »Wenn Du der Beste ein willst, musst Du Respekt kriegen. Wenn Du Respekt kriegen willst, dann darfst Du zu keinem anderen Respekt zeigen!« Anders als Bobby in KuRZ UND SCHMERZLos von Fatih Akın ahmt er dabei weder Tony Montana noch Mohamed Ali nach, und die Geschichte ist auch nicht darauf angelegt, eine globale zu sein. Vielmehr steht die Frage der Loyalität zwischen Freund und finanziellem Aufstieg und besonders eine bestimmte Form des Handelns im Zentrum der Erzählung, die die eigene Identität bestimmt. Chiko hat beispielsweise auf seinen rechten Arm sehr deutlich seinen Rufnamen tätowiert. Seinen eigentlichen Namen erfahren wir im Film nicht. Siehe hierzu: YILDIRIM (2008). 
Die Kabarettisten verorten sich aber auch selbst. Wenn sich Yanar beispielsweise in seiner Show MADE IN GERMANY ${ }^{191}$ von 2006 sehr oft als Frankfurter ausweist und nicht selten auf Frankfurter Stadtteile und Frankfurter Verhaltensweisen eingeht, treiben diese Praxis der Verortung Kabarettisten und Comedians wie Django Asül, Fatih Cevikkollu und Bülent Ceylan mit ihren bayrischen, rheinländischen und kurpfälzischen Dialekten auf die Spitze. So oft, wie Bülent Ceylan auf die mannheimische Sprechweise und auf Mannheim als Ort seiner eigenen Identität Bezug nimmt, so oft hat kein Deutscher und kein Türke in den 1980er Jahren auf das Land Bezug genommen, in dem er lebt oder in das er zurückkehren will. ${ }^{192}$ Vielfalt ist in diesen Veranstaltungen Programm. In Shows wie HALB GETÜRKT (2005), KEBABBEL NET (2007) und GANZ SCHÖN TÜRBÜLENT! (2009) sitzen Ceylans Eltern oft im Publikum, worauf er auch immer aufmerksam macht. Bereits aus dieser Übersicht wird deutlich, dass neben den Verortungspraktiken eine weitere tragende erzählerische Kategorie der Reflexionen zu den Folgen der Migration in der Bundesrepublik in Literatur und Film der 2000er Jahre eine Rolle spielt: die Familie.

Die Rahmung der Folgen der Migration in die Bundesrepublik durch spezifische Orte und Familienkonstellationen ist darüber hinaus in den vielen Dokumentarfilmen der Dekade auffällig. In Bettina Brauns mehrfach prämiertem Dokumentarfilm WAS LEBST DU? ist das Kölner Jugendzentrum »Klingelpütz« für ihre Protagonisten Ali, Ertan, Kais und Alban der soziale Treffpunkt. ${ }^{193}$ Mehrfach wird dieser Ort mit establishing shots eingeführt. Dabei sehen wir die jugendlichen Protagonisten oft in den »Klingelpütz« gehen, worauf Aufnahmen folgen, in denen sie eigene Rapsongs am Tisch in der Küche dichten oder sich im Gemeinschaftsraum über Bewerbungsschreiben austauschen. Kais möchte zum Beispiel ein bekannter Rapper mit Abitur werden. Warum dieser Ort so wichtig ist, zeigt Bettina Braun auch. Denn zu Hause in den Wohnungen haben die Jungs zwar kein grundlegendes Problem mit den Eltern oder Geschwistern, aber ihnen fehlen dort definitiv Raum und Ort für gemeinsame Unternehmungen. So steht der »Klingelpütz« für eine besondere Verschränkung und Verhandlung von innen und außen. ${ }^{194}$ Dabei ist das Verhältnis zu den Eltern immer wieder Thema. In Bettina Blümners Dokumentarfilm PRINZESSINNENBAD von 2007 hat das "Prinzenbad" in Berlin-Kreuzberg eine ähnliche Funktion. In dieser Langzeitdokumentation begleitet Blümner den Alltag der jungen Frauen Klara, Mina und Tanutscha. Es geht um Eltern, um Jungs,

191 Siehe hierzu: YANAR, Kaya (2007): Kaya Yanar. Made in Germany, TV-Serie, Deutschland, Sony Music Entertainment Germany. Als »made in Germany« bezeichnet sich auch die Erzählerin Canan zu Beginn von Almanya. Siehe hierzu: ŞAMdereli (2011).

192 Siehe hierzu: CEylan, Bülent (2008): Halb getürkt, TV-Serie, Deutschland, tonpool Medien. 193 Braun, Bettina (2004): Was lebst Du?, Dokumentarfilm, Deutschland, Icon Film. 194 Ebd. 
um Schule und vor allem darum, wie die Protagonistinnen mit diesen Themen umgehen und sich $\mathrm{zu}$ ihnen verhalten. Verhandlungs- und Mitteilungsort ist oft das Bad, wenngleich auch häufig die Wohnungen der Akteure gefilmt werden. ${ }^{195}$

Der Zusammenhang von Ort und Auftreten bzw. Lebensweise steht auch in den Dokumentarfilmen MEIN VATER, DER TÜRKE (2005), AM RANDE DER STÄDTE (2006), AUS DER FERNE (2006) und WIR SITZEN IM SÜDEN (2010) der Regisseurinnen und Regisseure Marcus Vetter, Aysun Bademsoy, Thomas Arslan und Martina Priessner im Vordergrund. Vetter hat seinen autobiografischen Dokumentarfilm ausschließlich in dem türkischen Dorf gedreht, aus dem sein Vater stammt. In den 1960er Jahren arbeitete er als Koch in Deutschland, kehrte ein paar Jahre später in die Türkei zurück und ließ seine deutsche Frau schwanger in Hamburg sitzen. Er hat bereits zwei Kinder in der Türkei. Im Alter von 38 Jahren beschließt Regisseur Vetter, seinen Vater in der Türkei aufzusuchen und ihn überhaupt kennenzulernen. ${ }^{196}$

Bademsoys Dokumentarfilm AM RANDE DER STÄDTE zeigt eine Siedlung an der Peripherie der Küstenstadt Mersin im Süden der Türkei. Dort leben vorwiegend »Almancıs«, Rückkehrer aus Deutschland. Der Film zeigt eindrücklich, dass die Protagonisten in dieser Dokumentation physisch zwar in der Türkei angekommen sind, psychisch aber nicht. Dabei ist diese Zerrissenheit nicht der eigentliche Befund und auch nicht das, was Bademsoys Film zeigt. Vielmehr interessiert die Regisseurin und ihre Akteure, womit und vor allem wie sie leben. Sie beobachtet, wie die Almancıs das Paradox des Angekommen- und zugleich Nicht-Angekommen-Seins in ihrem Alltag leben. Dieser Fokus gelingt, weil Bademsoy die Peripherie, die Stadt und die nahe Umgebung der Akteure als Rahmungen verwendet, also mit vielen establishing shots arbeitet. Die Praxis wird hierbei zu einem Sehen der Realität, das sich von Folklore und zerrissener Moderne abgrenzt. Dabei ist auch dieser Film autobiografisch grundiert, denn Bademsoy und ihre Familie stammen selbst aus Mersin. »Wenn man nach Mersin hineinfährt«, erläutert die Regisseurin zu ihrem Dokumentarfilm,

steht da ein Schild - das ist den Amerikanern abgeschaut -, auf dem die Einwohnerzahl der Stadt angegeben ist; irgendetwas mit zweihunderttausend. Mersin hat aber heute mehr als eineinhalb Millionen Einwohner. Die Stadt ist ungeheuer gewachsen, ganz planlos. Die Dinge, an die ich mich erinnere, sind fast ausnahmslos verschwunden. Deshalb geht es mir tatsächlich wie den Menschen in meinem Film. Male ich ein Paradies, das ich verlassen musste? - Gleichzeitig ist es gerade das ganz Unparadiesische, das mir an Mersin gefällt. Da ist nichts Folkloristisches, wie in Kreuzberg. Die Ghetto-Attitüde dort, das Komplexe, Moderne, Zerrissene - das ist ja auch Folklore. Was mir gefällt, ist, zu beobachten und zu

195 BLÜMnER, Bettina (2007): Prinzessinnenbad, Dokumentarfilm, Deutschland, Reverse Angel Factory.

196 VetTER, Marcus (2005/2006): Mein Vater, der Türke, Dokumentarfilm, Deutschland, SWR. 
erleben, wie die Menschen damit zurechtkommen, dass ihre Familien zerfallen, wie sie versuchen, Entwicklungen aufzuhalten oder den Fortschritt im Gegenteil beschleunigen wollen. ${ }^{197}$

Ein vergleichbares Interesse an der Türkei, am Land und am Leben der Menschen muss auch Thomas Arslan bewegt haben. Denn in seinem zeitgleich entstandenen Dokumentarfilm Aus DER FERNE (2005-2006), dessen Aufnahmen von Istanbul über Ankara nach Gaziantep und weiter in den Osten der Türkei bis an die iranische Grenze reichen, rahmen unterschiedlichste Städte und Landschaften das Leben der Menschen. Die Kamera ist dabei distanziert, es dominieren, wie in Akıns AUf DER ANDEREN SEITE, halbtotale Einstellungen, Nahaufnahmen gibt es kaum. Auch Akıns Spielfilm ist von besonderen autobiografischen Aspekten bestimmt. Nejats Reise an die Schwarzmeerküste hat für Regisseur und Hauptdarsteller "familienhistorische Bezüge«. Aus Camburnu kommen deren Eltern und Großeltern. ${ }^{198}$ Sowohl Akıns Spielfilm als auch Arslans Dokumentarfilm wollen weder ein modernes noch ein traditionelles Land zeigen, sondern vielmehr dessen Alltäglichkeit darstellen bzw. einfangen. ${ }^{199}$ Ähnlich wie in Asads Abhandlung führt der Fokus auf die Praktiken und die dazugehörigen Orte dazu, dass es keine Grenze und keine Übergänge mehr zwischen Tradition und Moderne gibt. Wenn doch Überschreitungen stattfinden, dann sind sie die Grundlage von neuen Grenzziehungen und Verortungen. Im Sinne von Harmut Esser und der New Assimilation Theory (NAT) aus den 2000er Jahren ist, wie oben bereits ausgeführt, an die Stelle des boundary crossing das boundary blurring getreten. Zugleich handelt es sich aber in allen genannten Fällen auch um persönliche Filme. So besucht denn auch Arslan in der Mitte der Dokumentation seinen Onkel in Ankara. ${ }^{200}$

In Martina Priessners Dokumentation WIR SITZEN IM SÜDEN (2010) geht es wie in Bademsoys Film um Rückkehrer aus Deutschland, um »Almancıs in Istanbul, die dort in Call-Centern für Neckermann oder für Lufthansa gegen geringen Lohn arbeiten. Sie melden sich mit Namen wie Ralf Becker oder Ilona Manzke, sprechen süddeutschen Dialekt und auf Fragen der Kunden, wo sie denn arbeiten, antworten sie, dass sie im Süden säßen. ${ }^{201}$ Die meisten von ihnen sehnen

197 Siehe hierzu: http://peripherfilm.de/fsk-kino/archiv/amrandederstaedte.html (30.03.2018). 198 GöKTÜRK (2010): S. 25.

199 Arslan, Thomas (2005/2006): Aus der Ferne, Dokumentarfilm, Deutschland, Pickpocket Filmproduktion.

200 Thomas Arslan ist zwar 1962 in Braunschweig geboren und wuchs bis 1967 in Essen auf, besuchte aber zwischen 1967 und 1971 eine Grundschule in Ankara, bevor seine Eltern und er wieder nach Essen zurückkehrten. Siehe hierzu: https://www.filmportal.de/person/thomas-arslan_ c01d5dfb9a3c45698d2d3840ed0b14f0 (20.09.2018).

201 Priessner, Martina (2010): Wir sitzen im Süden, Dokumentarfilm, Deutschland. 
sich nach Deutschland zurück und entwickeln in ihrem Alltag in Istanbul ein "Ersatz-Deutschland«. Es sind Akteure unter ihnen, die abgeschoben oder von ihren Eltern gezwungen wurden, zurück in die Türkei zu gehen. Erneut ist die Darstellung ihrer Arbeitsweise und vor allem ihres Alltags zentral. Viele von ihnen treffen sich wöchentlich zu einem selbst initiierten deutschen Stammtisch. ${ }^{202}$

Der thematische und territoriale Bezug auf die Türkei oder Deutschland, wie er sich in diesen Dokumentarfilmen zeigt, begegnet uns auch in den bereits erwähnten Romanen Leyla (2006) von Feridun Zaimoğlu und Die Tochter des Schmieds (2005) von Selim Özdoğan; in den Romanen Alman Terbiyesi (»Deutsche Erziehung«, 2006), Yolculuk nereye (»Wohin geht die Reise«, 2007) und Köşk (»Der Pavillon «, 2008) von Zafer Şenocak, die er alle auf Türkisch geschrieben hat; in Mein Name ist Revolution (2010); Der Mond ist unsere Sonne (2011) und Dilek Güngörs Roman Das Geheimnis meiner türkischen Großmutter (2008). Güngörs Ich-Erzählerin ist wie die Autorin Journalistin in Deutschland. Als die türkische Großmutter schwer erkrankt, fliegt sie mit ihren Eltern in die Türkei und besucht das Dorf, aus dem ihre Eltern stammen. Das Dorfleben mit seinen Regeln wird regelrecht dokumentiert. Die Ich-Erzählerin entwickelt während dieser Zeit ein besonders enges Verhältnis zu ihrer Großmutter, die sie zuvor nicht kannte, weil sie nur hin und wieder mit ihr telefoniert hatte. Die meisten fiktiven und dokumentarischen Reflexionen in den 2000er Jahren handeln von solchen intergenerationalen Verhältnisbestimmungen, wie Theorien zu Migration und Integration sie vorschlagen, um wieder eine allgemeine Theorie des Sozialen und der Integration entwickeln zu können. ${ }^{203}$ Diese hatte der sogenannte $»$ Race-Relation-Cycle« in den klassischen Integrationstheorien lediglich anvisiert, konnte sie aber aufgrund des Mangels an Material analytisch nicht weiter verfolgen. Die bislang genannten Elemente werden uns in den Materialanalysen von Film und Literatur in dieser Zeit beschäftigen. Sie sind auch deshalb interessant, weil aktuellere Produktionen wie WeISSBRotmusIK (2011) von Marianne Salzmann, LUKS GLÜCK (2012) von Ayşe Polat, Die Ungehaltenen (2015) von Deniz Utlu, Siebentürmeviertel (2015) von Feridun Zaimoğlu, Ellbogen (2017) von Fatma Aydemir, Ausser SICH (2017) von Marianne Sasha Salzmann, Fatih Akıns Aus DEM Nichts (2017) und Dilek Güngörs Ich bin Özlem (2019) das Verhältnis zu Orten, Alltag und sozialen Bindungen aus unterschiedlichsten Gründen aufzulösen beginnen.

Nachfolgend analysiere ich vor allem MEINE VERRÜCKTE TÜRKISCHE НOCHZeit, Auf Der ANDEREN SeITe, ZeIt DER WÜNSChe, Die Fremde und schließlich Almanya, binde aber auch die Komödien Kebab Connection, SüPERSEKs, Evet,

202 Ebd.

203 Siehe hierzu: ESSER (2009); WIMMER (2005). 
ICH WILl!, SOUL KITCHEN, die Serie TÜRKISCH FÜR ANFÄNGER und die zeitgleich entstandenen Tragödien WuT, KNALLHART und CHIKo mit ein und verweise auf die Dokumentarfilme MEIn VATER, DER TÜRKE, AM RANDE DER STÄDTE, Wir SITZEN IM SÜDEN und WAS LEBST Du? in den Kapiteln Der Kulturdialog zwischen Kampf und gemeinschaftlichem Erzählen und Entscheidungen und Integration. Im darauf folgenden und abschließenden Kapitel Die Praxis der Kultur in der Literatur werde ich die Literatur auf die Wirkmächtigkeit unseres Leitsatzes befragen. Und wie die Analysen zuvor wird auch dieses Kapitel zu den 2000er Jahren mit einem Fazit abgeschlossen. Mit dem Schluß und Ausblick der vorliegenden Kulturgeschichte werden aktuelle filmische, literarische und dokumentarische Produktionen in Augenschein genommen. Der ausblickartige Einblick in rezente Veröffentlichungen wird zeigen, warum eine Kulturgeschichte der Migration, wie sie hier vorgelegt wird, notwendig ist, um wieder ins Gespräch zu kommen.

\subsection{Der Kulturdialog zwischen Kampf und gemeinschaftlichem Erzählen}

»Aylin, mal angenommen, ich würde tun, was alle Türken tun, würdest du dann auch tun, was alle Türken tun?«, fragt der deutsche Götz seine türkische Freundin Aylin in MEINE VERRÜCKTE TÜRKISCHE HochZEIT. Aylin hatte das Gespräch damit begonnen, dass ihr Vater »sein Gesicht «, seine Ehre verloren habe - weil Aylin und Götz auf der Beschneidungsfeier ihres Bruders beim Liebesspiel ertappt worden waren. Wie ein Türke zu handeln, schließt ein, einen Heiratsantrag zu stellen, und Aylin würde ebenfalls wie eine Türkin handeln, wenn sie ihn annehmen würde. So bittet denn auch Horst in der nächsten Sequenz stellvertretend für einen deutschen Familienangehörigen ${ }^{204}$ in kaum verständlichem Türkisch im Namen Gottes und seines Propheten Muhammad für seinen Freund Götz um Aylins Hand. ${ }^{205}$

204 Götz' Mutter Helena kommt hierfür nicht in Frage, weil sie als Alt-68erin gegen die Ehe ist. Sie schreibt außerdem feministische Bücher. Zu ihren »Hobbys« gehöre, wie Götz etwas despektierlich äußert, »mit Männern Schluss zu machen«. Siehe hierzu: Holtz (2005). In Sinan Akkuş’ Film EvET, ICH wILL! repräsentieren die Eltern von Dirk, der die Deutsch-Türkin Özlem heiraten möchte, ebenfalls die Alt-68er-Generation. Sie sind aus Überzeugung nicht verheiratet, das Anliegen des Sohnes ist ihnen fremd. Auf Drängen von Dirk halten sie dennoch in türkischer Tradition um die Hand von Özlem für ihren Sohn bei deren Eltern an. Siehe hierzu: AKkuŞ (2008). In Bora Dağtekins sehr erfolgreicher TV-Serie TÜRKISCH FÜR ANFÄNGER heiratet die deutsche überzeugte Alt-68erin Doris ihren türkischen Freund Metin auch erst in der dritten Staffel. Siehe hierzu: DAĞTEKIN (2006-2009).

205 Der türkische Heiratsantrag wird eingeleitet mit den Worten »Allahın emri ve peygamberimizin kavli ile kızınızı (Name) oğlumuz (Name) istiyoriz« (»Mit dem Befehl Gottes und der Zu- 
Aylins Familie lehnt den Antrag ab, weil Götz kein Muslim ist. ${ }^{206}$ Das erläutert Aylins ältester Bruder Yusuf: Ein Muslim könne zwar eine Ungläubige heiraten, nicht aber eine Muslima einen Ungläubigen, weil in diesem Fall der Islam aussterben würde, da die Kinder in der Religion der Väter erzogen werden. Was würden außerdem die Nachbarn in Kreuzberg dazu sagen, wenn Aylin einen Ungläubigen heiratet? Während das Überleben einer Kultur in den 1990er Jahren in Theorie, Film und Literatur von Artikulation und Selbstbeschreibung abhing, sind es nun Erziehung und das dementsprechende Leben. Es reicht also nicht aus, dass Götz zum Türken wird (indem er sich so verhält); er muss zum Muslim werden. Und tatsächlich will Götz zum Islam konvertieren, was Aylins Vater Süleyman damit kommentiert, dass eher bin Laden Weihnachtsmann werde. ${ }^{207}$ Götz fragt, warum Süleyman gegen diese Ehe sei: „Süleyman, sag doch einfach, ist es, weil ich kein Moslem bin oder weil du mich nicht magst? «. Dieser antwortet darauf gelassen: »Nein, keine private Problem, aber so sind Spielregeln«. Ohne nationale oder religiöse Rahmung hatte bereits $\mathrm{zu}$ Beginn des Films der türkische Gemüsehändler um die Ecke Götz eingeschärft, wenn er bei Aylin landen wolle,

stimmung unseres Propheten möchten wir um die Hand eurer Tochter [Name] für unseren Sohn [Name] anhalten«). In MEINE VERRÜCKTE TÜRKISCHE HOCHZEIT ist es der einzige türkische Satz, der gesprochen wird. In Akkuş' Film EvET, ICH wILL! spielt dieser Satz ebenfalls eine markante Rolle, den Dirks Vater hier auf Deutsch ausspricht und an die Stelle »und der Zustimmung unseres Propheten « bewusst von »eurem Propheten « spricht. Siehe hierzu: AKKUŞ (2008). In Hatice Akyüns erfolgreichem Roman Einmal Hans mit scharfer Soße ist der türkische Heiratsantrag ebenfalls prominent. Ein ganzes Kapitel widmet Akyün der Darstellung dieses Rituals, bei dem sie als türkische Tochter mitwirkt, weil sonst ihre Eltern wochenlang nicht mit ihr reden würden. Siehe hierzu: AKYÜN (2005): S. 108-123. Der Heiratsantrag in Akıns GEGEN DIE WAND hatte hingegen eine andere Funktion: Während es dort darum ging, bestehende Rahmen zu brechen, etabliert man in den 2000er Jahren Rahmungen, um Kompatibilität zu gewährleisten. Siehe hierzu: AKIN, Fatih (2003): Gegen die Wand, Spielfilm, Deutschland.

206 Auch Hatice Akyün erläutert in Hans mit scharfer Soße, wie die türkische Tochter den türkischen Vater von ihrem Zukünftigen überzeugt: »Man liebte sich zunächst heimlich, und wenn es ernster wurde, brachte man den Eltern schonend bei, dass man gedenke zu heiraten. Das bedeutete keineswegs zwangsläufig, dass man Ärger mit den Vätern oder Brüdern bekam. Wichtig war das Versprechen, dass der zukünftige Ehemann zum islamischen Glauben übertreten werde. « Siehe hierzu: AKYün (2005): S. 153. In Akkuş’ Evet, IcH wILL! gibt Dirk zunächst nur vor, zum Islam zu konvertieren. Da Dirk seine Vorhaut behalten möchte, fotografiert er den Penis eines Türken und legt dieses "getürkte Bild« Özlems Eltern als Beweis seiner Konversion vor. Am Ende lassen sich sowohl Dirk als auch sein Vater beschneiden. Siehe hierzu: AKKuş (2008). 207 Im Türkischen lautet die Redewendung, wenn man etwas ausdrücken will, das man nicht für möglich hält, dass der Papst eher Muslim wird (»Papa Müslüman olur«), bevor eintritt, was versprochen wird. Siehe hierzu: ÜN, Memduh (1983): Kllıbık, Spielfilm, Türkei. 
müsse er wie ein »taşfırın erkek«, wie ein »Steinofenmann«, auftreten, der weiß, was er will und bestimmend ist. ${ }^{208}$

Auf den rituell in türkischer Sprache gehaltenen Antrag, der in den 1980er Jahren von einer türkischen Familie mit Freude angenommen worden wäre, reagiert die türkische Familie in Holtz' Film sehr unwirsch - weil Götz eben kein Muslim ist. Obgleich damit auch ein Leben nach den islamischen Regeln verbunden ist, drängt sich im weiteren Verlauf des Films die transkulturelle Kategorie in den Vordergrund, sich wie ein Mann zu behaupten. Denn Muslim wird man in MEINE VERRÜCKTE TÜRKISCHE HocHZEIT nur, wenn man ein »Steinofenmann« ist und den Ramadan übersteht. Ob man dabei wirklich glaubt oder nicht, ist hier weniger wichtig. Die türkische Familie wird ganz anders als in den 1980ern auch keineswegs gastfreundlich dargestellt. ${ }^{209}$ Götz bekommt beispielsweise außer beim Fastenbrechen niemals etwas angeboten. Zum Fastenbrechen ist er dann das erste Mal richtig bei Aylins Familie eingeladen. Das Sichtbare zählt. Diese kulturell mehrdeutige, irritierende und unruhige Erzählstruktur betrifft nicht nur die Abfolge unterschiedlicher Auftrittsformen vom Türkischen über die muslimische Praxis bis zu einer sich rüde selbst behauptenden Männlichkeit.

Schon Götz’ Aussage irritiert, dass er und Aylin türkisch handeln sollten, um zusammenzukommen, weil Aylin selbst Türkin ist und sich als eine solche in akzentfreiem Deutsch im Film auch immer wieder behauptet. Auch Süleymans Behauptung, er habe »kein privates Problem« mit Götz, ist nicht einsichtig, da die Verheiratung der eigenen Tochter doch sehr intim ist. Diese intime Frage wird in MEINE VERRÜCKTE TÜRKISCHE HOCHZEIT nicht als eine persönliche, sondern als eine kulturelle und öffentliche Frage behandelt, als eine, in der es darum geht, kulturelle Regeln zu befolgen. Während die Regel »nur ein Muslim darf eine Nicht-Muslima heiraten, aber nicht eine Muslima einen Nicht-Muslim«, einzuhalten ist, werden an anderer Stelle islamische Regeln entweder nicht eingehalten oder gebrochen. Aylin trägt etwa kein Kopftuch. Außerdem haben Götz und Aylin schon vor dem Heiratsantrag Sex miteinander. ${ }^{210}$ Und $\mathrm{zu}$ Beginn des Films isst Aylin einfach aus Neugier eine Currywurst aus Schweinefleisch. Dennoch kann sie kurze Zeit später von Götz verlangen, dass es auf jeden Fall kulturell zwischen

208 »Taşfırın erkek« ist neben dem Antrag und dem einmaligen Gebrauch des Wortes »sik» (»Schwanz«) die einzige türkische Formulierung in diesem Film.

209 Siehe hierzu: PAZARKAYA, Yüksel (1983): Unsere Nachbarn, die Baltas, hg. v. Adolf-Grimme-Institut: Begleitheft zur Fernsehserie im Medienverbund AUSLÄNDER - INLÄNDER, Marl: Deutscher Volkshochschul-Verband e.V.

210 Ähnliches lesen wir bei Hatice Akyün, wenn sie schreibt, dass sie kein Kopftuch trage, 35 Jahre alt und immer noch nicht verheiratet sei, Alkohol trinke und bestätigen könne, »dass es tatsächlich Türkinnen gibt, die Sex vor der Ehe haben«. Siehe hierzu: AKYÜN (2005): S. 185. 
ihnen beiden passen müsse. Für Yasemin hatte es in den 1980er Jahren noch ausgereicht, dass Jan die türkische Sprache lernt, um sich noch mehr in ihn zu verlieben. Für sie war wie für viele Deutsch-Türken der zweiten Generation das Türkisch-Sein eine zweite Haut, die nicht ihre wirkliche Identität »zwischen zwei Stühlen « repräsentierte. Bei Aylin und anderen Akteuren sieht es in den 2000er Jahren anders aus. ${ }^{211}$

Das Phänomen, einen Türken zu spielen, besonders von Türken selbst, oder anders formuliert einen Türken $\mathrm{zu}$ türken, ${ }^{212}$ ist in Film, Literatur und Kabarett der 2000er Jahre sehr verbreitet, ja sogar entscheidend für die Verhandlung der Folgen der Migration. In der Komödie SüPERSEKS spielt Elviz, der eigentlich fließend Deutsch spricht, einen Türken mit gebrochenem Deutsch, um an seine Traumfrau heranzukommen. In Yade Karas Roman Selam Berlin lernt Protagonist Hasan den Deutsch-Türken und Schauspieler Kazim kennen. Dieser konnte alles:

schauspielern, Taxi fahren, relaxen. [...] Er war locker. [...] Er erfand Leute, ließ sie ein paar Minuten leben und sprach dann von etwas anderem, als habe es sie nie gegeben. Er verwandelte sich in den Gastarbeiter Ali mit Kassettenrekorder und Bayernhut, oder er stand vor einem imaginären Telefon, dabei plapperte er wie ein Papagei. Es war wie ein Film im Film. ${ }^{213}$

Und Hasan, der perfekt Deutsch spricht und ein deutsches Abitur hat, wird später ebenfalls einen kriminellen `Kanaken `spielen, um in Berlin anzukommen. Doch dieses Spiel im Spiel gilt nicht nur für Gebildete, für Abi-Türken. In Sonnentrinker beschreibt Hakan die Unzufriedenheit und Enttäuschung eines Freundes seines Vaters über Deutschland auch bei der zweiten Generation in Brennpunktviertelschulen: "Sogar in der Schule machte sich diese Unzufriedenheit bemerkbar. Wenn die Lehrer sie etwas fragten, antworteten die türkischen Kids manchmal absichtlich in gebrochenem Deutsch. Mit geprobtem Akzent «. ${ }^{214}$ Der Kabarettist und Berufspolizist Murat Topal leitet sein Programm Getürkte Fälle. Ein Cop packt aus! (2005) damit ein, dass Berliner Türken im Flur der Kreuzberger Polizeidirektion noch astrein berlinern, aber im direkten Kontakt zum Kommissar sofort in ein Ausländerdeutsch à la »ich Türke, nix verstehn« übergehen

211 Siehe zu den 1980er Jahren: BoHm (1988); HÜBNER, Irene (1985): "... wie eine zweite Haut«. Ausländerinnen in Deutschland, Weinheim: Beltz; STRAUBE, Hanne/KöNIG, Karin (1982): Zuhause bin ich »die aus Deutschland«. Ausländerinnen erzählen, Ravensburg: Mayer.

212 Siehe hierzu auch: El-Hissy, Maha (2012): Getürkte Türken. Karnevaleske Stilmittel im Theater, Kabarett und Film deutsch-türkischer Künstlerinnen und Künstler, Bielefeld: transcript.

213 KARA (2003): S. 206.

214 KURT (2002): S. 153. 
würden. ${ }^{215}$ Genauso schnell wechselt Cem Öztürk (Elyas M'Barek) in Türkisch für Anfänger zwischen Kanakendeutsch und akzentfreiem Deutsch. ${ }^{216}$ Und in Hans mit scharfer Soße schreibt Hatice über ihren Bruder, dass er sich weigere, ordentlich Deutsch zu sprechen. Er begründet das wie folgt: „Schiwesta, bin ich Türke, hab isch türkisch Bulut, ist Schiprache von türkisch Kollege und mir«. Einen Abschnitt zuvor hatte sie ihn als jemanden beschrieben, dessen Heimat Duisburg ist, dessen Familie und Freunde in Deutschland leben und er nur den deutschen Pass hat. »Er liebt seinen 3er-BMW, Käsebrötchen und seine aktuelle deutsche Freundin. ${ }^{217}$ Mustafa habe allerdings etwas geschafft, das keinem assimilierten Türken gelungen sei: »Er fühlt sich wohl in seiner Welt, weil er nicht zwanghaft versucht, alles Türkische aus seinem Leben zu verbannen «. ${ }^{218}$ Dass er aber umgekehrt geradezu zwanghaft das Türkische produziert, lässt Akyün unkommentiert. Wie in MEINE VERRÜCKTE TÜRKISCHE HOCHZEIT ist in diesen kurz skizzierten Passagen das Verhältnis zwischen Diskriminierung, Wohlbefinden und Angekommen-Sein unausgewogen. Dennoch ist Hans mit scharfer Soße der meistverkaufte deutsch-türkische Roman überhaupt.

Ähnlich erfolgreich ist MEINE VERRÜCKTE TÜRKISCHE HOCHZEIT: In den Jahren 2005 und 2006 von Pro 7 produziert, erstmals 2006 ausgestrahlt, erhält der Film den Grimme-Preis, den Preis der deutschen Akademie der darstellenden Künste, wird Gewinner des 3sat-Zuschauerpreises und erhält sowohl den Deutschen als auch den Bayerischen Fernsehpreis. ${ }^{219}$ In der Begründung des Grimme-Preises wird besonders hervorgehoben, dass kulturelle Klischees in diesem Film »hervorgekehrt«, explizit gemacht werden, »um sie vergnüglich - mal mit feiner Ironie, mal in derben Späßen - auf die Schippe zu nehmen«. Genau darin liegt sein besonderer Wert. Über erzählerische Mittel der Überspitzung wird das Ernste dieser Thematik ins Komische überführt. Dasselbe gilt für EVET, ICH WILL!, Hans mit scharfer Soße und TÜRKISCH FÜR ANFÄNGER.

Doch was ist genau damit gemeint? Was ist letztlich Komik? Und kann sie überhaupt politisch sein, wie die Jury in der Begründung für den Grimme-Preis annahm? Die Forschung zur Gattung der Komödie meint, Komik oder das Komische als konstitutives Element der Erzählung könne nur dann greifen, wenn ihr

215 Topal, Murat (2005): Getürkte Fälle. Ein Cop packt aus!, Audio-CD, Berlin: SilberblickMusikproduktion.

216 DAĞTEKIN (2006-2009).

217 АKYÜN (2005): S. 129.

218 Ebd.

219 Siehe hierzu: https://www.kino.de/film/meine-verrueckte-tuerkische-hochzeit-2006/ (zuletzt 30.04.2018). Siehe auch: https://www.filmportal.de/film/meine-verrueckte-tuerkische-hochzeit_ d72313ab5ff240a0ad9275d1ec41b745 (30.04.2018). 
eine feste Ordnung und Normen vorausgehen, die sie explizit macht und überschreitet. ${ }^{220}$ Besonders in »kolonialen, postkolonialen oder neokolonialen >Kontaktzonen«" komme nach Göktürk der »Komik als Taktik zur Destabilisierung von Machtverhältnissen « eine bestimmte Rolle zu. ${ }^{221}$ Uwe Wirth stellt fest, dass Komik "genau genommen nur dann entsteht, wenn unausgesprochene - als implizit vorausgesetzte - Regeln verletzt werden «. ${ }^{222}$ Da fragt man sich, ob in MEINE VERRÜCKTE TÜRKISCHE HochZEIT eine vorhergehende Ordnung in Frage gestellt oder umgekehrt bestätigt wird. Die kurz skizzierten Widersprüche zwischen Innenleben und Auftritt der Subjekte, der Familien, die untrennbare Verschränkung von privat und öffentlich (Intimität und Regeln) sowie die Abfolge von türkischem zu muslimischem und zu männlichem Handeln machen in Holtz' Film vielmehr auf ein Bedürfnis und die Notwendigkeit einer Ordnung aufmerksam als dass sie in erster Linie eine bestehende Ordnung bloßstellen würden. Anders gesagt verlangt der Film nach einer öffentlichen Arbeit an einer sozialen Ordnung. Denn was soll Götz nun werden, ein Muslim, ein Türke, »echter « Mann oder alles zugleich?

Wie bei der 2006 gegründeten Deutschen Islam Konferenz ist der Islam auch in MEINE VERRÜCKTE TÜRKISCHE HOCHZEIT entscheidend, indem er als Kategorie zugleich bestätigt und gebrochen wird. Dass die Arbeit an einer integrativen Ordnung mit dem Islam auch anders aussehen kann, zeigt Fatih Akıns zeitnah entstandener Film Auf DER ANDEREN SEITE. Auf jeden Fall gelingt Komik und mit ihr ein Umgang mit Klischees nur dann, wenn das der Komik »Entgegenstehende nicht vernichtet wird «, sprich die soziale öffentliche Ordnung, und damit der eigentliche Referenzrahmen zur Bearbeitung kultureller Ähnlichkeit und Differenz einer komplexen und heterogenen Gesellschaft. ${ }^{223}$ Dafür müsse man unbedingt, so Wirth, das "Spielmoment « starkmachen. ${ }^{224}$ Anders ließen sich vorgeprägte Schemata nicht in Frage stellen oder in einen Verhandlungsprozess überführen. Die zentrale Frage ist letztlich, ob die soziale Ordnung, die den hier behandelten Filmen zugrunde liegt, die einer Einwanderungsgesellschaft ist oder ob sie umgekehrt erst als eine solche erzählt werden muss. Sind es nur der Islam und die >Mannwerdung` von Götz, die die Grundlagen der Einwanderungsgesellschaft in MEINE VERRÜCKTE TÜRKISCHE HOCHZEIT ausmachen oder gibt es noch

220 Siehe hierzu: Wirth (2019).

221 GöKтÜRK, Deniz (2019): „Reisen nach Jerusalem. Mit Dr. Freud im Eisenbahnabteil«. In: Komik der Integration. Grenzpraktiken und Identifikationen des Sozialen, hg. v. Özkan Ezli, Deniz Göktürk und Uwe Wirth, Bielefeld: Aisthesis, S. 43-64, hier S. 56.

222 WiRTH (2019): S. 25, Hervorhebung im Original.

223 Siehe hierzu: GrEINER, Bernard (2017): »Komödie/Tragödie«. In: Komik. Ein interdisziplinäres Handbuch, hg. v. Uwe Wirth, Stuttgart: Metzler, S. 30-34, hier S. 31.

224 Ebd. 
eine weitere Vergesellschaftungsform, die darüber hinausweist? Nach Ansicht der Jury ist das Besondere dieses Films, dass er das Private politisch mache. Das erinnert an die »Multikulturalisten«, denen es darum ging, die Ethnizität des Anderen als Anderssein zu verstehen und anzuerkennen. Diese Anerkennung dürfe im sozialen Prozess jedoch nicht als »Ressource der Unterscheidung (d.h. der Diskriminierung)« gebraucht werden, meinte Frank-Olaf Radtke. ${ }^{225}$ Auch aufgrund dieser Trennung von Privatheit und Öffentlichkeit ließen sich in den Filmen der 1990er Jahre Klischees und Stereotypen nicht »hervorkehren«, sondern man musste durch sie hindurchgehen, um nach draußen zu gelangen und um auf etwas anderes verweisen zu können, das jenseits des Türkischen und Deutschen lag. ${ }^{226}$ Die politische Konstellation in den 2000er Jahren ist, wie zu Beginn dieses Kapitels gezeigt, eine andere. Die Einwanderungsgesellschaft wird als soziales Faktum angenommen, und öffentlich und privat sind eng miteinander verschränkt. Daher wird uns im Folgenden etwa die Frage beschäftigen, worauf die Filme der 2000er Jahre verweisen. Doch bevor wir im ersten Analyseteil dieses Kapitels zu diesem vorhandenen oder nicht vorhandenen Referenzrahmen zunächst in MEINE VERRÜCKTE TÜRKISCHE HOCHZEIT, später in AUF DER ANDEREN SEITE, kommen, kurz die Synopse vom ersten Film:

Der Protagonist Götz Schinkel besitzt mit seinem Freund Horst zusammen einen Plattenladen im von Türken dominierten Berlin-Kreuzberg. Der Erzähler im Film stellt Götz als jemanden vor, der zu gut für diese Welt sei. Das zeigt sich etwa daran, dass Götz zweimal vom selben Türken angegriffen wird: einmal, als er einem türkischen Jungen helfen will und das zweite Mal, als sich eine Menschentraube von Leuten um Götz' Plattenladen bildet, weil das Fenster des Geschäfts eingeschlagen wurde und er schlichtend eingreifen will - denn Horst hatte die Türken als islamistische Terroristen beschimpft, woraufhin die Situation eskalierte. Götz liegt Nase blutend am Boden, als die schöne Türkin Aylin hervortritt und ihm hilft. Götz verliebt sich sofort in sie. Aber auch andere Türken, »liberale Muslime«, helfen den Ladenbesitzern beim Einbau eines neuen Fensters.

Das vermeintlich interkulturelle Gefüge setzt sich zusammen aus Stadtteil, Nachbarschaft, Religion, Konflikt, Gewalt, Liebe und Hilfsbereitschaft und bildet

225 Vgl. RAdTKE, Frank-Olaf (1998): „Lob der Gleich-Gültigkeit. Die Konstruktion des Fremden im Diskurs des Multikulturalismus«. In: Das Eigene und das Fremde. Neuer Rassismus in der Alten Welt?, hg. v. Ulrich Bielefeld, Hamburg: Hamburger Edition, S. 79-98, hier S. 92.

226 Interessanterweise lautet die Begründung für die Verleihung des Grimme-Preises an Züli Aladağs WUT im Jahr 2007 ganz ähnlich. Erneut sieht man die »Offenlegung« als besonderen Verdienst an. Siehe hierzu: http://www.grimme-preis.de/archiv/2007/preistraeger/p/d/wut-ardwdr/ (13.05.2018). 
die Grundlage von MEINE VERRÜCKTE TÜRKISCHE HochZEIT. Was den Verlauf der Erzählung betrifft, wird in diesem Film eine umgekehrte Integrationsgeschichte erzählt. Denn ein Mitglied der Mehrheitsgesellschaft wie Götz passt sich der Kultur einer Minderheit an. Obwohl Aylin schon seit einem Jahr mit ihrem Cousin Tarkan verlobt ist - einem Muslim, der als Arzt einen finanziell sicheren und gesellschaftlich angesehenen Beruf ausübt -, verliebt sie sich in Götz, der wie gesagt für sie zum Islam konvertiert. ${ }^{227}$ Während dieses Übergangs entwickelt sich Götz von einem zu guten zu einem fordernden und teilweise gewalttätigen Deutschen. Dieser dramaturgische Verlauf wird zwar immer wieder durch die Form der Komödie konterkariert, die auch die Charaktere überzeichnet wirken lässt. Hinzu kommt, dass der Film mit der Hochzeit ein Happy End hat. ${ }^{228}$ Was aber nicht zur Disposition der Umkehrung in diesem Film steht, ist die Rolle und Funktion des Islam und seines Regelwerks, das trotz abweichender Praktiken keiner Kritik unterzogen wird. Warum? Einerseits weisen die islamischen Regeln Götz einen Weg, von Aylins Familie anerkannt zu werden. Andererseits bestimmt der Islam auch die inneren Befindlichkeiten der Akteure. Beide Aspekte sind in MEINE VERRÜCKTE TÜRKISCHE HochzeIT der Komik, aber auch den sozialen Praktiken entzogen.

Auf der ersten, integrativen Ebene erfüllt Götz alle Auflagen. Er ist integrationswillig und zeigt sich am Ende als starker und ernst zu nehmender Mann. Dass die Unterscheidung zwischen stark und schwach eine Leitkategorie der Integration darstellt, zeigt sich besonders am Ende des Films: Als die Verlobung zwischen Götz und Aylin im Haus von Götz’ Mutter Helena (Katrin Sass) eskaliert, weil sie dagegen ist, dass die Kinder ihres Sohnes im islamischen Glauben erzogen werden - bis zu dieser Szene weiß Helena nicht, dass ihr Sohn zum Islam konvertiert ist -, kippt der Film in einen Kulturkampf. Er beschreibt die zweite Ebene des Films. Für Götz' Mutter ist der Islam eine Religion, »die Millionen von Frauen durch Zwangsehen unterdrückt «. ${ }^{229}$ Während sie das sagt, wirft sie eine

227 Nach islamischer Regel genügt es, wenn beim Aufsagen des Einheitsbekenntnisses auf Arabisch (»Ich bezeuge, es gibt keinen Gott außer Gott und Mohammed ist sein Gesandter«) zwei Muslime als Zeugen zugegen sind. Der Ort spielt dabei keine Rolle. Siehe hierzu: BuHĀRĪ (1997): Nachrichten von Taten und Aussprüchen des Propheten Muhammad, Stuttgart: Reclam, S. 44. In MEINE VerRüCKTE TÜRKISCHE HochzeIt erfolgt diese Prozedur in einer Moschee in Berlin in Anwesenheit der gesamten Familie. In Joel Zwicks MY BIG FAT GREEK WEDDING von 2002 konvertiert der Amerikaner Ian Miller für seine griechische Freundin Tuola Portokalos auf Wunsch ihrer Familie zum orthodoxen Christentum in einer orthodoxen Kirche im Beisein der griechischen Großfamilie. Siehe hierzu: ZwICK, Joel (2002): My Big Fat Greek Wedding, Spielfilm, USA.

228 Nach Bernard Greiner ist das gute Ende das Entscheidende an einer Komödie. Siehe hierzu: GREINER, Bernard (2017): »Komödie/Tragödie«. In: Komik, S. 30-34, hier S. 31.

229 Helena ist eine feministische Alt-68erin, die für "verstaubte Ideale« des individuellen und freien Glücks steht. Sie hat im Film keinen Partner, und es erschließt sich auch nicht, ob sie 
Handvoll Zeitschriftenausgaben auf den Esstisch. Darunter ist ein Artikel, den sie kürzlich redigiert habe und der aufzeige, wie in Kreuzberg türkische Frauen von ihren Männern unterdrückt würden. ${ }^{230}$ Gegenseitige Beleidigungen führen in dieser Sequenz dazu, dass Aylins Familie das Haus verlässt. Götz beschwichtigt darauf seine Mutter, beide fahren der türkischen Familie hinterher, und es folgt die dramatischste Sequenz des Films, die nicht irgendwo im Privaten, sondern mitten auf der Straße in Kreuzberg stattfindet.

Vor ihrer Wohnung erreicht Götz die türkische Familie und will über das Geschehene reden. Yusuf reagiert mit einem Faustschlag in Götz' Magengrube. Er sei an allem schuld. Der türkische Mann, der Götz zu Anfang des Films eine Kopfnuss verpasst hatte, eilt herbei, da Yusuf Götz auf sein parkendes Auto stößt. Er verlangt Schadensersatz von Götz, der sein Portemonnaie zückt und Geld auf den Boden wirft. Nun hätten sie sein Geld, beginnt er seine Wutrede, seine Religion, seine Vorhaut und was sie denn sonst noch alles wollten. Diese Szene wird immer intensiver und beleidigender für beide Seiten. Götz wird vorgeworfen, dass er »Schiss« habe, kein richtiger Mann sei und jetzt alles »hinschmeißen« wolle. Er entgegnet, dass die Türken Schiss hätten und sich hinter ihrer »verfickten Ehre» und Religion verstecken würden und sie »Scheißtürken « und »Rassisten « seien. Die Szene endet damit, dass Götz Aylin sagt, dass sie in Wirklichkeit Angst habe, er sie aber trotzdem liebe. Sie wendet sich mit einem »vergiss es« ab und zieht

jemals verheiratet war. Götz’ biologischer Vater wird jedenfalls mit keinem Satz erwähnt. Fragile deutsche familiäre Konstellationen sind in vielen Produktionen der 2000er Jahre, die die Folgen der Migration in der Bundesrepublik thematisieren, bestimmend. Siehe hierzu: SAUL (2005); ALADAĞ (2006); AKIN (2007); BuCK (2005); DAĞTEKIN (2006-2009).

230 Die Metapher des Tischs verwendet auch Necla Kelek in ihrer Replik auf ihre Kritiker in der Zeit vom 8. Februar 2006. Sie reagiert darin auf eine Petition von 60 prominenten Forschern und Aktivisten, die besonders ihr Buch Die fremde Braut kritisierten. Sie machen auf den Widerspruch der Interpretationen Keleks zwischen ihrer Dissertation Islam im Alltag von 2003 und ihrer Publikation Die fremde Braut von 2005 aufmerksam. Denn die Ergebnisse ihrer wissenschaftlichen Arbeit decken sich mit vielen anderen wissenschaftlichen Ergebnissen, jedoch nicht mit ihrem zweiten Buch. Wenn sie in dieser Petition aus ihrer ersten Arbeit mit den Worten zitiert wird, dass das »Bekenntnis zum Muslim-Sein« unter den Türken zweiter Generation »im Regelfall nicht als traditionelle Selbstverortung missverstanden werden darf«, greifen sie dagegen eine zentrale Aussage aus Die fremde Baut auf, dass die muslimischen Werte mit den westlichen nichts gemein hätten. Und es seien die muslimischen Werte, die das »Handeln der muslimischen Migranten in Deutschland bis in den letzten Winkel ihres Altags« bestimmten. In ihrer Entgegnung geht Kelek nicht auf den vorgebrachten Widerspruch zwischen ihren beiden Arbeiten ein, verlangt aber, dass die erwähnten Forschungen, die auf »rationale Weise« zeigten, dass der Islam der jüngeren Generationen kompatibler mit den Werten der Ankunftsgesellschaften sei, auf »den Tisch sollen«. Siehe hierzu: KARAKAŞoĞLU, Yasemin (2006): »Gerechtigkeit für die Muslime! «. In: Transit Deutschland, S. 317-320, hier S. 318; KeLEK, Necla (2006): »Entgegnung«. In: Transit Deutschland, S. 320-321. 
sich mit ihrer Familie zurück. Nun soll Tarkan wieder der Auserwählte sein. Götz schlägt mit einem Besen aus Süleymans Trödelgeschäft mitten auf der Straße auf Tarkans Auto ein. Süleyman ist beeindruckt und rät Götz, Aylin wieder zurückzugewinnen: „Götz, holst Du Frau zurück«. Götz folgt Süleymans Rat und am Ende findet die Trauung statt. ${ }^{231}$

Der TV-Sender Pro 7, der diesen Film produzierte, bewarb ihn 2006 als eine romantic comedy. Und man muss sicher zugeben, dass es sich insgesamt um eine Multikulti-Komödie handelt - allerdings nicht um eine Feelgood-Comedy wie My Big FAt Greek Wedding (2002), mit dem MEINe VerRÜCKTE tÜRKISCHE HochzEIT verglichen wurde. ${ }^{232}$ Vielmehr begegnen wir in diesem Film auch der politischen Disposition der deutschen Migrationsgesellschaft $\mathrm{zu}$ Beginn des 21. Jahrhunderts, die sich zwischen Skandalisierung und Integration mit und durch den Islam ergeben hat. ${ }^{233}$ Die Türken, die vor fünfzig Jahren aus der Türkei nach Deutschland emigrierten, ihre Kinder und Enkel sind nun in der Mitte der Gesellschaft angekommen - nicht als Südländer, nicht als Orientalen, nicht als `Kanaken` und auch nicht als Europäer, sondern als Muslime. Daher sind auch

231 Der Tag spielt als eine erzählerische Einheit in vielen Texten und Filmen der 2000er Jahre eine zentrale Rolle. Emine Sevgi Özdamars Roman Seltsame Sterne starren zur Erde beginnt mit einer Nacht, in der die Ich-Erzählerin nicht schlafen kann, weil ein Hund die ganze Nacht bellt. Am nächsten Morgen wird sie sich an der Volksbühne in Berlin vorstellen. Und der Roman endet damit, wie sie abends in Paris in der Metro an der Schulter von Benno Besson einschläft, der sie dorthin als Assistentin mitgenommen hat. Siehe hierzu: ÖzDAmaR (2003): S. 9 und S. 247. Fatih Akıns AUf DER ANDEREN SEITE beginnt morgens bei hellichtem Sonnenschein an einer Tankstelle in der Türkei. Er endet an einem Strandabschnitt an der Schwarzmeerküste, als die Abenddämmerung einbricht. Siehe hierzu: AKIN (2006). Die Grundstruktur des Romans Die Tochter des Schmieds von Selim Özdoğan folgt dem Verlauf der Gezeiten (Frühling, Sommer, Herbst und Winter) und dem Beginn und Ende eines Tages. Letzteres gilt ebenso durchgehend für Dilek Güngörs Roman Das Geheimnis meiner türkischen Großmutter. Die 15 Kapitel im Roman beginnen jeweils morgens und enden abends. Und Aladağs Skandalfilm WuT beginnt hell vormittags und endet nachts mit dem tödlichen Ausgang des Kampfes zwischen Simon, Felix’ Vater und Can, dem deutsch-türkischen Protagonisten. Siehe hierzu: ÖzdoĞAN (2005); GüNGÖR (2007); ALADAğ (2005).

232 Siehe hierzu: Berghahn, Daniela (2012): »My Big Fat Turkish Wedding. From Culture Clash to Romcom «. In: Turkish German Cinema in The New Millennium. Sites, Sounds, and Screens, hg. v. Sabine Hake, Barbara Mennel, New York: Berghahn Books, S. 19-31.

233 Besonders der Themenkomplex der Zwangsehe wird mit den Publikationen von Ayan Hirsi Ali in den Niederlanden, von Seyran Ateş und von Necla Kelek in der Bundesrepublik Anfang und Mitte der 2000er Jahre gesellschaftspolitisch sehr relevant. In Folge des 11. September 2001, dem Mord an Theo van Gogh sowie den Anschlägen in Spanien und in England setzt sich in den 2000er Jahren eine Rhetorik durch, die eine grundlegende Kritik am Multikulturalismus verlangt und nicht selten mit den Worten eingeleitet wird, »dass man dies doch noch werde sagen dürfen«. Siehe hierzu: ButTERWEGGE, Christoph (2007): »Zuwanderer im Zerrspiegel der Medien. Migrationsberichterstattung als Stimmungsmache«. In: Transit Deutschland, S. 200-204; KELEK (2006). 
die deutsch-türkischen Akteure in Meine türkische Hochzeit trotz aller ersichtlichen Widersprüche vom Islam nicht zu trennen. Als sich Helena und Aylin das erste Mal bei einer Buchpräsentation von Helena begegnen, kommt es zu einer Kette von Diskriminierungen. Helena glaubt etwa, die hübsche junge Frau an der Seite ihres Sohnes sei eine Angestellte und reicht ihr ihr Sektglas, das sie wieder füllen soll. ${ }^{234}$ Aylin lässt das leere Glas auf den Boden fallen, es zerbricht, Helena dreht sich überrascht zu ihr um und Götz klärt auf, dass Aylin seine Freundin sei. Woher sie denn komme, fragt Helena. «Aus Berlin«, antwortet Aylin. »Nein, ich meine ursprünglich«, fragt Helena weiter nach. »Ich bin Türkin«, antwortet Aylin. »Türkin« wiederholt Helena und bittet darauf ihre Freundin Gitte zu ihrem Gespräch, die gerade ein Buch schreibt über Türken, Zwangsehen und Ehrenmorde in Kreuzberg. Gitte fragt umgehend und überheblich, warum die türkischen Mädchen sich das alles gefallen ließen. Aylin entgegnet wütend und zugleich in der komödiantischen Diktion des Films: „Ach, das ist ganz normal. Wir türkischen Mädchen sind ein bisschen doof, weil wir in den Koranschulen nur kochen, putzen und beten lernen, und bei diesen ganzen Schlägen auf den Kopf. Aber ich habe mir heute zum ersten Mal eine Monatskarte gekauft und Götz bringt mir gerade das S-Bahn fahren bei. Extrem aufregend «. ${ }^{235}$ Götz ergänzt, dass Aylin Jura studiere. Helena will die peinliche Situation auflösen, indem sie Aylin ein volles Sektglas reicht und ihr ihr Buch »Happy Single» mit einer Widmung schenkt. Götz erklärt, dass Aylin als Muslima keinen Alkohol trinke, während Aylin wütend und gar nicht mehr selbstironisch meint, sie zwar kein Happy Single, dafür aber ein »Happy Muslim «. ${ }^{236}$

Diese Szene einer kulturellen Diskriminierung beginnt mit einer sozialstrukturellen Ausschließung. Denn Helena gibt Aylin das Sektglas, weil sie glaubt, Aylin gehöre zum Service-Personal. Erst als Götz ihren Namen nennt, beginnen die kulturellen Marker wirkmächtig zu werden. Außerdem wird diese Szene eingeleitet mit einem Gespräch zwischen Götz und Aylin im Auto. Aylin fragt Götz, ob seine Mutter denn wirklich Single sei. Götz bejaht dies und ergänzt, dass Schlussmachen ihr Hobby sei, Aylin sich aber keine Sorgen machen müsse, denn sie hätte nichts gegen Türken, sie wähle schließlich grün. Die fragile Bindung

234 Eine ganz ähnliche diskriminierende Sequenz findet sich in der dritten Folge der dritten und letzten Staffel von Bora Dağtekins TÜRKISCH FÜR ANFÄNGER, als Metin dem deutschen Polizeichef seinen Sohn Cem vorstellen möchte. Cem möchte nämlich Polizist werden, aber der Polizeichef spricht ihn als Putzkraft an. Siehe hierzu: DAĞTEKIN (2006-2009).

235 Holtz (2007). In einer identischen Diktion und ähnlichem Wortlaut reagiert in ALMANYA. Willkommen in Deutschland Canan in Berlin in der U-Bahn auf diskriminierende Aussagen einer älteren deutschen Frau, die nicht an sie, sondern an Ausländer mit vielen Kindern im Abteil gerichtet sind. Siehe hierzu: ŞAMDERELI (2011).

236 Holtz (2007). 
von Sozialstruktur und kultureller Diskriminierung wiederholt sich in der Begegnung von Aylin und Helena, als letztere zweimal nach der Herkunft der ersteren fragt. Dass genau diese Stelle im Film für kulturelle Diskriminierung steht, steht im Einklang mit den Theorien zur Postmigration, die zeitnah beginnen, die Multikulturalismustheorien zu ersetzen. Sie meinen, dass die Frage und Bedeutung nach der vermeintlich eigentlichen Herkunft von zugewanderten Menschen nach 50 Jahren Migrationsgeschichte in der Bundesrepublik einen Akt der Diskriminierung darstelle. ${ }^{237}$ Aylin wehrt sich dagegen auch gar nicht, indem sie etwa ihre hybride Existenz als Deutsch-Türkin betont. Sie sagt nicht nur, dass sie Türkin, sondern auch ein »Happy Muslim« sei. $^{238}$

237 Wie sehr dieser Gedanke mittlerweile Teil der Migrationsdebatten im Internet und in den sozialen Medien geworden ist, und nicht mehr als realphysische Interaktionsform zwischen zwei oder mehreren Menschen, zeigt beispielsweise auch die MeTwo-Debatte über Alltagsrassismus in Deutschland aus dem Jahr 2018. In vielen Beschreibungen zu Diskriminierung wird auch die Frage nach der eigentlichen Herkunft immer wieder genannt, ohne dass dabei die andere Seite mit einer Form der Schlichtung reagieren könnte. In MEINE VERRÜCKTE TÜRKISCHE HochzeIT schenkt Helena Aylin im Bewusstsein, dass sie sich falsch verhalten hat, am Ende der Sequenz Aylin ihr Buch. Solch eine Verhandlung ist im Netz nicht mehr möglich. Siehe zur MeTwo-Debatte: ReInSCH, Melanie (2018): »MMeTwo Ein Hashtag gegen Alltagsrassismus«. In: BERLINER ZEITUNG, 27.07.2018, https://www.berliner-zeitung.de/politik/-metwo--ein-hashtaggegen-alltagsrassismus-31025882 (08.09.2018). FLEISCHHAUER, Jan (2018): »Hauptsache ihr, favt meine Tweets. Die \#MeTwo-Debatte ist deshalb so interessant, weil sie so reich an Paradoxien ist. Eine davon: Die Stärke der Bewegung ist gleichzeitig ihre Schwäche - die rührende Selbstbezogenheit«. In: DER SPIEGEL, 02.08.2018, http://www.spiegel.de/politik/deutschland/metwodebatte-hauptsache-ihr-favt-meine-tweets-a-1221348.html (08.09.2018).

238 Die kulturell bestimmte Aktion und Reaktion auf eine allgemeine Form der Ausschließung (hier: Gast/Bedienung) wirkt so, als ob die kulturellen Marker auf eine vielfach stattfindende Diskriminierung einfach aufgesetzt würden. Die Lösung könnte auch anders sein. Doch der spezifische Einsatz kultureller Marker als »Aufsatz« ist in den Produktionen der 2000er Jahre äußerst konstitutiv. Eindrücklich zeigt sich dies etwa im von der Rezeption sehr positiv aufgenommenen Erzählband Hürriyet Love Express von Imran Ayata. In der zweiten Erzählung »Liebe ist mächtiger als Tito« geht es um die Clique von Deniz, Hürşad und dem namenlosen Ich-Erzähler. Als explizit »arabesken Zustand « beschreibt der Ich-Erzähler den folgenden: »Deniz verliebt sich immer wieder. [...] Er begegnete einer Frau, die attraktiv war, eine unglaubliche Ausstrahlung besaß, in einer Beziehung steckte, Deniz aber sehr nett fand, seine Freundschaft suchte, aber keine Liebe für ihn empfand und schon gar keinen Sex mit ihm haben wollte. Mit diesem arabesken Zustand hatte sich Deniz arrangiert. « Die kulturelle Spezifizierung eines nicht kulturspezifischen Zustands wird in der Erzählung noch weiter getrieben. Ich-Erzähler und Hürşad empfehlen ihrem Freund Deniz, es wie im türkischen Popsong Gül döktüm Yollanna des bekannten türkischen Sängers Tarkan zu machen. Er solle seiner Angebeteten ihren Weg und ihre Wohnung mit Rosen bedecken. Siehe hierzu: AyATA, Imran (2005): »Liebe ist mächtiger als Tito«. In: ders., Hürriyet Love Express, Köln Kiepenheuer \& Witsch, S. 21-45, hier S. 22-28. Außerdem taucht in der Erzählung Emre auf, der als Strategie »um bei Frauen zu landen, [...] wahlweise sich als Türke, Kurde oder Armenier ausgibt« 
Wie Yasemin in Hark Bohms gleichnamigem Film aus dem Jahr 1988 trägt Aylin kein Kopftuch, ist modern gekleidet und wäre auf kognitiver, struktureller und sozialer Ebene als assimiliert zu bezeichnen. Allerdings ist Aylin weder mit der Mehrheitsgesellschaft verschmolzen noch ein Happy Single. Ihre Identifikation teilt die kulturelle Kontaktzone nicht in Individuen, sondern erneut in Gruppen ein. So unterscheidet sich Aylin von Yasemin auch eindrücklich darin, dass sie ihre Eltern an keiner Stelle als »anatolische Bauern « bezeichnet und sie als traditionell im Gegensatz zu modernem Leben begreift, ${ }^{239}$ sondern im Gegenteil wie ihre Eltern von Götz verlangt, dass er sich an sie anpasst. Diese Form der kollektiven Identifikation gepaart mit einem selbstbewussten individuellen Auftreten, die auf Kompatibilität mit den Eltern zielt und sowohl die türkische als auch die deutsche Seite in MEINE VERRÜCKTE TÜRKISCHE HOCHZEIT betrifft, zeigt sich besonders an den dargestellten Sequenzen, die diese Multikulti-Komödie ins Dramatische und Beleidigende kippen lassen. Wenn nämlich der Islam auf der einen Seite oder die Freiheit auf der anderen Seite verbal verletzt werden, fühlen sich die jeweiligen Akteure persönlich verletzt. Auch Helena wird von den türkischen Muslima verlacht und beleidigt, worauf sie entsprechend reagiert. ${ }^{240}$

Insgesamt kann kein Akteur in diesem Film auf eine Beleidigung souverän reagieren, indem das Gesagte in Frage gestellt wird, entweder weil es nicht richtig ist oder weil das Gesagte mit einer vorhandenen islamischen Ethik nicht übereinstimmt. Zu sehr dominieren hier die Abstrakta und Nomen wie »Islam «, »Muslim«, »Türke«, »Deutscher« sowie ihre materiellen Repräsentationen »Moschee«, »Kopftuch«, »Beschneidung « und »Koran«. Zu sehr sind die Akteure in ihrem eigenen Auftreten gefangen. Das Potential des Komischen erschöpft sich in diesem Film darin, diese Abstrakta umzukehren, nicht sie einzubetten oder eine heterogene Sozialordnung anzuvisieren. Die Akteure lachen immer über die anderen, nicht mit ihnen. Bei dieser Art der Komik muss nach Umberto Eco immer der Verlachte den Preis zahlen. Er ist in der Regel der »Barbar«, der sich nicht angemessen zu verhalten weiß. ${ }^{241}$ In MEINE VERRÜCKTE TÜRKISCHE HochzEIT gilt dies für beide Seiten, so dass bis zum Schluss an keiner Stelle gemeinsam gelacht wird. Im Unterschied zu Bohms und Başers Filmen aus den 1980ern bricht so auch kein kulturelles Gesetz in diesen Film ein, das eine vorhandene soziale Fluidität irritieren würde. In Bohms Film YASEMIN reden ältere Frauen in der Hochzeitsnacht von Yasemins Schwester

und dabei in unterschiedlichen Varianten eine Opfergeschichte zum Besten gibt. Dazu bekocht er seine »Auserwählte mit seinem Standardgericht Ali Nazik, einer Spezialität mal aus der Türkei, dann aus Kurdistan oder Armenien«. Siehe hierzu: Ebd., S. $37 \mathrm{f}$.

239 Вонм (1988).

240 Siehe hierzu: Holtz (2006).

241 Zitiert nach: WIRTH (2019): S. 19 u. S. 39. 
vor ihrem Schlafzimmer darüber, wie ein frisches Paar den Nachweis der Jungfräulichkeit, falls das Mädchen nicht mehr Jungfrau sein sollte, umgehen kann, wie das Paar einfach die Regeln aushebeln kann. Für die türkischen Frauen in Film und Literatur der 1980er sind Regeln auch dafür da, dass sie umgangen werden. Solche Reaktionen, solch eine Fluidität bleiben in Holz' Film aus, weil weder der Islam, die Freiheit als Abstraktum oder die Personen als vielschichtige und mehrdimensionale Entitäten oder Akteure gezeigt werden. In MEINE VERRÜCKTE TÜRKISCHE HochzEIT ziehen die Grenzen die Akteure von Beginn an selbst. In der Erzählung »Gottesanrufung 1« aus Zaimoğlus Erzählband Zwölf Gramm Glück wird dem Ich-Erzähler, der für eine gläubige Deutsch-Türkin einen angemessenen Mann suchen soll, von ihrem Cousin erklärt, dass seine Cousine besonderen Wert darauf lege, dass er dem potentiellen Jungen »eine wichtige Regel klarmacht: Sie ist unberührbar, bis sie auf den richtigen Mann trifft «. ${ }^{242}$

Kulturelle Marker gehören zu den Handlungen der Akteure, werden ihnen sogar visuell und auditiv vorangestellt. Diese Abfolge erschwert die soziale Fluidität. MEINE VERRÜCKTE TÜRKISCHE HOCHZEIT beginnt mit dem muslimischen Gebetsruf als voice-over. Zugleich sehen wir den Fernsehturm am Berliner Alexanderplatz. Darauf folgt von hinten aufgenommen eine Frau mit Kopftuch, ein Minarett und mit dem Berliner Bären ein weiteres Berliner Wahrzeichen. Auf der Tonspur geht dabei der muslimische Gebetsruf in Fatboy Slims Song Praise you über. Die Bilder sind digital aufgelöst und auffallend scharf. ${ }^{243}$ Wie in Akıns Film Auf DER ANDEREN SEITE und Kurts Roman Sonnentrinker scheint die Sonne. Sprich, wir sehen alles, worum es geht. Es gibt zu dem Sichtbaren nichts weiter zu interpretieren. Nun übernimmt der Erzähler des Films, Götz’ Freund Horst, und führt Berlin-Kreuzberg als »Little Istanbul« ein, das absolut in türkischer Hand sei. Die Verbindung von Islam und deutschem Territorium bestimmt als Rahmung das Thema dieses Films, den Kulturdialog, von Beginn an mit. Aufgrund dieser Rahmung können nur noch die Akteure in Verhandlung treten und eine soziale Fluidität generieren, aber nicht die religiösen und nationalen Bestimmungen. Diese sind gesetzt, stehen fest und treten als verkörperte Erinnerungen zutage, die sich zu Traditionen verdichtet haben. An prominenter Stelle bezeichnet der Religionssoziologe Talal Asad diese Form des Auftritts als eine »verkörperte Praktik«. ${ }^{244}$

Soziale Fluidität und Regelbruch haben allein die Akteure in der Hand. Aylin isst Currywurst, hat Sex vor der Ehe, trägt kein Kopftuch, betet nicht, trinkt

242 Siehe hierzu: ZaimoğLu, Feridun (2004): »Gottesanrufung 1«. In: ders., Zwölf Gramm Glück, Köln: Kiepenheuer \& Witsch, S. 82-91, S. 87.

243 Siehe hierzu: Holtz (2006).

$244 \operatorname{AsAD}$ (2017): S. 221f. 
aber keinen Alkohol und bezeichnet sich offensiv als »Happy Muslim«, wenn es darauf ankommt. Da sie durchgehend akzentfrei und ausschließlich Deutsch spricht, ist sie eher als eine deutsche denn als eine türkische Muslima zu bezeichnen. Zum Vergleich schreibt etwa die Ich-Erzählerin in Hatice Akyüns autobiografisch grundiertem Roman Einmal Hans mit scharfer Soße, dass ihr »akzentfreies Deutsch [...] schon lange nicht mehr auf [ihre] Herkunft schließen« lasse. »Manchmal fühle ich mich monatelang nicht ein einziges Mal türkisch. Erst wenn ich neue Menschen kennenlerne, die mich fragen, woher ich komme, reißen sie mich aus meiner deutschen Welt. ${ }^{245}$ Dennoch meinen Forscher, dass ihr Roman kulturelle Vermischung verhandle. ${ }^{246}$ Für die >Kanaken` der 1990er Jahre wäre Aylins Sprache in MEINE VERRÜCKTE TÜRKISCHE HochzEIT auf jeden Fall »zu deutsch « und ihre besondere Bindung zu ihren Eltern im Unterschied zu den Figuren Yasemin in YASEMIN, zu Leyla in Thomas Arslans GESCHWISTER und zu Sibel in GEGEN DIE WAND zu konservativ. ${ }^{247}$ Das Ignorieren von Regeln, das sie vollzieht, führt hier nicht zu einem gemeinsamen Verbundenheitsgefühl von Deutschen und Türken, sondern zur Distinktion; zur Aktualisierung von unbeweglichen Selbstbestimmungen im Modus eines Kampfes. Ihre spannungsgeladene Zwischenlage lässt sich vielleicht mit dem Titel von Melda Akbaş’ Buch So wie ich will. Mein Leben zwischen Moschee und Minirock beschreiben. ${ }^{248}$ Da dieser kaum aufzulösende Widerspruch zwischen Moschee und Minirock die Diktion des Films bestimmt, erzeugt die narrative Dichte und Folge von Komik, Gewalt, Liebe

245 AKYÜN (2005): S. 180.

246 Siehe hierzu: YeşILADA, Karin (2011): ») Nette Türkinnen von nebenan`. Die neue deutsch-türkische Harmlosigkeit als literarischer Trend «. In: Von der nationalen zur internationalen Literatur. Transkulturelle deutschsprachige Literatur und Kultur im Zeitalter globaler Migration, hg. v. Helmut Schmitz, Amsterdam: Rodopi, S. 117-142, hier S. 131f.

247 Dasselbe gilt für die Figur Hatice in der literarischen Vorlage von Hans mit scharfer Soße und in ihrer filmischen Umsetzung durch die Regisseurin Buket Alakuş. AlaKUŞ (2013).

248 Siehe hierzu: AквAŞ, Melda (2010): So wie ich will. Mein Leben zwischen Minirock und Moschee, München: C. Bertelsmann. Im zweiteiligen Fernsehfilm ZEIT DER WüNSCHE finden wir diese Konstellation zwischen Moschee und Minirock ebenfalls. Kadirs Tochter, die in Deutschland auf die Welt kommt, trägt zu Hause und im Umgang mit konservativen Türken ein Kopftuch, geht aber zugleich mit Freunden im Bikini im Schwimmbad schwimmen. Auch Hatice in Einmal Hans mit scharfer Soße zieht sich jedes Mal, wenn sie von Hamburg nach Salzgitter zu ihren Eltern fährt, immer an derselben Autobahn-Raststätte auf der Strecke um. Dort wechselt sie ihren Minirock mit einem über die Knie reichenden »Vaterrock«, wie sie ihn nennt. Im Film sehen wir diese Sequenz ganze viermal. Siehe hierzu: ALAKUŞ (2013). In Hark Bohms Film YASEMIN verlängert die Protagonistin ihren Rock erst, als sie im öffentlichen Raum ihren Bruder sieht, der auf sie aufpassen soll. In MEINE VERRÜCKTE TÜRKISCHE HOCHZEIT und Einmal Hans mit scharfer Soße entscheiden zwar die Akteure aus sich selbst heraus, wann und wo sie den »Vaterrock« anziehen, doch sind sie insgesamt auf Kompatibilität und nicht auf Überschreitung aus. 
und Beleidigung, auch wenn die darin liegenden Auseinandersetzungen immer wieder karikiert werden, ein gewisses Unbehagen, das sich zwar in den dramatischen Sequenzen entlädt, aber nicht aufgefangen wird. Ein Problem der Ankunft gibt es hier nicht. In MEINE VERRÜCKTE TÜRKISCHE HOCHZEIT sind die Türken als Muslime, wie in der politischen Diktion der 2000er, angekommen, letztlich auch als deutsche Muslime. Das Problem ist vielmehr eines der Aufnahme, die ein sozial fluides und zugleich stabiles Verhältnis zwischen Akteur und Religion ermöglichen könnte - ein Verhältnis, das in folgender Haltung kulminieren könnte: Nicht alles, was über den Islam oder den Westen und ihre Freiheit gesagt wird, löst Identifikation oder Betroffenheit aus. ${ }^{249}$ Aufgrund ihrer Komik reichen die Entdramatisierungen über die jeweiligen Sequenzen nicht hinaus. Dies liegt nicht allein an der vermeintlichen Unbeweglichkeit des Islam, sondern auch am expliziten Hervorkehren der Freiheit, wie Helena sie praktiziert. ${ }^{250}$

So gibt es in MEINE VERRÜCKTE TÜRKISCHE HOCHZEIT keinen Innenraum, keine Privatheit, die einem die Kraft und Gelassenheit geben könnte, öffentlich anders zu reagieren. Da dieser Raum und diese Technik der Entdramatisierung und Verhandlung fehlt, ist man am Ende des Films bei der Hochzeit auch nicht erleichtert. Die Erzählweise und das, was der insgesamt sehr hell aufgenommene Film alles zeigt, fragen vielmehr danach, was man lebt und letztlich, ob diese Lebensweisen mit einem muslimischen oder westlichen Modell wirklich in Einklang zu bringen sind. Zwanzig Jahre vor MEINE VERRÜCKTE TÜRKISCHE HochzEIT hatte sich beim Schluss von Hark Bohms YASEMIN und von Jeanine Meerapfels DIE KÜMMELTÜRKIN GEHT ebenfalls keine Erleichterung oder Freude eingestellt. Damals fragte man sich allerdings, wohin die fiktiven und realen Akteure mit ihrer erkämpften Freiheit denn hin sollten, welcher Raum sie aufnehmen würde. In beiden Fällen gab es einen solchen Raum weder in der Türkei noch in Deutschland. Am Ende von MEINE VERRÜCKTE TÜRKISCHE HOCHZEIT fragen wir uns hingegen, wie lange es denn überhaupt gutgehen wird, bis es zum nächsten Streit kommt, bis sich wieder jemand beleidigt fühlt. Damit hat MEINE VERRÜCKTE TÜRKISCHE HoCHZEIT kein richtiges Happy End. Ein gelungener Einsatz von Komik hätte dies ändern können. Besonders für die Komödie gilt: einfache Charaktere lösen ein Verlachen aus, komplexe Charaktere ein

249 Tatsächlich entfachte der Karikaturenstreit um die Mohammed-Abbildungen Anfang 2006 eine Debatte und eine sich daraus ergebende Logik, dass nur diejenigen als echte Muslime bezeichnet werden könnten, die sich von den Karikaturen auch beleidigt und verletzt fühlten. Siehe hierzu: MaLIK, Kenan (2017): Das Unbehagen in den Kulturen. Eine Kritik des Multikulturalismus und seiner Gegner, Berlin: Novo Argumente, S. 93.

250 Siehe hierzu: Holtz (2007). 
Mitlachen. ${ }^{251}$ Doch lachen Deutsche und Türken erst am Ende in der letzten Sequenz des Films gemeinsam, wenn Aylin und Götz vor und in seinem Plattenladen ihre Hochzeit feiern. Und selbst dieses gemeinsame Lachen wird nicht gehört, da es vom türkischen Popsong Isyankar (Rebell) des Sängers Mustafa Sandal übertönt wird.

Obwohl MEINE vERRÜCKTE TÜRKISCHE HochZEIT vor allem vom Zusammenleben von Deutschen und türkischen Muslimen handelt, liegt das zentrale Problem im Gebrauch deutscher und türkischer Kennzeichen darin, dass in die Performanz- und Erzählstruktur des Films der Islam und eine bestimmte Form der Freiheit als Regel- und als ordnungsstiftende Systeme, als Normen und als Substantive und als Teile der öffentlichen Debatten so sehr eingeschrieben sind, dass sie andere mögliche Praktiken der Integration ausschließen und die Form der Komödie am Ende nicht die Oberhand gewinnen lassen. Der Weg der Integration verläuft hier wie auf der Islamkonferenz sowie den Ausführungen von Jürgen Habermas und den anderen genannten Wissenschaftlern nur entlang der engen Schiene der Religion und darüber, was als freiheitliche Gesellschaftsordnung verstanden wird. Dass sich Religion aber tatsächlich als Teil einer gesellschaftlichen Ordnung in MEINE VERRÜCKTE TÜRKISCHE HOCHZEIT beschreiben lässt, stellen der häufige Wechsel zwischen komischen Situationen und Beleidigungen sowie die Dominanz des Verlachens (statt Mitlachen) in Frage. Religion und Freiheit sind hier keine persönlichen Angelegenheiten oder kulturelle Entitäten, die entwickelt oder entdeckt werden können. Sie sind hier umgekehrt von Beginn an gesetzt. Letztlich ist MEINE VERRÜCKTE TÜRKISCHE HochzEIT eher von Integrations- und Ordnungsfragen als von Fragen nach sozialen und intimen Beziehungen bestimmt. Diese Fragen beantwortet AUf DER ANDEREN SEITE von Fatih Akın auf andere Art und Weise. Im Gegensatz zu MEINE VERRÜCKTE TÜRKISCHE HOCHZEIT rückt er an die Stelle der Ordnung die soziale und intime Beziehung.

Welchen Ort und welchen Stellenwert der Islam einnehmen sollte, musste sich Mitte der 2000er Jahre aber auch Fatih Akın fragen. Denn er war wie viele andere »säkulare Muslime« zur Deutschen Islam Konferenz eingeladen worden neben etwa Necla Kelek, Feridun Zaimoğlu, Seyran Ateş und Navid Kermani. Im Unterschied zu den eingeladenen Verbandsvertretern der DITIB, dem Zentralrat der Muslime, sollten sie die »nicht-organisierten Muslime«, die schweigende Mehrheit der Muslime vertreten. ${ }^{252}$ Für Akın persönlich stellte sich jedoch schnell

251 Siehe hierzu: GREINER (2017): S. 33.

252 Siehe hierzu: TEZCAN (2013): S. 169. Auf der Islam Konferenz wollte sich die Regierung nicht allein mit muslimischen Verbänden beraten, sondern besonders mit den nicht-organisierten »Individualisten«. Durch diese Vielfalt der Stimmen über und um den Islam entstand das Problem, 
heraus, dass die Art, wie der Islam auf der DIK verhandelt wurde, mit seinen Vorstellungen und Erfahrungen nicht übereinstimmte, weshalb er in der Folge der Konferenz fernblieb. ${ }^{253}$ Nach Tezcan war die Vertretungsfunktion der »nicht-organisierten Muslime« auf der Konferenz tatsächlich von einem Paradox bestimmt, das Seyran Ateş auf dem vierten Plenum wie folgt auf den Punkt gebracht habe: Der Glaube sei für die »nicht-organisierten« bzw. »säkularen Muslime«

etwas sehr Persönliches. Das [über die DIK, Ö.E.] zu organisieren, gar zu institutionalisieren bedeutet für viele Muslime und Musliminnen, ihre Religion zu politisieren. Sie wollen ihren Glauben nicht wie ein Schild vor sich herschieben und zeigen. Das wollen sehr viele Muslime nicht. Sie werden die schweigende Mehrheit genannt. ${ }^{254}$

Zur Zeit der Entwicklung dieser identitätspolitischen Konstellation, die das Private, wie in MEINE VERRÜCKTE TÜRKISCHE HoCHZEIT zum Politischen erklärt, ${ }^{255}$ ist Fatih Akıns Auf DER ANDEREn SEITE entstanden. ${ }^{256}$ AUF DER ANDEREN SEITE

dass die nicht-organisierten Muslime nun selbst beginnen mussten, sich zu organisieren oder zumindest ihr Verhältnis zur Religion zu erklären. Für Tezcan, der selbst an der DIK teilnahm, hatte das Vorhaben der Regierung, mit den Individualisten die »schweigende Mehrheit« zu berücksichtigen, eine verstärkte »Politisierung der Religion« zur Folge. Siehe hierzu ebd., S. 170f. Tatsächlich sind in der Folge 2008 ein »Zentralrat der Ex-Muslime« und 2011 sogar eine »Alternative Islamkonferenz« ins Leben gerufen worden. Siehe hierzu: https://alternativeislamkonferenz. wordpress.com/ (01.05.2018); http://exmuslime.com/ (01.05. 2018).

253 Kurze Zeit darauf blieb auch der Autor Feridun Zaimoğlu der DIK fern, die er anfangs sehr gelobt hatte. Für ihn fehlte eine Vertretung individuell gläubiger Muslima. Damit hatte er recht: Von den nicht-organisierten Muslima trug keine ein Kopftuch. Siehe hierzu: IsLAMISCHE ZEITUNG (2007): »Interview: Autor Feridun Zaimoğlu über seinen Ausstieg aus der Islamkonferenz«. In: ISLAMISCHE ZEITUNG, 24.04.2007, https://www.islamische-zeitung.de/interview-autor-feridun-zaimoglu-ueber-seinen-ausstieg-aus-der-islam-konferenz/ (04.05.2018).

254 Zitiert nach: TEZCAN (2012a): S. 91f. Wie wichtig in der DIK die Performanz, ihre Produktion und das sichtbare Auftreten war, zeigt sich eindrücklich in der Gründung der liberalen Ibn-RushdGoethe Moschee von Seyran Ateş im Sommer 2017 in Berlin-Moabit. Siehe hierzu: DobRINSKI, Matthias (2017): »Ein Gebetshaus namens Goethe«. In: SüDDEUTSCHE ZEITUNG, 19.06.2017 (http://www. sueddeutsche.de/panorama/islam-in-deutschland-eingebetshaus-namens-goethe-1.3546306).

255 Dazu gehört auch, dass Fatih Cevikkollu sich von dem islamischen Terrorismus distanzieren musste, obwohl er dazu als Muslim überhaupt keinen Bezug hat. Einen Umgang mit dieser paradoxen Konstellation war für ihn möglich, indem er diese Demonstration bewusst ins Komische wendete. Er distanzierte sich nämlich nicht nur als Muslim von der islamistischen terroristischen Gewalt, sondern er distanzierte sich auch als Mann von der Gewalt gegenüber Frauen und als Wassertrinker von Nestlé. Siehe hierzu: PFAHLER, Lena (2017): „Deutsch-Türkischer Komiker distanziert sich vom Terror - Doch dann legt er richtig los«. In: Huffpost, 18.06.2017, http://www. huffingtonpost.de/2017/06/18/cevikkollu-friedensmarsch_n_17190556.html (20.09.2018).

256 In Feridun Zaimoğlus und Günter Senkels Theaterstück Schwarze Jungfrauen von 2006 steht ebenfalls der individuelle Einsatz der Religion im Vordergrund. Das monologisch aufgebaute und 
erzählt Geschichten von sechs Figuren, die zugleich sechs Handlungsstränge auslösen. Dabei erstreckt sich der kulturelle und nationale Hintergrund der Protagonisten vom Deutsch-Türkischen (Ali, Yeter [1. Generation], Nejat [2. Generation, Alis Sohn]) über das Türkische (Ayten [Linksaktivistin, Yeters Tochter]) bis zum Deutschen (Susanne [Alt-68erin]) und Lotte [Susannes Tochter]). Nejat ist ein zurückgezogen lebender Germanistikprofessor in Hamburg, sein Vater Ali ein verwitweter, einsamer Mann, der in Bremen lebt. Nejat sieht das Zusammenleben seines Vaters mit einer türkischen Prostituierten sehr skeptisch, bis er Yeter näher kennenlernt, die ihrer Tochter Ayten in Istanbul regelmäßig Geld schickt. Als Ali Yeter unabsichtlich tötet, macht sich Nejat, der mit seinem Vater wegen des Totschlags bricht, auf die Suche nach Ayten. Diese ist aber längst in Deutschland, eine linke politische Aktivistin auf der Flucht vor der türkischen Polizei. Sie lernt die deutsche Studentin Lotte kennen und lieben, was wiederum deren Mutter Susanne nicht gutheißt. Durch ein Missgeschick landet Ayten in Abschiebehaft und wird nach einem erfolglosen Asylverfahren in die Türkei abgeschoben. Lotte reist ihr nach und kommt dabei in Istanbul unerwartet durch Straßenkinder ums Leben, die mit einer Pistole spielen, die Ayten Lotte zur Aufbewahrung gegeben hatte. Damit ist Ayten für Lottes tragischen Tod mitverantwortlich. Davor, als Lotte auf einen Gerichtsprozess wartet, sucht Nejat weiter nach Ayten. Er übernimmt während seiner Zeit in Istanbul einen deutschen Buchladen, in dem er auch Lotte begegnet, die zur Untermiete bei ihm einzieht. Nach ihrem plötzlichen Tod reist ihre Mutter Susanne nach Istanbul, um mit den Menschen Kontakt aufzunehmen, die Lotte zuletzt kannten. Zur gleichen Zeit wird Nejats Vater Ali in die Türkei abgeschoben. Ohne seinen Sohn zu besuchen, reist er an seinen Herkunftsort am Schwarzen Meer. Gegen Ende des Films sehen wir Nejat zu seinem Vater fahren, was zugleich die Anfangssequenz des Films war. ${ }^{257}$

Trotz Fatih Akıns Unbehagen auf der Deutschen Islam Konferenz übt Religion in Auf DER ANDEREN SEITE ebenfalls, wie in MEINE VERRÜCKTE TÜRKISCHE HochzEIT, erzählerisch eine organisierende Funktion aus: Sie rahmt Anfang und Ende beider Filme. Wie bereits erwähnt, ist der erste gesprochene Satz in AuF DER ANDEREN SEITE ein Glückwunsch zum muslimischen Opferfest: »Bayramınız kutlu olsun «. ${ }^{258}$ Diese Anfangssequenz, die sich am Ende wiederholt, hat inhalt-

strukturierte Stück gibt Einblick in das Leben von 10 kopftuchtragenden jungen muslimischen Frauen. Es wurde am 17. März 2006 in Hebbel am Ufer in Berlin uraufgeführt und entstand als Auftragsarbeit unter der Kuration von Shermin Langhoff für das Theaterfestival beyond belonging. Migration hoch zwei. Siehe hierzu: https://gorki.de/de/schwarze-jungfrauen (20.09.2018). Regie führte der Film- und Theaterregisseur Neco Celik.

257 AKIN (2007).

258 Ebd. 
lich und formal eine integrative Funktion. Obwohl es auch in MEINE VERRÜCKTE TÜRKISCHE HOCHZEIT offensichtlich um Integration geht, könnte der Umgang mit Religion in beiden Filmen nicht unterschiedlicher sein. In Holtz' Film ertönt zu Straßenbildern aus Kreuzberg der Gebetsruf als voice-over, und Horst erklärt, dass der Stadtteil den Türken gehöre. In Akıns Film sehen wir in der ersten Einstellung hingegen einen verwahrlosten Schuppen mit einem Straßenhund davor sowie einen Mann, der mit seinem Auto an eine Tankstelle fährt und eine religiöse Grußformel ausspricht. Religion ist hier Teil eines unbestimmten öffentlichen Raums und des alltäglichen öffentlichen Lebens. Der muslimische Gebetsruf, die Minarette und Moschee-Besucher werden auch in AUF DER ANDEREN SEITE noch folgen, nur an einem anderen Ort und an anderer Stelle. Neben der Rahmung ist der Einsatz von Religion in AUf DER ANDEREN SEITE im Gegensatz zu MeINE VERRÜCKTE TÜRKISCHE HOCHZEIT daher tiefenstrukturell eingebettet. Denn Gebetsruf, Minarette und Moschee-Besucher folgen im dritten Teil des Films, der als Schlüsselstelle der Erzählung den Wendepunkt von Akıns Film einleitet: ein Gespräch zwischen Susanne und Nejat über das muslimische Opferfest. Allein diese mehrdimensionale Einbindung der Religion macht deutlich, dass es in AuF DER ANDEREN SEITE im Unterschied zu MEINE VERRÜCKTE TÜRKISCHE HOCHZEIT nicht um die Befolgung kultureller Regeln geht, sondern um ihre Eingebundenheit in den konkreten Alltag. Doch trotz dieser bestimmten Verortung der Religion wird umgekehrt weder die Modernität oder Säkularität der Akteure thematisiert. Denn durch die Einbindung der Religion ist ein Überschreiten ihrer Grenzen und Regeln nicht nötig. Die Akteure vollziehen also nach klassischen Integrationstheorien kein »boundary crossing «. Auch in AUf DER ANDEREN SEITE stehen, wie in MEINE VERRÜCKTE TÜRKISCHE HOCHZEIT, die alltäglichen Praktiken der Akteure im Vordergrund des Geschehens und schaffen eine Zone des »boundary blurring «. ${ }^{259}$

Auch wenn das interkulturelle und das binationale biografische Gefüge sowie die Bewegung der Akteure auf den ersten Blick bestimmend wirken, stehen die Figuren in Akıns Film weder als Individuen noch ihre Bewegungen als eine Form des »Aus-der-Haut-kommen-wollens « im Zentrum. Sie suchen nicht Freiheit oder Emanzipation, sondern den Anderen. ${ }^{260}$ Akteure und ihre Bewegungen sind Ele-

259 Siehe zu boundary blurring: ESSER (2008): S. 86.

260 Diese Suche oder das Bedürfnis nach dem Anderen statt Freiheit und Emanzipation begegnet uns auch in den Filmen Der SCHÖNE TAG (2001) von Thomas Arslan, EINE ANDERE LigA (2005) von Buket Alakuş und EN Garde (2004) von Ayşe Polat. Im Unterschied zu den beiden letztgenannten findet in Arslans Film die Protagonistin den Anderen nicht. Siehe hierzu: Arslan, Thomas (2011): Der schöne Tag, Spielfilm, Deutschland; Alakuş, Buket (2005): Eine andere Liga, Spielfilm, Deutschland; Polat, Ayşe (2004): En Garde, Spielfilm, Deutschland. 
mente eines Settings, anhand dessen die Bedürfnisse, Beziehungen und Lebensweisen der Protagonisten dargestellt werden. Im Zentrum der Erzählung stehen die »Notwendigkeit einer Beziehung “ $^{261}$ und das Zusammenleben.

Interessant sind hierbei die Platzierung und der Einsatz der religiösen und kulturell unterschiedlichen Marker. Sie stehen für Inhalt und Form zugleich. So leitet etwa der Gastarbeiter Ali seine Frage an die türkische Prostituierte Yeter, ob sie mit ihm zusammenleben möchte, auf Türkisch mit den Worten ein, dass er allein lebe, Witwer sei und als Rentner kein schlechtes Einkommen habe. Später wird er noch hinzufügen, dass er einen Sohn habe, der Professor sei und ihnen auch finanziell aushelfen könne. Er beendet die Darstellung seiner Lebenssituation mit einem fragenden Verweis auf den gemeinsamen türkisch-muslimischen Hintergrund: »Eh, ne demişler?« (»Und wie heißt es so schön?«). Yeter antwortet: "Yalnızlık Allaha mahsus« (»Die Einsamkeit steht nur Gott $\mathrm{zu}$ «). Der Einsatz religiöser Formeln dient dazu, die eigene Situation auf den Punkt zu bringen, ohne ihn ausführlich erklären zu müssen. Wenn in der religiösen Volksweisheit die Einsamkeit nur Gott zusteht und der Mensch als ein im Kern der sozialen Beziehung und des Zusammenlebens bedürftiges Wesen beschrieben wird, ist Religion in Auf DER ANDEREN SEITE gegen Ende des Films nicht mehr nur verbal, sondern auch materiell und symbolisch in die eigene Lebenserzählung eingebettet. Besonders eindrücklich ist diese Konstellation in der bereits erwähnten Schlüsselstelle des Films im dritten Kapitel »Auf der anderen Seite».

Nach Lottes Tod in Istanbul und der Überführung ihrer Leiche nach Deutschland reist Susanne in die Türkei, um, wie schon erwähnt, die Menschen kennenzulernen, mit denen Lotte zuletzt zu tun hatte. Sie zieht bei Nejat in Lottes Zimmer ein und besucht Ayten im Gefängnis. Sie will ihr helfen, weil ihre Tochter genau das vorhatte. Susanne vergibt Ayten und bietet ihr ihre Hilfe an. Im Zentrum steht allerdings ein Gespräch zwischen Susanne und Nejat am ersten Tag des Opferfestes. In den ersten drei Einstellungen sehen wir Aufnahmen von Minaretten und eines Kirchturms in Istanbuler Stadtteilen. Dabei sind die Türme der Gotteshäuser, die beide die Funktion haben, zum Gebet zu rufen, umgeben von Wohnhäusern, die ihnen wiederum keine eindeutige Bedeutung verleihen. Man muss beispielsweise in der dritten Einstellung genau hinsehen, um zu erkennen, dass neben einem Minarett auch eine Kirche steht. Als voiceover hören wir zu diesen Aufnahmen den muslimischen Gebetsruf, denn es ist der Tag des Opferfestes. ${ }^{262}$

261 Siehe hierzu: ELSÄSSER (2011): S. 63.

262 Siehe hierzu: AKIN (2007). 
Diese Zusammenführung wird mit der nächsten Einstellung weitererzählt, in der wir sehen, wie Menschen allein und paarweise die Straße, in der Nejat wohnt, entlanglaufen. Wenn man diese Aufnahme genau betrachtet, sieht man im oberen linken Viertel des Bildes, wie Susanne langsam an das geöffnete Fenster tritt und schaut, wohin die Menschen gehen. Erst danach sehen wir Susanne in einer halbtotalen Einstellung, wie sie aus ihrem Zimmer heraus auf die Straße blickt. Von hinten sehen wir dabei Nejat aus seinem Zimmer in ihr Zimmer kommen. Als er dann neben ihr steht, fragt ihn Susanne, wohin denn all diese Menschen gehen. Nejat antwortet, dass sie in die Moschee gehen, denn heute beginne »Bayram «, das dreitägige Opferfest. Susanne fragt, was denn da eigentlich genau geopfert werde und Nejat erzählt:

Gott wollte von Ibrahim [Abraham, Ö.E.] wissen, wie stark sein Glaube ist. Deshalb befahl er ihm, seinen Sohn zu opfern. Ibrahim führte seinen Sohn Ismail auf den Opferberg, aber in dem Moment, in dem er zustechen wollte, war das Messer stumpf geworden. Gott war zufrieden und schickte Ibrahim ein Schaf. Er sollte es anstelle des Kindes opfern.

Nejats Blick wandert dabei langsam zu Susanne, die Nejat ansieht und erwidert, dass es diese Geschichte »auch bei uns gibt «. ${ }^{263}$ Ein Kulturdialog scheint sich anzudeuten, doch geht das Gespräch anders weiter.

Auf die Aussage, dass es diese Geschichte auch bei »uns«, also im Christentum gebe, reagiert Nejat mit einer unwillkürlich einsetzenden Erinnerung aus seiner Kindheit, einer memoire involontaire im Proust'schen Sinne. »Ich weiß noch, wie ich meinen Vater fragte, ob er mich auch opfern würde«, sagt Nejat zu Susanne. Bis hierin sind beide Protagonisten in einer Halbtotalen, in einem Bild aufgenommen. Erst jetzt folgt ein Schnitt, der uns nun Nejat über die rechte Schulter von Susanne von der Seite zeigt. Er wendet seinen Kopf zu Susanne und führt weiter aus, dass er früher große Angst vor dieser Geschichte gehabt hätte, denn seine Mutter sei früh verstorben. Nach dieser Aussage sehen wir über Nejats Schulter hinweg Susanne in Großaufnahme, die ihn betroffen anblickt. Sie fragt Nejat, was sein Vater geantwortet habe. Darauf sehen wir wieder Nejat von der Seite in Großaufnahme über Susannes Schulter hinweg. Er blickt sich erinnernd und ergriffen an ihr vorbei und antwortet: »Er sagte, er würde sich sogar Gott zum Feind machen, um mich zu beschützen «. ${ }^{264}$ Susanne ist sichtlich gerührt und beeindruckt von dieser Antwort und fragt, ob sein Vater noch lebe. Nejat antwortet leise »ja«, und in der nächsten Einstellung sehen wir wieder Menschen auf der Straße in die Moschee laufen. Die Kamera nimmt dabei nun einen älteren

263 Ebd.

264 AKIN (2007). 
Mann mit Takke auf. ${ }^{265}$ Darauf folgt wieder eine Einstellung über Susannes Schulter hinweg auf Nejat und er fragt sie erfreut, ob sie für ein paar Tage seine Buchhandlung beaufsichtigen könne. Die Kamera nimmt nun beide von hinten auf, sie sehen sich und wir sehen hinter ihnen die Menschen die Straße zur Moschee entlanglaufen. Es folgt ein Schnitt, und die nächste Einstellung ist die leicht modifizierte Eröffnungssequenz des Films. Nun wissen wir, dass Nejat in der ersten Sequenz des Films, am ersten Tag des Opferfestes, unterwegs zu seinem Vater ist, um sich mit ihm zu versöhnen. Tatsächlich ist eine der sozialen Grundfunktionen des muslimischen Opferfestes nach islamischen Ritus die Versöhnung unter Familienangehörigen und Freunden. ${ }^{266}$ Auch der Gang der Menschen in die Moschee, ihr Weg, der im Wechsel mit der Entstehung der kulturellen Erzählgemeinschaft zwischen Susanne und Nejat konstituiert wird, zeigt die Verschränkung von Inhalt und Form in diesem Film.

Religion rahmt nicht nur die Geschichte in AUF DER ANDEREN SEITE, sondern bestimmt sie auch tiefenstrukturell. Dabei geht es gar nicht darum, dass die Akteure ihre Regeln befolgen. Sie ist Teil der Erzählung und Anlass für ein gemeinsames Gespräch. ${ }^{267}$ Ihr Einsatz kultureller Marker dient hier eher als ein »thematischer Ansatz einer offenen Kommunikation, als dass sie den Kern eines Dialogs « bildet. ${ }^{268}$ Erneut geht es nicht darum, Grenzen zu ziehen oder zu überschreiten (boundary crossing), sondern sie zu verwischen (boundary blurring). So ergänzt Susanne Nejats Geschichte nicht etwa damit, dass Abrahams Sohn in der christlichen Version Isaak heißt. Vivien Silvey und Roger Hillmann interpretieren Susannes Zurückhaltung an dieser Stelle dahingehend, dass für sie die »confluence of narratives « relevant sei und nicht die exakte Bestimmung und Markierung von Eigenem und Fremdem. ${ }^{269}$ Diese Interpretation lässt sich vor allem durch die Abfolge des Dialogs stützen. Denn bevor sich Susanne und Nejat über das muslimische Opferfest austauschen, sehen wir die Symbole der Religion eingebettet in den Lebensalltag der Menschen: als Häuser neben anderen Häusern. Im Gespräch wird genau diese Einbindung wiederholt. Die Symbole werden nicht isoliert und getrennt nach außen gekehrt wie die Klischees in MEINE VERRÜCKTE

265 Die Takke ist ein kippaähnliches Scheitelkäppchen, das in der Regel beim rituellen Gebet von Männern oder Jugendlichen in der Moschee getragen wird.

266 Später wird sich zeigen, dass in Feo Aladağs Spielfilm DiE FREMDE diese traditionelle integrative Funktion des muslimischen Festes in ihr Gegenteil verkehrt ist.

267 TEZCAN (2010): S. 62.

268 Ebd.

269 Siehe hierzu: Hillmann, Roger/SilvEy, Vivien (2010): »Akin’s `Auf der anderen Seite (The Edge of Heaven) and the widening periphery". In: German as Foreign Language, No 3/2010, S. 99-116, hier S. 104. Susanne sagt im Film: »Diese Geschichte gibt es bei uns auch«. Siehe hierzu: AKIN (2007). 
TÜRKISCHE HochzEIT. Religion ist ein kultureller Marker oder eine Kategorie, keine unveränderliche Essenz.

Diese Übersetzung und Dialogizität gelingen in AUf DER ANDEREN SEITE besonders deshalb, weil uns die Lichtverhältnisse und Perspektiven sehr viel sehen lassen. Trotz der vielen Charaktere, Biografien, Beziehungen und Bindungen, die der Film thematisiert, werden wir von den Geschehnissen nicht überrumpelt. Die Kamera bewegt sich kaum; wichtiger ist das Einfangen von Beziehungen und Bindungen. Im Gegensatz zu Filmen der 1990er Jahre ist der Film viel ruhiger geschnitten. Dies gilt hinsichtlich des immerwährenden Wechsels zwischen Komik und Konflikt auch für MEINE verRüCKTE TÜRKISCHE HochZEIT. Außerdem sind beide Filme, wie bereits erwähnt, im Gegensatz zu den 1990er Jahren von hell fotografierten Einstellungen bestimmt. Der entscheidende Unterschied liegt darin, dass in AUF DER ANDEREN SEITE in der Regel halbtotale Einstellungen auf totale folgen. In MEINE VERRÜCKTE TÜRKISCHE HOCHZEIT wechseln hingegen Halbtotale und Nahaufnahmen, wobei letztere insgesamt dominieren; ebenso wie Interieur-Aufnahmen. Diese Nähe zum türkischen Leben in Deutschland zeigt in MEINE VERRÜCKTE TÜRKISCHE HochzeIT allerdings keine Privatheit. Jedes persönliche Anliegen ist integrationspolitisch ein öffentliches, was natürlich an die Arbeiten von Necla Kelek und Seyran Ateş erinnert. Auch wenn sich eine kopftuchtragende Frau noch so selbstbewusst im öffentlichen Raum zeigt und bewegt, gilt sie nicht als integriert und modern, meint Kelek. Denn ihr Auftritt stehe immer für die Einhaltung des muslimischen Gesetzes, nie für die Repräsentation eines modernen Lebens. Dieses Gesetz geht auf ein privates Empfinden des islamischen Propheten Mohammed zurück: ${ }^{270}$

270 Was die Verschleierung betrifft, gibt es im Koran zwei zentrale Stellen: Vers 31 in der Sure 24 (Das Licht `al-Nur`) und die Sure 33 (Die Parteien `al-Ahzab`) der Vers 59. Beim ersten Vers geht es explizit um die Frage des sittlichen Verhaltens. Dort heißt es: »Und sprich zu den gläubigen Frauen, sie sollen ihre Blicke senken und ihre Scham bewahren, ihren Schmuck nicht offen zeigen, mit Ausnahme dessen, was sonst sichtbar ist. Sie sollen ihre(n) Tücher/Schleier um ihre Busen schlagen und ihren Schmuck nicht offen zeigen, es sei denn ihren Ehegatten, ihren Vätern, den Vätern ihrer Ehegatten, ihren Söhnen ihrer Brüder und den Söhnen ihrer Schwestern, ihren Frauen, denen, die ihre rechte Hand besitzt, den männlichen Gefolgsleuten, die keinen Trieb mehr haben, den Kindern, die die Blöße der Frauen nicht beachten. Sie sollen ihre Füße nicht aneinanderschlagen, damit man gewahr wird, was für einen Schmuck sie verborgen tragen.» Durch sittliches Verhalten soll die Frau ihre Scham (`awra) bewahren und vermieden werden, dass erogene Atmosphären und Zonen zwischen gläubigen Frauen und Männern, die nicht zur Familie gehören, im öffentlichen Raum entstehen. Verhaltensweisen wie »Blicke senken«, nicht prahlend den Schmuck, die eigene Zierde und die »Blöße« zeigen, stehen im Vordergrund. Dass es zentral um die Vermeidung erogener Atmosphären geht, zeigt auch Vers 60 in Sure 24, wo es heißt, dass es kein Vergehen sei, wenn Frauen, »die sich zur Ruhe gesetzt haben und nicht mehr zu heiraten hoffen [...] ihre Kleider ablegen«. Im zweiten Vers geht es um Schutz. »O Prophet, 
Aus dem relativ harmlosen Vorgang, dass Mohammed sich in seiner Privatsphäre eingeschränkt fühlte und sich mit einem Vorhang schützte, ist die nachdrückliche Bestimmung der Stellung der Frau im Islam, die Trennung der islamischen Gemeinschaft in die Männerund Frauenwelt geworden. Und daraus erwuchs eine Tradition, die bis heute das Leben von Millionen Frauen bestimmt. ${ }^{271}$

Demgegenüber lebe eine zivile Gesellschaft »nicht von Verboten, sondern von Normen und Werten, über die ein gesellschaftlicher Konsens erzielt worden ist und die verinnerlicht wurden «. ${ }^{272}$ Erst wenn man das Kopftuch im öffentlichen Raum weglässt, wird Selbstbestimmung, Verinnerlichung des modernen Lebens sichtbar. Während Kelek einer derartigen Repräsentationslogik anhängt, die das Innere nach außen kehrt, verhandelt AUF DER ANDEREN SEITE die Beziehungen der Akteure untereinander und ihre Verhältnisse und Positionen zu Orten, Dingen und in Räumen. ${ }^{273}$ So folgt auf die Eröffnungssequenz eine Fahrt durch die türkische Provinz, die die Dinge und die Landschaft hell ausleuchtet mit einbezieht. Das sich darin bewegende Subjekt, der Germanistikprofessor Nejat, ist in die Umgebung eingebunden. ${ }^{274}$ Er ist auf der Fahrt zu seinem Vater an die Schwarzmeerküste, was zugleich die zweite Bindungslogik in diesem Film aufzeigt: die Familie. Gebunden werden diese beiden Ebenen, Verortung der Akteure im Raum und ihre familiären Bindungen, durch die Bewegungen der Protagonisten von a nach b, die zwischen Bremen, Hamburg, Istanbul und Schwarzmeer-

sag deinen Gattinnen und deinen Töchtern und den Frauen der Gläubigen, sie sollen etwas von ihrem Überwurf über sich herunterziehen. Das bewirkt eher, dass sie erkannt werden und dass sie nicht belästigt werden.« Diese Anweisung soll auf die Begebenheit zurückgehen, dass Gäste des Propheten Mohammad über die zeitliche Gebühr hinaus seine Gastfreundschaft an einem Abend beanspruchten und dies an der Schönheit seiner Frauen gelegen haben soll. Siehe zu den Koranversen: Der Koran, Übersetzung von Adel Theodor Khoury (unter Mitwirkung von Muhammad Salim Abdullah), Gütersloher Verlagshaus 1987, S. 267, S. 270 u. 323f.

271 KELEK (2005): S. 174.

272 Ebd., S. 238.

273 Siehe hierzu: CHA, Kyung-Ho (2010): „Erzählte Globalisierung. Gabentausch und Identitätskonstruktion in Fatih Akıns >Auf der anderen Seite«. In: Kultur als Ereignis, S. 135-150.

274 So vertraut wie Nejat sich in der zweiten Hälfte des Films durch die Türkei bewegt, war er im ersten Teil des Films zwischen Hamburg, seiner Arbeitsstelle, und Bremen, dem Wohnort seines Vaters in Deutschland unterwegs. Ähnliche Zustände in der Türkei und in Deutschland berichtet die Ich-Erzählerin in Hans mit scharfer Soße. »Als wir in Deutschland losfuhren, verließ ich meine Heimat. Aber jetzt nach drei Tagen verspürte ich wieder Vertrautheit um mich herum." Das Dorf Akpınar (im Film von 2013 heißt es Tepeciköy) war ein Ort »zwischen Vertrautheit und Fremdheit, irgendwo zwischen Niemandsland und Heimatland. [...] Ich würde die nächsten Wochen Heimweh nach Deutschland haben, aber dennoch nicht von hier wegwollen. Ich war mit allem einverstanden, ohne zu wissen, worauf dieses Einverständnis eigentlich beruhte.« Siehe hierzu: AKYÜN (2005): S. 53 u. 56. 
küste auf der Suche nicht nach sich selbst, sondern nach alter und neuer Familie und Geborgenheit sind. Was die Figuren miteinander in Beziehung treten lässt, sind die Tode von Yeter und Lotte. Die Bindungen zwischen Landschaft, Orten, Familie und Protagonisten werden in vielen Sequenzen sichtbar aktualisiert. ${ }^{275}$

So sehen wir etwa Lotte in einer Telefonzelle im Hotel in Istanbul mit ihrer Mutter telefonieren. In dem Telefonat geht es vor allem darum, wann Lotte denn nun endlich nach Deutschland zurückkehrt, um ihr Studium fortzusetzen. Lotte antwortet genervt, dass es noch ein halbes Jahr dauern könne und dass sie zum ersten Mal in ihrem Leben das Gefühl habe, etwas Richtiges zu machen. Während dieser Diskussion sitzt Lotte in einer embryonalen Haltung auf dem Boden. Die Position der Kamera ist distanziert: eine Totale, die genau diese Haltung einfängt, die repräsentativ gesehen im Gegensatz zum verhandelten Inhalt, einem kleinen Familienstreit, steht. Am Ende bricht nicht Lotte das Gespräch ab, sondern ihre Mutter, die Lotte in der besagten Haltung unsicher und ängstlich wie ein Kleinkind zurücklässt.

Wiederholt wird diese Szene in umgekehrter Richtung nach Lottes Tod. Wir sehen Susanne in Lottes Zimmer in Istanbul das Tagebuch ihrer Tochter lesen, das sie während ihrer Zeit in Istanbul verfasst hatte. In der mit Lottes Stimme vorgelesenen Passage, vergleicht die Tochter ihre politische Odyssee in die Türkei mit der ihrer Mutter als diese in den 1960er Jahren nach Indien aufgebrochen war.

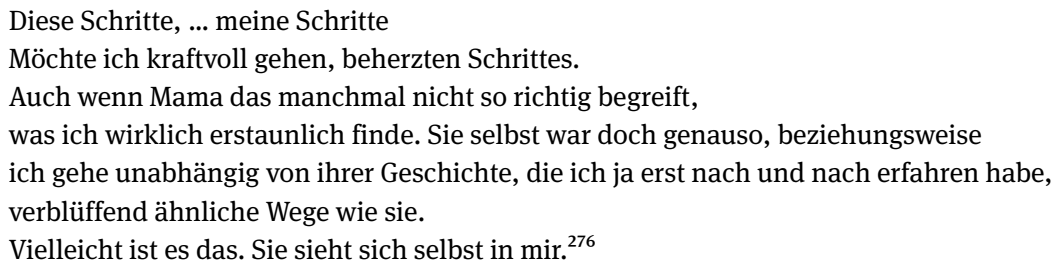

In der nächsten Szene verlässt Susanne das Haus und grüßt auf der gegenüberliegenden Straßenseite zwei Backgammon-(Tavla-)Spieler mit der gleichen Hand-

\footnotetext{
275 Auch Zafer Şenocaks Protagonist Hamit aus Pavillon, der 1957 wegen seines Studiums nach Wien und dann weiter nach München zieht, fühlt sich innerhalb kurzer Zeit in München wohl: „Wenn man im Zentrum der Stadt anfing und bis an den nördlichen Rand gelangte, so war der Englische Garten der Ort, den er am häufigsten aufsuchte. Sobald er das entdeckt hatte, besuchte er ihn - ohnehin nicht weit weg von seinem Zuhause - regelmäßig. [...] Auch wenn er nur ein Stäubchen darin gewesen wäre, so fühlte er sich doch als ein Teil dieser Gegend.« Und als Hamit gemeinsam mit seiner deutschen Freundin Hilde Istanbul besucht, fühlt er sich auch dort, trotz des Militärputschs von 1961, wohl. Siehe hierzu: ŞENOCAK (2009): S. 31 u. 57.
}

276 AKIN (2007). 
bewegung wie zuvor ihre Tochter. Wie Nejat werden weder Lotte noch Susanne als Touristen in der Türkei dargestellt. ${ }^{277}$ Das Verhalten tritt an die Stelle der Artikulation. Denn die Gespräche zwischen Mutter und Tochter darüber, dass Lotte Ayten helfen muss, enden in Deutschland immer im Streit. Hinsichtlich ihres Verhaltens ähneln die beiden aber einander. Ein vergleichbares Bindungsverhältnis, das über den Dialog hinausreicht, macht Akın auch für Nejat und seinen Vater Ali sichtbar. Auch hier sind es körperliche Handlungen, denen filmtechnisch derselbe Stellenwert wie dem Sprechen eingeräumt wird. Dieser Zusammenhang verwandelt Orte in Räume, die die intimen Beziehungen sowie den Umgang mit Kultur prägen. Denn die Akteure machen etwas mit den eingefangenen Orten und verändern so ihre Ordnungen. Ein weiteres plastisches Beispiel für die Verwandlung eines Ortes, einer Ordnung in einen Raum, in eine mehrdeutige Ordnungsstruktur, zeigt uns die Analyse folgender Sequenz.

»Eh, sen şimdi kimi diş ediysin?« (»Wen bumst Du zur Zeit?«), fragt Ali mit lasischem Akzent seinen Sohn Nejat. Sie sitzen Eis essend vor dem Bremer Bahnhof auf einer Parkbank. Die Kamera nimmt sie mit einer Totalen auf. Verdutzt hebt Nejat den Kopf, hört auf, sein Eis zu essen und blickt in Richtung Kamera. Sein Vater rückt näher an ihn heran und wiederholt die Frage mit einer ausholenden Handbewegung: »Kimi bum bum ediysin, da?« (»Wen Du bumst, meine ich?«) Nejat antwortet ihm: »Baba, gentlemen adam böyle birşey konuşmaz«. (»Baba, ein Gentleman spricht nicht über so was«). Ali wendet seinem Sohn ein wenig beleidigt den Rücken zu und antwortet in einer Art Gastarbeiterdeutsch: »Ach so, das wusste ich nicht«, fügt aber auf Türkisch hinzu: »Seninle de birşey konuşulmaz ki!« (»Mit Dir kann man aber auch über nichts reden!«) Nejat isst wie sein Vater sein Eis auf, klopft seinem Vater zum Abschied auf den Rücken und empfiehlt ihm, das Buch zu lesen, das er ihm geschenkt hat. Sein Vater grummelt auf Türkisch zurück, dass er es »verfickt nochmal lesen werde« (»okuruz, amına koyum «). 278

Die ganze Szene lebt von einer Einstellung, die beide auf einer Parkbank vor dem Bremer Bahnhof zeigt. Keine Schuss- und Gegenschuss-Aufnahme trennt Vater und Sohn voneinander. Selbst der Gesprächsverlauf und sein Inhalt reißen

277 Siehe hierzu: GöKtÜRK (2010): S. 20; Silvey/HiLlman (2010): S. 111.

278 AKIN (2007). In dieser Sequenz zeigt sich wie in vielen anderen Szenen in den 2000er Jahren, dass bei Verwendung beider Sprachen keine Mischung innerhalb eines Satzes geschieht. Es entsteht also kein hybrides Sprachkonstrukt wie die Kanak Sprak. Siehe hierzu auch die Analysen und Ergebnisse von Helga Kotthoff zur Ethno-Comedy in den 2000er Jahren: КоттноғF, Helga (2013): Komik (in) der Migrationsgesellschaft, Konstanz: UVK; dies. (2019): »Ethno-Comedy zwischen Inklusion und Exklusion. Komische Hypertypen und ihre komischen Praktiken«. In: Komik der Integration, hg. Özkan Ezli, Deniz Göktürk und Uwe Wirth, Bielefeld: Aisthesis, S. 48-84, hier S. 57 u. S. 61. 
die beiden nicht auseinander. Vielmehr kommentieren die zu Ende geführten Handlungen das Gespräch diametral und verwandeln den Ort am Bahnhof in einen Raum, was einer nicht-sprachlichen Übersetzung gleichkommt, die durch die Körper erfolgt, denn beide essen ihr Eis weiter wie vorher, und Nejat entsorgt sogar die Eisbecher. So entsteht ein Raum zwischen Nejat und Ali. Nejat wird sich später im Film zwar von Ali lösen, weil ein Mörder nicht sein Vater sein könne. Dennoch bleibt der anfangs entstandene Raum bestehen und erfährt sogar noch eine deutliche Ausdehnung durch die bereits beschriebene bemerkenswerte Kopplung an das religiöse Narrativ der Opfergeschichte Abrahams. Kurz davor sehen wir, wie Ali in Istanbul auf einem öffentlichen Platz das von Nejat geschenkte Buch sichtbar gerührt zu Ende liest. ${ }^{279}$ Die Bahnhofsequenz zwischen Nejat und Ali ähnelt dem Gespräch über das Opfer zwischen Nejat und Susanne insofern, als beide Sequenzen als Handlungen zu Ende geführt werden und dadurch eine Einheit darstellen. Diese Aufnahmeform, die Inhalt und Form eng verknüpft, finden wir auch in den Dokumentarfilmen AM RANDE DER STÄDTE und WIR SITZEN IM SüDEN. Mag es das Gebet von Fikrets Mutter in Bademsoys Film sein oder dass ihr Sohn auf der Langhalslaute ein Stück (zumal eines über die Migration und ihre Folgen ${ }^{280}$ ) spielt - im Unterschied zu Film und Literatur in den 1990er Jahren sind in den 2000er Jahren Inhalt und Form viel enger und intensiver miteinander verschränkt.

$\mathrm{Zu}$ Beginn des ersten Kapitels "Yeters Tod« besucht Nejat seinen Vater in Bremen und bringt ihm den Roman von Selim Özdoğan als Geschenk mit. Währenddessen bereitet Ali für seinen Sohn ein Fischgericht vor. Später werden sie erneut Fisch essen, dann mit Yeter. ${ }^{281}$ Nach Yeters Tod erwirbt Nejat auf der Suche nach Yeters Tochter in Istanbul einen deutschen Buchladen. Im letzten Teil des

279 Dabei handelt es sich um den Roman Die Tochter des Schmieds des deutsch-türkischen Autors Selim Özdoğan. Er erzählt darin eine türkische Familiengeschichte zwischen den vierziger und sechziger Jahren in der türkischen Provinz. Die letzten Seiten des Romans sind der Arbeitsmigration der Protagonistin Gül nach Deutschland gewidmet. Ähnlich wie bei Akın spielen in diesem Roman Dinge, Landschaften und Alltag eine besondere Rolle. Das Subjekt ist ebenso eingebunden und in Beziehungen verwoben. Letztlich ist Alis Lektüreerfahrung insofern mit derjenigen von Susanne vergleichbar, als bei letzterer Lotte auf die Jugend ihrer Mutter verweist, während Özdoğans Buch auf die erste Gastarbeitergeneration, zu der Ali gehört, anspielt. Das erklärt auch seine sichtbare Rührung. Interessant ist außerdem, dass es bis zum Dreh des Films noch keine türkische Ausgabe von Die Tochter des Schmieds gab, die Ali im Film jedoch liest. Dafür wurde einfach das deutsche Buchcover mit dem türkischen Titel Demircinin Kızı versehen. Siehe hierzu: ÖzDoĞAN, Selim (2005): Die Tochter des Schmieds, Berlin: Aufbau. Siehe auch: AKIN (2007).

280 BADEMSOY (2005).

281 Während Ali in Akıns Film deutlich zu Fisch in Bezug gesetzt wird, ist es in Hatice Akyüns Roman kaum möglich, sich ihren Vater Ismail ohne Grill vorzustellen. "Soweit es draußen zwei 
Films fährt Ali an seinen Herkunftsort, um zu fischen. Diese Verdopplungen, Fischgericht/fischen, Buch/Buchladen wirken verbindend und verdeutlichen die Bindungslogik in diesem Film.

So werden auch Landschaften, Städte und die mit ihnen verbundenen Akteure erst durch sich wiederholende Ortsaufnahmen und Übergangsräume eingeführt. Viele Analysen von Auf DER ANDEREN SEITE halten fest, dass sich kein Akteur hinsichtlich seiner Verhaltensweisen als Tourist bezeichnen lasse; ebenso wenig aber auch als Alteingesessener in einem der Länder. Dieser Eindruck von Vertrautheit und Fremdheit zugleich entsteht durch die filmische Erzählung, indem wiederkehrende Orte und Ziele die Bewegungen der Akteure rahmen und dadurch koordinieren. ${ }^{282}$ Im ersten Teil sehen wir eine 1. Mai-Demo in Bremen, im zweiten Teil eine weitaus gewalttätigere 1. Mai-Demo in Istanbul. Gegen Ende des ersten Teils sehen wir Ali im Gefängnis in Deutschland, gegen Ende des zweiten Teils Ayten in einem türkischen Gefängnis. In Bremen sehen wir mehrmals den Bahnhofsplatz, in Istanbul den Taksimplatz. Aytens Bewegung in Bremen über den Bahnhofsplatz ist identisch mit derjenigen Lottes in Istanbul über den Taksimplatz. Nach Barbara Mennel spiegeln die »Verdopplungen und Überschneidungen [...] den Wandel der familiären, aber auch der zeitlichen und räumlichen Verhältnisse [...] unter den Bedingungen der Globalisierung wider «. ${ }^{283}$ Mit den Orten expandiert aber auch der an diesen Orten anhand sozialer und Beziehungen zu den Dingen (Buch, Fisch, Schuhe und Waffe) angelegte Raum vom ersten Teil über den zweiten bis zum dritten Teil, der denselben Titel trägt wie der Film: »Auf der anderen Seite«.

In Bremen und Hamburg sehen wir vor allem geschlossene Räume wie Alis Wohnung mit ihrem recht geschlossen wirkenden Garten, Nejats Wohnung und der Hörsaal an der Uni in Hamburg, die geschlossenen Züge und Busse, die die Protagonisten benutzen. In Istanbul und an der Schwarzmeerküste dominieren hingegen Außenaufnahmen. Eindrücklich wird diese Ausdehnung des Raums

Grad über null hat, stellt mein Vater seinen Grill im Garten auf«, schreibt sie. Siehe hierzu: AKYÜN (2005): S. 31f.

282 Özdamar beschreibt die Berliner Straßen in Seltsame Sterne starren zur Erde, auf denen sie zum Theater unterwegs ist, weder als neues fremdes Territorium noch als Orte, die sie bald wieder verlassen wird, wie im Karawanserei-Roman. In ihrem Roman von 2003 sind die Straßen und Viertel nicht fremd: »Als ich zum Grenzübergang Friedrichstraße zurückging, wurde mir leichter und leichter, meine Arme waren Flügel geworden, ich war ein Vogel, der über Ostberlin fliegen würde, der sich alle Straßen, über die Brecht und Besson gelaufen sind, anschauen und vor Freude lachen wird «. Siehe hierzu: ÖzDAMAR (2003): S. 34.

283 Mennel, Barbara (2010): "Überkreuzungen in globaler Zeit und globalem Raum in Fatih Akıns Auf der anderen Seite«, In: Kultur als Ereignis, hg. v. Özkan Ezli, Bielefeld: transcript, S. 95-118, S. 103. 
in den letzten Sequenzen, der Fahrt an die Schwarzmeerküste und der letzten Einstellung mit Blick auf das Meer. Nejat sitzt leicht von der Mitte nach links dezentriert am Strand und wartet auf seinen Vater. Diese letzte Aufnahme wurde auch für das Kinoplakat und das Cover der DVD verwendet. ${ }^{284}$ Sie macht deutlich, welchen privilegierten Stellenwert das Sehen für die Protagonisten und die Rezipienten des Films einnimmt. ${ }^{285}$ Daher ist auch die Expansion des Raums durch die Verdopplung von Orten, von politischen Ordnungen und von Handlungsmustern nicht als die Entstehung eines Repräsentationsraumes und dem Vollzug einer Emanzipations- oder Integrationsbewegung zu verstehen, sondern vielmehr als Aktualisierung eines biografisch-historisch vorhandenen Verhandlungsraums, beispielsweise zwischen Lotte und ihrer Mutter, zwischen Nejat und seinem Vater. ${ }^{286}$

Die Grundlage dieser Expansion des Raums sind aktives Sehen und Handeln. Mit »aktivem Sehen« ist gemeint, dass die Kamera mit einer durchgehenden Alternanz von Halbtotalen und Totalen, beispielsweise im Unterschied zu KuRz UND SCHMERzLos, in die Tiefe aufnimmt. ${ }^{287}$ Dass die Geschichten des Sorgetragens um den Anderen zwischen den Akteuren Räume schaffen, die über das Verstehen und Nicht-Verstehen, über die Sprache hinausgehen, lässt sich als »aktives Handeln« begreifen. Denn die Bewegungen der Akteure von einem Ort zum nächsten implizieren nicht Versuche, sich selbst, den Anderen, seine eigene und die andere Kultur zu verstehen oder innere Verwundungen und Diskriminierungen zu versprachlichen. Sie sind vielmehr als körperliche Handlungen zu verstehen, denen filmsprachlich, wie bereits erwähnt, derselbe Stellenwert eingeräumt wird wie dem Sprechen. Sie verwandeln Orte in Räume, die wiederum

284 Siehe hierzu: AKIN (2007).

285 Auch Aysun Bademsoy wirft in ihrem Dokumentarfilm über zurückgekehrte Almancıs in AM RANDE DER STÄDTE einen besonderen Blick darauf, worin und wie deren Leben generationenübergreifend stattfindet. Nachdem sie in kurzen Einzelinterviews ihre Probanden an bestimmten Orten vorgestellt hat, folgt eine Autofahrt, bei der wir mehrere gated communities von außen sehen. Am Ende dieser Fahrt landen wir wieder bei der geschlossenen Wohnanlage, von der aus die Fahrt begonnen hatte. Es folgen Aufnahmen von Kränen der Gartenanlage und des gemeinschaftlichen Swimming Pools, die beide auch von den Bewohnern genutzt werden. Bademsoy unternimmt dann später weitere Fahrten ins Zentrum der Stadt Mersin, anhand derer sie dann auch die Wohnanlagen am Rand der Stadt erneut rahmt und verortet. Siehe hierzu: BADEMSOY (2005).

286 In Bademsoys Dokumentarfilm erfolgt aus den Erzählungen der Interviewten ebenfalls eine historische Aktualisierung ihrer Migrationserfahrungen; die deutsche Rindswurst oder Knödel, die Pınar Keskin sehr vermisst oder die deutschen Musikerfreunde, mit denen Fikret Cember in Mannheim oft unterwegs war. Siehe hierzu: BADEMSOy (2005); siehe auch Interview mit der Regisseurin, In: http://peripherfilm.de/fsk-kino/archiv/amrandederstaedte.html (11.09.2018).

287 Diese Aufnahmeform bestimmt auch die Dokumentarfilme AM RANDE DER STÄDTE, MEIN VATER DER TÜRKE Und WIR SITZEN IM SÜDEN. 
die intimen Beziehungen und den Umgang mit Kultur und mit politischen Ordnungen prägen. Lottes Tod und Susannes Hilfe, die sie Ayten trotz des Todes ihrer Tochter anbietet, bringen Ayten dazu, ihrem linken Kampf gegen den türkischen Staat abzuschwören. ${ }^{288}$ Und Nejats Verurteilung des Totschlages seines Vaters weicht der Erinnerung daran, wie dieser sich sogar Gott zum Feind erklärt hätte, um ihn zu beschützen. Nach Thomas Elsässer deutet sich damit ein neues ethisches Kino an, das als eine "Art Platzhalter für eine noch ausstehende Politik» dient. ${ }^{289}$ Akıns Film führe im positiven Sinne »zurück zur Einsamkeit der ethischen Entscheidung, die stets nur singulär sein kann, allerdings Folgen für die Gemeinschaft haben muss, um eine Ethik herzustellen, d.h. einer höheren Ordnung genüge zu tun «. ${ }^{290}$

Dieser Idee folgt auch Der Pavillon von Zafer Şenocak. Drei Wochen nach Hamits und Hildes Ankunft in Istanbul putscht das türkische Militär die Regierung von Adnan Menderes. Davon berichten nur wenige Sätze wie die, dass Hamit versuche, im dritten Stock des Pavillons zu verarbeiten, »was er vor ein paar Tagen gesehen hatte « und dies »in seinem Kopf wieder in eine Ordnung zu bringen «. ${ }^{291}$ Hamit und sein Autor vertreten dabei folgende Ansicht: Wenn man die kleinen Ereignisse nicht für wichtig erachtet, geht man bei den großen Ereignissen unter. Hamit fühlt sich dem Pavillon zugehörig, wie zuvor dem Englischen Garten in München. Ein Putsch oder ein bestimmtes politisches Programm, das versucht, „die Revolution auf den Körper des Menschen, auf die Familienordnung« zu übertragen, »betrachtet die Politik nicht als Ort der Bewegung in Richtung irgendwelcher tiefgründiger Veränderungen«. Politisch wäre für Hamit hingegen, wenn in die Geschichte jedes einzelnen Individuums Veränderungen eingingen, die in Handlungen und sozialen Zusammenhängen sichtbar gemacht würden. Wie Susanne beispielsweise in Auf DER ANDEREN SEITE Ayten hilft, obwohl Letztere auch mitverantwortlich für den Tod ihrer Tochter ist. Doch berührt die aktuelle politische Geschichte ihrer Tochter vor ihrem Tod auch ihre politische Vergangenheit. Durch ihre Hilfe für Ayten, ihre politische Praxis, wird diese Veränderung in ihrem Inneren sichtbar. ${ }^{292}$

Ein Großteil der Filme von Regisseuren mit Migrationshintergrund aus den 2000er Jahren hat nach Ansicht einiger Wissenschaftler »our understanding of European identity as constructed and narrated in European national cinemas«

288 Siehe hierzu auch: ElSÄSSER (2011): S. 60.

289 Ebd., S. 45.

290 Ebd., S. 60.

291 ŞENOCAK (2009): S. 51.

292 Siehe hierzu: AKIN (2007). 
neu definiert. ${ }^{293}$ Es wird vor allem darauf aufmerksam gemacht, dass die Globalisierung dabei neu gerahmt wird. Berna Güneli konstatiert beispielsweise, dass Akıns multiethnisches Europa in Auf DER ANDEREN SEITE »is presented to the viewer as lived experience of his protagonists «. Und Vivien Silvey und Roger Hillmann finden, dass Akıns Film sowie viele andere jener Zeit, etwa von Michael Haneke, Paul Thomas Anderson und Alejandro Gonzales Iñárritu »fractal narratives« seien, die besonders den »cultural impact« der Globalisierung re-präsentierten. ${ }^{294}$ Die erzählerischen Strukturen dieser Filme seien »multistrand, temporally jumbled, and at first chaotic yet in the end fatefully coincidental«. Nach dem Konzept der fraktalen Geometrie aus der Chaostheorie stellten diese Filme Welten dar, »in which borders are perforated and, as in The Edge of Heaven, significantly questioned «. ${ }^{295}$ Globale Themen würden dabei in den filmeigenen und erzählerischen Rahmungen situiert. ${ }^{296}$ In ihrer Analyse von Akıns »nicht-linearer Erzählweise« in AUF DER ANDEREN SEITE macht Barbara Mennel eine filmische Poetik ausfindig, bei der die Darstellung der Gleichzeitigkeit von transnationaler Mobilität und regionaler Bindung weder der globalen noch der regionalen Ebene eine definitorische und, damit verbunden, auch keine identifikatorische Hoheit zuspricht. ${ }^{297}$ In diesem Zusammenhang ändere sich auch die Bedeutung und Funktion von Regisseur oder Autor, ${ }^{298}$ Fragen nach repräsentativen Strategien und der Wahl künstlerischer Mittel stehen im Zentrum der Beobachtungen vieler Forscher, die sie nicht mehr an ihren globalen Reichweiten messen, sondern an der erzählerischen Stärke ihrer Rahmungen. Dabei gehen sie davon aus, dass Autoren und Regisseure der zweiten und dritten Generation zwar zwischen der »migrant « und »diasporic experience« unterscheiden, beide Erfahrungen jedoch intergenerational in ihren Erzählungen wieder zusammenführen. ${ }^{299}$

Tatsächlich ist bei den bisher erwähnten und analysierten Filmen die Kompatibilität und nicht der Bruch zwischen den Generationen entscheidend. Würde

293 Berghahn, Daniela/Sternberg, Claudia (2010): »Locating Migrant and Diasporic Cinema in Contemporary Europe«. In: European Cinema in Motion. Migrant and Diasporic Film in Contemporary Europe, hg. v. Daniela Berghahn, Claudia Sternberg, London: Palgrave Macmillan, S. 12-49, hier S. 12.

294 Silvey/Hillman (2010): S. 106.

295 Ebd.

296 Ebd., S. 12.

297 Siehe hierzu: MenNEL (2010): S. 99 u. 103.

298 So konstatiert etwa Monika Stranáková, dass diese Autoren mit ihrer Literatur nun definierten, was Europa ist. Siehe hierzu: STRAŇÁKovÁ, Monika (2009): Literarische Grenzüberschreitungen. Fremdheits- und Europa-Diskurs in den Werken von Barbara Frischmuth, Dževad Karahasan und Zafer Şenocak, Tübingen: Stauffenburg, S. 9 u. S. 27.

299 Siehe hierzu: BERGHAHN/STERNBERG (2010): S. 44. 
man sie einfach abstrakt als europäische oder als globale Geschichten rahmen, dann würde man aus dem Blick verlieren, wie unterschiedlich Integration in einer Einwanderungsgesellschaft verlaufen und ausgehandelt werden kann. Am Ende von MEINE VERRÜCKTE TÜRKISCHE HochZEIT bekommt man als Zuschauer den Eindruck, wenn der Film weitergehen würde, dass es trotz Hochzeit am Schluss des Films sehr schnell wieder Beleidigungen, Verletzungen und Gewaltausbrüche sich einstellen würden. Das gilt für AUF DER ANDEREN SEITE nicht. Hier vermutet man eher, dass Ali, Susanne, Nejat und Ayten, die Überlebenden also, eine neue Familie bilden. Das Prinzip der Erzählgemeinschaft verdeutlicht in AUF DER ANDEREN SEITE also nicht, dass die Kultur oder die Kulturen überleben, sondern die Menschen und mit ihnen Formen sozialer Einheit wie die Familie.

Bereits hingewiesen habe ich auf den unterschiedlichen Einsatz von Religion in MEINE VERRÜCKTE TÜRKISCHE HochzeIt und Auf DER ANDEREN SEITE. Während der Islam im ersten Film die Integrationsgeschichte von Götz rahmt und normiert, ist er im zweiten ein inhaltlicher Anlass, um weiter miteinander zu sprechen. Dass er dabei überraschenderweise im ersten weniger grundsätzlich als im zweiten Film verhandelt wird, liegt vor allem daran, dass Öffentliches und Privates jeweils unterschiedlich verschränkt werden. Während die Expansion des Raums in AUf DER ANDEREN SEITE erzählerisch über den Zusammenhang von Dingen, Personen, Orten und Bedürfnissen sowie filmästhetisch durch Aufnahmen in die Tiefe gelingt, bleibt in MEINE VERRÜCKTE TÜRKISCHE HOCHzEIT als einziger Ort für die Hochzeitsfeier Götz' Plattenladen übrig. Denn in allen anderen Räumen wurde zuvor schon ohne Unterlass gestritten, entweder weil der Islam dies und das verlange oder weil er die Frauen unterdrücke. Anders formuliert: In MEINE VERRÜCKTE TÜRKISCHE HOCHZEIT machen die Akteure nichts aus den Orten, sondern wollen vor allen Dingen eine bestimmte Ordnung sichtbar machen. Dies tun sie, weil sie so handeln wollen, wie Türken eben handeln. Dieses Vorhaben ist nicht nur deshalb fragwürdig, weil Götz selbst Aylin ihr Türkischsein abspricht, indem er sie darum bittet, wie eine Türkin $\mathrm{zu}$ handeln. ${ }^{300}$ Fragwürdig ist ebenso, dass die Türken an sich getürkt werden, denn sie sprechen nur Deutsch und verlassen nie ihren Berliner Kiez. Diese Spannung lässt sich kaum mit der einfachen Identitätspolitik lösen, die der Film zwischen Deutsch und Türkisch anbietet.

Wir werden sehen, wie sehr dieses neu entstehende Spannungsfeld zwischen Deutsch und Türkisch, nach einer Dekade der Infragestellung beider Zuschreibungen in den 1990er Jahren, im Positiven wie im Negativen Film und Literatur

300 Der ausdrückliche Hinweis auf das Türkische ist in den Romanen und Erzählbänden Selam Berlin, Hürriyet Love Express und Mein Name ist Revolution erzählerisch ebenfalls äußerst wichtig. 
der 2000er Jahre entweder personal, sprachlich oder territorial durchzieht. Denn bemerkenswert ist trotz der Differenzen zwischen MEINE VERRÜCKTE TÜRKISCHE Hochzeit und Auf DER ANDEREN SEITE, dass alle Akteure in beiden Filmen ihre Kulturen verinnerlicht haben und sie in ihrem Alltag verhandeln. Hierin stimmen sie mit den oben skizzierten Kultur- und Integrationstheorien von Andreas Wimmer und Rogers Brubaker überein, in denen die »verinnerlichte Kultur« den Ausgangspunkt des Aushandelns im öffentlichen Raum bildet. Es geht also nicht um die individualpsychologische und zugleich philosophische Frage, wie man wird, was man ist. Was man ist, ist hier bereits der Ausgangspunkt. Wir wissen von Beginn an, dass Nejat Muslim ist und wir wissen auch, dass Kreuzberg in MEINE VERRÜCKTE TÜRKISCHE HochzeIT der Kiez der Türken ist, in den Götz sich integrieren muss. Es geht also nur um die Frage, was man daraus macht, wofür man sich durch die eigene Lebensweise entscheidet. Integrationspolitisch geht es um die Initiierung des Prozesses, die "sinnlich-physische Anwesenheit in den Tatbestand ihrer Zugehörigkeit zur Gesellschaft zu verwandeln ${ }^{301}$ Und in diesem Prozess ist die Frage ausschlaggebend, wofür man sich entscheidet und in welcher Beziehung diese Entscheidung mit dem eigenen und gesellschaftlich kompatiblen Verhalten steht. Unter diesen Bedingungen kann die Frage des Zusammenlebens zu einer integrationspolitischen Frage avancieren: »social cohesion and national identity can coexist with valuing diversity in the public sphere« ${ }^{302}$ In MEINE VERRÜCKTE TÜRKISCHE HOCHZEIT steht dieser Prozess nur Götz zu, in Auf DER ANDEREN SEITE allen Akteuren. Bereits diese unterschiedlichen Prozesswege zwischen einem Individuum auf der einen Seite und einer sich entwickelnden Erzählgemeinschaft auf der anderen Seite in diesen beiden erfolgreichen Filmen zeigen, dass es in den 2000er Jahren die Akteure sind, die entscheiden, welcher Wert kulturellen Markern wie der Religion zukommt. Daher zeigt sich Integration mehr an Lebensweisen und Entscheidungen statt an dem, was sie sagen. Außerdem sind wir über die Erzählformen und Kameraeinstellungen oft im Bilde, d.h. wissen, wo und worin etwas stattfindet oder endet. Die Akteure sind in den Erzählungen von Beginn an Angekommene. Es stellt sich nicht die Frage, ob sie integriert sind oder nicht, sondern was sie daraus machen oder welche Entscheidungen sie aus desintegrierten Zuständen heraus treffen. ALmanya. Willkommen in Deutschland beginnt beispielsweise damit, dass die ehemaligen Gastarbeiter Hüseyin und Fatma die deutsche Staatsbürgerschaft annehmen und die türkische ablegen. Feo Aladağs Film Die FrEMDE setzt damit

301 PREUSS (2011): S. 480.

302 Vertovec, Steven (2010): »Towards Postmulticulturalism? Changing Communities, Conditions and Contexts of Diversity«. In: International Social Science Journal, Volume 61, Issue 199, March 2010, S. 83-95, hier S. 94. 
ein, dass die türkeistämmige Protagonistin Umay von Istanbul in ihre Heimat Berlin zurückkehrt. Trotz dieser jeweils eindeutigen Zugehörigkeit verhandeln beide Filme Integration sehr unterschiedlich.

\subsection{Entscheidungen und Integration}

»Was sind wir denn nun? Deutsche oder Türken?«, fragt der achtjährige Cenk beim gemeinsamen großfamiliären Mittagessen bei seinen türkischen Großeltern in Dortmund. Zuvor hatte sein Großvater Hüseyin vor der versammelten Familie am Tisch verkündet, dass er der Familie etwas $\mathrm{zu}$ sagen habe, »eine Überraschung «. ${ }^{303}$ Seine Frau Fatma glaubt zu wissen, was ihr Mann meint, und verkündet allen hocherfreut, dass sie nun endlich Deutsche geworden seien und zeigt allen die deutschen Pässe. Doch Hüseyin greift harsch ein und winkt ab. »Nein, das nicht Überraschung. Überraschung ist, ich habe Haus gekauft. In Türkei. Im Dorf. In Heimat. « Sein ältester Sohn Veli fragt irritiert: »Warum das denn? Wollt ihr zurückkehren oder was?« Fatma erschrickt, denn wie die anderen wusste sie nichts von diesem Hauskauf. Hüseyin antwortet nicht, zeigt seinem Enkel Cenk aber ein altes Foto, auf dem nur eine Landschaft zu sehen ist, die in ihrer Unbestimmtheit ein wenig an die Hütte am Anfang von AUF DER ANDEREN SEITE erinnert. Und wie in ZEIT DER WÜNSCHE ist die Herkunft als Foto ein Teil der deutschen Wohnung. »Da kommen wir her«, sagt der Großvater zu Cenk. Cenk sieht das Bild an und fragt irritiert: »Da kommen wir her? « ${ }^{304}$ Hüseyin, der Mann, Vater und Großvater in dieser Runde, wünscht sich, dass die gesamte Familie in den nächsten Ferien dorthin fährt. Das löst eine Diskussion aus, einige können nicht, andere sehen darin keinen großen Sinn, worauf der Großvater versucht, sie darauf zu verpflichten, dass sie doch eine Familie seien etc. In diese Auseinandersetzung hinein stellt Cenk laut die oben zitierte Frage. Sein Vater Ali und seine Mutter Gabi machen die Sache noch komplizierter. Er sagt, er sei ein Türke, sie sagt, er sei ein Deutscher. Diese Antwort frustriert Cenk noch mehr. Daraufhin setzt sich seine 22-jährige Cousine Canan zu Cenk und beginnt, ihm die Geschichte der Familie zu erzählen. Im Verlauf dieser Geschichte und der Reise der Familie in die Türkei wird sich Cenks Frage erübrigen. Eine klare Antwort ist nicht mehr nötig. Stattdessen gibt der Film am Ende eine allgemeine Antwort darauf, was Identität ist: all das, »was es nicht gäbe, wenn man nicht gelebt hätte.$^{305}$ Man ist also das, was

303 ŞAMDERELI (2011).

304 Siehe hierzu: ŞAMDERELI (2011).

305 Ebd. Siehe hierzu auch: MARTENSTEIN, Harald (2011): »Identitätsfragen. Die deutsch-türkische Komödie >Almanya wirkt wie eine direkte Reaktion auf die Thesen von Thilo Sarrazin. Es 
man lebt. Almanya. Willkommen in Deutschland war ein äußerst erfolgreicher Film. Mehr als 1,4 Millionen Kinobesucher haben ihn gesehen und er erhielt 2011 den Deutschen Filmpreis, den Bernhard-Wicki-Filmpreis, den Gilde-Filmpreis sowie ein Jahr später den Preis des Verbands der deutschen Filmkritik. ${ }^{306}$

Feo Aladağs Film Die Fremde von 2010 war mit 137.336 Zuschauern an den Kinokassen nicht annähernd so erfolgreich, erhielt jedoch weitaus mehr Auszeichnungen als ALMANYA, besonders auf internationalen Festivals. Im Unterschied zu Şamderelis Film wird die Frage, ob man Türke oder Deutscher sei, nicht gestellt. Und auch wenn Religion überwiegend außen vor bleibt, so spielt doch das muslimische Opferfest wie in Akıns Film oder der Festtag zum Ende des Fastenmonats Ramadan in Kemal Kurts Roman Sonnentrinker ebenfalls eine wesentliche Rolle. Außerdem greift der Film auf der inhaltlichen Ebene auf das türkischste Thema in der Historie der Migration in der Bundesrepublik zurück: DIE FREMDE erzählt nämlich anhand einer Familiengeschichte die Geschichte eines Ehrenmords. ${ }^{307}$ Damit widmet er sich auch eines der aktuellen Themen, die seinerzeit Debatten, politische Beiträge und Gesetze zu arrangierten und Zwangsehen beschäftigen. ${ }^{308}$ Wie in Almanya stehen in dieser Erzählung ein kleiner Junge und die türkische Familie im Zentrum. Es gibt wenige Sequenzen in Aladağs Film, in denen der Junge als Beobachter nicht dabei ist. ${ }^{309}$ Er spricht kaum, aber wir sehen, dass er alles registriert. In der folgenden vergleichenden Analyse werde ich zeigen, wie sehr sich DIE FREMDE und ALMANYA in ihrer politischen Aussage ähneln, obwohl sie sich in ihrer Gattung und Thematik sehr unterscheiden. In der Frage der Ehre stehen sie sogar konträr zueinander. Wie in MEINE VERRÜCKTE TÜRKISCHE HOCHZEIT und AUF DER ANDEREN SEITE stärken sich Form und Inhalt der Erzählungen wechselseitig. Und auch hier geht es weniger darum, was gesagt wird, sondern darum, was man sieht.

Der Wendepunkt in Aladağs Film DiE FrEmDE ereignet sich wie in AUF DER ANDEREN SEITE am muslimischen Opferfest. ${ }^{310}$ Umay (Sibel Kekilli), die Protago-

ist eine überzeugende Antwort, weil einfach nur eine Familiengeschichte erzählt wird«. In: Der Tagesspiegel, 15.02.2011 (https://www.tagesspiegel.de/kultur/harald-martenstein-4-identitaetsfragen/3815106.html) (16.05.2018).

306 Siehe hierzu: https://www.filmportal.de/film/almanya-willkommen-in-deutschland_49beb 1344dff4076bb582a03262f15c8 (16.05.2018).

307 Aladă̆ (2010).

308 Siehe hierzu: ButTERWEgGe (2007).

309 Siehe hierzu: Gramling (2012): S. 36.

310 Beim Opferfest (Kurban Bayramı, tr.; Id al-Adha, ar.) wird an Abraham, den Stammvater der Buchreligionen Judentum, Christentum und Islam gedacht. Es ist mit dem Ende des Ramadans das wichtigste islamische Fest. Im Zentrum dieses Festes stehen das Gottvertrauen Abrahams und das Thema der Familie. Denn Gott fordert Abraham in seinen Träumen auf, für ihn seinen 
nistin des Films, will mit ihrem Sohn Cem am ersten Tag des Opferfestes ihre Eltern besuchen. Sie wünscht sich vor allem, dass ihr Vater ihr vergibt. Er lässt sie nicht über die Türschwelle in die Wohnung, sagt ihr, dass sie sein Herz zutiefst gebrochen habe und dass sie für sein Versagen als Vater stünde. Außerdem kann er sie nicht hereinbitten, weil er türkischen Besuch hat. Umay geht, ihr Vater kehrt zurück zu den Gästen. Seine Frau fragt ihn, wer an der Tür gewesen sei. Er antwortet: ein Fremder. Er läuft ans Fenster und beobachtet, wie ein blonder junger Mann auf seine Tochter und seinen Enkelsohn wartet und sie herzlich empfängt. Dann folgt der letzte Teil des Films, der auf das zusteuert, was der Zuschauer von Beginn an erwartet. Denn in der Eröffnungssequenz des Films, die wie bei Akın ohne Vorspann einsetzt, sehen wir Umay und ihren Sohn von hinten in Kopfhöhe aufgenommen einen Bürgersteig entlanglaufen. $\mathrm{Zu}$ ihnen gesellt sich ein junger Mann; Umay dreht sich um zu ihm, lächelt ihn an, kennt ihn. Er richtet aber eine Waffe auf sie. Ihr Blick erstarrt. Dann folgt ein Schnitt, und wir sehen den jungen Mann aufgelöst wegrennen, in einen Bus einsteigen, darin bis zum Ende des Ganges laufen. Von dort schaut er erschrocken aus dem Fenster, während der Bus seiner Blickrichtung entgegengesetzt weiterfährt. Es folgt ein Schnitt, und der Film beginnt. Die geschilderte Sequenz wird sich am Ende des Films wiederholen - wie in Auf DER ANDEREN SEITE und in ZEIT DER WüNSCHE die Anfangssequenz auch am Ende vorkam. Dann werden wir wissen, warum es zu diesem Mordversuch kommt und wie die Geschichte endet. ${ }^{311}$

Während die Tankstellensequenz am ersten Tag des muslimischen Opferfestes in AUF DER ANDEREN SEITE erzählerisch und inhaltlich integrativ wirkt, steht die Privilegierung der Eröffnungssequenz hier mit dem mutmaßlichen Ehrenmord und seinem Täter zwar für eine erzählerische Integration, aber zugleich

liebsten Sohn Ismail zu opfern. Nach jüdischer und christlicher Tradition geht es um seinen anderen Sohn Isaak. Dennoch ist diese Geschichte eine wichtige Erzählung in den drei Buchreligionen. Nach dem Islamischen Narrativ wird das Messer stumpf als Abraham nach lange währendem inneren Kampf, sich entscheidet seinem Gott zu vertrauen. Dieses Vertrauen wird belohnt, indem Abraham nun anstelle seines Sohnes ein Tier opfern soll. Daher ist es für jeden Muslim oder jede Muslima, die es sich leisten können, verpflichtend zum Id al-Adha ein Tier, in der Regel ein Hammel oder ein Schaf, zu opfern. Verpflichtend für jeden Muslim ist auch deshalb, am Morgen des Opferfestes an der Predigt und am gemeinsamen Gebet in der Moschee teilzunehmen. Das zweite Thema Familie spiegelt sich auch in der Praxis der Festivitäten wieder, da der gegenseitige Austausch und Besuch von Verwandten nach dem Moscheebesuch ebenfalls im Zentrum des Opferfestes stehen. Es ist ein Fest, das public sociability und das Familienleben ins Zentrum des gottgefälligen Lebens rückt. Siehe hierzu: KREISER, Klaus/WiELANDT, Rotraud (1992): Lexikon der islamischen Welt, Stuttgart: Kohlhammer.

311 Mit dem Thema des Ehrenmords beginnt und endet auch der Film ZEIT DER WÜNSCHE. Siehe hierzu: SözEN (2005). 
für eine familiäre und gesellschaftliche Desintegration. Im Unterschied zu den Widersprüchen zwischen Inhalt und Form in den Erzählungen der 1990er Jahre ist die inhaltliche Seite des Films, die Entwicklung der Handlung bis hin zum Ehrenmord, hier entscheidend. Doch bevor ich dieses Verhältnis genauer analysiere, skizziere ich kurz den Plot des Films.

Nach der Einstiegssequenz von DiE FREMDE sehen wir Umay in einem türkischen Krankenhaus bei einer Abtreibung. Es wird kaum geredet, von Arzt und Krankenschwester sehen wir keine Gesichter. Danach ist Umay mit einem Türban $^{312}$ unterwegs in die Peripherie Istanbuls, zu einem Neubaugebiet. An der Bushaltestelle wird sie von einer Frau ohne Kopfbedeckung und von ihrem achtjährigen Sohn abgeholt. In der nächsten Sequenz sitzt Umay mit einer türkischen Großfamilie beim Essen am Tisch. ${ }^{313}$ Auch hier wird wenig gesprochen. Von der Abtreibung scheint Umays Mann Kemal nichts zu wissen. Als Cem auf Türkisch verrät, dass sie gar nicht zu Besuch bei einer Freundin waren, reagiert Kemal äußerst gereizt. Er schleudert Umay gegen eine Wand und sperrt Sohn und Ehefrau in verschiedenen Zimmern ein. Tage später verlässt Umay mit ihrem Sohn heimlich ihren Mann und seine Familie und kehrt $\mathrm{zu}$ ihren Eltern nach Berlin zurück. Ihre Herkunftsfamilie dort - ihr älterer Bruder Mehmet, der jüngere Bruder Acar, die jüngere Schwester Rana sowie die Eltern Halime und Kader - , nimmt sie anfangs sehr erfreut wieder auf. Außer Mehmet. Als sich recht bald herausstellt, das Umay nicht mehr zurückkehren und nicht mehr mit Kemal und seiner Familie zusammenleben möchte, stellt das die türkische Familie in Deutschland vor eine große Herausforderung. Sie versucht, sie davon zu überzeugen, zu ihrem Ehemann zurückzukehren. Vor allem Mehmet warnt, dass sie Cem zum »Bastard « mache, »wenn er nicht bei Kemal bleibt«. ${ }^{314}$ Trotz des verbalen und psychischen Drucks, den die Familie immer mehr auf Umay ausübt, zeigt Aladağ sie, d. h. vor allem den Vater und die jüngeren Geschwister, als Per-

312 Der »Türban« unterscheidet sich grundlegend vom Kopftuch. Der bekannte türkische Hürriyet-Kolumnist Ahmet Hakan listet 12 Unterschiede zwischen Türban und Kopftuch (»Başörtü«) auf. Am wichtigsten ist, dass ersterer eine städtische und neue Erscheinung ist, für einen selbstbewussten und modernen Islam stehe. Letzterer stehe für den traditionellen und dörflichen Islam. Das Kopftuch wird zudem lose am Kopf getragen, während der Türban mit Haarklammern und einer besonderen Falttechnik sehr eng an Kopf und Hals der Frau befestigt wird. Der Türban ist erst mit dem Aufstieg der Refah-Partei zu einer Koalitionspartei Mitte der 1990er Jahre aufgekommen und wurde während der Regierungszeit der AKP bis heute zu einem Emblem dieser politischen Bewegung. Siehe hierzu: HAKAN, Ahmet (2007): »Türban ile başörtüsü arasındaki 12 fark« (Die zwölf Unterschiede zwischen einem Türban und einem Kopftuch). In: Hürriyet, 05.12.2007, http://www.hurriyet.com.tr/turban-ile-basortusu-arasindaki-12-fark-7812960 (07.06.2018).

313 Aladağ (2010).

314 Ebd. 
sonen, die Umay auch lieben. Dennoch planen Mehmet und Kader, Cem zurück zu seinem Vater in die Türkei zu bringen. Als Umay in diesem Zusammenhang zufällig ein Gespräch zwischen Kader und Mehmet mitbekommt, ruft sie nachts die Polizei, die Umay und ihren Sohn in einem Frauenhaus unterbringt. Von weiteren Versuchen der Familie, besonders der Mutter, sie zur Rückkehr zu bewegen, lässt sich Umay nicht überzeugen. ${ }^{315}$ Schließlich möchte auch ihre Mutter nichts mehr mit ihr zu tun haben. Denn Umays Geschichte hat unter ihren türkischen Bekannten in Berlin schon die Runde gemacht. Und die bereits geplante Hochzeit zwischen ihrer jüngsten Tochter Rana und einem türkischen Jungen aus Berlin, wird nun von der Familie des Bräutigams in Frage gestellt. Und als Umays Eltern zudem erfahren, dass Rana von diesem Jungen schwanger ist, wird diese Heirat noch wichtiger. Kader bietet der Familie des Jungen Geld an, um sie umzustimmen - mit Erfolg. Damit könnte die Geschichte schon zu Ende sein. Umay könnte wegziehen und mit ihrem Sohn woanders weiterleben. Und wäre Umay die Sibel aus GEGEN DIE WAND oder die Yasemin aus Hark Bohms gleichnamigem Film von 1987/88 würde sie sicher nicht zurückkehren, und der Film könnte tatsächlich hier enden. Doch Umay kann sich von ihrer Herkunftsfamilie nicht trennen, auch wenn sie unter Polizeischutz aus deren Wohnung ausgezogen ist. Sie kommt mit ihrem Sohn zur Hochzeit ihrer Schwester und bittet ihre Eltern vor allen Hochzeitsgästen um Vergebung. Daraufhin wirft Mehmet sie rabiat hinaus. Er macht ihr klar, selber darunter leidend, dass sie nicht mehr zurückkommen und aus ihrem Leben verschwinden soll.

Umay beginnt, in der Küche einer Kantine zu arbeiten. ${ }^{316}$ Diesen Job vermittelt ihr ihre beste Freundin Atife, von der wir nicht so recht wissen, ob sie eine Türkin oder Deutsche ist. Sie spricht nur Deutsch, ist blond und groß, hat aber einen türkischen Vornamen. In der Kantinenküche lernt Umay Stipe kennen, der sich in sie verliebt. Er wird Umay beim Umzug in eine Wohnung helfen, nachdem ihre Brüder von einem anderen Türken erfahren haben, in welchem Frauenhaus sie lebt und dort randalieren. Umay ist nun so frei, wie es sich beispielsweise Sevim in Thomas Arslans Film GESCHWISTER wünschte. Doch Umay geht es nicht um Freiheit und Emanzipation, sondern um Zugehörigkeit. Für sie bedeutet die eigene Wohnung keinen Zusammenhang von Freiheit und Verortung. Verortung heißt für sie, auch eine Zugehörigkeit zu haben - so wie Cenk wissen möchte, ob

315 Umgekehrt kann aber auch ihre Mutter nicht den Mut aufbringen, die Entscheidung ihrer Tochter zu akzeptieren, obwohl sie in einer Sequenz im Bad am Rücken von Umay die Spuren von Kemals Gewalttätigkeit sieht. Siehe hierzu: Ebd.

316 Zu Anfang des Films erfahren wir, dass Umay mit Kemal in der Türkei eine Kantine führte. Siehe hierzu: ALAdAğ (2010). 
er Türke oder Deutscher ist, oder so wie in Auf DER ANDEREN SEITE die Akteure über die Fürsorge für den Anderen zugehörig werden. ${ }^{317}$

Nach der dramatischen Hochzeitssequenz fühlt sich die türkeistämmige Kantinenchefin Gül für Umay verantwortlich. Sie spricht bei ihren Eltern vor und erklärt ihnen, dass Umay sie liebe und zurückkehren möchte, sie aber zugleich Angst vor ihnen habe. Warum sollte sie Angst vor uns haben, erwidert der Vater auf Türkisch. Sie seien doch ihre Familie. Gül mahnt, dass er das Vorbild der Familie, auch für seine Söhne sei. Und er wolle doch sicher nicht ein weiteres Kind verlieren. Obwohl Gül die Möglichkeit des Ehrenmords hier nicht direkt anspricht, ist klar, was sie meint. Am Ende der Sequenz wendet sich Kader an der Türschwelle mit der religiösen Verabschiedungsformel »Allaha emanet olun« (»Vertrauen sie in Gott«) an Gül. »Gott hat mit dieser Angelegenheit rein gar nichts zu tun«, erwidert Gül auf Türkisch. »Bringen Sie ihn mit diesem Problem bitte nicht in Verbindung«, redet sie weiter auf Türkisch auf Kader ein. ${ }^{318}$ Dieser akzeptiert ihren Einwand schweigend. In der nächsten Sequenz will Gül wissen, warum Umay denn unbedingt zu ihrer Familie zurückkehren möchte. Auf Deutsch sagt sie ihr, »wenn sie sich zwischen Dir und der Gesellschaft entscheiden müssen, werden sie sich nicht für Dich entscheiden «. ${ }^{319}$ Doch Umay hofft darauf, dass ihre Familie sich für sie entscheidet, irgendwann.

Auf diese Sequenz folgt die oben beschriebene am ersten Tag des muslimischen Opferfestes. Erst nachdem Mehmet und Kader sie in ihrem Viertel in Umarmung mit dem Deutschen gesehen haben, setzt die Logik ein, die den Film zu seinem Ende führen wird. Der Vater reist anschließend in die Türkei. Wir sehen ihn irgendwann im Bus durch eine südliche Landschaft fahren, in einem verlassenen Dorf ankommen und ein Steinhaus betreten, in dessen einzigem Raum mit offenem Fenster ein Mann auf einem Divan schläft. Kader wartet, bis er aufwacht. In der nächsten Sequenz sitzen sich beide Männer schweigend gegenüber. Kader tritt aus dem Haus, schaut sich die Landschaft an und denkt nach. Zurück in Deutschland wird ebenfalls schweigend zwischen Kader, Mehmet und Acar über Blicke entschieden, wer die Tat zu begehen hat. Kurz danach erleidet Kader einen Herzinfarkt und wird ins Krankenhaus eingeliefert. Umay besucht ihn dort und erzählt, dass sie jetzt anfange, auf eigenen Beinen zu stehen, Abitur machen und studieren möchte. ${ }^{320}$ Kader bricht zusammen, weil ihm bewusst wird, dass er einen großen Fehler begangen hat. Er bittet seine Tochter, die gar nicht weiß,

317 Siehe hierzu: ŞAMDERELI (2011); AKIN (2007); ALADAĞ (2010).

318 Siehe hierzu: Aladă̆ (2010).

319 ALADAĞ (2010).

320 Einige Filme und Texte der 2000er Jahre verweisen auf Abitur und Studium. Im Unterschied zu den 1990er Jahren gilt man mit Abitur und Studium nicht mehr als ein Assimilierter oder als 
worum es geht, um Vergebung. Umay verlässt das Krankenzimmer und ihre Mutter umarmt sie auf dem Flur. Sie scheint vom geplanten Ehrenmord nichts zu wissen. Danach folgt mit der Wiederholung der Eröffnungssequenz der Schluss des Films, der dann aufklärt, dass Acar zwar eine Pistole auf Umay richtet, sie aber nicht zu töten vermag. Er läuft weg und lässt die Waffe fallen. Von hinten kommt nun Mehmet mit einem Messer in der Hand und möchte auf Umay einstechen. Doch weil sie sich zu ihm umdreht, trifft Mehmet aus Versehen seinen Neffen Cem, der an dem Messerstich stirbt. Mehmet verschwindet in Tränen aufgelöst. Nun sehen auch wir, was Acar erschrocken vom Bus aus beobachtet und wissen, dass das Opfer des Ehrenmords Cem ist. Mit der Tötung des Kindes symbolisiert der Ehrenmord hier das Auslöschen einer Zukunft und zugleich die Unbarmherzigkeit des Menschen im Unterschied zur Barmherzigkeit Gottes, der Abraham als Vertrauensbeweis das Tier als Opfer schickte.

In der Jurybegründung für die Verleihung des Filmpreises des ersten Kirchlichen Filmfestivals Recklinghausen heißt es, Feo Aladağ »zwingt uns [...] genau hinzusehen«. Denn nicht die Entscheidung zwischen »Freiheit hier« und »Sklaverei dort« werde in diesem Film verhandelt und zur Disposition gestellt, sondern »die Entscheidung zwischen zwei Einsamkeiten, einem Leben ohne die geliebte Familie oder dem Leben ohne Selbstentfaltung «. Auch andere Kritiken betonen das genaue Hinsehen. ${ }^{321}$ Tatsächlich haben wir es in Aladağs Film mit einer oft ruhenden Kamera $\mathrm{zu}$ tun, die mit wenigen Nahaufnahmen, dafür mit vielen Halbtotalen und in den Interieuraufnahmen häufig mit Aufnahmen in die Tiefe arbeitet. Wir sehen die Akteure oft in Bezug zueinander, etwa am Esstisch oder als Gül und Umay über Gesellschaft und Familie sprechen. Bei Tisch werden häufig Konflikte angesprochen. ${ }^{322}$ »Beim Essen entzünden sich die Konflikte, weil beim Essen die Familie zusammen ist und die Konfliktlinien durch die Familie laufen. Beim Essen wird Kemal grob zu seinem Sohn. Beim Essen erzählt Umay ihrer Familie, dass sie zu Kemal nicht zurückkehren wird. ${ }^{323}$ Dies gilt für die Auf-

ein »Abi-Türke«, sondern als jemand, der beginnt, auf eigenen Beinen zu stehen. Siehe hierzu: HoLTZ (2005); DAĞTEKIN (2006-2009); AKKUŞ (2008).

321 Siehe hierzu: KuRz, Joachim (2010): „Die Fremde«. In: Kino-Zeit, 22.03.2010, https://www. kino-zeit.de/film-kritiken-trailer/die-fremde (18.05.2018).

322 Das gemeinsame Essen am Tisch erfüllt in Auf DER ANDEREN SeITE und ALMANyA die gegensätzliche Funktion. Seine soziale Dimension reicht von der Schlichtung über das Kennenlernen bis zum gemeinsamen Genießen. Im Unterschied zu den 1990er Jahren wird in den Filmen der 2000er Jahre in allen mir bekannten Filmen auch tatsächlich gegessen; selbst in den Problemund Skandalfilmen WuT, KNALLHART und CHIKo.

323 DeLL, Matthias (2010): »Kritik zu ১Die Fremde«" In: epd Film, 01.03.2010, https://www.epdfilm.de/filmkritiken/die-fremde (18.05.2018). Das Essen spielt auch eine wichtige Rolle in Selam Berlin, Auf DER ANDEREn SeITE, Soul Kitchen und Hans mit scharfer Soße. In Yadé Karas Roman 
nahmen in der Trabantensiedlung an der Peripherie von Istanbul ebenso wie in den Wohnungen in Berlin. Wie in Akıns Film werden die Beziehungen zwischen Umay und Kader, zwischen ihr und ihrer Mutter und ihren Geschwistern deutlich. Zugleich entsteht über die Kameraperspektive ein intimer Zugang, der einen Einblick geben soll in das türkische Leben in der Bundesrepublik. Interessanterweise sehen manche Interpreten diese Intimität an als eine dekulturalisierende Lesart des Ehrenmord-Konflikts. Aladağs Perspektive lote demnach die »psychosoziale Mechanik« eines Ehrenmordvorhabens aus und verzichte dabei »auf die übliche Verschleierungsfolklore «. ${ }^{324}$ Der Film funktioniere »deshalb, weil er in der Welt junger Türken spielt, die man sintegriert ‘ bezeichnet. Kein Islamist weit und breit. «325 Die psychosoziale Ebene bemühen auch andere Rezensenten, die das Thema des Ehrenmords in DIE FREMDE um »die Ebene der Emotionalität« erweitert sehen. ${ }^{326}$ Zudem zeige der Aushandlungsprozess des Ehrenmords die Akteure nicht wie willenlose Täter eines unmenschlichen Systems, sondern mit »menschlichen Zügen «. ${ }^{327}$ Dadurch halte der Film bis zum Schluss die Möglichkeit offen, dass »Liebe und Zuneigung« sich gegen kulturelle Zwänge stellen könn-

wird insgesamt viel gegessen. Als Hasan einmal kocht, räsoniert er, dass darin sogar die Lösung aller Integrationsprobleme liege: »Beim Kochen war alles möglich. Was Politiker nicht an einem Tisch zusammenbrachten, das schaffte ich in meiner Küche. Deutsche, türkische, chinesische und französische Küche vermischte ich miteinander und zauberte Deftiges auf den Tisch«. Siehe hierzu: KARA (2004): S. 256. In Akıns Auf DER ANDEREN SEITE fragt Nejat Susanne mehrmals, ob sie schon gegessen habe. Nach ein paar Tagen der Trauer um Lotte hat sie wieder Hunger. Sie gehen gemeinsam essen und stoßen auf den Tod an. In dieser Sequenz wird der Esstisch von oben gefilmt wie in Almanya. Siehe hierzu: AkIN (2006). In Hans mit scharfer Soße definiert sich neben Hatices Vater auch ihre Mutter über das Kochen und Essen als Türkin. Der große Esstisch zu Hause ist das wichtigste Möbelstück in der Wohnung. "Den Mittelpunkt in unserem Wohnzimmer beschreibt ein Holztisch mit zahlreichen Stühlen, den meine Eltern aus der Türkei mitgebracht haben. Es haben locker zwölf Personen an ihm und ein ganzes gebratenes Lamm auf ihm Platz. Er war schon immer Dreh- und Angelpunkt unseres Lebens, und bis heute hat sich nichts daran geändert.« Siehe hierzu: AKYÜN (2005): S. 142. In Fatma Aydemirs Roman Ellbogen von 2017 und in Dilek Güngörs Roman Ich bin Özlem von 2019 gibt es diese geselligen Szenen am Tisch nicht mehr. Siehe: AYDEMIR (2017); GÜNGÖR (2019).

324 Darauf, dass das Leben der Rückkehrer am Stadtrand von Mersin in gated communities ebenfalls frei von jeder Folklore sei, macht die Dokumentarfilmerin aufmerksam. Siehe hierzu: Siehe hierzu: Interview mit der Regisseurin, In: http://peripherfilm.de/fsk-kino/archiv/amrandederstaedte.html (11.09.2018).

325 Buss, Christian (2010): „Ehrenmord-Drama ১Die Fremde«. Schrecken, ganz ohne Schleier«. In: DER SPIEGEL, 10.03.2010, http://www.spiegel.de/kultur/kino/ehrenmord-drama-die-fremdeschrecken-ganz-ohne-schleier-a-682504.html (18.05.2018).

326 KURZ (2010).

327 Mutschlechner, Lorenz (2010): »Die Fremde«. In: Film-Rezensionen, 09.10.2010, https:// www.film-rezensionen.de/2010/09/die-fremde/ (18.05.2018). 
ten. ${ }^{328}$ Tatsächlich sehen wir im Film, dass Kader einmal seine Tochter und ihren Sohn zudeckt, wie Tochter und Vater einen schönen Fernsehabend miteinander verbringen und gemeinsam lachen, und wir sehen am Ende des Films, wie Kader Umay um Vergebung bittet.

In der Forschung fällt die Beurteilung von Aladağs Film kritischer aus. Ganz im Gegensatz zu den Filmkritiken sieht Canan Turan eine Viktimisierung der Protagonistin auf »kulturalistische Weise«. Darauf deute Umays »mangelnde Fähigkeit« hin, über sich selbst zu bestimmen. Dies zeige der Film durch sein dramaturgisches Schema, das mit vier Phasen aus »Wiederholungen und kreisförmigen« Bewegungen bestehe. »Erstens: Die Protagonistin wird von ihrer Familie schlecht behandelt. Zweitens: Sie wehrt sich dagegen. Drittens: Sie sucht trotzdem den Kontakt zu ihren Unterdrücker_innen. Viertens: Ihre Familie lehnt sie ab. « ${ }^{329}$ Dem Verlangen nach Freiheit stelle der Film auf diese Art die »kulturell bedingte« Unfreiheit entgegen. Außerdem repräsentiere Gül, die Leiterin der deutschen Kantine, im Film den säkularen Islam als richtigen Islam, den nach Bryan S. Turner die europäischen Integrationspolitiken seit dem 11. September 2001 fördern. ${ }^{30}$ Durch diese Positionierung erhalte der »anti-muslimische Rassismus des Films durch die vermeintliche säkulare kulturelle Insiderin Gül eine höhere Legitimation, da sie die Unvereinbarkeit von individueller Freiheit und Islam quasi personifiziert«. Daher begreift Turan Aladağs Film in postkolonialer Diktion als einen »special Agent of Western power «. ${ }^{331}$

Der amerikanische Literaturwissenschaftler David Gramling sieht in DIE FREMDE hingegen weniger eine ideologische als eine semiotische Signatur am Werk. ${ }^{332}$ Als narrative Kernstruktur des Films identifiziert er Bildwiederholungen, »image doubling «. ${ }^{333}$ Diese reichten diegetisch von der Wiederholung identischer Esstischsequenzen in der Türkei und Deutschland über die extradiegetische Wiederholung des Ehrenmords an Hatun Sürücü vom Februar 2005 in Berlin bis zur Rezeption von DIE FREMDE im türkischen Feuilleton. Letztere zitiert Gramling mit dem Artikel »Sibel Kekilli türbana girdi« (»Sibel Kekilli hat den Türban übergezogen«), der den aktuellen Film und Umay im Verhältnis zu

328 KURZ (2010).

329 Turan, Canan (2016): "'Darf die Subalterne lachen?^ Ehrenmord in Die Fremde (2010) versus tragikomisches Generationentreffen in Almanya - Willkommen in Deutschland (2011)«. In: Deutsch-Türkische Filmkultur im Migrationskontext, hg. v. Ömer Alkın, Wiesbaden: Springer, S. 335-360, hier S. 346.

330 Siehe hierzu: TuRnER, Bryan (2007): »Managing Religions. State Responses to Religious Diversity«. In: Contemporary Islam, August 2007, Volume 1, Issue 2, S. 123-137. S. 125.

331 Ebd., S. 348.

332 GRAMLING (2012): S. 41.

333 Ebd., S. 38. 
Kekillis Rolle in GEGEN DIE WAND, aber auch im Verhältnis zu ihrer pornografischen Vergangenheit hin liest; eine Vergangenheit, die zu Zeiten von GEGEN DIE WAND von der türkischen Presse kaum bemüht wurde. ${ }^{334}$ Aber auch andere Darsteller, wie Tamer Yiğit, der Umays Bruder Mehmet spielt, brechen für Gramling ihre Rollen aus der Vergangenheit, mit denen sie bekannt wurden. Er spielte in Thomas Arslans Film Geschwister Erol, der sich für die Ehre seiner Schwester überhaupt nicht interessiert. Im Gegenteil versuchen Erol und Ahmed in der analysierten Tischsequenz aus GESCHWISTER, bei der nicht gegessen wird, obwohl alle Hunger haben, ihren Vater davon zu überzeugen, dass ihre Schwester Sevim ausziehen sollte, weil sie dann ja schon mehr Platz hätten. ${ }^{335}$ Für Gramling evoziert Aladağs Film eine spezifische Form der Migrationsgeschichte in der BRD, wobei er den Unterschied zu früheren Verhandlungsformen nicht darstellt. Vielmehr markiert DIE FREMDE für ihn eine »transformation from anti-identarian rupture to neobaroque cultural fetishism «. ${ }^{336}$ Auch wenn der Verweis auf den Barock etwas opak wirkt, teile ich mit Gramling den Befund der Evokation von Migrationsgeschichte in der Bundesrepublik ohne Herleitung oder Erklärung von deren Genese. Allerdings erschöpft sich der Hauptstrang nicht einfach in der Wiederholung von Bildern oder dem Zitieren alter Rollen, Ehrenmorde und alter Filmsequenzen. Stattdessen sehe ich auch in Aladağs Film den identitätspolitischen Satz »Was lebst Du?« aushandeln, der sich gerade aus einer noch nicht erzählten Geschichte ableitet. Wie in MEINE VERRÜCKTE TÜRKISCHE HOCHZEIT und AUF DER ANDEREN SEITE und in der Identitätspolitik der Bundesregierung in den 2000er Jahren ist eine Sache klar: Die Türken sind in Deutschland angekommen und sie gehören hierher. Dies markiert der Film von Beginn an, wenn Umay aus der Türkei zu ihrer Herkunftsfamilie nach Deutschland zurückkehrt. In den zeitnah entstandenen Romanen wie Mein Name ist Revolution und Der Mond ist unsere Sonne kehren die Protagonisten ebenfalls nach Bielefeld und Berlin zurück, weil sie erkennen, dass sie in diese Städte, Stadtteile und Straßen gehören. ${ }^{337}$ $\mathrm{Ob}$ aus dieser territorialen Konstellation in den Erzählungen und Bearbeitungen der Migration nun neue Räume, neue soziale Bindungen entstehen, oder Orte manifestiert werden, die wie in MEINE VERRÜCKTE TÜRKISCHE HOCHZEIT in einem Kampfmodus ausgetragen werden, ist auch in Aladağs Film die entscheidende Frage. Die Regisseurin meinte in einigen Interviews, sie wolle das Universelle im Spezifischen ausfindig machen. Der Alltag führt also nicht zum

334 Ebd., S. 41.

335 ARSLAN, Thomas (1997): Geschwister, Spielfilm, Deutschland.

336 GRAMLING (2012): S. 42.

337 Siehe hierzu: Ayata (2011); Caliş (2011). 
Verständnis des Universellen, das stattdessen in den alltäglichen Interaktionen selbst schon vorhanden ist. Im Gegensatz zum Prozess der Entortung, wie die Soziologen Dany Levi und Natan Sznaider den allgemeinen Mechanismus der Globalisierung Ende der 1990er Jahre skizzieren ${ }^{338}$, geht es in DIE FREMdE und Auf Der anderen SeIte um einen Prozess der Verortung. Akteure und kulturelle Marker sind erneut ineinander verschränkt.

Ich frage mich, ob die Perspektive in DIE FREMDE wirklich so »intim« ist und die Akteure wirklich so menschlich dargestellt werden, wie die Rezensenten behaupten. In den 1980er Jahren versuchten Autorinnen wie Saliha Scheinhardt, Aysel Özakın, Alev Tekinay und Regisseure wie Tevfik Başer, Hark Bohm, Jeanine Meerapfel und Hans-Dietrich Grabe in unterschiedlichen Konstellationen vom Innenleben der Türken in Deutschland zu berichten. ${ }^{339}$ Başer selbst wies darauf hin, dass die Deutschen bis zu seinen Filmen in den 1980er Jahren nur um das Thema herum erzählt hätten, es aber keine Erzählung "von innen heraus « gäbe. ${ }^{340}$ Konstitutiv für das türkische Sprechen in Başers Filmen, Dikmens Satire, Meerapfels und Grabes Filmen war in den 1980er Jahren, dass ein unbekannter und nicht eingeladener Deutscher anwesend war, der sie zum Sprechen brachte. Bei Grabe und Meerapfel ist dies mitunter ihrer Einstellung geschuldet, dass man als Deutscher nur zuhören dürfe und darf, aber nicht eingreifen. ${ }^{341}$ Da diese Begegnung nicht draußen stattfand, wurden die Türken auch nicht von allen gehört. In den Filmen und Texten der 2000er Jahre sind die Deutschen aber eingeladen, was sich bereits daran zeigt, dass zum Großteil Deutsch gesprochen wird oder türkische Aussagen sofort übersetzt werden. ${ }^{342}$ Kultur kann hier nicht von außen einbre-

338 Siehe hierzu: Levy, Daniel (1999): »The Future of the Past. Historiographical Disputes and Competing Memories in Germany and Israel«. In: History and Theory. Studies in the Philosophy of History, 38 (1), February 1999, S. 51-66. Siehe hierzu auch: LEVY, Daniel/SzNAIDER, Natan (2002): "Memory Unbound. The Holocaust and the Formation of Cosmopolitan Memory«. In: European Journal of Social Theory, 5 (1), S. 87-106. Dies. (2007): Erinnerung im globalen Zeitalter. Der Holocaust, Frankfurt a. M.: Suhrkamp.

339 Siehe hierzu: ScheinhaRdt, Saliha (1983): Frauen, die sterben, ohne dass sie gelebt hätten, Freiburg: Herder. ÖzAKIN, Aysel (1983): Die Leidenschaft der Anderen, Frankfurt a. M.: Luchterhand; Özakin, Aysel (1988): Die Blaue Maske, Frankfurt a. M.: Luchterhand; Tekinay, Alev (1986): Über alle Grenzen. Erzählungen, Hamburg: Buntbuch. Siehe auch: TeKINAY, Alev (1988): Die Deutschprüfung, Frankfurt a. M.: Brandes \& Apsel; BAŞER (1986, 1988); ВоHM (1988); MEERAPFEL (1985); GRABE (1986).

340 Siehe hierzu: Siehe: PÜTz, Anke/Scholten, Frank (1988): $40 \mathrm{~m}^{2}$ Deutschland. Materialien für einen Film von Tevfik Baser, Begleitheft zum Film, Duisburg: Atlas Film, S. 18.

341 Siehe hierzu: ACKermann/WeinRICH (Hg.) (1986): S. 9 f.

342 Resümierend hält Karen Yeşilada für Einmal Hans mit scharfer Soße von Hatice Akyün, Candlelight-Döner. Geschichten über meine deutsch-türkische Familie von Aslı Sevindim und Das Geheimnis meiner türkischen Großmutter von Dilek Güngör fest, dass diese Autorinnen mit ihren 
chen, wie es noch in den Arbeiten und Reflexionen der 1980er Jahre geschehen war. Es gibt keinen unbekannten Deutschen, sondern alle Akteure kommunizieren entweder verbal oder mit Blicken, meist sogar schweigend miteinander; insgesamt wird wenig gesprochen. Gewissermaßen geht es hier nicht um ein rationales Verstehen, denn der Vater handelt so, wie er handelt, weil er glaubt, nicht anders zu können und nicht weil die Kultur genau das von ihm verlangt.

Werner Schiffauers Probanden aus Die Gewalt der Ehre, Dursun, Abdullah und Ali aus den Filmen 40 QM Deutschland, Abdullah YakupoğLu. Warum HABE ICH MEINE TOCHTER GETÖTET und YASEMIN konnten hingegen nur so handeln, wie es ihnen die Gesetze aus ihren Herkunftsdörfern vorschrieben. ${ }^{343}$ Eine solche Erklärung des Ehrenmordversuchs greift in DIE FREMDE nicht. Schon die ersten Sequenzen könnten in jedem Neubaugebiet nahe einer südländischen Metropole spielen, und auch die Darstellung des Dorfes, mit einem schlafenden Mann in einem Zimmer, ohne ein gesprochenes Wort, ist geradezu mythisch, dass sie jeder realen Referenz entbehrt. ${ }^{344}$ In Aladağs Film geht es nicht um einen Raum außerhalb der Bundesrepublik, sondern ganz konkret um den gezeigten Ort und um die Ordnung vor Ort. Denn das eigentliche Problem der Familie ist das Zusammenleben mit den Türken in Berlin. Sie sind die Beobachter, die Gesellschaft, von der Gül und Umay sprechen. Dieser Fokus auf die Umgebung und die Anwesenden wird besonders daran deutlich, dass Umays Familie letztlich damit leben könnte, wenn Umay bei ihr leben, ihr Sohn jedoch bei seinem Vater aufwachsen würde: Zweimal unternimmt die Familie den Versuch, Cem in die Türkei $\mathrm{zu}$ seinem Vater zu bringen. Würde der Junge in Deutschland bleiben, wäre er immer der lebende Beweis für eine gescheiterte Familie. Dieses Mitspracherecht der Öffentlichkeit in Umays Familie wird im Unterschied zu den 1980er Jahren im Film auch explizit, als etwa Kader dem künftigen Schwiegervater seiner Tochter Rana eine beträchtliche Geldsumme zahlt, damit die Hochzeit stattfindet. Dabei sehen wir nur, wie Kader einer Person Geld im Auto überreicht, die selbst nicht spricht. Mehmet und Acar schnappen in einer Disko etwas Unbestimmtes auf und sind sich sicher, dass zwei andere Deutsch-Türken schlecht über Umay gesprochen hätten. Was das gewesen sein soll, hören wir als Zuschauer nicht. Es folgt eine Schlägerei. ${ }^{345}$ Von dem Türken, der Umay auf der Straße wiedererkennt und ihr nachläuft, um zu erfahren, in welchem Frauenhaus sie untergebracht ist,

Texten einladen, harmoniesüchtig und «schön anzuschauende Paradebeispiele sgelungener Integration« « seien, »bereitwillig ihre Tür öffnen« und »zeigen, was sie kochen«. Siehe hierzu: YeŞILADA (2011): S. 134.

343 Siehe hierzu: Schiffauer (1983); BAŞER (1986); GRABE (1986).

344 Alada ̌ (2010).

345 Aladă̆ (2010). 
erfahren wir auch nichts. Wir schließen nur, dass er Mehmet und Acar darüber informiert haben muss. Überspitzt formuliert könnte man sagen, dass die Position und Rolle der Deutschen als nicht sprechende Anwsende aus den 1980er Jahren die Türken in den 2000er Jahren nun selbst eingenommen haben.

Als geschulte Zuschauer von SHIRINS HochzEIT in den 1970er Jahren über die vermeintlichen Problemfilme der 1980er Jahre bis GEGEN DIE WAND denken wir zu wissen, das Problem ist die türkische Community, die Parallelgesellschaft. Aber auch Şerif Görens türkische Filme wie AlmanYA, ACI VATAN von 1979 und Polizei von 1988 machen auf den Einfluss der türkischen Gemeinschaft vor Ort aufmerksam. ${ }^{346}$ Im letztgenannten Film haben wir gesehen, wie zwei zeitunglesende Türken in Berlin den Müllmann Ali Ekber schon durch ihr Sprechen über die Ehre der türkischen Mädchen von der Gefährdung der Ehre überzeugen. Dabei ist Ali Ekber eigentlich ein freundlicher und sympathischer Akteur. ${ }^{347}$ Von dieser Konstellation eigentlich freundlich und nett, aber mit dem kulturellen Zwang der Ehre im Nacken, mit ihren eigenen Regeln und Gesetzen, ist auch die Theorie Werner Schiffauers bestimmt, der in seiner Arbeit Die Gewalt der Ehre das Einwirken der Dorfstruktur aus der Türkei auf die Türken in Deutschland als Grundlage des Ehrenkodexes in der Diaspora begreift. ${ }^{348}$ Barbara John betont in den 1980er Jahren »die Gastfreundschaft in türkischen Familien ${ }^{349}$ Solche sozialen und kulturellen Praktiken setzt Aladağs Film nicht voraus. Zum einen gibt es keinen stabilen Verweis auf ein Außen, das auf das angekommene Innenleben einwirken würde. Zum anderen sind die ersten Türken, die wir in Aladağs Film sehen, Familienmitglieder von Umays Mann Kemal, alles andere als sympathisch. Wir haben es mit einer Art Autokommunikation - von innen nach innen - zu tun. Das zeigt sich am deutlichsten am Verhalten des Vaters während der Hochzeit.

Als Umay ihn vor allen anderen türkischen Hochzeitsgästen um Vergebung bittet, ist dieser anfangs sichtlich ergriffen. Er weiß nicht, ob er seiner Tochter nachgehen soll, nachdem Mehmet sie und seinen Enkel vor die Tür gesetzt hat. Zugleich nimmt er aber in dieser sichtbar gemachten inneren Bewegung wahr, wie ihn die anderen beobachten. Als Zuschauer sehen wir allerdings nicht, ob sie das wirklich tun. Auf jeden Fall beobachtet er selbst, wie die anderen ihn wahrscheinlich beobachten. Die im Film zu sehende Sequenz steht interessanterweise genau an diesem Punkt im Widerspruch zu ihrer Entstehung, an der

346 Siehe hierzu: GöREN, Şerif (1979): Almanya, Acı Vatan, Spielfilm, Türkei; ders. (1988): Poli$z e i$, Spielfilm, Türkei.

347 Siehe hierzu: GöREN (1988).

348 Siehe hierzu: SchiffaUer (1983).

349 John (1982): S. 365. 
türkeistämmige Statisten beteiligt waren. Sibel Kekilli hielt in einem Interview fest, dass viele türkische Frauen um sie herum geweint hätten, als sie ihren Vater im Film um Vergebung bat. Eine Dame habe ihr sogar ein Taschentuch gereicht. All das sehen wir im Film nicht, nur der Vater Kader, der sich dabei beobachtet, wie er von den Anderen beobachtet wird. Gemessen an diesen Aufnahmebedingungen und den Reaktionen der türkeistämmigen Statisten auf Umays Rede hätte Kader seiner Tochter und seinem Enkelsohn ohne Weiteres nachlaufen können.

Zum Höhepunkt gelangt diese besondere selbstbezügliche Struktur in DIE FREMDE, als Umay am ersten Tag des Opferfestes ihre Familie ein weiteres Mal um Vergebung bittet. Als Kader aus dem Fenster sieht, wie Umay einen Deutschen umarmt, der dann auch noch Cem auf den Arm nimmt, erstarren seine Gesichtszüge und er wirkt zugleich entschlossen. Es folgt die Reise in die Türkei, die insofern imaginär wirkt, als niemand spricht. Den Rat, aufgrund dessen er offensichtlich die Reise antrat, bekommt er auch nicht. Stattdessen fällt Kader seine Entscheidung ganz allein. Nachdem die Wahl des Täters gefallen ist, sehen wir, wie Acar, der jüngste Bruder Umays, in seinem Zimmer auf dem Boden sitzt und weinend auf seinen Computer einschlägt. ${ }^{350}$

Als Hans-Dieter Grabe in seinem Dokumentarfilm ABdullah YAKupoğLu. WARUM HABE ICH MEINE TOCHTER GETÖTET von 1986 herausfinden und nachvollziehbar machen wollte, war ihm am wichtigsten, Abdullah ohne seine Intervention sprechen zu lassen. Abdullah erzählte viel vom türkischen Dorf und dass er wegen einer fehlenden Brücke über den Fluss nicht die Möglichkeit gehabt habe, die staatliche Grundschule zu besuchen. So sei er gezwungen gewesen, in die Koranschule zu gehen. Das habe sein Weltbild entscheidend geprägt. ${ }^{351} \mathrm{Mehr}-$ mals macht Abdullah darauf aufmerksam, dass seine Herkunftsgesellschaft, das türkische Dorf, noch nicht bereit sei für ein modernes Leben. Er selbst wäre gerne modern, wenn er es denn könnte. Dass es aber auch eine andere Türkei gibt, die von Staatlichkeit und Säkularität geprägt ist und von der etwa Aysel Özakın erzählt, verschweigen sowohl Abdullah als auch Grabe. Außerdem wird in Grabes Film deutlich, dass Abdullah nicht ausschließlich am Widerspruch zwischen Tra-

350 Necla Kelek skizziert ein anderes Bild der Familien, die unehrenhafte Töchter von den unter 18-jährigen männlichen Familienmitgliedern töten lassen. In Die fremde Braut schreibt sie zum Prozess zur Ermordung von Hatun Sürücü, dass sich die Familie es sich "ganz gut zurechtgelegt« habe, indem sie den jüngsten Bruder als Täter wählte, der die Tat aus eigener Motivation begangen habe, um die Ehre seiner Eltern wiederherzustellen. Siehe hierzu: KeleK (2006): S. 10. 351 Siehe hierzu: GRABE, Hans-Dieter (1986): „Abdullah Yakupoğlu. `Warum habe ich meine Tochter getötet«". In: ders: Hans-Dieter Grabe. Dokumentarist im Fernsehen, Berlin: Absolut Medien 2009. 
dition und Moderne leidet. Der deutsche Freund seiner Tochter Perihan bezeichnet ihn auch als einen psychisch immens verstörten Mann. ${ }^{352}$

Başers 40 QM DEUTSCHLAND und Bohms YASEMIN sind ebenfalls durch diese Konstellation von Säkularität (Atatürk), Tradition (Koran) und dem psychischen Unbehagen bezüglich des öffentlichen deutschen Raums gerahmt. Keiner dieser Aspekte taucht als Erklärung in DIE FREMDE auf: Weder wird Kaders Lebensweise als rückständig dargestellt - er könnte auch anders handeln, noch sehen wir als Gegenmodell ein modernes deutsches Leben. Der öffentliche deutsche Raum ist nicht nur kein Problem, sondern wird nicht einmal thematisiert. Wie in MEINE VERRÜCKTE TÜRKISCHE HOCHZEIT ist der Stadtteil, in dem die türkischstämmigen Akteure wohnen, auch hier ihr Kiez. ${ }^{353}$ Aladağs Film konzentriert sich stattdessen auf die Frage, wofür sich die Akteure entscheiden und wie sie mit diesen Entscheidungen leben. Trotz des schon zu Beginn angekündigten Endes begegnen wir vielen Situationen, in denen die Akteure auch hätten anders handeln können. Dabei scheint nicht der Islam das eigentliche Problem zu sein, sondern eher der Umgang mit ihm. An wichtigen muslimischen Feiertagen wie dem Opferfest ist das Aufsuchen und Zusammenkommen von Verwandten zentral - wie auch in AUF DER ANDEREN SEITE dargestellt. Eigentlich ist es ein Regelverstoß, an solch einem Tag den um Vergebung bittenden Besuch abzuweisen - vor allem, wenn es sich dabei um die nächsten Verwandten handelt. Wie also gehen Aladağs, aber auch Akins Akteure mit den kulturellen und gesellschaftlichen Formen, religiösen Ritualen und Fragestellungen um? Denn Gül macht klar, dass man entweder zur Gemeinschaft der Unterdrücker, aber zugleich familiären Lebens oder zur Gesellschaft des selbstbestimmten Lebens gehört. Die Zugehörigkeit ergibt sich über die eigenen Entscheidungen und das eigene Verhalten.

Keiner der dargestellten Türken will in die Türkei zurückkehren. Vielmehr steht die türkische Gesellschaft in Deutschland zur Disposition. Genau diese Verortung - als Türke in Deutschland zu leben - zwingt die Akteure in DIE FREMDE mitunter dazu, auch wie Türken zu handeln. Wenn sie selbst sehen könnten, dass sie in Wirklichkeit gar nicht in der Weise unter Beobachtung stehen, wie sie sich selbst beobachten, wären andere Entscheidungen, Identifikationen und Verhaltensweisen möglich. Wäre ihnen bewusst, warum und wie sie ihre Entscheidungen treffen, wovon sie ein Teil sind oder nicht - was Kader erst nach dem Herzinfarkt im Krankenbett gelingt -, würden sie erkennen, dass sie selbst entscheiden, was sie leben. Diese Interpretation zwingt uns der Film regelrecht auf, der nicht mehr präzise nach dem Kodex einer Kultur fragt, sondern danach,

352 Siehe hierzu: GRABE (1986).

353 Siehe hierzu: Holtz (2006). 
wie die Personen handeln. Mit Jürgen Habermas gesprochen wird der Ehrenmord in den 2000er Jahren weniger aus einer kulturellen Verpflichtung denn aus einer subkulturellen Eigenständigkeit heraus begangen. ${ }^{354}$ Kultur ist kein Schicksal, sondern eine Frage der Entscheidung. ${ }^{355}$ Bezeichnend ist in diesem Zusammenhang auch Aladağs Namenswahl für Umays Vater, denn Kader heißt auf Türkisch »Schicksal«.

Das Territorium und die damit einhergehende Verortung werden auch in Almanya. Willkommen in Deutschland verhandelt. Denn nach seiner Frage, ob die Familie nun deutsch oder türkisch sei, fragt Cenk weiter, warum sie in Deutschland lebten, wo sie doch Türken seien. ${ }^{356}$ Warum Cenk diese Fragen so sehr beschäftigen, wird schon vorher geklärt. Im Unterricht möchte Cenks Lehrerin die Orte der Herkunft ihrer Schüler und deren Eltern mit Steckfähnchen auf einer Europakarte markieren. Sie fragt Cenk, wo sie denn sein Fähnchen hinstecken solle. Dieser antwortet in einem fragenden Unterton sofort: »Deutschland«? Die Lehrerin entgegnet: "Ja, ja, das stimmt schon. Aber wie heißt das schöne Land, woher Dein Vater kommt? « - »Anatolien «. ${ }^{357}$ Später erfahren wir, dass auch Cenks Vater in Deutschland geboren wurde. Da die Europakarte aber bei Istanbul endet, muss die Lehrerin sein Fähnchen an die kahle Wand stecken. Die Eltern seines türkischen Klassenkameraden Engin kommen aus dem europäischen Teil Istanbuls, der gerade noch auf der Karte verzeichnet ist. Im Unterschied zu Engin spricht Cenk kein Türkisch. Das wird später thematisiert, als im Sportunterricht Deutschland gegen die Türkei spielen soll und Cenk mit den Worten »der kann ja gar nix. [...] nicht mal Türkisch ${ }^{358}$ in die deutsche Mannschaft geschubst wird. ${ }^{359}$ Für Cenks Dazwischen-Sein gibt es keine Mannschaft, keinen Raum. Cenks Frage nach der nationalen Identität seiner Familie stellt sich auch aufgrund solcher Erfahrungen in der Schule. Erneut sind öffentlicher und privater Raum auf besondere Weise miteinander verschränkt. Doch ist die Schwelle kein Austragungsort mehr für diese Verschränkung. Im Folgenden werden wir sehen, dass ALMANYA einen Zugang zur Verarbeitung der Migrationsfolgen anbietet, der in der Forschung in den 2000er Jahren an Breite gewinnt. Über eine Mischung aus Fiktion

354 Siehe hierzu: HABERMAS (2008): S. 39.

355 Siehe hierzu: SEN (2006): S. 20.

356 ŞAMDERELI (2011).

357 Siehe hierzu: ŞAMDERELI (2011).

358 Ebd.

359 Ebd. 
und historischem Archiv zur türkischen Migration rückt der Film die Historie der Migration in den Blickpunkt. ${ }^{360}$

Filme wie DIE FREMDE seien »natürlich wichtig«, äußert die Regisseurin Yasemin Şamdereli in einem Interview zu Almanya. Sie habe mit ihrer Schwester Nesrin Şamdereli ${ }^{361}$ aber ein »Gegenbeispiel« zeigen wollen; Leute wie ihre Familie, die in Deutschland »sehr gut leben «. ${ }^{362}$ Diese Intention und Rahmung spiegeln sich in den Kritiken und Besprechungen des Films wider, besonders was die Frage der Integration betrifft. Die Redaktion von Kino Vision überzeugt beispielsweise die »unaufdringliche Art, mit der das Thema Integration bearbeitet wird «. ${ }^{363}$ In der Filmzeitschrift epd-Film heißt es, dass Yasemin und Nesrin Şamdereli mit ihrem Film den aktuellsten Beitrag zur Integrationsdebatte liefern und Angela Merkels Befund »Multikulti ist in Deutschland gescheitert « in Frage stellten. ${ }^{364}$ Harald Martenstein konstatiert im Tagesspiegel, dass AlmANYA eine »überzeugende Antwort« auf die Thesen von Thilo Sarrazin sei, weil er »einfach nur eine Familiengeschichte [...] leichtfüßig und intelligent « ${ }^{365}$ erzähle. Andere Stimmen meinen hingegen, dass jedem deutsch-türkischen, deutschen und türkischen Akteur in diesem Film »die Integrationsproblematik wesentlich fremder

360 In den 2000er Jahren richten den Blick auf die Geschichte der Migration in der Bundesrepublik die wichtigen Arbeiten von Ulrich Herbert, Karin Hunn, Karen Schönwälder und Rita Chin. Auf dem 44. Deutschen Historikertag im Jahr 2002 machte der damalige Bundespräsident Johannes Rau in seiner Eröffnungsrede im Rahmen der deutschen Einwanderungsgesellschaft darauf aufmerksam, dass die Geschichte eine besondere Quelle der Identifikation und Identität in einer Gesellschaft sei. Migration und Integration seien in der Bundesrepublik dabei bisher nie berücksichtigt worden, was sich in Zukunft aber ändern müsse. Siehe hierzu: MotTE, Jan/ OHLIGER, Rainer (2004): »Geschichte und Gedächtnis in der Einwanderungsgesellschaft. Einführende Betrachtungen«. In: Geschichte und Gedächtnis in der Einwanderungsgesellschaft, hg. v. Jan Motte, Rainer Ohliger, Essen: Klartext, S. 7-16, hier S. 9f.

361 Regie führte Yasemin Şamdereli, das Drehbuch verfassten Yasemin und Nesrin Şamdereli gemeinsam. Siehe hierzu: https://www.filmportal.de/film/almanya-willkommen-in-deutschland_ 49beb1344dff4076bb582a03262f15c8 (13.06.2018).

362 https://www.kinofenster.de/filme/archiv-film-des-monats/kf1103/yasemin-samdereli-kf1103/ (zuletzt 16.05.2021).

363 HelBig, Björn (2010): Almanya. Willkommen in Deutschland, 30.12.2010, https://www.visionkino.de/filmtipps/filmtipp/movies/show/Movies/all/almanya-willkommen-in-deutschland/ (13.06.2018).

364 SiEms, David (2011): „Kritik zu Almanya. Willkommen in Deutschland«. In: epd Film. Mehr Wissen. Mehr Sehen, 01.03.2011, https://www.epd-film.de/filmkritiken/almanya-willkommen-deutschland (13.06.2018).

365 MARTENSTEIn, Harald (2011): »Identitätsfragen. Die deutsch-türkische Komödie >Almanya wirkt wie eine direkte Reaktion auf die Thesen von Thilo Sarrazin«. In: Der Tagesspiegel, 15.02.2011, https://www.tagesspiegel.de/kultur/harald-martenstein-4-identitaetsfragen/3815106. html (13.06.2018). 
ist als Sauerkraut«, ja dieser Film sogar jenseits der Integration stattfinde ${ }^{366}$ obwohl wir am Ende Cenks Rede im Bundeskanzleramt hören und sehen, wie ihn die Kanzlerin umarmt. ${ }^{367}$ Während MEINE VERRÜCKTE TÜRKISCHE HochzEIT, Auf DER ANDEREn SEITE und Die Fremde auf unterschiedlichste Art und Weise das Thema der Integration wie gezeigt im Hinblick auf Form, Debatten und Sachfragen bearbeiten, geht es in ALMANYA um die Entfaltung des Widerspruchs zwischen Integration und Nicht-Integration. Und ich werde zeigen, dass auch hier ein besonderes Verhältnis zwischen Öffentlichkeit und Intimität zum Tragen kommt, das wie in den anderen Filmen das Innen (das Persönliche) zum Außen (zum Politischen) erklärt.

Dieses Verhältnis zeigt sich bereits in der Titelsequenz. Diese beginnt mit Fotos der Familie und Worten der Erzählerin aus dem Off: Das erste Foto zeigt sie und ihren Großvater im Jahr 1987, das letzte die gesamte Familie »heute ${ }^{368}$ Kurz nach dieser Aufnahme habe sich alles verändert. Während weitere Fotos eingeblendet werden, reflektiert die Erzählerin darüber, wie ihr Leben wohl verlaufen sei, wenn sie nicht in Deutschland, sondern in der Türkei geboren wäre. Dass sie "made in Germany" sei, verdanke sie dem deutschen Wirtschaftswunder. ${ }^{369}$ Auf diese Aussage erscheint in goldenen Buchstaben der Titel des Films: ALMANYA. Willkommen in Deutschland. Auf die begleitenden orientalisch-mediterran wirkenden Klänge folgt nun der bekannte Wirtschaftswundersong »Konjunktur Cha-Cha« von 1961 (»Gehen Sie mit der Konjunktur«). Dann werden Fotos und Werbefilme aus der Wirtschaftswunderzeit eingeblendet; ein Originalfilmbeitrag, der die Anwerbung von Gastarbeitern mit Aufnahmen vom Gesundheitscheck als eine Prozedur »wie auf dem Viehmarkt« beschreibt; das Titelblatt des Spiegels Gastarbeiter in Deutschland; und zuletzt der damalige Arbeitsminister Theodor Blank in einem Interview. Er erklärt, warum türkische Facharbeiter

366 VAhABZAdeh, Susan (2011): "Leitkultur sachte verbogen«. In: SÜDDEUTSCHE ZEITUNG, 11.03.2011, http://www.sueddeutsche.de/kultur/im-kino-almanya-leitkultur-sachte-verbogen-1. 1070351 (13.06.2018).

367 ŞAMDERELI (2011).

368 Ein gerahmtes Bild steht auch am Anfang von Kadir Sözens ZEIT DER WüNSCHE. Siehe hierzu: SözEN (2005).

369 »Made in Germany« hieß auch das Live-Programm von Kaya Yanar, mit dem er 2006 durch Deutschland tourte. Siehe hierzu: YANAR, Kaya (2007): Made in Germany, DVD, Berlin: Sonic Music Entertainment. Neco Celiks Dokumentarfilm GANZ oBEN über fünf erfolgreiche Deutsch-Türken in Deutschland, darunter der Autor Feridun Zaimoğlu, der Musikproduzent Mousse T. und der Sternekoch Ali Güngörmüş, endet mit der Aussage Zaimoğlus, dass Deutschland solche »Vögel wie mich möglich gemacht« hätte, und er frei heraussagen könne, dass er »made in Germany« sei. Siehe hierzu: Celik, Neco (2007): Ganz oben. Türkisch - Deutsch - Erfolgreich, Dokumentarfilm, Deutschland, Mainz: ZDF/3Sat. 
nach Deutschland geholt werden. ${ }^{370}$ Anschließend sehen wir einen Zug in einen Bahnhof einfahren, aus dem ein südländisch aussehender Mann aussteigt. Die Erzählerin fährt nun fort und berichtet, dass am 10. September 1964 ein Gastarbeiter deutsche Geschichte geschrieben habe. Das Filmbild ändert sich von schwarzweiß zu Farbe und wir sehen Hüseyin, den Gastarbeiter, am Bahnhof Köln-Deutz ankommen und seine Koffer suchen. Wir sind sicher, dass der Film nun beginnt. Doch der Gastarbeiter, der an diesem Tag deutsche Geschichte schreiben wird, ist nicht Hüseyin, der Großvater der Erzählerin, sondern der Portugiese Armando Rodriguez de Sá, der als einmillionster Gastarbeiter an diesem Datum in Köln ein Moped geschenkt bekommt. Er wird neben Hüseyin eingeblendet und wir erkennen ihn daran, dass er genauso gekleidet ist wie auf dem zur Ikone gewordenen historischen Bild auf dem Moped. ${ }^{371}$ Hüseyins individuelle Geschichte in Deutschland wird also mit echten Archivaufnahmen verbunden. In dieser spielerischen Zusammenführung von Fiktion und Archiv sehen wir, dass Hüseyin aus Höflichkeit Armando Rodriguez bei der Registrierung den Vortritt lässt und somit nicht selbst der einmillionste Gastarbeiter wird, der an diesem Tag Geschichte schreibt und ein Geschenk bekommt. Aber heute, 45 Jahre nach diesem historischen Moment am Bahnhof in Köln-Deutz, so die Erzählerin, erzählen wir die Geschichte des einmillionen-und-ersten Gastarbeiters. ALMANYA bearbeitet die Folgen der Migration nach Deutschland, indem Vergangenheit und Gegenwart erzählerisch vergleichzeitigt werden.

Im weiteren Verlauf des Films wird dieser Beginn der Migration in drei voneinander getrennten Erzählabschnitten wiedergegeben. Hüseyin migriert nach Deutschland, weil er mit seiner Arbeit im türkischen Dorf eine fünfköpfige Familie nicht mehr ernähren kann. Genau aus diesem Grund migriert auch Melek in Ralf Schübels und Kadir Sözens Film ZEIT DER WüNSCHE von 2005 aus einem türkischen Dorf nach Deutschland. Und wie in Bekir Yıldız' autobiografischem Roman Türkler Almanyada von 1966 lässt auch Hüseyin in ALMANYA nach ein paar Jahren seine Familie nach Deutschland nachziehen. Im Unterschied $\mathrm{zu}$ Bekir Yıldız jedoch, der seine Frau nachziehen lässt, damit beide in Deutschland schneller mehr Geld verdienen, führt Hüseyin seine Familie zusammen, weil er nach Jahren ihrer Vaterlosigkeit erkennen muss, dass es seinen Kindern an Disziplin mangelt: Bei seinem ersten Urlaub in der Türkei erfährt Hüseyin, dass sein älterer Sohn Veli unentschuldigt 21 Tage in der Schule gefehlt hat. Er beschließt, seine Kinder und

\section{0 ŞAMDERELI (2011).}

371 Die amerikanische Historikerin Rita Chin geht in ihrer historischen Studie zur Geschichte der Gastarbeiter in der Bundesrepublik ebenfalls von dieser Fotografie aus, die sie als Ikone der Migration in die Bundesrepublik Deutschland bezeichnet. Siehe hierzu: CHIN, Rita (2007): The Guest Worker Question in postwar Germany, Cambridge: Cambridge University Press, S. 1-30. 
seine Frau mit nach Deutschland zu nehmen, denn eines könnten die Deutschen sehr gut: diszipliniert sein und Disziplin beibringen. ${ }^{372}$ Jahre später stellt Hüseyin fest, wie sich seine Kinder durch die neue Sprache, durch neue Feste wie Weihnachten und durch den Wunsch seiner Tochter, er solle seinen Schnurbart abrasieren und wie die Deutschen aussehen, von der eigenen Kultur entfremden. Bei einem weiteren Urlaub in der Türkei entscheidet Hüseyin, nicht wie geplant, in der Türkei ein Haus zu kaufen, sondern in Deutschland. In der Türkei würden nämlich alle nur noch ans Geld denken und im Dorf fällt immer wieder der Strom aus. ${ }^{373} \mathrm{Mit}$ dem Blick der Familie auf das in Deutschland gekaufte Haus endet die Geschichte der ersten Generation in Deutschland, die Canan ihrem Neffen Cenk erzählt.

Vor allem diese gegenwartsbezogene Rahmung der von Canan erzählten Geschichte stellt ein besonderes Verhältnis her zwischen Vergangenheit und Gegenwart, das auch in Bezug steht mit dem Kurzschluss von Anfang und Ende der Migration, wie ihn Wolfgang Schäuble in seiner Rede auf der vierten Islam Konferenz skizziert hatte. Denn nachdem Hüseyin Armando Rodriguez den Vortritt gelassen hatte, meint die Erzählerin, dass ihrem Großvater eine helle Zukunft bevorstehe. Dabei sehen wir ihn einen Flur betreten. Das Bild wird unscharf, wir hören aus dem Off eine ältere Frauenstimme seinen Namen rufen, es wird hell und Hüseyin steht nun als alter Mann auf einer am Ausgang eines Supermarktes und wartet auf seine Frau. Sie kommt mit einem vollen Einkaufswagen aus einem »Market«. »Market« ist der türkische Begriff für »Supermarkt«. Da alle Produktwerbungen an den Außenwänden auf Deutsch sind, ist klar, dass wir uns in Deutschland befinden. Der besondere establishing shot schließt den Supermarkt von heute mit dem Kölner Bahnhof von gestern kurz und überspringt 45 Jahre Leben in Deutschland. ${ }^{374}$ Hüseyins erster Satz im Film lautet, dass er es sich lange überlegt habe und nun doch nicht Deutscher werden möchte. Seine Frau Fatma ist darüber sehr verärgert und sagt, dass sie sehr wohl Deutsche würden und morgen ihre Pässe abholen. ${ }^{375}$

Gemäß Staatsbürgerschaftsgesetz müssen Fatma und Hüseyin für die deutsche Staatsbürgerschaft die türkische aufgeben. Dadurch, dass die Ehepartner diesbezüglich gleich am Anfang des Films unterschiedlicher Meinung sind, könnte man

372 ŞAMDERELI (2011).

373 Ein wichtiger Grund für die Migration aus dem türkischen Dorf ist in Feridun Zaimoğlus Roman Leyla, dass sich die gleichnamige Protagonistin ein »elektrisches Leben« wünscht. Siehe hierzu: ZAIMOğLU (2005): S. 234.

374 ŞAMDERELI (2011).

375 Aus einer vergleichbaren Situation heraus beschreibt Nuran David Calış die Position seines Protagonisten im Roman Der Mond ist unsere Sonne als einen unbehaglichen Zwischenzustand. Siehe hierzu: Calış (2011): S. 30. 
meinen, das Identitätsproblem sei insgesamt zentral. Diesen Eindruck berichtigt die Erzählerin allerdings gleich: »Wenn meine Großeltern dachten, sie hätten ein Problem, hatte ich selbst tatsächlich eines «. ${ }^{376}$ Denn die Erzählerin Canan ist von ihrem englischen Freund David schwanger. Wie oben schon angedeutet, lässt sich kein Zwischenzustand lange aushalten. Auch aus diesem Grund bringt den Großvater Engins Aussage, dass Cenk »kein richtiger Türke« sei, auf die Palme. Denn sie alle seien eine »richtige türkische Familie ${ }^{377}$ Als Hüseyin vom gemeinsamen Türkei-Urlaub spricht, sind die Angesprochenen weder hocherfreut noch halten sie explizit dagegen, dass ihre Heimat nun die Bundesrepublik sei. Die meisten haben einfach keine Zeit; Canan muss etwa auf ihre Prüfungen lernen. Hüseyin wird wieder wütend. Auf Türkisch wettert er, dass sie sich schämen sollten; er habe noch nie etwas von ihnen verlangt; wann würden sie denn alle jemals wieder gemeinsam einen Urlaub machen können; zudem seien sie eine Familie. Er erhebt sich vom Esstisch und ergänzt auf Deutsch, dass sie eine türkische Familie seien. ${ }^{378}$ In diese aufgeheizte Diskussion fragt Cenk hinein, ob sie nun Türken oder Deutsche seien. Cenks Eltern geben sich widersprechende Antworten auf seine Frage. »Türken« antwortet ihm sein Vater Ali, »Deutsche« seine Mutter Gabi. Beide schauen sich verwirrt an und Gabi erklärt Cenk, das »Dede [Großvater] und Nene [Großmutter] « jetzt den deutschen Pass hätten. Doch winkt Hüseyin ab und meint, das sei doch nur ein Stück Papier. »Wir sind immer noch Türken«, befindet Hüseyin und meint wieder zu Cenk: »und du auch«. Canan schlägt Cenk daraufhin vor, dass man doch beides sein könne. »Nein«, entgegnet Cenk entschieden: »entweder die eine Mannschaft oder die andere Mannschaft «. ${ }^{379}$

Canan erzählt in drei Teilen bis zum letzten Drittel des Films die erste Phase der Migration nach Deutschland von Hüseyin und seiner Familie. Der erste Teil endet damit, wie die Familie in Deutschland aus dem Flieger steigt

376 ŞAMDERELI (2011).

377 Ebd.

378 Dass die erste Migranten-Generation ihr Türkisch-Sein so sehr betont, begegnet uns auch in Selam Berlin von Yadé Kara. Als Hasan und seine Mutter nach dem Fall der Mauer erfahren, dass sein Vater, ihr Mann, in Ostberlin eine Geliebte und sogar ein Kind mit ihr hatte, denkt der Sohn: »Rosa paßte nicht zu Baba. Sie war zu zackig und hektisch und bevormundete Baba. Ich fand, das war zuviel. Schließlich war Baba, trotz seiner sozialistisch-marxistischen Gesinnung, ein Orientale. Mit Rosa konnte es nicht gutgehen - jedenfalls wünschte ich mir das.« Siehe hierzu: KARA (2004): S. 314. Auch Devrims deutsch-türkische Freundin Rüya in Imran Ayatas Roman Mein Name ist Revolution empfiehlt ihm, die Herkunftsstadt seiner türkischen Eltern zu besuchen, wo er sehr lange nicht mehr war: ")Du wirst es bestimmt nicht bereuen. Wenn du dort warst, wirst du mich besser verstehen. Es wird dir klar werden, wie viel Dersim [Gebiet in der Türkei, Ö.E.] du in dir hast, auch wenn du das abstreitest.« Siehe hierzu: AYATA (2011): S. 137.

379 ŞAMDERELI (2011). 
und Muhammed sagt, dass es hier ganz anders aussehe als bei ihnen. Wir sehen jedoch nicht, was er sieht, also woran er dies festmacht. Der Film wechselt an dieser Stelle wieder in die Erzählgegenwart. Es ist spät geworden, und die Familienangehörigen brechen nach dem Essen und der Erzählung auf. Cenk hingegen fragt aufgeregt: »Was war denn ganz anders?« »Das wirst Du sehen, wenn wir in der Türkei sind «, erwidert sein Großvater. Den zweiten Teil der Geschichte wird Canan Cenk am Flughafen erzählen, als ihm langweilig ist. Mit der Geburt von Cenks Vater Ali in Deutschland endet der zweite Teil der von Canan erzählten Geschichte. In der Gegenwart sind sie dann gerade in der Türkei angekommen.

Derartige Ankunftsszenen am Flughafen sehen wir in den Filmen der 2000er Jahre häufig, etwa im Dokumentarfilm WIR SITZEN IM SüDEN von Martina Priessner oder Fatih Akıns Auf DER ANDEREN SEITE. ${ }^{380}$ Den letzten Teil der Geschichte erzählt Canan Cenk im kleinen Bus, den Hüseyin für die Familie gemietet hat. Er endet mit Hüseyins Hauskauf in den 1970er Jahren in Deutschland, und mit der Einstellung, wie die Familie vor diesem Haus steht. Cenk erfährt dann, dass dies das Haus ist, in dem sie alle wohnen und von wo aus auch die Geschichte in der Geschichte ihren Ausgang genommen hat. Als auf dem Weg zum eigenen Haus in der Türkei Cenk dann wissen möchte, warum Opa und Oma so schlecht Deutsch sprechen, bemerken alle plötzlich, dass Hüseyin im Schlaf gestorben ist. Eine entsetzliche Trauer ergreift die Familie, die die Nacht in einem Hotel verbringt. Dort erfahren Leyla und Fatma von Canans Schwangerschaft, die zerstrittenen Brüder Veli und Muhamed kommen sich näher und Ali erklärt seinem Sohn, dass der Tod zum Leben gehöre und sein Großvater immer noch bei ihnen sei. ${ }^{381}$ Hüseyin dann in der Türkei zu beerdigen, stellt sich als große Herausforderung heraus. Da er kein Türke mehr ist, muss er auf dem Ausländerfriedhof, der sehr abseits liegt, begraben werden. Die Familie reagiert empört und meint, dass ihr Vater schon immer Türke gewesen und geblieben sei. ${ }^{382}$ Der Krankenhausangestellte macht der Familie darauf das Angebot, Hüseyin für zehntausend Euro auf dem Friedhof für Türken beizusetzen. Doch die Familie entscheidet sich dafür,

380 Siehe hierzu: PRIESSNer (2010); AKIN (2006).

381 Der Tod ist, wie gesehen, nicht nur in Auf DER ANDEREN SeIte ein zentrales Thema. Auch in Zafer Şenocaks Roman Der Pavillon ist er zentral. Denn der Roman endet mit dem Tod und der anschließenden Beerdigung des Vaters eines Nachbarn Hamits, des Protagonisten. Hamit, der Musiker, der glaubt, dass alle politischen Revolutionen mit Veränderungen in der Musik beginnen, komponiert am Ende des Romans ein kleines Stück auf der Violine für den verstorbenen Vater seines Nachbarn. Siehe hierzu: ŞENOCAK (2009): S. 173.

382 Wie in Akıns Auf DER ANDEREN SEITE zeigt sich, welche Folgen das deutsche Staatsbürgerschaftsrecht insbesondere für die erste Generation hat. In Akıns Film wird Ali nach dem Totschlag von Yeter in die Türkei abgeschoben, weil er nur die türkische Staatsbürgerschaft hat. 
Hüseyin illegal auf dem eigenen Stück Land im Dorf zu bestatten. Während der Beerdigung sieht der kleine Cenk neben Veli den kleinen Veli, neben Muhamed den kleinen Muhamed und neben seiner Oma Fatma die junge Fatma. So wie es sein Vater gesagt hat, verlassen uns die Sterbenden nicht wirklich. Nach der Beerdigung muss die Familie feststellen, dass das Haus, das Hüseyin gekauft hat, eine Ruine ist. Hinter der vorderen Hausfassade mit der Eingangstüre ist außer ein paar kleinen Steinmauerresten nur die schöne Dorflandschaft zu sehen. Dort findet dann ein gemeinsames Essen mit den Dorfbewohnern statt. Als die Familie sich aufmacht, nach Deutschland zurückzukehren, entscheidet sich Muhamed, im Dorf zu bleiben und das Haus aufzubauen. Der Rest der Familie kehrt zurück nach Deutschland. In der nächsten Sequenz sehen wir die Veranstaltung »Deutschland sagt Danke« im Kanzleramt der deutschen Regierung, zu der Hüseyin als Redner eingeladen war. Cenk wird für ihn sprechen, da er die Rede mit seinem Großvater geübt hatte. Cenk beginnt damit, dass er nun seit 45 Jahren in Deutschland lebe, und dass es in dieser Zeit gute wie auch weniger gute Zeiten gegeben habe. Der Film endet mit einem Picknick in einer Landschaft, die an das Bild zu Anfang des Films erinnert; an den Ort, von dem Hüseyin meint, dass sie dort herkämen. Canan läuft auf ihren Großvater zu. Die Kamera bewegt sich von beiden weg und wir sehen, wie auf einer Picknickdecke Hüseyins Familie aus den 1960er und 1970er Jahren gemeinsam isst und weiter hinten die Familie von heute. Der alte Hüseyin vom hinteren Teil des Bildes bewegt sich auf den jungen Hüseyin zu. Sie begrüßen sich wie alte Bekannte, umarmen sich, setzen sich nieder und beginnen miteinander zu sprechen. ${ }^{383}$ Die Kamera nimmt dabei beide von unten auf. Aus dem Off hören wir Canan sagen, dass

ein kluger Mann einmal auf die Frage, wer oder was wir sind, antwortete: Wir sind die Summe all dessen, was vor uns geschah, all dessen, was unter unseren Augen getan wurde, all dessen was uns angetan wurde. Wir sind jeder Mensch und jedes Ding, dessen Dasein uns beeinflusste oder von unserem beeinflusst wurde. Wir sind alles, was geschieht, nachdem wir nicht mehr sind und was nicht geschähe, wenn wir nicht gekommen wären. ${ }^{384}$

Vor dem Abspann des Films wird das berühmte Zitat von Max Frisch eingeblendet: »Wir haben Arbeitskräfte gerufen, und es kamen Menschen «. Kontrastiert wird es mit dem Ende des Interviews mit Arbeitsminister Blank Mitte der 1960er Jahre, das wir aus dem Vorspann kennen. Wenn man noch einmal vor der Wahl stünde, würde man nur türkische Facharbeiter rufen, prophezeit Blank. Im Abspann wird

383 ŞAMDERELI (2011).

384 Ebd. 
dann ein noch nicht geklärtes Verortungsproblem gelöst: Mit einer Türkeikarte in der Hand geht Cenk auf seine Lehrerin zu. Er möchte, dass sie diese an die Europakarte anfügt, was auch geschieht. Sein Herkunftsfähnchen steckt sie in den Osten Anatoliens. Und Engin, der ihm zu Beginn des Films im Sportunterricht ein blaues Auge verpasst hatte und ihn aus seiner Fußballmannschaft ausschloss, da er kein richtiger Türke sei, gesteht, dass er ursprünglich auch aus Anatolien komme, nämlich aus dem Dorf Ovacık und nicht aus Istanbul, woraufhin die Lehrerin sein Fähnchen neben das von Cenk pinnt. ${ }^{385}$

Die Verschränkung von Zugehörigkeit und Verortung, von Karte, Ort und Verhalten ist wie in den Filmen zuvor auch in ALMANYA wesentlich. Identität ist stets dargestellt als ein Resultat aus Verhaltensweisen und einer gewissen Dauer, wie bei Wimmer und Sen ein Ergebnis aus Verhandlungen; eine bereits vollzogene Inkorporation. Weitaus wichtiger als die Antwort auf die Frage, was man denn sei, ist diejenige, aufgrund welcher Entscheidungen man wie und was lebt und welche Zugehörigkeit sich dadurch ausdrückt: Sowohl Hüseyin als auch Cenk haben am Ende ihren Platz gefunden. Vor allem diese spezifischen Ortsbezüge rücken im Laufe des Films das Leben und Geschichten in den Vordergrund und die Identitätsfrage in den Hintergrund. Doch sind die kulturellen Marker auch in diesem Film so sehr Teil der Akteure, dass bei der nächsten sozialen Irritation und Deplatzierung erneut verhandelt werden müsste, wohin sie gehören und wozu man selbst gehört. ${ }^{386}$ Im Unterschied

\section{Ebd.}

386 Als die Şamdereli-Schwestern gerade ihren Film fertigstellten, fand am 8. Oktober 2010 im Berliner Olympiastadion das EM-Qualifikationspiel zwischen Deutschland und der Türkei statt. Das Spiel gewann die deutsche Nationalmannschaft mit 3:0. Der türkeistämmige deutsche Spieler Mesut Özil wurde von den türkischen Fans so lange ausgepfiffen, bis er das zweite Tor schoss. Im Unterschied zu den türkischen und türkeistämmigen Fans konnte der damalige türkische Ministerpräsident Recep Tayyip Erdoğan Özils Entscheidung, für die deutsche Nationalmannschaft zu spielen, sehr gut verstehen. Er sah sich das Spiel mit Bundeskanzlerin Angela Merkel im Stadion an. Siehe hierzu: Die WeLt (2010): »Mulitkulti-Nationalelf. Mesut Özil. Ein Tor gegen die Pfiffe«. In: Die Welt, 09.10.2010, https://www.welt.de/sport/fussball/ article10167870/Mesut-Oezil-Ein-Tor-gegen-die-Pfiffe.html (16.07.2018). Acht Jahre später lassen sich Ilkay Gündoğan und Mesut Özil kurz vor Beginn der Fußballweltmeisterschaft in Russland gemeinsam dann mit dem türkischen Präsidenten Recep Tayyib Erdoğan ablichten. Als Reaktion werden beide bei den Testspielen gegen Österreich und Saudi-Arabien nun von den deutschen Fans ausgepfiffen. In den sozialen Medien und nach dem Ausscheiden der deutschen Nationalmannschaft auch in Presse, Funk und Fernsehen werden Stimmen laut, die fordern, dass vor allem Mesut Özil die deutsche Nationalmannschaft verlassen solle. Siehe hierzu: BERG, Daniel/MEYN, Jörn (2018):»Zu viele Attacken. Mesut Özil stehtvor dem DFB-Rücktritt«.In:Der Westen, 29.06.2018, https:/www.derwesten.de/sport/wm2018/mesut-oezil-ruecktritt-wm-2018-dfb-nationalmannschaft-id214715431.html (20.07.2018); WINKLER, Pierre (2018):»Nach Treffen mit Erdoğan. Özil und 
zu MeIne VerRüCKTE TÜRKISche Hochzeit und zu Die Fremde ist es hier die Praxis des Erzählens und Weitersprechens in der Erzählung, die identitätspolitischen Beleidigungen und Betrachtungen keinen Raum gibt. Denn die Lösung am Ende von Almanya lautet nicht, dass die Familienmitglieder Deutsch-Türken, Deutsche oder Türken sind, sondern vielmehr, dass alle zusammenleben. So trifft der Befund der Filmkritikerin Susan Vahabzadeh in ihrem Artikel Leit-

Gündoğan nie mehr für Deutschland? Wer das fordert, ist verlogen«. In: FocUS ONLINE, 15.05.2018, https://www.focus.de/sport/fussball/wm-2018/nach-treffen-mit-erdogan-oezil-und-guendoganraus-aus-der-nationalelf-warum-das-unfug-ist_id_8931334.html (20.07.2018). Özils zehn Jahre zuvor getroffene Entscheidung, für die deutsche und nicht für die türkische Nationalmannschaft zu spielen, wurde damals als Zeichen für Integration gelesen: Özil erhielt einen Monat nach dem Spiel gegen die Türkei den Bambi für Integration. Siehe hierzu: DIE ZEIT (2010): »Özil erhält >Bambi`-Preis für >Integration««. In: DIE ZEIT, 10.11.2010, https://www.zeit.de/sport-newsticker/ 2010/11/10/260045xml (16.07.2018). Der DFB hatte sich zwar noch kurz vor der WM in Russland hinter Özil und Gündoğan gestellt und man besuchte gemeinsam den deutschen Bundespräsidenten Frank-Walter Steinmeier. Doch entzündeten Oliver Bierhoff, der Teammanager der deutschen Nationalmannschaft, und Reinhard Grindel, der Präsident des DFB, kurz nach dem deutschen WM-Aus die Debatte um Özil von Neuem, indem sie seine Nominierung für die WM in Russland im Nachhinein in Frage stellten. Siehe hierzu: GARTENSCHLÄGER, Lars (2018): "Aufbau der neuen DFB-Elf. Auch am Umgang mit Mesut Özil wird Löw jetzt gemessen«. In: Die Welt, 04.07. 2018, https://www.welt.de/sport/fussball/wm-2018/article178695448/ DFB-Nationalmannschaft-Auch-am-Umgang-mit-Oezil-wird-Loew-nun-gemessen.html (16.07.2018). Die deutsch-türkische Kabarettistin Idil Baydar alias Jilet Ayşe reagierte auf die Debatte um Özil mit einem YouTube-Video und dem Hashtag \#Wir sind alle Özil\#bokumuye. Sie kritisierte das Foto mit Erdoğan als ein sehr hässliches und beschrieb die Reaktion der Deutschen darauf als eine absolute Undankbarkeit. An dem Tag, als der DFB Özil und Gündoğan so an den Pranger stellte, seien die Deutschen für sie gestorben und sie sei wieder zu einer Türkin geworden. Siehe hierzu: https://www.youtube.com/watch?v=rOMz2Iz1ZEE (16.07.2018). Özil selbst reagierte erst 60 Tage nach den Bildern mit Erdoğan und zog sich aus der deutschen Fußball-Nationalmannschaft zurück. In einem Schreiben, das er über Facebook und Instagram veröffentlichte, warf er dem DFB-Präsidenten Reinhard Grindel Rassismus vor und sagte, dass in seiner Brust zwei Herzen schlügen. Aufgrund der Passage aus Özils Erklärung, dass er immer nur dann als Deutscher wahrgenommen werde, wenn er Erfolg habe und gute Leistungen bringe, er aber gleich wieder zum Türken werde, wenn beides nicht mehr gegeben sei, stieß der deutsch-türkische Blogger Ali Can die MeTwo-Debatte in den Deutschland an, bei der es darum geht, im Internet die eigenen Diskriminierungserfahrungen zu schildern. Siehe hierzu: LAUcK, Dominik (2018): »\#MeTwo. Das Netz diskutiert Alltagsrassismus«. In: Tagesschau.de, https:// www.tagesschau.de/inland/me-two-101.html (12.09.2018). Siehe hierzu auch: INTERVIEW MIT ÖZKAN EZLI (2018): „Özil ist Opfer, aber auch Täter«. In: SüDDEUTSCHE ZEITUNG, 24.07.2018, https://www.sueddeutsche.de/kultur/oezil-rassismus-interview-1.4066925 (21.09.2018); PAPSCH, Gregor (2018): »Das Spiel mit der Integration. Özils Rücktritt und die Folgen«. In: SWR2 Forum, 24.07.2018, https://www.swr.de/swr2/programm/sendungen/swr2-forum/das-spiel-mit-der-integration-oezils-ruecktritt-und-die-folgen/-/id=660214/did=22127614/nid=660214/142umba/index. html (21.09.2018). 
kultur, sachte verbogen die identitätspolitisch fragile Konstellation des Films sehr gut. Denn ob Cenk jetzt Deutscher, Türke oder Deutsch-Türke ist, »wird in Almanya dann doch nicht geklärt«. Aber aufgrund der erzählten und erlebten Geschichte frage er im Film auch nicht mehr danach. Und wenn »er Glück hat, ist es ihm egal «. ${ }^{387}$ Identität ist $\mathrm{zu}$ einer kurzzeitigen Frage der Identifikation und gesellschaftlichen Platzierung geworden. ${ }^{388}$

Ausgangspunkt der Irritationen, die Fragen nach der eigenen Identität auslösen, sind in den Erzählungen der 2000er Jahre das Hinterfragen und Sichtbarmachen kultureller Regeln und Gesetze. Lösungen werden anhand von sozialer Kompatibilität geschaffen, von individuellen Entscheidungen, die für Integration stehen. Dabei handelt es sich um Prozesse, die das Innen zum Außen machen. Prägungen werden in diesem Prozess in Verhandlungen gebracht und im Idealfall in neue Formen überführt. Diese Prozesse des Herausstülpens bestimmen auch die Gestaltung der Folgen der Migration in vielen Filmen und Texten, die von der Komödie über skandalträchtige Bücher bis hin zu einfacher oder komplexer Literatur reichen. Dies gilt im Besonderen für die in der Forschung etwas stiefmütterlich behandelten Werke der Journalistinnen Hatice Akyün, Asli Sevindim und Dilek Güngör. ${ }^{389}$ Karin E. Yeşilada bezeichnet die Romane und Texte dieser Autorinnen wie Einmal Hans mit scharfer Soße. Leben in zwei Welten, Candlelight Döner. Geschichten über meine deutsch-türkische Familie und Das Geheimnis meiner türkischen Großmutter als »Chik-Lit alla Turca ${ }^{390}$ Auffällig ist in jedem Fall, dass der Aspekt des Selbstgesprächs sowohl in anspruchsvollen als auch weniger anspruchsvollen Erzählungen in unterschiedlichen Ausprägungen zum Tragen kommt. Während Hüseyin in AlmanYA am Ende mit sich selber spricht, mit seinem

387 VAHABZADEH, Susan (2011): "Leitkultur, sachte verbogen«. In: SÜDDEUTSCHE ZEITUNG, 11.03.2011, http://www.sueddeutsche.de/kultur/im-kino-almanya-leitkultur-sachte-verbogen1.1070351 (11.07.2018).

388 »Platzierung« ist auch tatsächlich ein Begriff, den Hartmut Esser Ende der 2000er Jahre in seine modifizierte Integrationstheorie neben den der »Kulturation« aufnimmt. Wenn die zentralen Aspekte einer »multiplen Inklusion« das Erlernen der Sprache, die Aufnahme sozialer Beziehungen, die emotionale Hinwendung zu einer Gruppe seien, sei mit diesen Prozessen gleichzeitig »die Besetzung einer Position« verbunden. Siehe hierzu: EsSER, Hartmut (2009): »Pluralisierung oder Assimilation? Effekte der multiplen Inklusion auf die Integration von Migranten «. In: Zeitschrift für Soziologie, Jg. 38, Heft 5, Oktober 2009, S. 358-378, hier S. 359.

389 AKYÜN (2005); SEVINDIM (2007); GÜNGÖR (2008).

390 YeŞıLAdA, Karen E. (2009): »'Nette Türkinnen von nebenan`. Die neue deutsch-türkische Harmlosigkeit als literarischer Trend«. In: Von der nationalen zur internationalen Literatur. Transkulturelle deutschsprachige Literatur und Kultur im Zeitalter globaler Migration, hg. v. Helmut Schmitz, Amsterdam: Rodopi, S. 117-142. 
vergangenen Ich, konfrontiert sich Umays Vater damit, wie ihn die anderen Türken vermeintlich sehen. Sie lassen Umays Vater nicht so handeln, wie er eigentlich handeln will. Dennoch ist seine Figur mit den Vätern der 1980er Jahre nicht $\mathrm{zu}$ vergleichen. Wir sehen ihn nicht wie Abdullah das Haus nicht verlassen, weil er »sein Gesicht verloren hat «. ${ }^{391}$ Denn das territoriale Verhältnis zu Deutschland ist bei Umays Vater und bei vielen anderen Akteuren in den 2000er Jahren ein ganz anderes als noch zwei Jahrzehnte zuvor. Die Differenz zwischen den 2000ern und den 1980ern lässt sich anschaulich an einer vermeintlichen Gegenfigur zu Kader veranschaulichen. Im Film EINMAL HANS MIT SCHARFER Sosse führt eine peinliche Begebenheit für Hatices Familie dazu, dass ihr Vater Ismail für eine bestimmte Zeit nicht mehr in die Moschee im niedersächsischen Salzgitter gehen mag. ${ }^{392}$ Was war passiert? Nachdem sich Ismail damit abgefunden hatte, dass seine Tochter Hatice weder einen Mann aus seinem Dorf Tepecik, noch einen Türken, noch einen Muslim ehelichen will, sondern den deutschen Hans, tauchen auf der Hochzeit ihrer Verwandten in Hamburg, auf der sie Hans endlich kennenlernen möchten, plötzlich »zwei deutsche Hans« als Hatices Zukünftige auf. Hatice musste einen falschen »Hans« mitbringen, weil der echte wegen eines sehr wichtigen Basketballturniers nicht kommen konnte, was wiederum Hatices Eltern niemals verstanden hätten. Doch kommt Stefan, der richtige Hans, dann doch noch auf die Hochzeit, und es wird klar, dass Hatice den Eltern etwas vorgespielt hat, zu dem sie sich gezwungen sah. Dieser Umstand spricht sich, allein nach Aussagen der Familie, in Salzgitter unter den Türken herum. ${ }^{393}$ Die Lösung dieses Problems ist vielsagend. Denn sowohl Hatice als auch ihr Vater führen Selbstgespräche, die jedoch keineswegs in einem für niemanden zugänglichen psychologischen Inneren vonstattengehen. Die Selbstgespräche finden in beiden Fällen mit kleinen fiktiven türkischen Dorfmännchen statt, die für ihr sichtbar gemachtes Gewissen im Film stehen. Beispielsweise tauchen diese Männchen immer mahnend auf, wenn Hatice einen kurzen Rock anzieht, während sie den über die Knie reichenden »Vaterrock« mit Applaus gutheißen. Als Hatice eine Nacht mit Stefan verbringt, wirft sie diese Männchen aus ihrer Wohnung. Nach dem Eklat auf der Hochzeit lässt sie die Männchen wieder herein und berät sich mit ihnen. Anschließend fährt sie zu ihrem Vater, um sich mit ihm zu versöhnen. Sie versichert ihm, nie wieder zu lügen. Davor hatten die Dorfmännchen Ismail erfolgreich von seiner Sturheit abgebracht. ${ }^{394}$ Wie bereits in Kadir Sözens ZEIT

391 Siehe hierzu: GRABE (1986).

392 AlaKuş (2013).

393 Ebd.

394 Siehe hierzu: Alakuş (2013). 
DER WÜNSCHE deutlich wurde, sind die kulturellen Marker Teil der Akteure und die Frage ist nicht, was die Kultur mit ihnen macht, sondern was sie mit der Kultur machen. Der Film beginnt mit einem gerahmten fiktiven Dorfbild in einer Wohnung in München, das immer wieder auftaucht und mit dem Dorf in der Türkei auch in die Realität übersetzt wird. Diese Konstellation begegnet uns auch in den Romanen Leyla, Tochter des Schmieds und Das Geheimnis meiner türkischen Großmutter, und sie ist daran $\mathrm{zu}$ erkennen, dass implizite Ordnungen und Gesetze explizit gemacht werden, indem das Private in ein öffentliches politisches Anliegen übersetzt wird. Nicht mehr das Brechen eingefahrener, mitunter orientalistischer kultureller Vorstellungen und Marker wie in der Literatur und den Filmen der 1990er Jahre und der Verweis auf eine gemeinsame Weltverbundenheit und Schwelle beschäftigen Film und Literatur in den 2000er Jahren. Es geht stattdessen darum, wie mit den kulturellen Markern in und durch die Geschichte der Migration in der Bundesrepublik von Türken, Deutschen, von Deutsch-Türken, in Arbeitsplätzen, zu Hause, durch Medien wie Zeitungen und Filmen, von Institutionen wie Schulen, Kulturvereinen, Moscheen, politischen Initiativen und nicht zuletzt durch Gesetze auf türkischer wie auf deutscher Seite umgegangen wird und wie sie durch das Narrativ „Was lebst Du?“ produziert werden.

\subsection{Kultur als Praxis oder die Produktion von Vielfalt}

»Das ist meine Sohn, meine Löwe!«, ruft Mehmet, Taxifahrer und Gastarbeiter der ersten Stunde, beim Frühstück mit seiner Familie in den Raum. Am Tisch sitzen seine Frau Hatice, seine Tochter Ayla und ihm gegenüber sein Sohn Ibo. Während seines Ausrufs faltet er eine türkischsprachige Zeitung zusammen, klatscht mit ihr auf seine linken Handfläche und meint zu seiner Frau: »Hatice, ruf mal die Türkei an und erzähl allen: Ibo steht bei uns in Hürriyet «. ${ }^{395}$ Auf der Rückseite der Zeitung lesen wir tatsächlich in großen Buchstaben: „Süper Star Ibo«. Der Untertitel des Artikels lautet »)Iki el dolusu döner için`. Döner dükkanının Reklam Spot'u bu cümleyle son buluyor« (»>Für zwei Hand voll Döner«. Mit diesem Satz endet der Spot für einen Dönerladen«). Diese Frühstücksszene stammt aus der Culture-Clash-Komödie Кевав Connection, die auch genau mit dem in Hür-

395 SAUl, Anno (2005): Kebab Connection, Spielfilm, Deutschland. Tatsächlich unterscheiden sich die Ausgaben von Hürriyet in der Türkei und in Deutschland. Seit 1965 erscheint die deutsche Ausgabe. Siehe hierzu: KARACABEy, Makfi (1996): Türkische Tageszeitungen in der BRD. Rolle, Einfluß, Funktionen. Eine Untersuchung zum Integrationsverständnis türkischer Tageszeitungen in der BRD, Univ.-Diss., Frankfurt a. M. 
riyet genannten Werbefilm beginnt, den der Protagonist des Films Ibo für den Dönerimbiss »King of Kebab« seines Onkels Ahmet gedreht hat. Zwei Kung-FuKämpfer duellieren sich darin um den letzten Döner im »King of Kebab«. Etwas später erfahren wir dann auch, dass Ibo den großen Wunsch hegt, Filmregisseur zu werden und den ersten deutschen Kung-Fu-Film zu drehen. Jedenfalls läuft der Spot in einem Kino in Hamburg-Altona, wo er so gut ankommt, dass nach dem Kinobesuch knapp hundert Leute Onkel Ahmets Imbiss aufsuchen. Obwohl er den Werbefilm eigentlich furchtbar findet, ist Ahmet so froh über diesen Zuspruch, dass er sich mit seinem Neffen in seinem Laden von einem Hürriyet-Reporter ablichten lässt. Davor hatte er seinen Neffen noch enterben wollen, weil der sein Geld für einen so schrecklichen Werbefilm verprasst hatte. Wie gesehen, ist auch Ibos Vater Mehmet sehr stolz. Er zwinkert Ibo am Frühstückstisch mit den Worten zu: »Die Tochter des Adanalı Burhan möchte dich kennenlernen «. ${ }^{396}$ Adana ist eine bekannte Metropole im Süden der Türkei. Ibo muss bei diesem Verkupplungsversuch schlucken. Der Vater bemerkt die Sorge seines Sohnes und fragt ihn etwas gereizt: »Was ist los mit Dir, he? «. Ibo nimmt seinen ganzen Mut zusammen und wendet sich an ein Familienmitglied nach dem anderen: »Baba, Du wirst Opa, Mama, Du wirst Oma und Du Ayla wirst Tante«. Ibo beendet die Aufzählung damit, dass seine deutsche Freundin Titzi schwanger sei. Seine Schwester ist begeistert von dieser frohen Botschaft; Mehmet ist entsetzt. Sein Teegläschen zerspringt ihm in der Hand, und er schreit seinen Sohn nun mit rotem Kopf an: «Was?! Was sage ich Dir seit Geburt von Dir?«. Ibo schaut ihn erschrocken und irritiert an und zieht unwissend die Schultern hoch. Mehmet wiederholt seine Frage und Ibo antwortet nun fragend: »Mach einen Taxischein?«. Auf diese Antwort gibt er Ibo eine Ohrfeige und wiederholt die Frage zum dritten Mal. Die nächste Szene ist eine Rückblende, in der Mehmet als junger Vater versucht, seinem achtjährigen Sohn die besagte Regel einzubläuen. Mit demselben Akzent und hochgerecktem Zeigefinger sagt Mehmet: „Du kannst mit einem deutschen Mädchen ausgehen, Du kannst mit einem deutschen Mädchen einschlafen. Du kannst mit einem deutschen Mädchen auch aufwachen. Aber du darfst sie niemals, niemals, niemals ... «. Dann folgt ein Schnitt, und wir sehen Ibo als kleinen Jungen auf dem Boden sitzend den Satz seines Vaters mit dem Wort »schwängern « abschließen. ${ }^{397}$ Knapp zwei Jahrzehnte später wird am Frühstückstisch klar, dass Ibo diese Regel, das Hausgesetz gebrochen hat. Mehmet wirft Ibo deshalb aus der Wohnung; er wird bis zum Happy End dieser Komödie nicht mehr bei seinen Eltern wohnen. 
So dramatisch diese Frühstückssequenz auch wirken mag, wird sie darstellerisch als Komödie aufgelöst. Dazu trägt nicht nur der Akzent des Vaters oder das zerbrochene Teeglas, nicht allein die Kosenamen der Protagonisten oder die Umwertung der ernst gemeinten Frage des Vaters durch Ibos Antwort bei, er solle einen Taxischein machen. Es sind vor allem die darstellerischen Fähigkeiten der Akteure und ihre Verhaltensweisen, die das Spielerische hervorkehren, ${ }^{398}$ später besonders im öffentlichen Raum. Übrigens ist auch Titzis Mutter keineswegs glücklich darüber, dass ihre Tochter von Ibo schwanger ist. »Hast Du jemals einen Türken einen Kinderwagen schieben sehen? «, fragt sie ihre Tochter. ${ }^{399}$ Titzi stellt Ibo dahingehend auf die Probe, der tatsächlich ein Problem damit hat, einen Kinderwagen durch die Öffentlichkeit zu schieben. Er fürchtet, andere Türken oder seine Freunde könnten ihn dabei sehen. Am Ende des Films wird er jedoch selbst einen futuristischen Kinderwagen für seine junge Familie bauen. ${ }^{400}$ Dadurch schon angekündigt, endet der Film gut, wie es sich für eine Komödie gehört. Die beschriebene Frühstückssequenz, die zwischen Komik und Konflikt pendelt, ist insgesamt zentral. Sie verschiebt nämlich das Thema der Selbstverwirklichung ihrer Akteure, Regisseur (Ibo) oder Theaterschauspielerin (Titzi) zu werden, hin $\mathrm{zu}$ familien- und integrationspolitischen Fragen, wobei Vater Mehmet eine herausragende Bedeutung zukommt. ${ }^{401}$ Als Titzi und Ibo Streit haben, ist es am Ende des Films interessanterweise Mehmet, der die beiden wieder zusammenführt, mitunter weil Titzi ihn an die stolzen und mutigen Frauen aus seinem türkischen Dorf erinnert. Er erklärt, anders gesagt, das oben genannte Hausgesetz für ungültig. Integrationswillig zeigt er öffentlich, dass er und seine Familie auch anders leben, nämlich die eigenen Regeln brechen können. In MEINE VERRÜCKTE TÜRKISCHE HocHZEIT ist es ebenfalls der Vater, der Aylin und Götz wieder zusammenbringt, obwohl nach islamischem Gesetz, so der Bruder Aylins, eine Muslima einen Nicht-Muslim nicht heiraten darf. ${ }^{402}$ Aylins Vater bricht eine kulturelle Regel, zumal er am Ende zu Götz auch sagt, dass es besser ist, wenn er kein Muslim wird. ${ }^{403}$

Als in Deutschland zu Beginn der 2000er Jahre die Integrationspolitik aufkommt, erleben besonders Culture-Clash-Komödien eine Konjunktur, in deren

398 Siehe hierzu: GREINER (2017): S. 31.

399 SaUl (2005).

400 Ebd.

401 Derselben Konstellation begegnen wir in der dritten Staffel von TÜRKISCH FÜR ANFÄNGER. Dort wird Lena im Verlauf der drei Staffeln verantwortungsbewusst werden und eine mögliche Karriere als Mode-Redakteurin zugunsten des mit Cenk anstehenden Familienlebens hintanstellen. Siehe hierzu: DAĞTEKIN (2006-2009).

402 Siehe hierzu: Holtz (2005).

403 Siehe hierzu: Ebd. 
Zentrum die deutsch-türkische Ehe steht. Ein Jahr vor KeBAB ConNECTION und zwei Jahre vor MEINE vERRÜCKTE TÜRKISCHE HOCHZEIT läuft SüPERSEKS von Thorsten Wacker in den deutschen Kinos. Zwischen den Jahren 2006 und 2009 realisiert Bora Dağtekin die bereits mehrfach erwähnte Serie TÜRKISCH FÜR ANFÄNGER. 2008 legt Sinan Akkuş mit EvET, ICH WILL! eine Culture-Clash-Komödie vor, in der auch deutsch-türkische Homosexuelle zu den drei heiratswilligen Paaren gehören. 2013 folgen von Buket Alakuş die Komödie EINMAL HANS MIT SCHARFER Sosse und 300 WoRTE Deutsch von Züli Aladağ. ${ }^{404}$ Dass die Vielzahl deutsch-türkischer Eheschließungen im Film mit der Hochphase deutscher Integrationspolitik einhergeht, ist bemerkenswert. ${ }^{405}$

Die oben ausgeführten Definitionen von Komik haben verdeutlicht, dass besonders in postkolonialen Zusammenhängen eine ihrer zentralen Funktionen in der Destabilisierung von Machtverhältnissen liegt. ${ }^{406}$ Dafür ist die Frühstückssequenz in Кевав Connection ein Paradebeispiel: Die vom Vater aufgestellte Regel wird durch Titzis Schwangerschaft von seinem Sohn gebrochen, explizit und wird verhandelt. Entgegen der Mehrheitsgesellschaft steht hier der türkische Vater mit seinen Hausgesetzen. Dasselbe gilt für MEINE VERRÜCKTE TÜRKISCHE HochzeIT und Feridun Zaimoğlus Leyla. Eine bestimmte Lebensweise destabilisiert zunächst die Position des Vaters, des Regel aufstellenden Gesetzgebers. Im weiteren Verlauf von Кевав ConnEction werden sich Ibo, Titzi und Mehmet fast nur noch im öffentlichen Raum sehen und treffen, was für die Schlichtung des Konflikts und der Verhandlung neuer Regeln äußerst wichtig ist. ${ }^{407}$ In Filmen und Literatur der 1990er Jahre treffen wir die Eltern kaum auf Straßen, öffentlichen Plätzen oder in öffentlichen Einrichtungen. ${ }^{408}$ Interessanterweise fällt im Zusammenhang mit dieser neuen erzählerischen Bearbeitung und Rahmung der Folgen

404 ALADAğ, Züli (2013): 300 Worte Deutsch, Grünwald: sperl productions GmbH.

405 Eine Umfrage zu binationalen Ehen in Deutschland ergab 2013, dass sich die Anzahl deutsch-türkischer Ehen in den letzten Jahren verdoppelt habe. Insgesamt gab es in Deutschland 2,3 Millionen national gemischte Ehepaare und Deutsche heirateten am liebsten Türken. Allerdings dominieren weiterhin die rein deutschen oder rein türkischen Ehen mit jeweils über 85 Prozent der geschlossenen Ehen. Siehe hierzu: Kul, Ismail (2014): »Zahl der deutsch-türkischen Ehen fast verdoppelt«. In: Deutsch-Türkisches Journal, 07.02.2014, https://dtj-online.de/ mischehen-deutsche-tuerken-interview-sarah-carol-19712 (09.07.2018). Siehe hierzu auch: Focus ONLINE (2015): »2,3 Millionen Ausländer-Paare«. In: FocUS ONLINE, 19.02.2015, https://www. focus.de/politik/deutschland/bundesamt-fuer-statistik-deutsche-heiraten-am-liebsten-deutsche-oder-tuerken_id_4487355.html (09.07.2018).

406 Siehe hierzu: GökTÜRK (2019): S. 59f.

407 SAUl (2005).

408 Siehe hierzu: ÖzdAMAR (1992); ZAImoğLU (1995); ARSLAN (1997); AKIN (1998); YAvUZ (1998). 
der Migration auch das Aufkommen des Merkmals »Migrationshintergrund «. ${ }^{409}$ Dieser erzählerische Wandel in den 2000er Jahren hängt mit einer Praxis der Verortung zusammen: Die Akteure gehören zu Deutschland, was natürlich auch eine ordnungsstabilisierende Funktion hat. Der Einsatz von Komik kann im Gegensatz zur Destabilisierung von Machtverhältnissen und von Grenzüberschreitungen ebenfalls die Ordnung stärken. Dass Komik, wie gesehen, vorausgesetzte, implizite Regeln explizit macht und verletzt, hält auch Umberto Eco fest: »the broken frame must be presupposed, but never spelled out «. ${ }^{410}$ In diesem Zusammenhang spitzt Uwe Wirth Ecos Gedanken zu, dass die Komik gesellschaftliche Regeln überhaupt erst sichtbar macht. ${ }^{411}$ Letztlich handelt es sich dabei um einen Mechanismus, der die Ordnung für die Dauer des Konflikts und des Lachens aussetzt, sie aber keineswegs insgesamt aufhebt. Die Ordnung ist in unseren Beispielen die Integration. Sie zeigt, wie man zur neuen Gemeinschaft dazugehören kann - in КевAв Connection verdeutlicht dies der Seitenwechsel des Vaters. ${ }^{412}$ Integration führt in einen Prozess der Aufhebung des Regelbruchs, den wir in allen genannten Komödien der 2000er Jahre beobachten können. In MEINE VERRÜCKTE TÜRKISCHE HochzEIT werden Beleidigungen und Diskriminierungen mit der Hochzeit zwischen Ayten und Götz für eine kurze Zeit aufgehoben. Und in TÜRKISCH FüR ANFÄNGER werden alle diskriminierenden Aussagen von und gegen Machotürken, von und gegen fanatische Muslime, linken wie Nazideutschen und Griechen immer wieder durch schlichtende Praktiken und nicht explizit verbal aufgehoben. Wenn Lena sich in den ersten beiden Folgen der Serie über die strenge Religiosität Yağmurs lustig macht, sind sie in der dritten Folge bereits schon fast Freundinnen. Vermittelt durch Lenas Mutter Doris, nimmt Lena Yağmur mit in die Diskothek und Yağmur geht, weil Lena es will, ohne ihr dies explizit zu sagen. ${ }^{413}$

In den Programmen der deutsch-türkischen Kabarettisten Şinasi Dikmen und Muhsin Omurca ging es Mitte bis Ende der 1980er Jahre darum, multikulturell gesinnte Deutsche über nicht multikulturell gesinnte, oder gar ausländerfeindli-

409 Das Merkmal Migrationshintergrund wird seit 2005 im Mikrozensus erfasst. Dieses bezieht sich auf Menschen, deren Eltern oder Großeltern nach 1949 in die Bundesrepublik eingewandert sind. Während in den 1980er und besonders in den 1990er Jahren die zweite Migranten-Generation im Fokus von wissenschaftlicher Forschung, Film und Literatur stand, findet mit dem Begriff des Migrationshintergrunds ein »Wechsel der Beleuchtung « statt, der sich über eine Generation hinweg auf die Geschichte einer Familie erstreckt. Siehe PFALLER, Robert (2015): Wofür es sich zu leben lohnt, Frankfurt a. M.: Fischer, S. 15.

410 Zitiert nach: WIRTH (2019): S. 27.

411 Ebd.

412 In MEINE VERRÜCKTE TÜRKISCHE HOCHZEIT lachen erst ganz am Ende alle gemeinsam.Siehe hierzu: HoLTz (2005).

413 Siehe hierzu: DAĞTEKIN (2006-2009). 
che Deutsche zum Lachen zu bringen. Im Lauf der 2000er Jahre werden die Gegenstände des Lachens weitaus komplexer. Das liegt zum einen daran, dass nun Integration mit komödiantischen Mitteln bearbeitet wird. Zum anderen machen nicht nur Comedy und Kabarett implizite Regeln und Gesetze sichtbar, sondern auch Publikationen wie die von Ayan Hirsi Ali, Seyran Ateş und nicht zuletzt von Necla Kelek, die in der Folge des 11. September 2001 allesamt nachhaltig Integrationsdebatten entfacht haben. Beispielsweise haben Verlag und Autorin das Buch Die fremde Braut mit den Worten beworben, dass darin ein lang gehütetes Gesetz und Geheimnis der türkischen Familien in Deutschland explizit und öffentlich gemacht werde: ${ }^{414}$ türkische Bräute aus der Türkei zu holen (»Importbräute«), um sich auf keinen Fall nicht mit der einheimischen deutschen Bevölkerung zu vermischen. ${ }^{415}$ Auch Mehmet aus KeBAB Connection hatte für seinen Sohn eine arrangierte Ehe mit der Tochter eines Kollegen aus Adana im Sinn. ${ }^{416}$ Würde Ibo am Ende doch noch eine Türkin heiraten oder Aylin am Ende von MEINE VERRÜCKTE TÜRKISCHE HocHzEIT statt Götz den Türken Tarkan, dann wären beide Filme Tragödien. Da aber die türkischen Väter im Unterschied zu DIE FREMDE hier die richtigen Entscheidungen treffen, was sie gemäß der Logik der Filme auch aus freien Stücken tun, ist das Ende ein gutes, integratives. Das Gefühl, alles könnte noch gut werden, stellt sich nach der Lektüre von Keleks Buch Die fremde Braut nicht ein. Denn im Unterschied zu den genannten Filmemachern traut sie der türkischen Elterngeneration keinen Gesinnungswandel zu. Für Kelek sind die Migranten der ersten Stunde Türken geblieben und dann Muslime geworden. ${ }^{417} \mathrm{Zu}$ ihrem Alltag gehören Zwangsverehelichungen und arrangierte Ehen, die man vor dem Hintergrund der eigenen demokratischen Verfassung und der Menschenrechte eigentlich verbieten müsste. ${ }^{418}$ Ihr geht es darum, das türkisch-muslimische Patriarchat durch den Staat in Deutschland zu unterbinden und zu brechen. Das

414 Siehe hierzu: https://www.kiwi-verlag.de/buch/die-fremde-braut/978-3-462-03469-1/ (20.07.2018). 415 KELEK (2005): S. 11f.

416 Die Unterscheidung zwischen arrangierter Ehe und Zwangsehe wird in den 2000er Jahren vor allem als politischer Konflikt ausgetragen. Die meisten Islamkritiker machen überhaupt keinen Unterschied, weil beide Formen dem Willen der Eltern nachkämen und der zweiten Migranten-Generation jede Möglichkeit der Selbstbestimmung nähmen. Nach einer Studie von Gaby Straßburger schließen sich familienorientierte Eheschließungen und Individualisierungsprozesse jedoch keineswegs aus. Töchter, die die Meinung ihrer Eltern einholen, seien nicht weniger autonom als ihre deutschen Altersgenossen. Siehe hierzu: STRASSBuRgER, Gaby (2003): Heiratsverhalten und Partnerwahl im Einwanderungskontext. Eheschließungen der zweiten Migrantengeneration türkischer Herkunft, Baden-Baden: Ergon. Hilal Sezgin bestätigt Straßburgers Ergebnisse in: SEzgIN, Hilal (2006): Typisch Türkin? Portrait einer neuen Generation, Freiburg i. Br.: Herder, S. 44.

417 Ebd., S. 275.

418 Ebd., S. 237. 
Verhältnis von Staat, Gesetz und Patriarchat steht auch im Zentrum von Feridun Zaimoğlus Roman Leyla, der in der Kritik als Epos der türkischen Migration nach Deutschland und als der Roman zur Debatte im Frühjahr 2006 gefeiert wurde; gewissermaßen das literarische Pendant zu Keleks Die fremde Braut.

Obwohl Zaimoğlus Roman weder in der aktuellen Gegenwart noch in Deutschland, sondern in der südtürkischen Provinz von Malatya und in Istanbul in den 1950er und 1960er Jahren spielt, erzählt er keine »alte Geschichte«, führt der Prolog aus. ${ }^{419}$ Mit einer deutlichen Verbindung von Vergangenheit und Gegenwart der Migration in die Bundesrepublik, wie wir sie aus Schäubles Abschlussrede der Islam Konferenz 2009 und den bislang analysierten Filmen der 2000er Jahre kennen, leitet auch Feridun Zaimoǧlu seinen Roman Leyla ein, der, so heißt es im Prolog, seinen Autor im deutschen Kulturbetrieb habe ankommen lassen. ${ }^{420}$ Knapp zwei Jahre zuvor hatte der Literaturkritiker Hubert Winkels über Zwölf Gramm Glück noch geschrieben, dass Zaimoğlu mit den zwölf enthaltenen Erzählungen den »Höhenkamm der Literatur erreicht, ja, zumindest touchiert« habe. ${ }^{421}$

Ich werde zeigen, dass ein Ankommen wie in KeBAB Connection und Die fremde Braut damit zusammenhängt, dass beide verborgene, implizite Ordnungen sichtbar machen. Diese Formen der Visibilisierung sind die Träger und Garanten für ein Leben zwischen Moschee und Freiheit. Nur der kritische Muslim ist ein moderater Muslim, der als integriert gilt. ${ }^{422}$ Für den amerikanischen Soziologen und Politologen Jeff Weintraub ist der Prozess des Sichtbarmachens eine der zentralen Formen der Veröffentlichung und des öffentlich-Machens in westlichen Zivilgesellschaften überhaupt. ${ }^{423}$ Diesen Prozess und den Zusammenhang von Subjekt und Kultur verhandelt auch Zaimoğlus Roman. Auch hier werden im Privaten und im Haus geltende Regeln und ihr Brüche sichtbar gemacht. Es geht darum, sich wie ein Türke zu verhalten, um am Ende doch keiner zu sein, weil sich in den Erzählungen immer wieder andere Handlungsmöglichkeiten ergeben. Interessant ist außerdem, dass im Sommer 2006 eine Germanistin eine sechs Wochen andauernde Plagiatsaffäre lostrat, bei der es darum ging, ob Zaimoğlu von Özdamars Karawanserei-Ro-

419 ZAIMOğLU (2007): S. 7.

420 Siehe hierzu: LÜDKE, Martin (2006): »Nicht ohne meine Tochter zu schlagen«. In: DIE ZEIT, 16.03.2006, Literaturbeilage, https://www.zeit.de/2006/12/L-Zaimoglu-TAB (09.07.2018). Siehe auch: VoIGT, Claudia (2006): „Wörter wie Silberringe«. In: DER SPIEGEL, 13/2006, S. 165-166, hier S. 165.

421 Winkels, Hubert (2004): »Der Dreck und das Heilige. Feridun Zaimoğlu will ein richtiger Dichter werden«. In: DIE ZEIT, 25.03.2004, https://www.zeit.de/2004/14/L-Zaimoglu (12.07.2018). 422 Vgl. hierzu: TURNER (2007).

423 Weintraub (1999): S. 5. 
man abgeschrieben hat. ${ }^{424}$ Die Affäre selbst verlief und versandete im Konjunktiv, ${ }^{425}$ zumal Özdamar auch keine Anklage erhob. ${ }^{426}$ Mit Ausnahme einiger frappierender Ähnlichkeiten sind beide Romane besonders hinsichtlich der Verhandlung von Integration und Migration vollkommen verschieden. Während in Das Leben ist eine Karawanserei, wie in vielen Produktionen der 1990er Jahre, etwa die Schwelle dominiert, stehen in Zaimoğlus Roman spezifische Orte wie Wohnung, Haus und Klassenzimmer sowie die mit ihnen verbundenen Regeln und Gesetze im Vordergrund.

In Leyla erzählt Zaimoǧlu die Geschichte einer Frau aus der südanatolischen Provinz Malatya und Istanbul, deren erzählte Zeit biografisch von deren 5. bis 19. Lebensjahr und zeithistorisch vom Koreakrieg (1950-1953) bis zur ersten Hochphase der Migration der Türken Mitte der 1960er Jahre nach Deutschland reicht. Am Ende des Romans migriert Leyla mit ihrem Sohn und ihrer Schwiegermutter zu ihrem Mann, dem Gastarbeiter Metin, im Kontext der Familienzusammenführung nach Deutschland. In dieser Geschichte erleben wir Leyla zunächst als kleines Mädchen beim Spiel auf der Straße, in Gärten und zu Hause ${ }^{427}$, etwas später in der Schule $\mathrm{e}^{428}$. Bereits auf den ersten Seiten zeigt sich, dass Leyla nicht nur sehr aktiv ist - sie holt etwa den Vater aus dem Kaffeehaus nach Hause oder geht von zu Hause in die Schule, ins Kino oder zu ihrer Freundin Fulya - , sondern auch ihre Umgebung genau beobachtet. In Özdamars Roman hingegen wissen wir nie, wo die Protagonistin hingeht, wenn sie die Wohnung verlässt; in Leyla sind Gehen, Sehen und Ankommen spezifische Koordinaten der Erzählung. Später erfahren wir von Leylas erster Menstruation und dass sie sich daraufhin von Männern fernhalten soll. ${ }^{429}$ Kurz darauf wird der »Mann meiner Mutter«, ihr Vater, wegen Drogenhandels inhaftiert. In der Mitte des Romans verlebt Leyla ihre schönsten Tage auf einem längeren Schulausflug bei den Eltern ihrer kurdischen Freundin Manolya, die Großgrundbesitzer in einem Dorf am Euphrat sind. ${ }^{430}$ Kurze Zeit

424 Siehe hierzu: WeIDERMANN, Volker (2006b): »Abgeschrieben? Streit um den Roman `Leyla««. In: FRANKFURTER ALLGEMEINE ZEITUNG, 01.06.2006, http://www.faz.net/aktuell/feuilleton/ buecher/abgeschrieben-streit-um-den-roman-leyla-oezdamar-gegen-zaimoglu-1327374.html (20.07.2018).

425 Siehe hierzu: Pflitsch, Andreas (2009): »Fiktive Migration und migrierende Fiktion. Zu den Lebensgeschichten von Emine, Leyla und Gül«. In: Wider den Kulturenzwang. Migration, Kulturalisierung und Weltliteratur, Bielefeld: transcript, S. 231-252, hier S. 231.

426 Siehehierzu: BREITFELD, Arndt(2006): „Özdamar dementiert Plagiatsvorwurf «.In:DERSPIEGEL, http://www.spiegel.de/kultur/literatur/zaimoglu-roman-oezdamar-dementiert-plagiatsvorwurfa-420334.html (30.07.2018).

427 ZAimoğLU (2006): S. 18f.

428 Ebd., S. 99.

429 Ebd., S. 113.

430 Ebd., S. 220-254. 
darauf bricht Leylas Familie nach Istanbul auf, weil Leylas ältere Brüder dort studieren wollen und Leylas Vater Arbeit sucht. Zunächst wohnen sie bei einer Großtante. In Istanbul lernt Leyla ihren zukünftigen Ehemann Metin kennen. Ihr älterer Bruder Djengis wird das Studium abbrechen, auf das Drängen seines Vaters heiraten. Und der Vater selbst wird ein Geschäft eröffnen und nach einer Weile in ein eigenes Haus mit der Familie ziehen. Da aber auch Halids neues Geschäft, wie zuvor das alte im Dorf, die Familie in den Ruin führt, ${ }^{431}$ nötigt das Familienoberhaupt seine zwei älteren Töchter, Yasemin und Selda, als Gastarbeiterinnen nach Deutschland zu gehen und für die Familie Geld zu verdienen. ${ }^{432} \mathrm{Zu}$ dieser Zeit lebt Leyla bereits bei der Familie ihres Ehemanns, der aus zwei Gründen ebenfalls als Gastarbeiter nach Deutschland gehen will: Zum einen erhält er ein Stipendium für ein Praktikum bei einer Ledergerberei in Deutschland; zum anderen empfindet er das Leben in der Türkei als »Hölle«. Der entscheidende Unterschied zwischen beiden Ländern liegt für Metin nicht einfach im Wohlstand, sondern darin, dass in Deutschland die Regeln wichtig seien: "Jeder hält sich an die Regeln. Das ist der Unterschied. « ${ }^{433}$ Während Metins erstem Jahr in Deutschland bekommt Leyla ihr gemeinsames Kind. Ihre Schwestern schicken ihr Geschenke. Sie wohnen in Deutschland in einem Frauenwohnheim und möchten bald wieder in die Türkei, weil sie finden, sie seien »nicht dafür gemacht, mit Männern am Fließband zu arbeiten «. ${ }^{434}$ Kurze Zeit darauf stirbt das Familienoberhaupt Halid, und Leyla empfindet keine Trauer. Sie »weiß nur, dass sich unsere Sippe zerstreuen wird«. Für die älteste Tochter Yasemin ist der Todestag des Vaters ein Segen, denn an diesem Tag habe sich der »Teufel sein Hinterbein [gebrochen] «. ${ }^{435}$ Gemeinsam mit

431 Ebd., S. 443.

432 Als in Kadir Sözens Film ZEIT DER WÜNSCHE aufgrund der zweiten Migrationswelle kaum noch Menschen im Dorf leben und Yaşar mit seinem Dorfcafé und dem Krämerladen kaum noch Geld verdient, nötigt seine Mutter ihn dazu, seine Frau nach Deutschland zum Arbeiten und Geldverdienen zu schicken. Zu dieser Zeit werden in der Bundesrepublik für feinmotorische Arbeiten beispielsweise im Bereich der Elektronik vor allem Frauen als Arbeitskräfte gesucht. In dieser Zeit, Mitte der 1960er Jahre, kam auch Emine Sevgi Özdamar nach Berlin. Dort arbeitete sie bei Telefunken und fertigte Radiolampen. In ZEIT DER WÜNSCHE arbeitet Melike in einer Pralinenfabrik in Köln. Siehe hierzu: SözEN (2005). JÄHNER, Harald (2012): »Wörter ziehen uns voran. Laudatio auf Emine Sevgi Özdamar, der am Sonnabend der Alice-Salomon-Poetik-Preis verliehen wurde«. In: FRANKFURTER RUNDSCHAU, 15.01.2012, http://www.fr.de/kultur/ehrung-woerter-ziehen-uns-voran-a-871973 (13.09.2018). Siehe zu Gastarbeiterinnen in der Bundesrepublik zwischen den 1950er und 1970er Jahren: MATTES, Monika (2005): `Gastarbeiterinnen in der Bundesrepublik, Frankfurt a. M.: Campus.

433 Ebd., S. 446f. Hüseyin aus Almanya ist vor allem von der Disziplin der Deutschen angetan. Davon ist in der Literatur jener Zeit kaum die Rede. Siehe: ŞAMDERELI (2011).

434 ZAIMOğLU (2006): S. 516.

435 Ebd., S. 520. 
ihrem Sohn und ihrer Mutter reist Leyla im Rahmen der Familienzusammenführung nach Deutschland zu ihrem Mann Metin. Der Roman endet mit ihrer Ankunft am Münchener Hauptbahnhof. ${ }^{436}$

So linear der Plot hier auch wirken mag, ist die Geschichte ästhetisch ganz anders gestaltet. Leylas Entschluss, mit Mutter und Kind nach Deutschland zu gehen, ist für den Leser eher überraschend als erwartbar. Denn bis zum Tod des Vaters sprechen weder Metin noch Leyla über eine mögliche Familienzusammenführung. ${ }^{437}$ Erst der Tod des Vaters lässt die Akteurin gewissermaßen frei. Mitunter ist es auch Halids Figur, seine Aussagen, seine Verhaltensweisen und Repräsentanz, die diese Geschichte »aus der alten Zeit«, wie es im Prolog heißt, aktuell machen.

Um Bedeutung und Vorrangstellung der Lebensweisen in diesem Roman zu ergründen, lohnt schon, sich die Wirkung und die Verwendung des Begriffs »Gesetz« näher anzusehen. Schon auf den ersten Seiten des Romans beschwert sich Halid, dass die »Hunderasse«, so bezeichnet er seine Familie, sich nicht um sein »Hausgesetz« schere, sobald er das Haus verlasse. ${ }^{438}$ Eine andere Situation: Halid versucht, Orangen in der Stadt zu verkaufen. Hasan Bey kann sich selbst nach der Verkostung einer Orange nicht zum Kauf entschließen, verlangt jedoch von Halid, er solle ihm zwei Orangen als Geschenk vor die Haustür legen. Halid ist brüskiert, weil er kein Geschäft machen kann, und will Hasan keine Orangen schenken. Hasan entgegnet darauf, dass er vielleicht ein »Bergfürst« sei, aber kein »Geschäftsmann«, und er sich jetzt mit seinen »zwei Lustknaben«, die die Orangen von Haus zu Haus tragen, verziehen solle. Hasan Bey hat damit nicht das »Hausgesetz«, sondern das »Ehrengesetz« verletzt, weshalb Halid außer sich vor Wut nun »mit seinen Kriegerreiterstiefeln [Hasan Beys] Tür eintreten« will. Die Orangen-Träger halten ihn davon ab; wenn er den »Hausfrieden dieses Gottlosen « breche, hetze der doch die Gendarmerie auf sie. ${ }^{439}$ Die Wiederherstellung der Ehre würde also mit einem anderen Gesetz kollidieren, und so entlädt Halid seine aufgestaute Wut zu Hause, indem er Frau und Kinder schlägt, weil sie sich angeblich nicht an sein Hausgesetz halten. Nachdem er sich derart abreagiert hat, schlägt er den Koran auf und verkündet:

436 Ebd., S. 525.

437 In Almanya stellt Hüseyin den Antrag auf Familienzusammenführung, ohne seine Frau oder seine Kinder zu fragen oder sie überhaupt davon in Kenntnis zu setzen. Sie erfahren davon erst, als Hüseyin die Bewilligung seines Antrags erhält. Siehe: ŞAMDERELI (2011).

438 Ebd., S. 12.

439 Ebd., S. $28 f$. 
Hier steht es, schreit er, ihr seid meine Untergebenen. Der Schlüssel zum Paradies ist in meinen Händen, ihr Hundebrut! Nicht ich habe die Regeln aufgestellt, sondern der Erhabene, dessen Namen ihr nicht in den Mund nehmen dürft, so schmutzig seid ihr [...] Hier, an dieser Stelle, lese ich: Ihr Frauen tut den Feinden Gottes einen großen Gefallen, wenn ihr eure Vorderseiten von fremden Männern aufreißen laßt. Der Vater ist der Herr des Weibes und der Kinder ... Der Vater ist euer Fürst! Der Vater ist euer Bollwerk gegen den Bolschewisten! [...] Das steht alles im Koran, ihr Dämonenbrut! ${ }^{440}$

Frau und Kinder seien selbst dann noch sein »Besitz«, wenn sie verheiratet und aus dem Haus wären. ${ }^{441}$ So tyrannisch Halid auch im eigenen Haus herrscht, so wenig wirkt sein »Hausgesetz« im öffentlichen Raum, wie bereits die Szene mit Hasan zum »Ehrengesetz« gezeigt hat. Als er seine jüngste Tochter Leyla nicht mehr in die Schule gehen lässt, damit sie die Hausarbeit übernimmt und ihm in seinem Geschäft hilft, greifen Rektor, Lehrer und Gendarmerie ein: Mit Staatsgewalt zwingen sie ihn in seiner Wohnung, die Tochter wieder zur Schule zu schicken. Dabei droht ihm der Gendarm, dass er ihm im Falle einer Weigerung am Bahnhof vor Augen aller verhaften würde. ${ }^{442}$ Als Halid seiner Tochter später einen Schulausflug ins südliche Kurdengebiet am Euphrat verbieten will, klärt ihn der Rektor der Schule auf, dass das »Staatsrecht das Verwandtschaftsrecht bricht «; wenn Halid sich dagegen stelle, könne er im Gefängnis landen. ${ }^{443}$ Halid entgegnet wütend, dass Rektor und Kommissar eine »Erpresserbande« seien und ihm das Kind wegnähmen. ${ }^{444}$

Bis zu dieser Stelle in der Mitte des Romans war mehrfach von »Hausgesetz«, »Ehrengesetz« und »Staatsgesetz« sowie deren negativen wie positiven Kon-

440 ZAIMOğLU (2006): S. 82.

441 Yeter aus Auf DER ANDEREN SeIte hat einmal keine Lust auf Oralverkehr mit Ali und meint genervt, sie sei nicht sein Besitz. »Natürlich bist du mein Besitz«, antwortet Ali, »ich versorge dich doch «. Siehe hierzu: AkIN (2007). Neben »der Mann meiner Mutter« nennt Leyla ihren Vater auch »Nährvater«. Siehe hierzu: ZAIMoğLU (2006): S. 227 u. S. 262.

442 Siehe hierzu: ZaimoğLU (2006): S. $98 f$.

443 In vielen Beiträgen zur Integrationsdebatte der 2000er Jahre werden Fälle genannt, in denen Eltern ihren Töchtern aus religiösen Gründen nicht erlauben, am Schwimmunterricht in der Schule oder an Klassenfahrten teilzunehmen. Im Unterschied zu den 1980er und 1990er Jahren stehen die Wünsche der Eltern nun im Konflikt mit dem Grundgesetz. Siehe hierzu für viele: PReUSS (2001): S. 482. Auch Kelek beleuchtet im Kontext dieser Debatte ihre Vergangenheit in der Bundesrepublik. Zu Hause sei ein Gefängnis gewesen, und die deutsche Schule sei zu ihrem Leben geworden. Sie lernte innerhalb von einem halben Jahr Deutsch. Doch kümmerte es aus ihrer Rückschau die deutschen Lehrer auf dem Gymnasium nicht, »dass ich an keiner Aktivität teilnahm und dass meine Eltern nie zum Elternabend erschienen. Mein Ausschluss vom Sportund Schwimmunterricht wurde als individuelle Entscheidung akzeptiert. Nie hat mich jemand gefragt, was ich selbst denn wollte«. Siehe hierzu: KELEK (2005): S. 121.

444 Ebd., S. 214. 
notationen die Rede. Doch es tauchen noch zwei weitere normative Dimensionen auf: ${ }^{445}$ das Gesetz, an das sich die Kurden am Euphrat halten und das vom Großgrundbesitzer, dem Ağa, stammt. Die Bauern dort »leben von der Gnade des Fürsten, sie berufen sich auf eherne Gesetze«. Der Vater von Leylas Freundin Manolya hat einen »unsichtbaren Kreis um das Dorf gezogen und wer unberechtigterweise hinaustritt, [...] gilt als Gesetzesbrecher«. Doch im großen Unterschied zu Leylas »Nährvater« lieben die Bauern ihren Ağa. »Er steckt in einem westlichen Anzug, ich hätte erwartet, daß er auf seinem eigenen Grund und Boden Traditionstracht trüge. ${ }^{446}$ Leylas Vater argumentierte hingegen ständig mit der Tradition. Ein letztes Mal ist explizit von Regeln und Gesetzen die Rede, als Metin seiner Frau Leyla von Deutschland vorschwärmt. Der Unterschied zwischen Deutschland und der Türkei liegt nicht im technischen Fortschritt, sondern darin, dass die Deutschen nach öffentlichen für alle verbindlichen Regeln leben. Das Leben in Istanbul folge hingegen keiner solch allgemeinen Ordnung. ${ }^{447}$ Das Leben Halids ist allein ein Beispiel hierfür.

Die Regel- und Gesetzestreue der Deutschen wird in den Texten und Filmen der 1960er und 1970er Jahre nicht reflektiert. In Bekir Yıldız' autobiografischem Gastarbeiterroman Türkler Almanyada von 1966, in Türkan Şorays Film DöNüş (RÜCKKEHR) von 1972 und in Aras Örens Poem Was will Niyazi in der Naunynstraße von 1973 verspricht Deutschland zwar zivilisatorischen Fortschritt, Entwicklung und Solidarität, birgt aber auch die Gefahren des Konsums und der Verführung. So führen Autoliebe bzw. eine regelrechte Autosucht der türkischen Gastarbeiter bei Yildız und Şoray zum Tod der Akteure. ${ }^{448}$ Dass die Deutschen nach ihren Regeln lebten, was besonders nachahmenswert sei, ist in den 1960er und 1970er Jahren wenig verbreitet. Hinzu kommt, dass der Ağa, der Großgrundbesitzer, in Film und Literatur der 1960er und 1970er Jahre für ein unterdrückerisches, amoralisches und kapitalistisches System steht. ${ }^{449}$ Das Verhältnis der Akteure zu Ordnungen ist im Roman Leyla anders und vielfältiger als in Büchern und Filmen der

445 Ähnlich dominant ist die deutsche Verfassung in Keleks Die fremde Braut. Siehe hierzu: KeLEK (2005): S. 21, 28, 264, 271 u. 281f. Im Zentrum steht dabei der Gedanke, dass die Verfassung nicht einfach befolgt werden solle, sondern verinnerlicht werden müsse. Siehe hierzu: KeLEK (2005): S. 16.

446 ZAIMoĞLU (2006): S. 227.

447 Ebd., S. 446.

448 Siehe hierzu: YILDIZ, Bekir (1966): Türkler Almanyada, Istanbul: Selbstverlag. ŞoRAY, Türkan (1972): Dönüş, Istanbul: Akün Film. ÖREN, Aras (1973): Was will Niyazi in der Naunynstraße, Berlin: Rotbuch.

449 Siehe hierzu auch: BAYKURT, Fakir (1966): Die Rache der Schlangen, Stuttgart: Europäischer Buchklub. Die türkische Originalversion dieses Romans erschien 1958. BAYKURT, Fatih (2016): Yılanlarnn Öcü, Istanbul: Literatür Yayıncllık. 
1960er und 1970er Jahre. Erst in der Abfolge und in der Logik des Romans von Zaimoǧlu, von Haus- und Ehrengesetz über das Gesetz des Großgrundbesitzers bis zum Staatsgesetz, wird Metins positive Assoziation mit Menschen, die nach Regeln leben, plausibel. Attraktiv wird die Regeltreue der Deutschen in Leyla außerdem, weil kaum eine Regel oder ein Gesetz wirklich erklärt oder ausformuliert wird. Von den immer wieder genannten »Hausgesetzen« erfahren wir nur indirekt, wenn es etwa heißt, es zeuge »von Hochmut, wenn eine Frau gepreßte Kleider trägt «. ${ }^{450}$ An anderer Stelle wird Leyla als kleines Mädchen bestraft, weil sie keine Unterhose trägt. Ungläubig fragt sie, ob Unterhosen tragen ein Gesetz sei. ${ }^{451}$ Leylas Mutter dreht immer die Spiegel im Haus um, wenn ein Gast kommt. Denn ein »schlechter Mensch, der in den Spiegel des Hauses schaut, hinterläßt den Abdruck seiner Bosheit, und das Böse strahlt auf die Hausbewohner und verleitet sie zur Niedertracht «. ${ }^{452}$ Was sich wie eine abergläubische Tradition anhört, wird nicht als ein Aberglaube verhandelt, sondern als Gesetz begriffen und von Zaimoğlu auch so dargestellt. Von den staatlichen Gesetzen erfahren wir ebenso wenig, nur dass die Ordnung des öffentlichen Raums auch das Privatleben bestimmt. Wenn auf der einen Seite Schule und Gendarmerie den Bildungsauftrag des Staates gegen Halids »Hausgesetz« durchsetzen, lesen wir später, wie auf der anderen Seite der Polizeichef der Provinzstadt gemeinsam mit Halid im Drogenhandel aktiv ist. ${ }^{453}$ Von den »ehernen Gesetzen«, denen die Kurden folgen und den Regeln, nach denen die Deutschen leben, erfahren wir ebenfalls nichts Genaues. Wie die Ich-Erzählerin sehen wir nur bestimmte Lebensweisen. Am Ende des Romans vermutet Leyla, dass alle Familienmitglieder nur ihre eigenen Interessen verfolgen.

Sie [Leylas Familienmitglieder, Ö.E.] machen sich weis, daß sie nach dem Gesetz handeln, doch in Wirklichkeit leben sie nach ihren eigenen Regeln. Ich habe zwanzig Jahre meines Lebens verschlafen, das ist die Wahrheit. Ich bin nichts weiter als ein dummes sentimentales Mädchen, eine junge linkische Person, die Großtante hat recht. Ich werde die Armut nicht als mein Schicksal ansehen. Ich werde die Gesetze der Männer nicht als Gottes gesprochenes Wort begreifen. ${ }^{454}$

Und auch wenn der Roman die Gesetze und die eigenen Regeln kaum erklärt, teilt der Erzähler mit Leyla die Erkenntnis über ihre Sippe, weil das Verhältnis zwischen Haus, Ehre und Staat und zur eigenen Geschichte nicht von Gesellig-

450 ZAIMOĞLU (2006): S. 38.

451 Ebd., S. 42.

452 Ebd., S. 86.

453 Ebd., S. 159.

454 Ebd., S. 445. 
keit, von sociability, bestimmt ist, sondern ausschließlich von egoistischen Interessen und individuellem Eigensinn. ${ }^{455}$ Interessanterweise liegt genau in dieser Haltung der Erzählung die Kompatibilität dieser Geschichte aus der alten Zeit mit der Gegenwart, mit den Debatten in Deutschland. So konstatiert der Rechts- und Politikwissenschaftler Ulrich K. Preuss Anfang der 2000er Jahre, dass »wir [...] die durch Zuwanderung bereits entstandene, gewissermaßen bloß sinnlich-physische Anwesenheit der Fremden in den Tatbestand ihrer Zugehörigkeit zu unserer Gesellschaft verwandeln [müssen] «. ${ }^{456}$ Wie die Deutsch-Türken in den 2000er Jahren in Deutschland hat auch Halids Familie einen »Migrationshintergrund«. Für diese narrative Kompatibilität mit den Debatten der Integration gibt es zwei Gründe, die uns in den Kern dieses Romans führen. Zum einen haben wir es wie im Film von Feo Aladağ mit einer mythischen Art der Verhandlung der Migration zu tun. So meint der Leser, die Formulierung, dass es von Hochmut zeuge, wenn Frauen aufreizende Kleider tragen, sei eine islamische Regel. Und tatsächlich ist das Thema Hochmut in einem Koran-Vers, der die Verschleierung behandelt, eng mit der Frage des sittlichen Verhaltens verbunden. ${ }^{457}$

Dies muss Zaimoğlu in seinem Roman nicht ausführen; nicht weil alle diesen Vers genauestens kennen würden, sondern weil man weiß, dass im Islam die Frau besonders unterdrückerischen Regeln zu folgen hat. Dass hinter Halids repressivem Verhalten jedoch nicht nur der Islam steht, halten viele Rezensenten des Romans fest. ${ }^{458}$ Weidermann von der Frankfurter Allgemeinen Zeitung konzentriert sich ausschließlich auf Halids Verhalten; Iris Alanyalı schreibt, dass Zaimoğlus Roman zeige, »wie wenig haarsträubende moralische Vorstellungen mit dem Islam zu tun haben müssen «. ${ }^{459}$ Dennoch sind sich alle Rezensenten einig, dass sehr

455 Siehe zu sociability: WeInTRAuB (1997): S. 16-25.

456 PREuSS (2011): S. 480. Auch Gerhard Schröders Imperativ aus dem Jahr 2000 - »Verfassung achten, die Gesetze befolgen und die Landessprache beherrschen « - wird nach dem 11. September 2001 und mit den Integrations- und Islamkonferenzen fragwürdig. Denn die Achtung des Grundgesetzes reicht für eine Integration nicht mehr aus. Es gilt die Verfassug zu leben, so dass zu ihr konkurrierend stehende Ordnungen gebrochen werden. Siehe zur Schröder'schen Diktion: LÖFFLER (2011): S. 182.

457 DER KoRAn, Übersetzung von Adel Theodor Khoury (unter Mitwirkung von Muhammad Salim Abdullah), Gütersloh: Gütersloher Verlagshaus, S. 267.

458 Siehe hierzu: Alanyali, Iris (2006): »Die Flucht vor dem Mann im Pyjama«. In: Die Welt, 26.04.2006, https://www.welt.de/print-welt/article209366/Die-Flucht-vor-dem-Mann-im-Pyjama. html (13.07.2018). Siehe auch: RÜDENAUER, Ulrich (2006): "Sich herausnehmen, was sonst nur Jungs tun«. In: FRANKFURTER RUNDSCHAU, 15.03.2006, http://www.fr.de/kultur/literatur/ulrich-ruedenauer-sich-herausnehmen-was-sonst-nur-jungs-tun-a-1196569 (13.07.2018); LÜDKE, Martin (2006): »Nicht ohne meine Tochter zu schlagen«. In: DIE ZEIT. Literaturbeilage, 16.03.2006, https://www.zeit.de/2006/12/L-Zaimoglu-TAB (13.07.2018).

459 Ebd. 
wohl so tyrannische Väter unter den muslimischstämmigen Menschen in Deutschland existieren. Zaimoğlus Darstellung mache nach Iris Alanyalı diese Menschen vor Ort nach all dem, was wir »jetzt über sie wissen, uns noch fremder als zuvor «. ${ }^{460}$ Daran schließen sich folgende Fragen an: Welches Wissen verarbeitet Zaimoğlu in Leyla, wie bereitet er es auf und wie gelingt es ihm, den Islam zugleich ein- und auszuschließen? Wie im Beispiel mit dem Hochmut werden ein Wissensreservoir und ein bestimmtes Erfahrungssubstrat nur angedeutet: die Trennung des Mannes von der Frau im öffentlichen Raum und die Sexualisierung des weiblichen Körpers.

Der Einsatz und Gebrauch von Mythen gehören nach Aleida Assmann und Peter Novick in gesellschaftlichen Selbstverständigungsdiskursen zur öffentlichen Praxis des »kollektiven Gedächtnisses «, das im Unterschied zum sozialen Gedächtnis viel stärker geformt ist: »Es sieht die Ereignisse aus einer einzigen, interessierten Perspektive«, erlaubt keine Mehrdeutigkeit und »reduziert die Ereignisse auf mythische Archetypen«. Dabei werden »mentale Bilder zu Ikonen und Erzählungen zu Mythen, deren wichtigste Eigenschaft ihre Überzeugungskraft und affektive Wirkmacht ist «. ${ }^{461}$ Der Gebrauch solcher Bilder und Mythen führt in Leyla aber nicht zu einer eindeutigen Interpretation und Zuordnung mit dem Islam. Dies liegt besonders an dem, was Halid lebt. In den wenigsten Fällen können wir nämlich sagen, wann er wirklich ein Gesetz verletzt. Sein Verweis auf den Koran, der sein Handeln legitimiere, ist dabei vieldeutig. Dass er als Mann und Vater der Familie und seiner Frau vorsteht, steht zwar im Koran, aber sicher nicht, dass die Männer Fürsten seien. ${ }^{462}$ Welchen Einfluss der Koran tatsächlich auf die Verhaltensweisen des Vaters nimmt, ist nicht zu klären. Es geht aber auch gar nicht um die Interpretation des Korans, sondern vielmehr darum, wie der Vater sich verhält, wie er den Koran zu seinen eigenen Zwecken einsetzt und sich dabei selbst als gesetzestreuen Muslim begreift.

Kritik, Bestätigung oder Bruch hinsichtlich des Verhältnisses zwischen System und Akteur gibt es hier nicht - ganz anders als in den 1960er Jahren bis heute. Der Roman rückt, wie die zuvor besprochenen Filme, Lebensweisen und Handlungen der Akteure in den Vordergrund. Halid und der Koran gehören zum Haus und irgendwie auch zueinander, aber die zentrale Frage ist hier nicht, ob

460 Alanyali (2006).

461 Novick, Peter (2003): Nach dem Holocaust. Der Umgang mit dem Massenmord, München: dtv, S. 14. Siehe hierzu auch: Assmann, Aleida (2007): Geschichte im Gedächtnis. Von der individuellen Erfahrung zur öffentlichen Inszenierung, München: Beck, S. 25-30.

462 Dass der Mann der Frau im Koran vorsteht, interpretiert beispielsweise der Islamwissenschaftler Nasr Hamid Abu Zaid nicht im Zusammenhang der Macht, sondern der Verantwortung für die Familie. Siehe hierzu: ABu ZAID, Nasr Hamid (2001): Ein Leben mit dem Islam. Erzählt von Navid Kermani, Freiburg: Herder, S. 86ff. 
sein Verhalten ein adäquat islamisches ist, sondern durch welches Verhalten er sich und seine kulturellen Bindungen in den privaten und öffentlichen Raum übersetzt. Der »Kurdenfürst« und die Deutschen werden nicht geliebt, weil sie Gesetze und Regeln haben, sondern aufgrund eines bestimmten Lebensstils.

Halid selbst hält sich offensichtlich überhaupt nicht an Regeln. Er begeht nicht nur Ehebruch, sondern vergeht sich sexuell sogar an seiner ältesten Tochter Yasemin. ${ }^{463}$ Als Geschäftsmann handelt er mit Orangen und Opium. Seinen ältesten Sohn Djengis zwingt er, ein unansehnliches und äußerst schwieriges Istanbuler Mädchen zu heiraten, weil dessen Familie wohlhabend ist. Seine Triebhaftigkeit und sein Egoismus werden am deutlichsten, als seine Tochter Leyla Metin ehelicht und Halid sie daraufhin wüst beschimpft, dass sie damit die Ehre der Familie beschmutze. Tatsächlich fehlt ihm durch die Hochzeit nur eine weitere Kraft im Haus, die Geld verdient. Darauf deutet auch die Tatsache hin, dass er seine beiden älteren Töchter nach Deutschland schickt, um Geld für die Familie $\mathrm{zu}$ verdienen. ${ }^{464}$ In Özdamars Roman Das Leben ist eine Karawanserei wollte die Familie die Tochter unter die Haube bringen, weil ihr Körper ein sexuelles Verlangen entwickelt hatte und es besser wäre, sie mit einem Mann zusammenzubringen, bevor sie ihre Scham verliere und damit die Ehre der Familie verletze. ${ }^{465}$ Hier geht es tatsächlich darum, der muslimischen Regel folgend, den sexuellen Trieb der eigenen Tochter oder des eigenen Sohnes gesellschaftlich zu kontrollieren. ${ }^{466}$ Auch Werner Schiffauers Ausführungen zur Ehre im türkischen Dorf aus den 1980er Jahren widersprechen Halids Verhaltensweisen. ${ }^{467}$ Denn das

463 Siehe hierzu: ZaimoğLU (2006): S. 121.

464 Bei einer genauen Lektüre von Keleks Buch Die fremde Braut wird trotz der Verweise auf den Islam und auf Mohammed deutlich, dass die eigentlich ausschlaggebenden Kategorien für die Importbräutekultur der Türken in Deutschland Egoismus und Kapitalismus sind. An vielen Stellen beschreibt Kelek, wie die Familien aus Deutschland die jungen Frauen aus der Türkei damit locken, dass sie dort ein freies, von Konsum bestimmtes Leben würden führen können. Tatsächlich werden sie fast wie Sklavinnen gehalten: Sie verrichten die Hausarbeit, kaufen ein und kümmern sich um die Kinder; im Endeffekt sollen sie das Leben der türkischen Familie in Deutschland erleichtern. Ihre Freiheit beschränkt sich nach Kelek auf den Weg aus der Wohnung in die Moschee und wieder zurück. Siehe hierzu exemplarisch das Kapitel »Brautpreis Deutschland. Oder Geschichten von den Importbräuten«. In: KELEK (2006): S. 182-226.

465 Siehe hierzu: ÖzDAmaR (1992): S. 330.

466 Siehe hierzu: EzLI, Özkan (2015): »Kulturelle Ungleichgewichte. Der Burkini im öffentlichen Bad als Kennzeichen und Praxis der Ambivalenz«. In: Religion als Prozess. Begriffe - Zuschreiben - Motive - Grenzen, hg. v. Thomas Kirsch, Dorothea Weltecke, Rudolf Schlögl, Paderborn: Schöningh, S. 91-112.

467 Nach Schiffauer weist besonders die Funktion und der Begriff der Ehre jedem Mann »einen Bereich persönlicher Integrität und Würde [zu], der die eigene körperliche Unversehrtheit wie die der Familienangehörigen umfasst«. So ist ein ehrenhafter Mann jemand, »der seine Frau zu 
Verhältnis zwischen privatem und öffentlichem Raum ist in Zaimoğlus Roman stets gebrochen. So gibt es beispielsweise keine einzige Szene, in der Halid seine Familie öffentlich züchtigt. Vielmehr ist der öffentliche Raum für ihn äußerst problematisch, weil dessen Gesetze mit seinen eigenen kollidieren. Quelle seiner unendlichen Wut ist keineswegs der Staat allein. Halids Familie migrierte einst vom Kaukasus in den Süden der Türkei, weil im südrussischen Kaukasus Krieg herrschte. Um welchen Krieg es dort ging, erfahren wir aus Zaimoğlus Roman nicht. So folgen auf Halids Wutausbruch zu Hause nicht nur der Verweis auf den Koran, sondern auch Träume von der Vertreibung aus dem Kaukasus:

\begin{abstract}
Meine Mutter schläft. Meine Schwestern und Brüder schlafen. Er liegt auf dem Rücken, er stößt laut Luft durch den offenen Mund aus. Über dem Kopfende der Ehematratze hängt an einem krummen Nagel das Heilige Buch, worin er in seltenen Stunden der Muße blättert: die Kraft überträgt sich auf seine Zunge, auf seine Arme und Beine. Die Verse gehen in einen Traum, der ihn in den Nächten des Frühjahrs und in den Nächten des Winters heimsucht. Der Kaukasus, für eine kleine Ewigkeit verloren, eine Öde jenseits der bolschewistischen Schranke, erscheint ihm, dem Vertriebenen, als ein weites Land, das von den Leichen, der Totgeschlagenen bedeckt ist. Er versetzt ihn in Unruhe, dieser Traum, er läßt seine Wimpern zittern, dieser Traum. ${ }^{468}$
\end{abstract}

Die Gründe für die Migration in die Türkei sind noch tiefer in die Familiengeschichte eingeschrieben. Oft beschimpft Halid seine Frau als eine »Hurenjungfer «, die froh sein könne, dass er sie überhaupt geheiratet habe. Am Ende des Romans erzählt er auf dem Sterbebett allen anwesenden Familienangehörigen, dass seine Frau von mehreren bolschewistischen Soldaten vergewaltigt worden sei und er diese Tat aus einem Versteck heraus beobachtet habe. ${ }^{469}$ Trotzdem habe er sie geheiratet. Wut und Bösartigkeit des Vaters gehen nicht auf Traditionen, Regeln und Gesetze, letztlich nicht auf eine transzendentale Ordnung zurück. Ihr Ursprung liegt in einer nicht verarbeiteten äußerst gewalttätigen weltlichen Vergangenheit. Anders als Hüseyin aus ALMANYA gelingt es Halid nicht, ein Gespräch mit seinem alten Selbst zu führen. Sein Verhältnis zu sich selbst ist bestimmt von Krieg, Vergewaltigung und Vertreibung. Halids Verhältnis zur Öffentlichkeit ist sowohl in der Provinz als auch in der Metropole vollkommen gestört. Dennoch stellt Zaimoğlu ihn nicht als Opfer dar, sondern als Täter. ${ }^{470}$ Halid ist eine Figur, die ganz anders ist als die Väter in Yüksel Pazarkayas Serie UnSERE NACHBARN, DIE BALTAS von 1983, in Hark

verteidigen vermag, der Stärke und Selbstbewusstsein zeigt«. Siehe hierzu: SCHIFFAUER, Werner (1983): Gewalt der Ehre, Frankfurt a. M.: Suhrkamp, S. 70 u. S. 74.

468 ZAIMOĞLU (2006): S. 30.

469 Ebd., S. 518f.

470 Das gilt auch für die Figur Can in Züli Aladağs Film WuT. In Interviews erläuterte Aladağ, warum Can so gewalttätig und böse sei, dass er befürchte, mit seinem Film nicht politisch kor- 
Bohms Film YASEMIN, in Grabes Dokumentarfilm oder Özdamars Das Leben ist eine Karawanserei. Im Gegensatz zu diesen Werken greift bei Leyla auch die Unterscheidung zwischen Moderne und Tradition nicht. Der Unterschied zwischen Provinz, Stadt und Deutschland ist der technische Fortschritt, ein »elektrisches « und nach Regeln geordnetes Leben, das das Zusammenleben sichert. Das ist das moderne Leben. Dabei rebellieren Halid - und Leyla. Denn obwohl Leyla ein »elektrisches Leben « führen will, sie also konsumorientiert ist, wird sie im Zusammenhang ihrer Familie als rebellisch dargestellt. Mehrmals betont sie, dass sie den Gesetzen des Mannes ihrer Mutter entkommen möchte. ${ }^{471}$ Doch Leyla durchläuft keine Emanzipation im klassischen Sinne, denn sie selbst sagt zu sich, wie bereits zitiert, dass sie zwanzig Jahre ihres Lebens verschlafen habe. ${ }^{472}$ Wie Umay in Feo Aladağs DiE FREMDE vermag sie es trotz Migration nach Deutschland - in die »Freiheit « - nicht, sich von der Familie zu lösen. Als sie sich durch die Heirat mit Metin von ihrer Herkunftsfamilie befreit hat, zeigt sich bei einem Arztbesuch, wie tief sich die Regeln der Scham in sie eingeschrieben haben. Die Augen des Arztes würden sie entehren, ruft sie aus. ${ }^{473}$ Er erwidert, dass sie sich »wie ein Weib aus dem Gesindehaus« verhalte. ${ }^{474}$ Und als Metin sie am Bahnhof in München »am Ohrläppchen fasst«, fühlt Leyla Scham vor ihrer Mutter, denn das "gehört sich nicht in ihrer Gegenwart«. Umgekehrt ist das erste, was ihr am Münchener Bahnhof auffällt, dass dort Frauen ohne männliche Begleitung »in der Bahnhofshalle unterwegs sind«. Sie laufen »auf hohen Absätzen voran, als kennten sie ihr Ziel genau. [...] Sie gehen an den Männern achtlos vorbei, die Männer schauen ihnen nicht nach. « ${ }^{475}$ In Istanbul hatte Leyla ganz andere Erfahrungen gemacht:

Die Männer drängen sich auf den Bürgersteigen, und wenn ihnen eine Frau entgegenkommt, stoßen sie einander an, fangen an, vor sich hinzureden, ohne den Blick von der Frau abzuwenden. Sie bleiben stehen und lassen so viel Platz, daß ich gerade noch hindurchschlüpfen kann, ohne sie zu berühren, dabei muß ich aber die Arme eng an meinen

rekt zu sein. Er verstehe zwar die Wut seines Protagonisten, aber nicht sein Verhalten. Siehe hierzu: ALADAĞ (2005).

471 ZAimoĞLU (2006): S. 87 u. S. 445.

472 Ebd., S. 445.

473 Ebd., S. 476.

474 Ebd.

475 Ebd., S. 524. In Einmal Hans mit scharfer Soße steht das Tragen von High Heels für eine besondere Form der Emanzipation; es erfordere Mut und Entschlossenheit: »Vielleicht finde ich High Heels so sexy, weil sie eine unwiderstehliche Mischung aus Risiko, Tollkühnheit und Eleganz darstellen«. Siehe hierzu: AKYüN (2005): S. 101. Dass Hatice Akyün mit diesem Bekenntnis zu einem bewusst femininen Auftritt im öffentlichen Raum, der auf eine konservative und beziehungsfokussierte Emanzipation zielt, verweist implizit auf die Philosophie der Anfang der 2000er Jahre sehr erfolgreichen amerikanischen TV-Serie SEX AND THE City. Siehe hierzu: ebd., S. 102. 
Körper pressen, und ich zwinge mich, keinen Fluch laut auszustoßen, denn sie starren mir nach, einer jungen Frau, von der sie nicht wissen, ob sie vielleicht zugänglich sei. ${ }^{476}$

In der türkischen Provinz war das anders. Auch dieser Unterschied zwischen Münchner Hauptbahnhof und Istanbuler Stadtteil macht Deutschland für Leyla attraktiv. Im letzten Satz des Romans äußert sie, dass sie dieses Land lieben wolle, »weil es vermißt werden will«. ${ }^{477}$ Für die Germanistin Dorothee Kimmich spricht sich die Protagonistin an dieser Stelle des Romans auf naive Art Mut zu, ${ }^{478}$ indem sie sagt: »Ich werde den Wolf streicheln, und er wird vielleicht die Hand nicht beißen, die ihm über das Rückenfell fährt. « ${ }^{479}$ So verbindet der Wolf Anfang und Ende, Vergangenheit und Gegenwart, denn mit einer zeitlos wirkenden Szenerie jagender Wölfe hatte schon der Prolog begonnen.

Leyla sei der passende Roman zur aktuellen Integrationsdebatte, halten viele Rezensenten fest. Ein Beitrag in der Frankfurter Allgemeinen Zeitung zur Taschenbuchausgabe fragt, wie vergangen denn die Wirklichkeit sei, die Zaimoğlu beschreibt. Viele Gespräche aus diesem Roman würden heute auch in Kreuzberg stattfinden, führt der Rezensent fort, der seinen Artikel mit der Bemerkung schließt: »[W]er die Situation der Türken heute verstehen will, muss wissen, aus welchen Umständen sie gekommen sind «. ${ }^{480}$ Martin Lüdke weist in der Zeit darauf hin, dass es die »türkischen Familientyrannen«, die Zaimoğlu beschreibt, auch heute »bei uns gibt «. ${ }^{481}$ Was die Aktualität des Romans betrifft, hält Ulrich Rüdenauer in der Frankfurter Rundschau fest, worüber sich schon Harald Martenstein hinsichtlich ALMANYA gefreut hatte: dass es im Zusammenhang der aktuellen Integrationsdebatten gut tue, »einmal keine Statistik und Expertenanalyse vor sich zu haben, sondern die greifbare und ergreifende Geschichte eines Mädchens « ${ }^{482}$ Iris Alanyalı konstatiert ähnlich wie Rüdenauer und Lüdke, dass

476 ZAimoğLU (2006): S. 330.

477 Ebd., S. 525.

478 Кіммісн, Dorothee (2011): »Metamorphosen einer Biographie. Bemerkungen zu Feridun Zaimoğlus >Leyla««. In: Feridun Zaimoğlu in Schrift und Bild, hg. v. Klára Erdei, Rüdiger Schütt, Kiel: Edition Fliehkraft, S. 57-74, hier S. 60.

479 Ebd., S. 525.

480 Frankfurter AlLGemeine Zeitung (2007): „Feridun Zaimoğlu. >Leylar. In: FRANKFURTER ALLGEMEINE ZEITUNG, http://www.faz.net/aktuell/feuilleton/buecher/romanatlas/tuerkei-anatolien-feridun-zaimoglu-leyla-1306255.html?printPagedArticle=true\#pageIndex_0 (19.07.2018).

481 LÜDKE, Martin (2006): »Nicht ohne meine Tochter zu schlagen«. In: DIE ZEIT. Literaturbeilage, 16.03.2006, https://www.zeit.de/2006/12/L-Zaimoglu-TAB (19.07.2018).

482 RÜDENAUER, Ulrich (2006): „Sich herausnehmen, was sonst nur Jungs tun «. In: Frankfurter Rundschau, 15.03.2006, http://www.fr.de/kultur/literatur/ulrich-ruedenauer-sich-herausnehme n-was-sonst-nur-jungs-tun-a-1196569 (19.07.2018). 
Leyla »nicht als soziologisches Dokument, aber als ein Roman [...] viel von der Psyche und den Familienstrukturen einer der meisten Deutschen unbekannten Gesellschaft «, der türkischen Gesellschaft innerhalb der Bundesrepublik vermittele. Einer türkischen Gesellschaft in Deutschland begegnen wir in Leyla jedoch ebenso wenig wie in DIE FREMDE oder ALMANYA. Volker Weidermann meint gar, Zaimoǧlu habe mit Leyla einen deutschen Bildungsroman geschrieben, "aus einer Welt, von der wir fast nichts wußten «. ${ }^{483}$ Ein paar Monate später wird er in seinem zweiten Beitrag zu Leyla, in dem er den oben skizzierten Plagiatsverdacht thematisiert, im Gegensatz dazu schreiben, dass wir die Geschichte, die Zaimoğlu erzählt, hätten kennen müssen, denn Özdamar habe sie bereits knapp 15 Jahre zuvor auf eine andere Art erzählt. ${ }^{484}$

Auf der Suche nach der Antwort auf die Frage, warum ein Roman, der in der Türkei der 1950er und 1960er Jahre spielt, als der Roman zur aktuellen Integrationsdebatte gehandelt wird, stößt man in allen erwähnten Artikel auf dieselbe Argumentation: Zaimoğlu gelinge es, trotz Themen wie Ehre und türkische Provinz nicht in »orientalische Klischees abzudriften «, heißt es an einer Stelle. ${ }^{485}$ Ijoma Mangold schreibt, dass der Roman zwar in einem »Märchenton « beginne, sich aber dann als eine absolut »realistische Geschichte« ausweise, vielleicht mit der »Wucht eines Melodrams«, doch »ohne jedes falsche Pathos «. ${ }^{486}$ Auch der bereits erwähnte Weidermann attestiert dem Text einen »archaisch-schönen Märchenton, ohne kitschig zu sein«. Er sieht ihn aber auch als eine »Horrorgeschichte, ohne voyeuristisch zu sein «, und schließlich als eine »Geschichte aus der Fremde, ohne folkloristischen Zierrat «. ${ }^{487}$ Die Folklore war auch bei den türkischen Rückkehrern am Rande von Mersin verschwunden. ${ }^{488}$

Die Ansicht, Leyla sei der Roman zur aktuellen Debatte, ändert sich schlagartig mit dem bereits genannten Plagiatsvorwurf. In »Abgeschrieben? « ${ }^{489}$ bezieht

483 WeIDERMANN, Volker (2006a): »Der fremde Bräutigam«. In: FRANKFURTER ALLGEMEINE ZEITUNG, 12.02.2006, http://www.faz.net/aktuell/feuilleton/buecher/rezensionen/belletristik/ der-fremde-braeutigam-1307180-p2.html (19.07.2018).

484 WeIdERMANN, Volker (2006b): »Abgeschrieben? Streit um den Roman >Leyla««. In: FRANKFURTER ALLGEMEINE ZEITUNG, 01.06.2006, http://www.faz.net/aktuell/feuilleton/buecher/abgeschrieben-streit-um-den-roman-leyla-oezdamar-gegen-zaimoglu-1327374.html (19.07.2018).

485 Frankfurter Allgemeine Zeitung (2007).

486 MANGold, Ijoma (2006): »Die Mitte der Sitte. Poetisch und soziologisch, nah und fern zugleich. Feridun Zaimoğlu erzählt in `Leyla` vom Leben unter dem Gesetz«. In: SZ Literaturbeilage, 14.03.1006, S. 61 .

487 WEIDERMANN (2006a).

488 Interview mit der Regisseurin, In: http://peripherfilm.de/fsk-kino/archiv/amrandederstaedte.html (11.09.2018).

489 WEIDERMANN (2006b). 
sich Volker Weidermann auf das »vielseitige Textkonvolut« einer süddeutschen Germanistin, die damals anonym bleiben wollte. ${ }^{490}$ Sie zeigt knapp 60 Parallelen zwischen Leyla und Das Leben ist eine Karawanserei auf motivischer und inhaltlicher Ebene auf. Darüber hinaus würden sich viele Konstruktionselemente überschneiden, so Weidermann, der als Fazit festhält, dass jedes aufgezeigte Detail an sich zwar harmlos sei, aber die Menge insgesamt irritiere. ${ }^{491}$ Er fragt sich, ob Zaimoǧlu tatsächlich die Geschichte seiner Mutter wiedergegeben habe und besucht Emine Sevgi Özdamar. Beide sitzen stundenlang über den besagten Texten. Weidermann darf keine Äußerung von diesem Treffen zitieren, schreibt jedoch, dass sich Özdamar um ihre eigene Lebensgeschichte betrogen fühle. ${ }^{492}$ Daraufhin ruft Weidermann Zaimoğlus Mutter an und erfährt, dass diese ebenfalls finde, ihre Geschichte sei nun gestohlen worden. Abschließend fragt Weidermann, wem denn nun die Geschichte gehöre. ${ }^{493}$ Für Zafer Şenocak geht es dabei gar nicht darum, wem die Geschichte gehört, sondern vielmehr um eine »Prüfung der Authentizität« der Türkinnen. Denn die Romane destillierten »aus einzelnen Biografien heraus [...] eine Typisierung der Türken«, bedienten eine Politik, »die permanent Ressentiments schürt und eine Kultur des Unterschieds pflegt«. Kunst werde zum Schauplatz "gesellschaftlicher Auseinandersetzung« und die ästhetische Frage $\mathrm{zu}$ wenig bedacht. Doch besonders »in einem von fixen Bildern und verengten Perspektiven gezeichneten Umfeld wird die differenzierende Eigenschaft der Ästhetik in besonderem Maße herausgefordert «. ${ }^{494}$ Auch manche Beiträge, die sich auf ästhetische Fragen konzentrieren, setzen sich mit der Plagiatsfrage auseinander. In der Neuen Züricher Zeitung begreift etwa Sieglinde Geisel Zaimoğlus Roman als die Travestie von Özdamars Roman. Während Özdamar einen »derb-ironischen Schelmenroman« geschrieben habe, dominiere bei Zaimoğlu das Motiv der unterdrückten Frau. Ähnlich gegensätz-

490 Drei Jahre später gibt sie sich dadurch zu erkennen, dass sie ihr Konvolut als Aufsatz in einem Sammelband veröffentlicht. Siehe hierzu: BRUnNER, Maria E. (2009): »Parallele kulturelle Identifikationsräume in F. Zaimoglus Leyla und E. S. Özdamars Roman Das Leben ist eine Karawanserei oder Absorption von Textteilen?«. In: Der deutschsprachige Roman aus interkultureller Sicht, hg. v. Gabriella Rácz, László V. Szabó, Veszprém: Universitätsverlag Veszprém, S. 31-52.

491 WEIDERMANN (2006b).

492 Ebd.

493 Diese Frage stellt auch: PfLitsch, Andreas (2009): »Fiktive Migration und migrierende Fiktion. Zu den Lebensgeschichten von Emine, Leyla und Gül«. In: Wider den Kulturenzwang, S. 231-252.

494 ŞENOCAK, Zafer (2006): »Authentische Türkinnen. Der Streit zwischen Feridun Zaimoğlu und Emine Sevgi Özdamar zeigt, wie sehr die so genannte Migrantenliteratur in der biografischen Falle sitzt. Sie spielt das Spiel der Typisierungen mit«. In: taz am Wochenende, 10.06.2006, http://www.taz.de/!421146/ (26.07.2018). 
lich sähen die Vaterfiguren aus: bei Özdamar ein »liebenswürdige[r], selbstironische[r], melancholische[r] Versager«; bei Zaimoǧlu ein »engstirnige[r], despotische[r], fundamentalistische[r] Familienvater, den alle fürchten - und der sich passgenau in das Islam-Bild des Westens fügt«. Geisel geht mit ihrer Verkehrung so weit, dass sie in Zaimoğlus Roman einen »literarischen Muttermord «sieht und Leyla insgesamt eine "politische Propaganda « unterstellt. ${ }^{495}$

Vergleichbar geht der deutsche Literaturwissenschaftler Norbert Mecklenburg vor: Das Leben ist eine Karawanserei sei eine »einzigartige Verbindung von zeitgeschichtlichem Ernst und komischer Verfremdung«, während Leyla eine Art »Pseudorealismus« verkörpere; eine mit Klischees durchsetzte »Geschichte eines armen türkischen Mädchens«. Sie diene im Unterschied zu Özdamars Roman der »sozialen Erbauung einer bestimmten Schicht von Gutmenschen in Deutschland«. Dabei ist nach Mecklenburg das Spiel mit der Konstruktion des Türken durch die »Reproduktion von Klischees, Stereotypen und Vorurteilen« durchaus legitim, müsse dann aber auch wieder unterlaufen werden, »Denk- und Deutungsmuster « aufbrechen, »festgefahrene Sichtweisen « konterkarieren. Dies gelinge Zaimoǧlu im Unterschied zu Özdamar allerdings nicht. ${ }^{496}$

Ganz anders sieht es in zwei Veröffentlichungen der englische Literaturwissenschaftler Tom Cheesman. Er bezieht sich in der späteren von 2008 auf Mecklenburg, wenn er fragt, warum Zaimoğlu woanders Stoff suchen sollte, der ja doch Stereotypen eher problematisiere und unterlaufe statt sie $\mathrm{zu}$ bestärken, wenn doch genau Letzteres in Leyla stattfinde. ${ }^{497}$ Er erkennt andere Unterschiede zwischen den beiden Werken als Mecklenburg und Geisel: Vor allem hinsichtlich des Umgangs mit sozialen Tabus würden sie sich konzeptionell unterscheiden. Özdamar stelle in ihrem Roman alle Tabus »unkommentiert benannt « und listenartig dar. Dabei sei bemerkenswert, dass der Tabubruch in Das Leben ist eine Karawanserei »kaum mit ernsthaft $\mathrm{zu}$ befürchtenden Folgen verbunden ist «. ${ }^{498}$ Alles bewege sich im »Theoretischen«. Demgegenüber seien Tabus in Leyla funktionalisiert: »Hier sind die Tabus richtige Handlungsanweisungen. Alle sind mit fürchterlichen Bedrohungen verbunden, mit gewaltigen körperlichen bis tödli-

495 GeISEL, Siglinde (2006): »Leyla«. Eine Travestie?«. In: Neue Züricher Zeitung, 24.06.2006, https://www.nzz.ch/articleE8O0G-1.41751 (26.07.2018).

496 MECKLENBURG, Norbert (2006): »Ein türkischer Literaturskandal in Deutschland? Kritischer Kommentar zum Streit um Feridun Zaimoğlus `Leyla` und Emine Sevgi Özdamars `Das Leben ist eine Karawanserei««. In: literaturkritik.de rezensionsforum, 12.06.2006, https://literaturkritik.de/ id/9610 (26.07.2018).

497 CheEsman, Tom (2008): »Pseudopolitisch, pseudokorrekt: Ein deutscher Literaturskandal. Ein später Nachtrag zur Debatte um Feridun Zaimoğlus `Leyla««. In: literaturkritik.de rezensionsforum, 29.05.2008, https://literaturkritik.de/id/11966 (26.07.2018).

498 Ebd. 
chen Sanktionen«. Mit der vorliegenden Kulturgeschichte können wir ergänzen, wenn die Spache das Medium der Verhandlung der 1990er Jahre ist, sind es die Praktiken in den 2000er Jahren. Deshalb kann Cheesman Leyla auch als eine rebellische Figur begreifen. ${ }^{499}$ Alanyalıs Einschätzung, dass Leyla ihr Schicksal »ertrage, ohne daran zu zerbrechen «, ${ }^{500}$ erinnert ein wenig an Umay in Feo Aladağs DiE FREMDE, denn weiter bemerkt sie, dass Leyla sich »Unmut über die herrschenden Zustände [zugesteht], sie zu verändern dagegen nie «. ${ }^{501}$ Von diesen Überlegungen ausgehend, interessiert Cheesman nicht die Frage des Plagiats, sondern die der literarischen Repräsentation. ${ }^{502}$ Denn Zaimoğlu bediene in Leyla nicht einfach Stereotypen, sondern er übertreibe sie. Ähnlich schätzt Helga Kotthof die deutsch-türkischen Kabarettisten und Comedians der 2000er Jahre ein: Sie seien über das lediglich Stereotypenhafte hinaus »überspitzt«. Die Technik der »Überspitzung« sei insofern ambivalent, als sie ein Mitlachen oder ein Auslachen auslösen könne. Für Cheesman ist das »overfilling « der Stereotypen in Leyla hingegen zugleich ein Unterlaufen:

Halid's futile, Gothic revolt against humane conventions invokes ancient cultural traditions - the mythology of Islam - against the modernity that denies him a place. His excessive and self-defeating barbarism dramatizes the violence of superimposed class and ethnic divides not only in his own society, where he is an unwelcome immigrant, but also by implication on other societies. ${ }^{503}$

499 Ebd.

500 Auch wenn es sich in Selim Özdoğans Buch Die Tochter des Schmieds um ein ganz anderes Vater-Tochter-Verhältnis handelt, wird die Protagonistin Gül in der Rezeption, in der Forschung und auch vom auktorialen Erzähler selbst als Frau beschrieben, die ihr Schicksal ertragen könne. Siehe hierzu: ÖzDoĞAN (2006). Siehe hierzu auch: ChEESEMAN, Tom (2007): »Postscripts: Astronauts in Search of a Planet«. In: ders.: Novels of Turkish German Settlement. Cosmopolite Fictions, New York: Camden House, S. 183-196, S. 185. Siehe auch: Hofmann, Michael (2013): »Güls Welt. Erzählen und Modernisierung in Selim Özdoğans Roman Die Tochter des Schmieds«. In: ders.: Deutsch-türkische Literaturwissenschaft, Würzburg: Königshausen \& Neumann, S. 120132. Ähnliches gilt für Özlem aus Dilek Güngörs Roman Das Geheimnis meiner türkischen Großmutter. Hier wird die Kraft, sein Schicksal zu ertragen, mit dem Durchhaltevermögen der ersten Gastarbeitergeneration gleichgesetzt. Siehe hierzu: GÜNGÖR (2008): S. 92. Eine Kraft, die die Protagonisten aus den aktuellen Romanen von Fatma Aydemir und Dilek Göngör nicht mehr aufbringen können. Siehe hierzu: AYDEMIR (2017); GÜNGÖR (2019).

501 Alanyali, Iris (2006): »Die Flucht vor dem Mann im Pyjama«. In: Die Welt, 08.04.2006, https://www.welt.de/print-welt/article209366/Die-Flucht-vor-dem-Mann-im-Pyjama.html (zuletzt 26.07.2018).

502 Siehe hierzu: CheEsman (2007): S. 192.

503 Ebd., S. 195. 
Man habe es mit einer neuen Form der literarischen Repräsentation in der deutsch-türkischen Literatur zu tun, die helfe, Deutschland zu kosmopolitisieren. ${ }^{504}$ Diese Einschätzung halte ich für problematisch, weil z. B. Halid, nach Leyla der wichtigste Akteur, aufgrund seines Verhaltens gar kein Teil einer kosmopolitischen Welt sein kann. Er definiert sich nur durch Gewalt und ein immerwährendes Unbehagen an allem, was ihn umgibt und in Beziehung zu ihm steht. Figuren wie Yusuf oder Yakup aus YASEMIN und ABDULlaH YAKUPoğLU der 1980er Jahre hätten hingegen an einer kosmopolitischen demokratischen Welt teilhaben können, hätten sie nur entsprechende Bildungs- und Aufstiegschancen bekommen. ${ }^{505}$ Denn Schuld an dem Vergehen gegen ihre Töchter waren die Umstände ihrer Geschichte und eine Kultur, eine Norm, die von außen über sie hereinbrach und der sie gewissermaßen ausgeliefert waren. Dieses Außen gibt es bei Halid nicht. Seine Handlungen sind Ergebnisse verkörperter Traditionen, über deren Einsatz und Umgang er selbst entscheidet. Can aus Züli Aladağs WuT, der eine wohlhabende deutsche Familie terrorisiert, kann ebenfalls unmöglich Teil einer kosmopolitischen Welt sein. ${ }^{506}$ Wenn es einen Kosmopolitismus in diesen Werken gibt, dann produziert er keinen Raum und keine Möglichkeiten, sondern stellt Ordnungen auf, die aufgrund der Entscheidungsfreiheit eine neue kulturelle Trennung herbeiführen mag.

Im Zusammenhang mit Zaimoğlus Literatur aus den 2000er Jahren stellt Dorothee Kimmich fest, dass Literatur zu dieser Zeit das Medium zur Darstellung von Missverständnissen und Kommunikationshindernissen im »transkulturellen Dialog« sei. Literatur sei dabei »nicht das Resultat einer vollends globalisierten weltweiten Kommunikation, sondern markiert vielmehr die Brüche und die Übersetzungsfehler «. ${ }^{507}$ Ein solcher Bruch sei etwa in Zaimoğlus Erzählung Häute daran zu erkennen, dass die Unterscheidung von Moderne und Tradition aufgehoben sei. Denn am Ende gehe es darum, ob der Protagonist die Tochter eines türkischen Dorfladenbesitzers als Frau mit nach Deutschland nimmt. Zuvor wurde ständig um Waren gefeilscht, so dass noch unklar sei, ob es hier um einen archaischen Frauentausch gehe oder um einen »auf die Spitze getriebenen Kapitalismus «. ${ }^{508}$ Leyla ist für Kimmich ein »Protokoll einer ungewöhnlichen Krisenerfahrung«, eine »Geschichte der Angst», die sich nur mit der semiauto-

504 Ebd., S. 196.

505 Siehe hierzu: Grabe (1986); BoHm (1988).

506 Siehe hierzu: ALADAğ (2006).

507 Кіммісн, Dorothee (2009): „Öde Landschaften und die Nomaden in der eigenen Sprache. Bemerkungen zu Franz Kafka, Feridun Zaimoğlu und der Weltliteratur als >littérature mineure«. In: Wider den Kulturenzwang, S. 297-316, hier S. 300.

508 Ebd., S. 312. 
biografischen Stimme des Sohnes erzählen lasse. Nur »in dieser Überkreuzung der Geschlechter und der Generationen« sei es möglich, diese Geschichte der Angst aufzubewahren und $\mathrm{zu}$ rahmen. ${ }^{509}$ Tatsächlich ist der Ausgangspunkt des Romans, wie ihn Feridun Zaimoǧlu zumindest im Rahmen seiner Tübinger Poetikdozentur festhält, die Bitte seiner Mutter, er solle ihre Lebensgeschichte aufschreiben. ${ }^{510}$ Die ersten Beschreibungen aus ihrer Vergangenheit handeln zudem, wie gesehen, von Wölfen und »ihrer Hungersucht«. Dem entgegnet der Sohn, dass dies »eine Geschichte aus der alten Zeit, aber keine alte Geschichte sei «. ${ }^{511}$ Die Mutter von Zaimoǧlu und Özdamar wurden beide in Malatya geboren; erstere 1941, letztere 1946. In dieser Stadt hat Güzin Cecen, Zaimoğlus Mutter, sechzehn Jahre ihres Lebens verbracht. Ihr Vater war ein »glückloser Mann, ein tschetschenischer Heimatvertriebener aus dem Kaukasus, den nicht die Sehnsucht, aber das Pech plagte«. Er hatte den Beschreibungen der Tochter gemäß »keinen Geschäftssinn «. ${ }^{512}$

Neben biografischen Splittern macht Zaimoğlu in seiner Poetikvorlesung vor allem zwei Aspekte publik: die Haltung seiner Mutter zu dem, was man »türkische Tradition« nennen könnte, und die Frage der Übersetzung der Geschichte und ihre erzählerische Gestaltung für den Autor, den Sohn, also ihn selbst. Cecens Haltung macht Zaimoğlu anhand eines längeren Wutausbruchs seiner Mutter deutlich, der zugleich eine Kernaussage des Romans wiedergibt. Gegen die Gesetze des gelebten Glaubens, der Ahnen, das Ehrengesetz der Männer, »die es geltend machten, wenn es darum ging, einer Frau die Grenzen des Anstands aufzuzeigen«, wettert die Mutter:

Was ist das für ein gottverfluchter Anstand, [...], was ist das für eine Kultur der Gewalt, der Scham und der Schande?! Die Frauen werden ohnmächtig, und die Männer treiben sich auf den Straßen herum und schwätzen von ihrer Ehre, und sie fallen beim kleinsten Anlaß übereinander her, und dann erfährt man von der Nachbarin, daß wieder einmal ein Idiot am Ende eines Messerkampfes in seiner Blutlache verendet ist, wofür denn, in Gottes Namen? Die Ehre ist Geschwätz, ist sie das Gewebe im Herzbeutel, ist sie ein Knoten im Unterleib, ist sie ein Geschwulst hinter den Augen? Die Männer vergruben in uralten Zeiten ihre Töchter, wenn der Mann nach der Zahl seiner Kinder gefragt wird, erwähnt er nur stolz

509 Кіммісн (2011): S. 63.

510 ZAIMoĞLU, Feridun (2008): »Feridun Zaimoğlu. Leyla: Zweite Vorlesung«. In: Feridun Zaimoğlu/Ilija Trojanow. Ferne Nähe, hg. v. Dorothee Kimmich, Philipp Ostrowicz, Künzelsau: Swiridoff, S. 27-46, hier S. 30.

511 Ebd. Feridun Zaimoğlus Eltern leben an der türkischen Westküste in einer Sommerhaussiedlung nahe der Kleinstadt Burhaniye, die zwischen Izmir und Canakkale liegt. Interessanterweise bezeichnet eine der Protagonistinnen aus AM RANDE DER STÄDTE die Türken in der Siedlung ebenfalls als »hungrige Wölfe« (»ac kurtlar«). Siehe hierzu: BADEMSOY (2005).

512 ZAIMoĞLU (2008): S. 32. 
seine Söhne. Diesen kranken Stolz muss man diesen Idioten austreiben wie einem Schwein den ungesunden Geist. ${ }^{513}$

Für den Sohn ist die Mutter eine Frau, die viel erlebt hat und viel weiß. Sie steht, besonders mit der oben zitierten Wutrede, für die Verkörperung einer Tradition, die sich nicht aus Interpretation ergeben hat, sondern aus der Darstellung der Verhaltensweisen und »Stimmen «, wie er es nennt. ${ }^{514}$ Die Frage, wie er die Geschichte seiner Mutter aufschreiben könne, hat Zaimoğlu lange beschäftigt. Nach einem dreimonatigen Rechercheaufenthalt in der Türkei begann er, aus seiner Perspektive zu erzählen, vermochte dabei aber nicht, das wiederzugeben, was seine Mutter ihm erzählt hatte. Nach einem längeren Findungsprozess, besonders mehrmaligem Anhören der Tonbandaufnahmen mit der Stimme und den Erzählungen seiner Mutter, entschied er sich, die Geschichte aus der Perspektive einer Frau zu schreiben. Es kam ihm »falsch vor, in die Rolle des Vaters oder eines Bruders [seiner] Mutter zu schlüpfen, [er] wäre dem Widerstand ausgewichen «, dem Widerstand seiner Mutter. ${ }^{515}$

Wieder in Deutschland sprach er mit den Müttern deutsch-türkischer Bekannter und Freunde. Seine Fragen waren ganz andere als diejenigen, die er in den 1990er Jahren den `Kanaken ' gestellt hatte: wie es sich denn in ihrer Haut lebe. Nun interessierten ihn der Tagesablauf, der Alltag der Frauen in der Türkei, bevor sie nach Deutschland als Gastarbeiterinnen migrierten. ${ }^{516}$ Dieser dokumentarische Zugang zur Vorgeschichte der Migration nach Deutschland spiegelt sich auch in der Verarbeitung der aufgenommenen Interviews mit seiner Mutter: »Ich ließ die Kassette laufen und hörte die Stimme meiner Mutter über den Kopfhörer, ich übersetzte ihre Geschichten Satz für Satz simultan ins Deutsche«. ${ }^{517} \mathrm{Im}$ Vorwort zu Kanak Sprak hatte Zaimoğlu Mitte der 1990er noch programmatisch betont, dass er die aufgenommenen Interviews ummodelliert und eine Schablone darübergelegt habe, um einer bestimmten Orientalisierung vorzubeugen. ${ }^{518}$ Wie Zafer Şenocak, der Mitte der 2000er Jahre die Aufgabe der Übersetzung neu konzeptualisierte, will nun auch Zaimoğlu alles Innere nach außen stülpen. Vielsagend

513 Ebd., S. 33.

514 So beschreibt auch Hatice Akyün ihren Vater in Hans mit scharfer Soße: »Mein Vater ist ein Gefühlsmensch. Obwohl er kaum lesen und schreiben kann, ist er ein kluger Mann, der Weisheit und Bauchgefühl miteinander verbindet. Das Leben hat ihm beigebracht, was gut ist. Dabei ist es ihm egal, in welchem kulturellen Kreis er sich gerade aufhält, wenn er seine Entscheidungen trifft.« Siehe hierzu: AKYüN (2005): S. 189.

515 Ebd., S. 37.

516 Ebd.

517 ZAIMoğLU (2008): S. 40.

518 ZAimoğLU (1995): S. 13. 
ist dabei folgende Begebenheit: Cecen bittet ihren Sohn gleich zu Beginn des Interviews, die Fenster zu schließen, weil die Nachbarn nicht hören sollen, was sie erzählt. Ihr Sohn entgegnet überrascht und irritiert, dass in Deutschland Tausende lesen würden, was sie ihm jetzt erzähle. ${ }^{519}$

In diesem Zusammenhang sollten wir einen letzten Blick auf die Plagiatsaffäre werfen. Maria E. Brunner hat Zaimoğlu nicht nur vorgeworfen, abgeschrieben zu haben. Zudem werde in Leyla das »Erzählen selbst [...] nie einer Prüfung unterzogen «, ${ }^{520}$ d.h. es werde nie darüber reflektiert, dass das Erzählte eine Konstruktion ist. Im Unterschied dazu sei Özdamars Text »überstrukturiert «. ${ }^{521}$ Er »inszeniert Märchen, Mythen, Bilder und Erzählungen der moslemischen Alltagskultur, deren Authentizitätskultur damit untergraben wird«. Auf ähnliche Weise untergräbt Zafer Şenocak eine spezifische kulturelle Authentizität in Gefährliche Verwandtschaft, wenn sein Erzähler nach dem Besuch einer Berliner Moschee den Islam als eine Religion beschreibt, die ideal sei für Männer, die Fußgeruch, Sperma und Bärte produzieren. ${ }^{522}$ Das ähnelt wiederum dem Konzept der Kanak Sprak, das Türkische und Türkeispezifische entweder in Frage zu stellen oder außen vor zu lassen, weil die Wirklichkeit transkulturell sei. Man müsse, so Thomas Arslan, durch die Klischees und Stereotypen hindurchgehen, wenn man auf etwas anderes, auf etwas Gemeinsames verweisen wolle. ${ }^{523}$ Ohne Bruch, Subversion, Überkonstruktion und Verleugnung ist in den 1990er Jahren keine Repräsentation möglich bzw. genauer: eine Verschiebung der herrschenden Repräsentation, wie sie Anfang der 1990er Jahre Stuart Hall mit Blick auf den britischen Film der 1980er Jahre dargestellt hatte. ${ }^{524}$ Genau in dieser postkolonialistischen Logik macht Brunner in ihrem Vergleich von Özdamars und Zaimoğlus Romanen auf Bhabhas Modell der Mimikry aufmerksam: Die Repräsentation einer Differenz müsse auch immer eine Verleugnung und Verschiebung enthalten. ${ }^{525}$ Das ist die eine Seite der kulturellen Übersetzung in Literatur und Film der 1990er Jahre. Kulturelle Repräsentation war in den 1990er Jahren jedoch weder möglich noch erwünscht, dass Handlungen oder soziale Interaktionen der Akteure und wofür diese stehen in den Blick kamen. Im Vordergrund standen Intensität und Präsenz von Aussagen und Körpern. Außerdem blockierten damals Reflexionen

519 SeZgin, Hilal (2006): »Eine Stimme. Ein Unschuldsbeweis«. In: DIE ZEIT, 22.06.2006, https:// www.zeit.de/2006/26/L-Zaimoglu-Interview (01.08.2018).

520 BRUNNER (2009): S. 50.

521 Ebd., S. 46.

522 ŞENOCAK, Zafer (1998): S. 110.

523 ARslan, Thomas (1998): Filmheft zu Dealer, Berlin: Peripher.

524 Siehe hierzu: Hall, Stuart (2008): »Neue Ethnizitäten«. In: Kulturwissenschaft. Eine Auswahl grundlegender Texte, Frankfurt a. M.: Suhrkamp, S. 505-516, hier S. 512.

525 Ebd., S. 33. 
zum Multikulturalismus den Zusammenhang von Kultur und sozialer Praxis im öffentlichen Raum, weil die politische und theoretische Doktrin vorgab, dass die Ethnizität des Anderen zwar als Anderssein verstanden werden sollte, sie aber nicht als »Ressource der Unterscheidung « eingesetzt werden durfte. ${ }^{526}$ Folgerichtig ist es auch wirklich schwer, wie oben gezeigt, aus Özdamars Roman einen realistischen Alltag in den 1950er und 1960er Jahren der Türkei herauszulesen und nachzuvollziehen.

Ganz anders bei Leyla: Wir können uns denken und wissen oft, wo Halid sich befindet, wenn er nicht zu Hause ist; entweder macht er am Bahnhof Geschäfte, sitzt im Kaffeehaus und schlägt die Zeit tot oder vergnügt sich im Kino mit der freizügigen Ipek Hanım. Eine solche Darstellung der sozialen Welt finden wir in keinem Film und keinem Text der 1990er Jahre. Das hat damit zu tun, dass die politischen Bedingungen damals andere waren, das Private vom Öffentlichen noch getrennt war und als Folge die Schwelle zum privilegierten Ort der Erzählung wurde. Wenn in den 2000er Jahren nun hinsichtlich Integration »alles auf den Tisch« kommen soll und »man ja wohl noch wird sagen dürfen«, ist das nicht mehr möglich. Genau diese Verschiebung hat Brunner wie viele andere übersehen. Es ist richtig, dass Zaimoğlu im Unterschied zu Özdamar weitaus ethnologischer vorgeht und die türkische Kultur sogar vorführt. Doch muss man genauer hinsehen. Denn was er vorführt, ist das Hausgesetz des Vaters und die damit verbundene Tyrannei, die insofern mit dem Koran zu tun hat, als der Vater ihn für seine Zwecke einsetzt. Ob die Handlungen sich jedoch genau daraus ableiten lassen, ist niemals eindeutig. Vielmehr kollidieren sie mit anderen Handlungsnormen, wie denen des Staates, die ihre Repräsentationskraft stark einschränken.

Sehr wahrscheinlich wäre die Plagiatsdebatte weniger skandalös verlaufen, wenn man die Romane Die Tochter des Schmieds und Das Geheimnis meiner türkischen Großmutter von Selim Özdoğan und Dilek Güngör hinzugezogen hätte, die zur selben Zeit entstanden sind wie Leyla. Denn im Vergleich zu Das Leben ist eine Karawanserei weisen sie die gleichen Unterschiede auf wie Leyla. So ist der Austragungsort in beiden Romanen die türkische Provinz. Im Kern geht es ebenfalls nicht um Sprechweisen, Artikulationen, Mobilität oder die Schwelle wie bei Özdamar, sondern um spezifische Orte, Gesetzmäßigkeiten und nicht zuletzt die Lebensweisen der Akteure und ihre Entscheidungen.

Wie Leyla für Zaimoğlu stellt auch Die Tochter des Schmieds für Özdoğan einen einschneidenden Wandel im bisherigen Erzählkonzept des Autors dar. In

526 Vgl. RAdTKE, Frank-Olaf (1998): »Lob der Gleich-Gültigkeit. Die Konstruktion des Fremden im Diskurs des Multikulturalismus«. In: Das Eigene und das Fremde. Neuer Rassismus in der Alten Welt?, hg. v. Ulrich Bielefeld, Hamburg: Hamburger Edition, S. 79-98, hier S. 92. 
Özdoğans früheren, popliterarisch anmutenden Romanen und Erzählungen wie Es ist so einsam auf dem Sattel seit das Pferd tot ist (1995), Nirgendwo \& Hormone (1996) und Ein gutes Leben ist die beste Rache (1998) steht das Lebensgefühl einer Generation im Vordergrund, „die den Sinn des Lebens im Genuss findet, für die hic et nunc das Wesentliche ist «. ${ }^{527}$ Zugleich hat Özdoğan in seinen Texten der 1990er Jahre Migration und türkische Themen durchweg vermieden, wenn nicht gar verleugnet. ${ }^{528}$ Wie Ahmed aus GESCHWISTER hat er seinen türkischen Hintergrund nicht thematisiert. ${ }^{529}$ Ahmed hatte aus guten Gründen nicht begreifen können, warum sein Bruder Erol zum türkischen Militär wollte, obwohl ihr gemeinsamer Vater Türke war. Özdoğans Roman Die Tochter des Schmieds erzählt im Jahr 2005 hingegen eine türkische Familiengeschichte aus der türkischen Provinz, deren Protagonistin schließlich als Gastarbeiterin nach Deutschland migriert. Den Danksagungen am Ende des Buches entnehmen wir, dass Selim Özdoğan wie Feridun Zaimoğlu mit vielen Familienangehörigen Gespräche über die Türkei der 1950er und 1960er Jahre geführt hat. ${ }^{530}$ Auch seine Hauptfigur Gül ist biografisch geprägt. In seiner Kindheit habe er schon seine Zeit zu Hause »am liebsten in Gegenwart der türkischen Frauen verbracht «. ${ }^{531}$ Ihre Geschichte hat Özdoğan in den Romanen Heimstraße 52 (2011) und Wo noch Licht brennt (2017) weitererzählt. $^{532}$

527 KARAKuŞ, Mahmut (2012): „Selim Özdoğans >Die Tochter der Schmieds`. Möglichkeiten der Selbstverwirklichung der Frauen«. In: Alman Dili ve Edebiyat Dergisi 0 (19), S. 139-154, hier S. 140. Lars Beckers Verfilmung KANAK ATTACK von Feridun Zaimoğlus Roman Abschaum setzt nach dem Vorspann, in dem drei »Kanaken« vorgestellt werden, mit den Worten des Ich-Erzählers aus dem Off ein, dass ihre Geschichte ebenfalls eine Geschichte ohne Anfang und Ende sei; ein »Ausnahmezustand« im »hier und jetzt«. Siehe hierzu: BECKER, Lars (1999/2000): Kanak Attack, Spielfilm, Deutschland.

528 Siehe hierzu Pflitsch (2009): S. 238.

529 ARSLAN (1996). Auf Özdoğans Gesinnungswandel machen einige Forschungsbeiträge aufmerksam. Siehe hierzu: PfLITSCH (2009): S. 238; HofmANN, Michael (2013): »Güls Welt. Erzählen und Modernisierung in Selim Özdoğans >Die Tochter des Schmieds«". In: ders.: Deutsch-Türkische Literaturwissenschaft, Würzburg: Königshausen \& Neumann, S. 120; KARAKUŞ (2012).

530 ÖzDoĞAN, Selim (2005): Die Tochter des Schmieds, Berlin: Aufbau.

531 Auch Nuran David Calış hält für seinen Protagonisten in Der Mond ist unsere Sonne fest: »Ab und zu schnappte ich etwas auf [...] beim Familienessen [...] die Mutter erzählte jedoch kaum etwas, sie war wie ein schwarzes Loch [...] Mir zuliebe, meinte sie, wolle sie nichts erzählen. Ich solle nach vorne schauen und nicht zurück. So sampelte ich mir unsere Vergangenheit zusammen, von Familientreffen zu Familientreffen und von Fernsehabend zu Fernsehabend. Während die anderen spielten, saß ich die meiste Zeit am Tisch und hörte zu. Stellte keine Fragen, nahm an keiner Diskussion teil, stattdessen spitzte ich meine Ohren, und mein Kopf nahm jede Information wie ein Schwamm auf.« Siehe hierzu: CaLIş (2011): S. 73.

532 ÖZDoĞAN, Selim (2011): Heimstraße 52, Berlin: Aufbau; ders. (2017): Wo noch Licht brennt, Innsbruck: Haymon. 
Die Familie des Schmieds Timur lebt in Anatolien am südlichen Rand von Kappadokien in der Provinz Niğde. Die Geschichte ist in zwei Kapitel unterteilt, wobei das Letztere nur zwei Seiten umfasst - was hinsichtlich des Erzählkonzepts sehr aussagekräftig ist. Das erste Kapitel ist in der dritten, das zweite in der ersten Person erzählt, wobei dieser Wechsel der Erzählperspektive überraschenderweise fließend geschieht. Er verdeutlicht, dass bereits die Perspektive der ersten 310 Seiten eine personale war und dass es auch in diesem Roman um das Herausstülpen einer inneren Welt geht. Doch zunächst möchte ich kurz auf den Inhalt des Romans eingehen.

Obwohl Rezensionen und wissenschaftliche Beiträge dem Roman attestieren, dass er jegliche Art von Orientalisierungen und Folklore vermeide, könnte er nicht stereotypischer beginnen. "Mach meinen Mann nicht zum Mörder « ${ }^{53}$, lautet der erste Satz. Ihn spricht eine Frau auf dem Rücksitz eines Autos, die dessen Fahrer zum Anhalten bringen möchte. Kurz zuvor hatte er ihren Mann darum gebeten, sein stehengebliebenes Auto anzuschieben, ließ ihn dann aber stehen und fuhr mit seiner Frau weiter. Auf deren Drängen hält er tatsächlich an, statt sich, wie wohl geplant, an ihr zu vergehen. Ihr Mann Timur ist froh, dass er mit dieser Frau verheiratet ist: Sie sei »in das Buch seines Lebens eingeschrieben worden«. Bis zu ihrem Tod nennt er sie sein »Stück vom Mond«. Dabei hat ihm seine Mutter diese Frau ausgesucht: »Es war nicht das erste Mal, das seine Mutter jemanden vorgeschlagen hatte, aber dieses Mal hatte er ja gesagt «. ${ }^{534}$ Formulierungen wie »Stück vom Mond«, Themen wie Schicksal, Endlichkeit und Ehre tauchen in Özdoğans Roman immer wieder auf und sind für die Erzählung insgesamt konstitutiv. Trotzdem wirft kein Rezensent Özdoğan Orientalismus vor. Das liegt vor allem daran, weil für die Erzählungen nicht die Sprache oder Metaphern im Zentrum des Dargestellten stehen, sondern wie in der Einstiegsszene gesehen, bestimmte Handlungen und Entscheidungen. Sie lassen die lediglich sprachlich aufgegriffenen Orientalismen nicht essenzialistisch werden. Sie finden vielmehr als Kategorien Verwendung, denn tatsächlich für eine andere Welt wie den Orient zu stehen. In diesem Zusammenhang ist Güls Verhältnis zu Gesetzen und Normen ausschlaggebend. Anders als in Leyla ist hier nicht ständig von Gesetzen die Rede. Sie kommen aber zum Tragen, wenn Gül Entscheidungen trifft.

Auf den ersten Blick fällt in Die Tochter des Schmieds auf, wie detailliert der Erzähler das Leben von Timurs Familie in der türkischen Provinz beschreibt: seine Arbeit als Schmied, die Arbeit im Haus, das Heranwachsen seiner drei Töchter Gül, Melike und Sibel, und dass dieses Leben vom Wechsel der Jahres-

533 ÖZDOĞAN (2005): S. 7.

534 Ebd., S. 14. 
zeiten bestimmt ist. In einer Kritik aus der Süddeutschen Zeitung heißt es dazu treffend, dass Özdoğan »handlungsreich und schnörkellos« erzähle:

Da wird die eine Sache nicht viel ausführlicher beschrieben als die andere, egal, ob hier jemand ein Kind zur Welt bringt oder sich dort jemand das Nasenbein bricht. Das hat etwas von epischer Einfachheit. Erzählen kommt von Aufzählen. Hat jemand etwas vor, ist es im nächsten Satz getan. ${ }^{535}$

Neben diesem Fokus auf Handlungen und dem interaktiven Zusammenhang von Erzählung und Erzähltem wissen wir in der Regel auch, wo die Familie sich in den jeweiligen Erzählabschnitten befindet und weshalb. Im Sommer wohnt die Familie in der Stadt, im Winter im Dorf, weil es im Stadthaus keine Heizung gibt. Von der historischen Zeit erfahren wir wie in Zaimoğlus Roman durch politische Ereignisse wie den Militärputsch in der Türkei 1961, durch die Meldung von der Ermordung Kennedys, durch den Kauf eines Radios oder den Einzug der Elektrizität in die Provinzstädte und in die Dörfer. ${ }^{536}$ Auch hier ist das moderne Leben elektrisch.

Bevor jedoch diese Form des modernen Lebens Einzug in das provinzielle türkische Dorf hält, lesen wir besonders nach dem Tod von Timurs erster Frau Fatma die Schilderung von Güls Leben. Die älteste Tochter meint, nach dem Tod der Mutter deren Rolle übernehmen zu müssen. Da ist sie gerade einmal sechs Jahre alt.

Menschen laufen hin und her, Gül weiß nicht, wo Melike und Sibel sind, sie sieht Tante Hülya und Onkel Yücel, sie sieht Nachbarn und auch Menschen, die sie noch nie vorher gesehen hat. Sie hat aufgehört zu weinen und denkt: Ich muß ein großes Mädchen sein, ich muß auf Melike und Sibel achtgeben. ${ }^{537}$

Für das Wohl der Töchter heiratet Timur ein zweites Mal, eine neue Frau namens Arzu, die ihrer neuen Verantwortung mehr pflichtbewusst als liebevoll nachkommt, da ihr selbst stets bewusst ist, dass sie Fatma nie ersetzen kann. Im völligen Gegensatz zu Halid aus Leyla ist Timur eine dankbare Person. Er habe, heißt es einmal, ein so ein großes Herz, dass selbst sein Widersacher Tufan darin Platz finde. ${ }^{538}$ Ein anderes Mal bejaht Timur die Frage, ob er Arzu gegen Fatma eintauschen würde, ist aber trotzdem zufrieden, weil seine Töchter gesund sind

535 Wiegandt, Kai (2005): "Das Gewicht der einfachen Dinge«. In: SÜDdEutsche ZEITUNG, 06.07.2005, https://www.buecher.de/shop/buecher/die-tochter-des-schmieds/oezdogan-selim/ products_products/detail/prod_id/13273664/\#reviews (03.08.2018).

536 Siehe hierzu: ÖzDoĞAN (2005): S. 156 u. S. 273.

537 ÖZDOĞAN (2005): S. 60.

538 Ebd., S. 49 u. S. 171. 
und er arbeiten kann. ${ }^{539}$ Diese besondere Perspektive vermitteln uns vor allem Güls Beobachtungen. Wie in Leyla und anders als in Özdamars Roman wissen auch wir hier immer, wohin jemand geht oder wo jemand ankommt. ${ }^{540}$ Die Schule spielt in beiden Romanen eine wichtige Rolle. Für Gül mag sie ein Ausgleich sein zur anstrengenden Arbeit zu Hause. Sie hat aber auch ihre Klassenkameraden und die Lehrerin sehr gern.

Auch wenn an keiner Stelle explizit von Gesetzen und Normen die Rede ist, spielt das Verhältnis von Lebensweise und wie man sich $\mathrm{zu}$ verhalten habe, in Özdoğans Roman eine herausragende Rolle. Dieses Verhältnis wird noch um eine erzählerische Dimension ergänzt, die über die Beobachtungen und das Leben von Gül hinausgeht. Geradezu ethnologisch beschreibt der Erzähler aus einer sachlichen Distanz in der dritten Person etwa, wie am Opferfest geschächtet wird. ${ }^{541}$ Oder er klärt uns darüber auf, dass das von Tufan eingeschlagene Fenster bedeutet, dass

539 Ebd., S. 171.

540 Siehe hierzu auch: WiEgandt (2005). Folgende drei literarische Beispiele zeigen, welche identitätspolitische Relevanz Richtungsvorgaben und -vektoren in den 2000er Jahren haben. Am Ende von Yadé Karas Roman Selam Berlin heißt es: "Ich liebte Berlin nach einem Regen und lief Richtung Potsdamer Platz. Die Lichter der Stadt spiegelten sich auf den nassen Pflastersteinen, die Straßen hatten mehr Raum, mehr Weite. Alles war heller und klarer, und die ganze Stadt gewann an Glanz. [...] Von weitem hörte ich Raketenschüsse. Sie kamen aus der Richtung vom Reichstag. Und ich wußte: In diesem Moment wurde die Freiheitsglocke geläutet und die Flagge gehißt. Und aus zwei deutschen Staaten wurde um Mitternacht wieder ein Deutschland. Ich wärmte mich an der Kippe und wußte plötzlich, wo es langgeht in meinem Leben ... Ha!« KARA (2004): S. 381f. Wie sehr die Akteure kulturelle Orientierung im Unterschied zu den 1990er Jahren verinnerlicht haben, zeigt auch der Schluss von Zaimoğlus Häute. Nachdem dem Ich-Erzähler anstelle des antiken Jungfernbluttuches die Tochter der Geschäftsinhaberin angeboten wird, betritt ein dem Mädchen versprochener junger Mann den Raum, der den Fremden, der die Sprache der Dörfler beherrscht, mit einer Rasierklinge bedroht. »'Du Geschminkter, wirst jetzt sofort aufbrechen`, sagt der Steinbrecher, >du hast den Weg in unser Dorf gefunden, du wirst auch wieder rausfinden. Oder sollen wir dich begleiten? `।Ist nicht nötig〈, sage ich, ich trete aus dem Laden und verlasse mich auf meinen inneren Kompaß, der meine Schritte zum Ortsausgang leiten wird, und wie ich mein Glück an solchen Tagen kenne, wird mich kein Stein aus einer Zwille treffen noch ein Hund anfallen.« ZAIMOğLU (2004): S. 121. Imran Ayatas erste Erzählung »Pokerci Ali« aus dem Erzählband Hürriyet Love Express beginnt in einem Stadtteil in Istanbul, in dem »Pokerci Ali« bekannt ist, und endet, nachdem er sich dafür entscheidet, der größte Pokerspieler in Deutschland zu werden und deshalb migriert, mit Alis Ankunft auf einer Baustelle in Pforzheim. Hier ist es der Leser, der nur zu gut weiß, dass Ali nicht in Baden-Baden im Spielcasino landen wird, sondern an einer Arbeitsstelle als Gastarbeiter. Erneut ist die Ankunft an einem bestimmten Ort symbolisch aufgeladen. »Und was sah Pokerci Ali? Da, wo das große Casino stehen sollte, war eine riesige Baustelle und sonst nichts. Das Casino, in dem Pokerci Ali Geschichte schreiben wollte, war noch nicht gebaut. "Siehe hierzu: AyATA, Imran (2005): »Pokerci Ali«. In: Hürriyet Love Express, Köln: Kiepenheuer \& Witsch, S. 14-20, hier S. 20.

541 ÖZDOĞAN (2005): S. 119. 
dieser »ein Auge auf seine [Timurs, Ö.E.] Frau geworfen hat «. ${ }^{542}$ Später erfahren wir, dass man Toten »ein Tuch um das Kinn « bindet, »damit der Mund nicht offensteht, wenn die Leiche steif wird«; oder dass man nicht vor seinen Eltern rauchen darf, »weil es eine Respektlosigkeit ist, sich im Beisein der Älteren einem Genuß hinzugeben ${ }^{543}$ Ebenso eingehend wird der genaue Ablauf von Heiratsanträgen beschrieben. ${ }^{544}$ Bei der standesamtlichen Vermählung muss der Mann z. B. auf den Fuß der Frau treten, wenn er im Eheleben »die Hosen anbehalten « will. ${ }^{545}$ Und hier zeigt sich eine weitere konstitutive Ebene des Romans, der sich nicht allein in der Darstellung von Lebensweisen erschöpft, sondern auch in sprachlicher Hinsicht dieselbe Übersetzungsleistung erbringt wie Zaimoğlus Leyla. Auch Özdoğan übersetzt nämlich türkische Formulierungen und Redewendungen eins zu eins ins Deutsche, gleich wie übertrieben kitschig sie auf Deutsch auch klingen mögen. ${ }^{546}$

Neben »Teil vom Mond « lesen wir als Timurs Antwort auf die Frage, ob er lieber einen Sohn oder eine Tochter hätte: »Die Hände und Füße sollen an den richtigen Stellen sein«, die exakte Übersetzung der türkischen Redewendung »eli ayağ1 düzgün olsun«. Seine Tochter Gül nennt der Schmied »meine Rose« (»Gülüm«) oder »Glanz meiner Augen« (»Gözümün 1şığı) $)^{547}$ Im Unterschied zu Özdamars Roman sollen die Übersetzungen nun nicht mehr kulturelle Zuschreibungen und Vorstellungen verfremden oder unterlaufen. Sie sind genau platziert, um soziale Praktiken zu beschreiben, sie verstärken also gewissermaßen das, was geschieht. Doch weitaus entscheidender ist, dass sie sich gegen einen klassischen Orienta-

\section{Ebd., S. 73.}

543 Ebd., S. 221. In Buket Alakuş’ Verfilmung von Hatice Akyüns Roman Einmal Hans mit scharfer Soße und in Imran Ayatas Roman Mein Name ist Revolution ist das Küssen oder Händchenhalten mit der Freundin oder dem Freund vor den Eltern schon respektlos.

544 Die türkische-muslimische Art des Handanhaltens ist in den bereits genannten CultureClash-Komödien der 2000er Jahre sehr wichtig. Auch hier werden die Handlungen bis zum Schluss ausgeführt. Siehe hierzu: HolTz (2005); WACKER (2004); AKKUŞ (2008); ALAKUŞ (2013). Sie wird in Einmal Hans mit scharfer Soße ausführlich beschrieben. In allen genannten Werken dominiert dabei das Spiel mit dieser Interaktion, nicht die Identifikation mit einem kulturellen Code.

545 Ebd. Auch Murat Topal macht in Getürkte Fälle. Ein Cop packt aus darauf aufmerksam. Siehe hierzu: Topal (2005).

546 Siehe hierzu: Branco, Carla (2005): „Ein Becher Meer«. In: FRANKFURTER ALLGEMEINE ZEITUNG, 31.10.2005, https://www.buecher.de/shop/buecher/die-tochter-des-schmieds/oezdoganselim/products_products/detail/prod_id/13273664/\#reviews (03.08.2018). Siehe auch: DREISTLER (2011).

547 In Einmal Hans mit scharfer Soße gibt es kaum eine Seite, auf der nicht steht: »im Türkischen heißt das so«, uns also ebenfalls viele wörtliche Übersetzungen aus dem Türkischen begegnen. Allerdings spielt die erzählte Geschichte fast ausschließlich in Deutschland. Einmal Hans mit scharfer Soße verkaufte sich 300000 Mal und gehört mit Necla Keleks Die fremde Braut zu den deutsch-türkischen Bestsellern der 2000er Jahre. 
lismus stellen und für die Frage der Integration in den 2000er Jahren stehen, die Entscheidungen der Akteure, besonders von Gül.

Dies wird mitunter daran deutlich, dass Güls Schwestern Melike und Sibelandere Wege gehen als sie. Wenn Gül beispielsweise die ersten Heiratsanträge ablehnt, um bei ihrer Familie zu bleiben, will Melike die Provinz auf jeden Fall verlassen und in Istanbul oder Ankara leben. Denn »da heißt es bestimmt nicht dauernd, wir werden zum Gespött der Leute«. Sie möchte in der Stadt »schöne Kleider tragen und Nylonstrümpfe« und sie »möchte Volleyball spielen, ohne dass mir jemand sagt, dass junge Frauen das nicht dürfen ${ }^{548}$ Sie besteht die Aufnahmeprüfungen für die staatliche Oberschule, besucht ein Internat und wird später sogar ihren zukünftigen Mann mit ins Dorf bringen und ihn ihren Eltern und Geschwistern vorstellen. ${ }^{549}$ Die jüngste Schwester Sibel, die klügste und begabteste von den Dreien, wird Kunstlehrerin, zieht mit ihrem Mann in die Stadt und bleibt kinderlos. ${ }^{550}$ Gül trifft andere Entscheidungen. Sie scheint die sozialen Normen und Regeln im Dorf so sehr verinnerlicht zu haben, dass sie niemand darauf aufmerksam machen muss, wie sie sich zu verhalten hat. Warum dies so ist, wird nicht eindeutig erklärt. Sie scheint einfach zu wissen, dass sie z. B. nach dem Tod der Mutter als ältestes Kind deren Rolle einnehmen muss. Niemand sagt ihr das. Doch sie führt zur eigenen Selbstvergewisserung häufig Selbstgespräche - etwa, als sie Fuats zweiten Heiratsantrag annimmt:

Als Gül am nächsten Morgen aufwacht, will sie immer noch. Möglicherweise ist es ihr vorherbestimmt. Deshalb ist Fuat zweimal gekommen. [...] Fuat ist kein Fremder, er gehört ja zur Familie. Früher oder später wird sie ja doch heiraten. Was sollte sie auch sonst tun. Früher oder später heiraten alle. Oder sie vertrocknen zu Hause und werden schief angesehen. Schicksal. Sie hat aus irgendeinem Grund ja gesagt, gestern Abend hat sie aus irgendeinem Grund ja gesagt. Und es hat sich richtig angefühlt. Oder etwa nicht? ${ }^{551}$

Interessant an diesem Passus ist, wie sehr Erzähler und Gül narrativ miteinander verwoben sind. Man beobachtet Reflexion, Beobachtende und Agierende zugleich. Nach Karakuş hat man als Leser von Die Tochter des Schmieds den Eindruck, »dass die betreffende Figur das Geschehen beobachten und erzählen würde, so dass die Innenwelt der betreffenden Figur zum Vorschein kommt «. Der Leser habe dadurch die Möglichkeit, »nach innen zu schauen, aber zugleich zu sehen, wie sie das Geschehen sieht und betrachtet $«{ }^{552}$ Diese besondere performative Struktur zeichnet den Roman insgesamt aus. Sie führt dazu, dass etwa der Zweifel an der Zustim-

548 ÖZDOĞAN (2005): S. 192.

549 Ebd., S. 242 u. 260.

550 Ebd., S. 195.

551 Ebd., S. 210.

552 KARAKUŞ (2009): S. 147. 
mung zu Fuats Heiratsantrag nicht wirklich irritiert. Auf eine besondere Art und Weise wird auch in diesem Roman das Innen zum Außen gemacht. Dass Özdoğans Roman im Unterschied zu Özdamars Karawanserei und zu Zaimoğlus Leyla sich weder durch »spektakuläre Handlungsmomente wie Rebellion oder durch brutale Unterdrückung« auszeichnet, liegt zum einen an der Figur Gül selbst, die von sich sagt, dass ihre Fähigkeit vor allem darin liege, erdulden zu können; im Unterschied zu ihrer Schwester Melike, die liebend gern kämpft. ${ }^{553} \mathrm{Zum}$ anderen spielt, wie in Leyla, auch die Figur des Vaters eine wichtige Rolle. Wie im Vergleich der Filme DIE FREMdE und ALMANYA begegnet uns in Halid und Timur ein gegensätzliches Paar: Während der eine nur an sich denkt, seine Frau als eine »Beschmutzte» und seine Familie als »Hundebrut« beschimpft, bezeichnet der andere seine erste Frau als »Teil vom Mond « und seine älteste Tochter als »das Licht seines Auges«. Ähnlich freundlich und gelassen reagierte Hüseyin in ALMANYA, als er von seiner Enkelin Canan erfährt, dass sie von einem Engländer schwanger ist. ${ }^{554}$ So hat man Özdoğans Roman zugute gehalten, identisch wie in den Besprechungen zum Spielfilm AlMANYA, dass er den gesellschaftspolitisch überhitzten Debatten um Ehrenmord und Zwangsehe eine »Normalisierung « entgegensetze. ${ }^{555}$ Wenn wir bei Leyla darauf hoffen, dass die Ich-Erzählerin endlich der autokratischen Unterdrückung entkommt, erscheint uns die Emanzipation in Özdoğans Roman weniger notwendig. Vielmehr wird verständlich, welch eine Erleichterung ein »elektrisches Leben« mit sich bringen könnte, ist doch der Arbeitsalltag im Dorf ohne technische Geräte sehr beschwerlich. ${ }^{556}$ Dieses Bedürfnis ist allerdings nicht der Kern der Erzählung, die zwar »unmerklich [...] Sehnsüchte nach einem leichteren Alltag wach[ruft]«, doch zugleich zeigt, dass das Leben dadurch auch »schwerer werden kann «. ${ }^{557}$ Damit unterscheidet er sich von der klassischen Botschaft der Migration, dass am Anfang der Wunsch stehe, anders und besser zu leben,, 58 wie ihn Bekir Yıldız, Aras Ören oder Helma Sanders-Brahms in ihren Reflexionen zur Migration in den 1960er und 1970er Jahren dargestellt haben. Die Tochter des Schmieds macht stattdessen deutlich, dass das Fehlen sozialer Teilhabe den

553 ÖZDoĞAN (2005): S. 192.

554 Siehe hierzu: ŞAMdERELI (2011). In Sinan Akkuş' Komödie EveT, ICH wILL! ist es ein Afro-Amerikaner, der heimlich mit der Türkin Nursel zusammen ist, die eigentlich mit dem homosexuellen Türken Emrah verkuppelt werden soll. Siehe hierzu: AKKuş (2008).

555 Hofmann (2013): S. 123.

556 So beschreibt auch Dilek Güngör in Das Geheimnis meiner türkischen Großmutter den Alltag der in die Familie eingeheirateten Özlem im türkischen Dorf. Siehe hierzu: GüNGÖR (2008): S. 130. 557 Siehe hierzu: https://opac.stadt.wuerzburg.de/opax/ftitle.C?LANG=de\&FUNC=full\&SORTX= 13\&509143=YES (03.08.2018).

558 EzLI, Özkan/STAUPE, Gisela (2014): „Vielfalt als soziale Utopie«. In: dies.: Das neue Deutschland, S. 6-11, hier S. 8. 
Menschen einsam macht. ${ }^{559}$ Ein im Roman verhandeltes Thema ist also Partizipation. Eine andere These lautet, dass kulturelle Unterdrückung auf den eigenen und nicht auf systemischen oder gesellschaftlichen Entscheidungen basiert. Gül hätte wahrscheinlich eine weitergehende Schule besuchen können, hätte sie das gewollt, ausgesprochen und durchgesetzt. Doch um Artikulation, wie sie sich Homi Bhabha, Stuart Hall und Gayatri Spivak noch gewünscht hatten, geht es in den 2000er Jahre nicht mehr - sondern darum, was man tut und wofür man sich entscheidet.

Alle besprochenen Filme und Bücher berichten aus dem Innenleben der Türken. Im Unterschied zu MEINE VERRÜCKTE TÜRKISCHE HochZEIT, Die FrEMdE, Leyla und Die fremde Braut werden Regeln in Die Tochter des Schmieds nicht gebrochen, sondern befolgt. Dafür werden sie aber ebenfalls sichtbar gemacht und nach außen gekehrt. Obwohl die Unterscheidung zwischen Moderne und Tradition natürlich mitschwingt, ist sie in den Erzählungen der 2000er Jahre nicht so entscheidend wie in den 1980er und 1990er Jahren. Özdoğan stellt etwa keine der Schwestern freier oder besser dar oder unterscheidet wertend zwischen Progressiven und Traditionellen. Gesellschaft ist außerdem keine abstrakte Kategorie. Sie ist zwar über Regeln und Normen im Spiel, aber zugleich nur »Kulisse «. ${ }^{560}$ Denn im Zentrum der Verhandlung von Kultur steht in den 2000ern, wie schon öfter betont, die Frage danach, was man lebt und auf welchen Entscheidungen dieses Leben beruht, nicht die klassische Frage der Integration, ob man sich wird anpassen können oder wie man die eigene Herkunftskultur in der Ankunftsgesellschaft am Leben hält. Auf die Erfahrung seiner Leser, dass sie Gül am liebsten »durchschütteln« würden, entgegnet Özdoğan, dass eine solche Reaktion auf seine Figur »einem anderen Denken geschuldet« sei:

Das ist einfach die Welt, in der sie lebt, das ist eine schöne Form für einen Roman, so eine Emanzipationsgeschichte, aber das ist nicht das, was mich interessiert hat. Es ist einfach nicht ihr Charakter, deswegen möchte ich sie auch nicht schütteln. ${ }^{561}$

In den 2000er Jahren entfalten literarisches und filmisches Erzählen verkörperte Traditionen und korrelieren darin mit dem Zusammenhang von Migration und Integration in der bundesrepublikanischen Politik der Zeit. In allen Bereichen geht es nicht um Einsicht (von draußen nach innen), Entwicklung oder Brüche, sondern um eine Abbildung politischer und ökonomischer Zustände. Dazu gehören Veröffentlichungen und Brüche von kulturell bedingten Familiengesetzen. Auch Dilek

559 ÖZDOĞAN (2005): S. 144.

560 KARAKUŞ (2009): S. 152.

561 Zitiert nach: DREISSLER (2011). 
Güngörs Roman Das Geheimnis meiner türkischen Großmutter von 2007, dem ich mich nun abschließend widmen werde, verbindet türkische Vergangenheit und deutsche Gegenwart so, dass das Leben von Kultur in den Vordergrund rückt.

Das Geheimnis meiner türkischen Großmutter erzählt vom mehrwöchigen Aufenthalt einer deutsch-türkischen Familie in ihrem türkischen Herkunftsdorf nahe der syrischen Grenze. Die Ich-Erzählerin Zeynep ist 32 Jahre alt und kündigt zu Beginn des Romans als Journalistin bei einer Zeitungsredaktion, mit deren Chefredakteur Stefan sie liiert war. Sie wird am Ende des Romans wieder eine Stelle als Journalistin und Redakteurin antreten, wie auch Devrim aus Mein Name ist Revolution am Ende wieder als Radiomoderator arbeiten wird. ${ }^{562}$ Doch davor zieht Zeynep von Berlin wieder zu ihren Eltern in die deutsche Provinz, wo die Nachricht eintrifft, dass ihre Großmutter, die Mutter ihres Vaters, todkrank ist. Die Familie fliegt in die Türkei, um die Großmutter beim Sterben zu begleiten. Wie viele literarische, filmische, aber auch politische Thematisierungen der Migration und Integration in den 2000er Jahren beginnt auch dieser Roman mit dem Bild und dem Gefühl einer Ankunft. Die Erzählerin erinnert sich, wie sie mit ihrer deutsch-türkischen Familie im Auto bei ihrer Großmutter ankommt. ${ }^{563}$ In dieser Erinnerung ist sie noch ein kleines Mädchen, das von der Großmutter in den Arm genommen wird. Dass die Großmutter am Hals »nach saurem Joghurt« riecht, ist die »erste Erinnerung « der Erzählerin an sie. ${ }^{564}$ Der Roman endet nicht mit der Rückreise der Familie nach Deutschland. Zeynep wird alleine zurückreisen. Sie kam nicht in die Türkei, um die Großmutter in den Tod zu begleiten, sondern um sie in erster Linie überhaupt kennenzulernen. ${ }^{565}$ Denn auch wenn sie anfangs lieber zu Hause in Deutschland geblieben wäre, fühlt sie sich mit dem angekündigten Tod der Großmutter auf einmal in das Leben ihrer Eltern hineingezogen. ${ }^{566}$

562 Devrim wird im ersten Drittel des Romans Mein Name ist Revolution gekündigt, weil er bei einem nächtlichen Live-Talk einen erfolgreichen deutsch-türkischen Schauspieler, der gerade den Golden Globe gewonnen hatte, nicht energisch genug unterbrochen hatte, als er über all das in Deutschland herzog, was hier rassistisch sei. Die Zuhörer zeigten sich über »Ayhan Akhans Nazi-Ausfall zutiefst enttäuscht. [...] Wenn Menschen wie er, deren Weg in Deutschland immer nach oben zeige, sich zu solchen Taktlosigkeiten hinreißen ließen, brauche man sich nicht zu wundern, wenn immer mehr Jugendliche aus Einwandererfamilien die Sprache der Gewalt wählten«. Siehe hierzu: AYata (2011): S. 317.

563 AlmanYa bereichert den Aufbruch der Familie in die Türkei mit Archivaufnahmen von dieser Strecke, von Gastarbeitern mit ihren Familien in langen Autostaus oder beim Picknicken in Raststätten. Siehe hierzu: ŞAMDERELI (2011).

564 GÜNGÖR, Dilek (2008): Das Geheimnis meiner türkischen Großmutter, München: Piper, S. 5.

565 Ebd., S. 54.

566 Ebd., S. 21. 
Ich hatte mich nie besonders dafür interessiert und auch nie so recht etwas damit zu tun haben wollen, aber ich hatte das Gefühl, dass ich mich jetzt mit ihrem türkischen Leben befassen musste, ob ich wollte oder nicht. Die Mutter meines Vaters lag im Sterben, ich konnte nicht so tun, als ginge mich das nichts an. ${ }^{567}$

Der Roman endet nicht etwa damit, dass Zeynep ein Jahr nach deren Tod nun die Großmutter und die türkische Kultur kenne, sondern mit ihrem Gedanken, dass sie als unabhängige Frau in Deutschland zu einer Minderheit gehöre - denn hier sei nur jede vierte Frau finanziell unabhängig. Als Journalistin mit kürzlich erfolgreich abgeschlossener Probezeit und einer eigenen Wohnung kann sie »tun und lassen, was [sie] will«. »Niemand schreibt mir etwas vor, außer bei der Arbeit natürlich. Ich bin gern allein. Ich brauche keinen Mann an meiner Seite. Vielleicht später einmal. ${ }^{568}$ Inwieweit dieser überraschende Schluss des Romans mit den Erfahrungen der Ich-Erzählerin im türkischen Dorf, mit ihrer Herkunftsfamilie zusammenhängt, entwickelt sich sukzessive zum Schwerpunkt von Das Geheimnis meiner türkischen Großmutter. Wesentlich ist, dass Ich-Erzählerin Zeynep und Autorin Dilek Güngör ein implizites Gesetz der Familie öffentlich machen, das sie zur Frage der Lebensführung und Entscheidung führt. Zunächst werde ich kurz den Inhalt des Romans zusammenfassen.

Ähnlich wie Zaimoğlu in Leyla und Özdoğan in Die Tochter des Schmieds erzählt Güngör die Geschichte linear. Nach dem ersten von vierzehn Kapiteln steht bereits fest, dass die Familie in die Türkei fliegen wird. Darauf folgen zwei Kapitel der Ankunft in der Türkei, in denen viele Vorstellungen und Erinnerungen dargelegt werden. Im alten Haus der Familie starb etwa der jüngste Bruder ihres Vaters, Onkel Yusuf, nach einer Schießerei. Die anschließende Fehde führte zur Aufspaltung der Familie. Zeynep erinnert aber auch Sinnliches und Schönes, wie das Waschen in der Küche: »Wenn sich jemand einseifte, schwammen kleine Schaumflöckchen quer durch die Küche und verschwanden in der Wand am anderen Ende «. ${ }^{569}$

Auf der Fahrt vom Flughafen zum Dorf im dritten Kapitel fühlt sich Zeyneps Vater neben seinem Bruder sichtlich unwohl. Wir erfahren erst später, dass dies mit einem Familiengeheimnis zu tun hat. Die weiteren Kapitel enden oft mit dem Ende eines Tages oder beginnen mit dem Anfang eines neuen Tages - wie die Romane von Özdoğan und Zaimoğlu. Zugleich ist trotz der Nähe der Protagonistin zu den anderen Akteuren eine ethnologische Perspektive zu erkennen. Oft

567 GÜNGÖR (2008): S. 21.

568 Ebd., S. 207. Eine ganz ähnliche Einschätzung steht am Ende von Einmal Hans mit scharfer Soße: »Ich stelle das Bild einer traditionellen Türkin ganz schön auf den Knopf. Ich bin eine Singlefrau, eine Großstädterin, die sich manchmal als Türkin verkleidet, wenn sie mit einem Kopftuch ihr anatolisches Dorf besucht.« AKYÜN (2005): S. 190.

569 GÜNGÖR (2008): S. 26. 
beschreibt Zeynep etwa, wie und warum sich Männer und Frauen im türkischen Dorf auf eine bestimmte Weise verhalten. Als neunjähriges Kind hatte sie schon auf der Trauerfeier zu Yusufs Tod beobachtet, wie die Frauen sich die Kopftücher vom Kopf zogen, sich weinend und klagend mit der flachen Hand auf die Brust schlugen. ${ }^{570}$ Die Männer hielten sich in einem anderen Raum des Hauses auf. Dort weinte oder schrie niemand. ${ }^{571}$

Erneut beschränkt sich die Übersetzung des türkischen Lebens im Dorf nicht nur auf die Beschreibung des Alltags. Wie schon zuvor häufiger beobachtet, begegnen wir auch hier wörtlichen Übersetzungen aus dem Türkischen, wobei offensichtlich keine Sorge darüber besteht, dass dies orientalisierend wirken könnte. Die Übersetzungen stehen hier direkt nach den türkischen Sätzen. Die Großmutter begrüßt die erwachsene Zeynep etwa mit den Worten: »Kurban olaym sana, nenesinin canı! Großmutters Liebling, mein Leben würde ich für dich geben «. ${ }^{572}$ Als es ihr kurzzeitig wieder besser geht, meinen die Verwandten: »Allaha bin şükür, dem Allmächtigen sei tausend Dank«. ${ }^{573}$ Diese Ausleuchtung der türkischen Kultur und ihr Explizitmachen geschehen nicht nur auf der sprachlichen Ebene, sondern werden auch auf der praktischen Ebene verhandelt. Das zeigt sich vor allem an den Frauenfiguren:

Ich mochte Özlem [Zeyneps Cousine, Ö.E.], mir gefiel ihre Einstellung, sie beklagte sich nicht und bemitleidete sich nicht selbst. Sie wusste, sie würde eines Tages ein Leben mit ihrem Mann und ihren Kindern führen, ohne die bettlägerige Großmutter und den Schwiegervater am Bein. Vielleicht rührte daher ihr Durchhaltevermögen. Wenn heute in Deutschland türkische Arbeiter gesucht würden, wäre Özlem eine der Ersten, die sich darum beworben hätte, da war ich mir ganz sicher. ${ }^{574}$

An einer Stelle wirft Özlem Zeynep sogar vor, dass sie sich nicht durchsetzen könne. Was war vorgefallen? Zeynep hatte anfangs vor, ihre Großmutter und das

570 Ein vergleichbares Trauerritual beschreibt Imran Ayata in Mein Name ist Revolution: „Eine Frau trauert und singt und schlägt sich auf die Brust. [...] Vor meinen Augen spielten sich Szenen der Beerdigung von Tante Güls Cousine Aylin auf dem islamischen Friedhof in Tempelhof ab. Es war die erste Beerdigung meines Lebens gewesen. Auch dort waren Traueroden gesungen worden. Frauen knieten am Grab und wünschten sich laut weinend Aylin zurück.« Genauso verhält sich seine türkische Freundin Rüya, als ihr Vater stirbt: »Irgendwann fing sie an, wie die Frauen am Flughafen eine Trauerode anzustimmen. [...] Dieses Mal wusste ich, wovon sie handelten. Ich hielt Rüyas Hand und streichelte ihre pechschwarzen Haare«. AYATA (2011): S. 140f. u. S. 298.

571 Ebd., S. $24 f$.

572 Ebd., S. 37.

573 GÜNGÖR (2008): S. 42.

574 Ebd., S. 92. 
Leben im Dorf filmisch zu dokumentieren. ${ }^{575}$ Für den Kauf einer Kamera hätte ihr Onkel Mehmet in die Stadt fahren müssen, was er aber nicht tat. Zeynep war es irgendwann egal, während Özlem ihr den obigen Vorwurf machte. Dass ein bestimmtes Bild von Männlichkeit das Leben im türkischen Dorf bestimmt, wird an einer anderen Stelle noch deutlicher. Zeynep besucht die von der Familie ausgeschlossene Döndü, die Schwiegertochter ihrer Großmutter, im alten Haus. Ihr wird nachgesagt, dass sie die Kinder ihres verstorbenen Mannes gegen seine Familie aufgehetzt habe. ${ }^{576}$ Von ihr erfährt Zeynep, dass der Mord an ihrem Mann auf eine lange Blutsfehde zurückging: Zuerst wurde der Bruder von Zeyneps Großvater väterlicherseits von einer fremden Familie getötet. Um seinen Tod zu rächen, zwangen Zeyneps Großvater und besonders ihre Großmutter ihren Sohn Mehmet, Zeyneps Onkel, dazu, ein Familienmitglied der verfeindeten Familie zu töten. Das hatte sie von ihrem Mann Yusuf erfahren, denn sie hatte einen großen Einfluss auf ihn. Er sollte das tun, wofür ihr Mann selbst nicht Manns genug war: "»Mehmet hat einen der Söhne des Mannes erschossen, der den Bruder deines Großvaters getötet hatte. So macht man das hier im Dorf. Jeder rächt seinen Toten selbst. « Sie verzog das Gesicht zu einer sarkastischen Grimasse. ${ }^{577}$ Döndü ergänzt, dass Mehmets Vater ein »furchtbarer Tyrann« gewesen sei, »dominant« und »rücksichtslos«. Dennoch sei er nicht in der Lage gewesen, die Tötung seines Bruders selbst zu rächen. Mehmet musste der Mann sein, der sein Vater nie war. ${ }^{578}$

Nach dem Besuch bei Döndü war Zeynep nun klar, warum ihre Mutter das Dorf, ihren Schwager und ihre Schwiegermutter hasste. Ihr Vater nahm »seine Herkunftsfamilie nie in Schutz«, machte ihr aber auch keine Vorwürfe. Nach Deutschland floh er vor der Tradition, und vor der damit zusammenhängenden Verantwortung. Mehmet büßte seine Tat mit mehreren Jahren im Gefängnis. Zurück in Deutschland ist Zeynep unendlich froh, dass sie hier lebt. ${ }^{579}$ Özlem wird Zeynep im neuen Haus ebenfalls erzählen, dass der Großvater ein »Tyrann,

575 Als der ehemalige Radiomoderator Devrim in Ayatas Roman Mein Name ist Revolution ein Gespräch über die alten Zeiten zwischen seinem Onkel und seinem türkischen Bruder in einem Dorf nahe Dersim verfolgt, bereut er es auch zutiefst, dass er kein Aufnahmegerät mitgenommen hat, um ihre Erinnerungen an die 1960er in der Osttürkei zu dokumentieren. Siehe hierzu: AYATA (2011): S. 205.

576 GÜNGÖR (2008): S. 103.

577 Ebd., S. 143.

578 Ebd., S. 144.

579 Ebd., S. 147. Dasselbe empfindet Feridun Zaimoğlu, als er von seiner ersten Recherchereise zu Leyla nach Deutschland zurückkehrt: »Fast hätte ich den deutschen Boden geküsst, meinen Freunden und Bekannten war mein Verhalten sehr peinlich, und sie ermahnten mich, es mit meiner Deutschlandliebe nicht zu übertreiben«. ZAIMoğLU (2008): S. 36. 
ein richtiges Ekel« gewesen sei: »Wenn ihm nicht schmeckte, was ich gekocht hatte, hat er seinen Teller gegen die Wand geschleudert «. ${ }^{580}$

Zeynep, die Großmutter und Großvater in guter und zärtlicher Erinnerung hat, ist äußerst irritiert über das, was sie aus unterschiedlichen Quellen über ihre Herkunftsfamilie erfährt. Für sie ist nicht die Tradition oder eine Kultur an der Familientragödie schuld, sondern die Akteure selbst: »Ob Onkel Mehmet nun von seinen Eltern dazu gezwungen worden war oder nicht: der Mann hatte jemanden getötet, und niemand in der Familie schien ihm das ernsthaft vorzuwerfen. Nicht einmal meine Eltern. ${ }^{581}$ Wie habe der Großvater nur »nicht in der Lage [sein können], sich gegen diese grausame Tradition durchzusetzen «. ${ }^{582}$

Dennoch bleibt Zeynep bis zum Tod der Großmutter in der Türkei und hat dabei das Gefühl, als habe sie die »Seiten gewechselt«. In einem Gespräch kommen Großmutter und Enkelin erneut auf den Großvater zu sprechen:

»Hat er [der Großvater, Ö.E.] Dir nicht gefallen?«

Jetzt war es mir auch egal.

»Einen, der seinen Sohn zu einem Mord angestiftet hat, den er nicht begehen wollte.»

»Allah kahretsin seni, verdammtes Biest. Du sprichst nicht so über deinen Großvater, hast du das von deiner Mutter? « Sie sah mich drohend an. »Geh raus, lass dich nicht mehr an meinem Bett blicken. Geberesice, verrecke, wie viel Zeit und Mühe habe ich verwendet, damit du mir das ins Gesicht spuckst? Geh zurück zu ihm [ihrem Freund Stefan, Ö.E.] und lebe dein Leben, sinnlos wie bisher. Ich will dich nicht mehr sehen, verschwinde. ${ }^{583}$

Vor lauter Wut krächzt sich die kranke Großmutter ganz heiser - als ob ihre Geschichte und Vergangenheit aus ihrer Haut nach draußen drängten. Anfangs war die Großmutterfigur fremd, auch weil sie bei den seltenen Telefonaten zwischen der Türkei und Deutschland immer danach fragte, wann Zeynep denn endlich heiraten würde. Später wird sie zu einer Freundin, mit der Zeynep über alles, vor allem über ihren Partner Stefan, reden kann. Der emotionale und körperliche Ausbruch am Ende des Romans steht dazu nicht im Gegensatz: Die Großmutter entschuldigt sich zutiefst bei ihrer Enkelin; sie sei so wütend gewesen, weil sie nicht möchte, dass Zeynep sich wegen eines Mannes ins Unglück stürze. ${ }^{584}$ Kurze Zeit später stirbt die Großmutter. Zeynep kehrt zurück nach Deutschland und entscheidet sich dafür, finanziell unabhängig ohne Mann glücklich zu werden - was selbst in Deutschland eine Seltenheit ist. Dabei hat

580 GÜNGÖR (2008): S. 160.

581 Ebd., S. 150.

582 Ebd., S. 187.

583 Ebd., S. 194.

584 Ebd., S. 195. 
sie sich die emanzipierte Haltung nicht in Deutschland, sondern im türkischen Dorf angeeignet; dort, wo die Frauen an den Konsequenzen ihrer falschen Entscheidungen litten. Die Autorin hatte den Roman ursprünglich Am falschen Ort nennen wollen, was den konstitutiven Zusammenhang von Ort, Praktiken und Entscheidungen noch besser verdeutlicht hätte als der vom Verlag durchgesetzte Titel Das Geheimnis meiner türkischen Großmutter. ${ }^{585}$

In einem längeren Interview in der Frankfurter Rundschau zur Erstveröffentlichung des Romans antwortete die Autorin Dilek Güngör auf die Frage, ob sie mit ihrer Blutrache-Geschichte nicht befürchte, Vorurteile gegenüber Immigranten zu nähren, dass ihr diese Gefahr bewusst sei, man sich ihr aber nicht beugen dürfe. »Man muss offen über die Dinge reden «, konstatiert Güngör. Sie habe ja nur aufgeschrieben, was sie verstanden habe. ${ }^{586}$ Das Dorf habe beispielsweise ihre Mutter, die dort aufgewachsen sei, nicht daran gehindert, »sich ihre eigenen Gedanken zu machen und schon gar nicht daran gehindert, anderen zuzugestehen, dass sie anders leben wollen, als sie es getan hat ${ }^{587}$ Wie in den anderen besprochenen Romanen und Filmen setzt Güngörs Roman den Fokus auf Handlungen, die wiederum historisch, örtlich und räumlich spezifisch gerahmt sind. Auch hier ist von anderen Türken und Deutschen die Rede, denen wir aber ebenfalls kaum begegnen. Gesellschaft ist auch hier nur Kulisse. Es geht ein weiteres Mal darum, was die Akteure in ihrem Alltag leben. Für die Sichtbarmachung und diesen Schwerpunkt wird erneut ein Hausgesetz geltend gemacht, das in einer modernen, vom Staat gelenkten Gesellschaft nicht mehr gelten darf. Um dies zu verdeutlichen, habe sich Güngör für den Begriff »Familienfehde« entschieden statt für »Blutrache«. Denn über den ersteren könne man im Vergleich zum letzteren »noch reden«: »Da gibt es ein Für und Wider, die Möglichkeit einer Auseinandersetzung. Das Urteil steht noch nicht fest $«{ }^{588}$ Wie bereits festgestellt, ist Kultur in den 2000er Jahren ein Material und ein Ensemble von Kategorien, aber nicht von unbeweglichen Essenzialismen. Es geht um die Frage, welche Bedeutung man ihr gibt und wie man sich entscheidet. Um dieses Verhältnis zwischen Kultur und Akteur in den 2000er Jahren ausleuchten zu können, ist eine ethnologische Übersetzungsarbeit unerlässlich.

585 INTERVIEW MIT DiLEK GÜNGÖR (2007): »Wir sind alle Hinterwäldler. Die Schriftstellerin Dilek Güngör über ihren ersten Roman Das Geheimnis meiner türkischen Großmutter«. In: FRANKFURTER RUNDSCHAU, 15.03.2007, http://www.fr.de/kultur/literatur/schriftstellerin-dilek-guengoerwir-sind-alle-hinterwaeldler-a-1195060 (08.08.2018).

586 Ebd.

587 Ebd. Diese Einschätzung der eigenen Eltern, die keine nennenswerte Bildung genossen haben, finden wir auch bei Hatice Akyün und Feridun Zaimoğlu, wenn erstere von ihrem Vater und letzterer von seiner Mutter erzählt. Siehe hierzu: AKYÜN (2005): S. 189; ZAIMOĞLU (2007): S. 34. 588 INTERVIEW MIT DILEK GÜNGÖR (2007). 
Die durchweg positiven Rezensionen von Dilek Güngörs Roman ähneln denen von Zaimoğlus Leyla und Özdoğans Die Tochter des Schmieds. Mit »literarischer Ruhe«, »schlichtem poetischen Erzählen« gelingen Güngör »hervorragende Alltagsbeschreibungen«. Obwohl die Erzählung - wie bei Zaimoğlu und Özdoğan - in der türkischen Provinz stattfindet, schafft es Güngör, beide Welten - das Türkische und das Deutsche - zusammenzuführen, indem sie sie in die deutsche Gegenwart übersetzt und am Ende in Deutschland ankommt. ${ }^{589}$ Zehn Jahre später stellt die Autorin diese Form der Migrationserzählung wieder in Frage; das Narrativ scheint nicht mehr zu funktionieren. Auch die Bindung von Vergangenheit und Gegenwart als Verweis auf eine handlungsorientierte Zukunft in Deutschland mit türkischem und muslimischem Hintergrund verliert ihren stabilen erzählerischen Rahmen - einen Rahmen, den auch die Deutsche Islam Konferenz anbieten wollte.

In vorab veröffentlichten Szenen aus einem längeren Text von Dilek Güngör in der Berliner Zeitung beschreibt die Erzählerin von einem Erlebnis, das sie überraschenderweise tief verletzte. In einem Berliner Bioladen, in dem sie seit mehr als 15 Jahren einkauft, legt sie Kiwis und Gurken aufs Band. Vor ihr hatte eine Gruppe Bauarbeiter eingekauft, und die eine Kassiererin klärt die andere auf: "Die sind von der Baustelle drüben, alles Ausländer«. Anstatt sich zu wehren wie Aylin aus MEINE VERRÜCKTE TÜRKISCHE HoCHZEIT oder Canan aus AlmANYA, ${ }^{590}$ merkt die Erzählerin »mit einem Mal, wie mir die Tränen kommen, wie ich richtig wütend werde, während ich meinen Bio-Scheiß da aufs Band lege«. Die Kassiererin fragt, was sie denn habe. Die betroffene Erzählerin erwidert: »Warum sagt sie das? - »Was denn?«, fragt die Kassiererin zurück. »Wie lange müssen wir uns das noch anhören, dass wir Ausländer sind?«. Erst danach wendet sie sich wütend an die andere Kassiererin und hält ihr vor, dass sie jede Woche hier einkaufe und Geld dalasse. »Wann ist es denn endlich gut?«; wie lange sollten sie

589 Laut Karen E. Yeşilada folgt Güngörs Roman einem aktuellen Trend der Migrationsliteratur der zweiten Generation, demgemäß »die eigene Migrationsgeschichte zum Gegenstand literarischen Schreibens« werde. Wie viele andere Autorinnen der 2000er Jahre komme Güngör dabei dem Verlangen des deutschen Publikums nach mustergültig integrierten türkischen Frauen nach. Diese lehnen sich nicht auf wie die `Kanaken « der 1990er Jahre, sondern sind »schön anzuschauende Paradebeispiele einer sgelungenen Integration««. Siehe hierzu: YeşILADA (2009): S. 134.

590 Canan fährt einer älteren deutschen Dame in der Dortmunder U-Bahn über den Mund, die sie als Nicht-Deutsche beleidigt. Ähnlich wie sie reagiert auch Hatice Akyüns Ich-Erzählerin in Einmal Hans mit scharfer Soße auf Diskriminierung. Als ihre Mutter bei einem Einkauf von einer deutschen Kassiererin mit den Worten »Du nix anfassen « zurechtgewiesen wird, meint die Tochter: »Ich frage die Verkäuferin höflich, ob sie den Satz bitte noch einmal grammatikalisch korrekt formulieren könnte, mache sie darauf aufmerksam, dass ihr Benehmen ausländerfeindlich sei, und fordere sie auf, sich bei meiner Mutter zu entschuldigen«. Siehe hierzu: AKYÜN (2005): S. 169. 
sich denn noch »beschimpfen « lassen? Sie habe ihr doch gar nichts getan, wehrt sich die Angesprochene. Die Kollegin pflichtet ihr bei, dass sie das gar nicht so gemeint hätte. Außerdem hätten die Männer ihren Müll fallenlassen und seien angetrunken gewesen. »Wenn die da ihren Müll hinwerfen, dann nicht, weil sie Ausländer, sondern weil es vielleicht Idioten sind«, ruft die Erzählerin. Die Kassiererin erwidert, dass sie nicht wisse, was sie von ihr wolle. »Ja, das kenne ich, dich meinen wir nicht, wir meinen die anderen Ausländer, seit 44 Jahren geht das so.« Wieder auf der Straße denkt die Erzählerin darüber nach, dass sie eigentlich nicht jemand sei, der »aus dem Haus [geht], um Ungerechtigkeiten aufzustöbern. Sie passieren mir, aber plötzlich regt sich etwas in mir, ich weiß gar nicht, was passiert ist «. ${ }^{591}$

Zehn Jahre zuvor hatte ihre Protagonistin Zeynep noch beherrscht auf Diskriminierungen reagieren können. Nach der Trennung von Stefan schlägt sie dessen Bitte ab, für seine Zeitung einen Artikel über muslimische Frauen in Berlin zu schreiben. Als Stefan sie später oft in der Türkei anruft, sagt sie ihm, dass er das nicht tun solle, weil ihr Onkel etwas dagegen habe. Stefan lacht und macht sich darüber lustig, dass das aber ein ganz schön »böser, böser Onkel sein muss«. Am liebsten hätte Zeynep aufgelegt, doch diese Zeiten waren vorbei. Zafer Şenocaks Protagonist Sascha Muhteşem konnte in Die Prärie aus den 1990er Jahren noch provokativ auflegen oder »falsch« übersetzen, wenn deutsche Chefredakteure von ihm Artikel zu Türken in den USA und Muslimen in Berlin verlangten. Dilek Güngörs, Yade Karas und Hatice Akgüns Protagonisten beherrschen sich Mitte der 2000er hingegen und wollen letztlich vermitteln. »Ich versuchte, mich zusammenzureißen « ${ }^{52}$, sagt Zeynep. Allerdings fragt sie sich dabei: Wenn »dumme Sprüche« über Onkel Mehmet sie »auf die Palme bringen konnten, wie hätte ich erst reagiert, wenn er einen Witz über Anatolier, Rachemorde und >deine Kultur gemacht hätte«. 593

Zehn Jahre später vermag Güngör Diskriminierungen nicht mehr individuell zu kontern bzw. sie auch nicht zu kontextualisieren. Dadurch geht die Möglichkeit verloren, einen kulturellen Kompromiss auszuhandeln, und es wird deutlich, dass selbst die Zeit der Integration in der Bundesrepublik nur eine Phase war. So stellen Güngörs Artikel seit 2016 die eigene Integration in Frage. ${ }^{594}$ Mit Menschen,

591 GÜNGÖR, Dilek (2016): »Ich habe es satt, immer den Kopf einzuziehen«. In: BERLINER ZEITUNG, 03.10.2016, https://www.berliner-zeitung.de/berlin/dilek-guengoer-ich-habe-es-so-satt--immerden-kopf-einzuziehen-24831704 (09.08.2018).

592 GÜNGÖR (2008): S. 202.

593 Ebd., S. $203 f$.

594 Siehe hierzu: GüNGÖR, Dilek (2016): »Anderssein ist kein Widerspruch«. In: DIE ZEIT, 31.10.2016, https://www.zeit.de/kultur/2016-08/anderssein-schule-schwaben-jugend-kindheit- 
die sie nicht kennt und die wahrscheinlich nicht einmal einen türkischen Hintergrund haben, fühlt sie sich auf einmal verbunden, weil die deutsche Kassiererin diese Männer als »Ausländer« bezeichnet, wobei Güngör doch Deutsche geworden war. Während sie sich zuvor als Individuum über ihre Lebensweise beschrieben und als ein Teil von Umgebungen, Orten und Kontexten begriffen hat, wird sie in diesem Erlebnis zu einem Teil eines unbestimmten Kollektivs, das nicht mehr ihren Verstand, sondern einzig und allein ihr Gefühl anspricht, nun schon seit Jahrzehnten als Ausländerin vermeintlich diskriminiert worden zu sein. Dabei geht es nicht um die Bauarbeiter selbst, denn diese scheinen sich wirklich nicht angemessen zu verhalten, sondern vielmehr darum, was der Gebrauch des Begriffs Ausländer auslöst, was er aus der Geschichte Güngörs hervorholt und ausbrechen lässt. Im Roman Ich bin Özlem von 2019, der mitunter auf der Supermarktszene aufbaut, bestimmt dieser Vorrang des Affektiven, einer negativen Identität, die gesamte Erzählung. ${ }^{595}$ Auch Hatice Akyün verliert durch die Sarrazin-Debatte ${ }^{596}$ von 2010 und ihren Folgen ihren Humor, ihre Reaktionsfähigkeit und überlegt, mit ihrer Tochter in die Türkei auszuwandern. Auch hier treten an die Stelle von humorvoller und kontrollierter Reaktion Affekte, die ein Unbehagen auslösen. Denn die Stimmung in Deutschland nach der Debatte mache ihr Angst. ${ }^{597}$ Tatsächlich schildert Akyüns anschließende Veröffentlichung Ich küss Dich, Kismet. Eine Deutsche am Bosporus (2013) den Versuch, mit der Tochter für immer in die Türkei zurückzukehren. Sarrazin habe ihr das Türkische aufgedrängt, während sie in der Türkei erfahren musste, dass sie Deutsche sei, aber

zugehoerigkeit-10nach8 (09.08.2018). Siehe auch: »Warten auf den Moment, in dem es auffliegt«. In: DIE ZEIT, 16.07.2018, https://www.zeit.de/kultur/2018-07/hochstapler-syndrom-gesellschaftliche-minderheiten-psychologie (09.08.2018).

595 Siehe hierzu: GüNGÖR (2019).

596 In einem Lettre-Interview von 2009 und in seinem Buch Deutschland schafft sich ab von 2010 verknüpft der damalige Berliner Finanzsenator Thilo Sarrazin die Zukunftsfähigkeit Deutschlands mit der Integrierbarkeit oder Nicht-Integrierbarkeit der unproduktiven, von Transferleistungen lebenden Unterschicht. In einer biologistisch-kapitalistischen Diktion zwischen brauchbarem Genpool und gesellschaftlichem Kosten-Nutzen-Verhältnis stellte im Zusammenhang von Prekariat und Gesellschaft insbesondere der Muslim ein erweitertes Gefahrenpotential für die deutsche Gesellschaft dar. Wenn die deutsch-deutsche Unterschicht durch spezifische Anreize wieder in den Arbeitsmarkt geführt und so eine »Verdummung« Deutschlands noch verhindert werden könne, so sei dieser Prozess der Integration bei Muslimen nicht möglich, weil sie aufgrund ihrer Religion nicht modern sein könnten und zudem gefährlich seien. Siehe hierzu: SARRAZIN, Thilo (2010): Deutschland schafft sich ab. Wie wir unser Land aufs Spiel setzen, München: Deutsche Verlags-Anstalt, S. 260-281. Diese Thesen lösten die bislang längste Integrationsdebatte in der Geschichte der Bundesrepublik aus.

597 Siehe hierzu: AKYÜN, Hatice (2011): »Wir stehen wieder bei null«. In: Migazin, 08.11.2011, http://www.migazin.de/2011/02/08/hatice_akyun-wir-stehen-wieder-bei-null/ (18.09.2018). 
die Türkei auch nicht lassen könnte. Mit dem »Hier komme ich her« ist zugleich die Erkenntnis verbunden, dass sie »hierher « nicht mehr will. ${ }^{598}$ Neben der Sarrazin-Debatte ist dafür auch die Politik des türkischen Präsidenten Erdoğan und die Reaktion des Staates auf die Geziproteste 2013 in Istanbul verantwortlich. Eine neue Form der Unbehaustheit und des kulturellen Unbehagens macht sich breit, die im Unterschied zu den Konstellationen zuvor (»Wir wollten alle Amerikaner werden«, »Wie lebt es sich als Türke in Deutschland?«, »Wie lebt es sich in Deiner Haut?« und »Was lebst Du?«) keine Projektion wie Zivilisation, kulturelle Tradition, Weltverbundenheit und kulturellen Lifestyle anbietet, mit der man sich identifizieren konnte. Was sich aber eindeutig zeigt, ist die Entscheidung für das Land, in dem man leben will - wobei die Gefühle für die dazugehörige Gesellschaft wieder ambivalent werden. Da im Unterschied zu den 1990er Jahren die filmischen und literarischen Erzählungen der 2000er Jahre weitaus mehr Türkisches und Muslimisches produzieren, obwohl der Begriff des Multikulturalismus damals prägend war, will ich im nachfolgenden Fazit die besprochenen Werke mit den Überlegungen zum Multikulturalismus abgleichen. Daran wird nachvollziehbar, um welche Art der Produktion von Vielfalt, ihrer Formen der Verhandlung, des Gesprächs es sich in der Phase der Integration in der Bundesrepublik überhaupt handelt und wie diese einerseits die Grundlagen aktueller Texte und Filme sind, andererseits letztere zugleich ihre Formen der Soziabilität suspendieren, weil sie sich diskriminiert fühlen.

\subsection{Fazit zu »Was lebst Du?»}

Mitte der 1990er Jahre konstatiert der kanadische Multikulturalismusforscher Will Kymlicka, dass es richtig und angemessen sei, wenn sich der Charakter einer Kultur - gemeint sind westliche Einwanderungsgesellschaften - durch die Entscheidungen ihrer Angehörigen verändere. Die Mitglieder einer bestimmten Kultur innerhalb einer Mehrheitsgesellschaft sollten die Möglichkeit haben zu entscheiden, was sie aus ihrer eigenen Kultur mit dem Erstrebens- und Bewundernswerten der anderen Kultur verbinden wollen. ${ }^{599}$ Bewundert und gewollt wurde in den 1960er und 1970er Jahren das Leben der Amerikaner, wobei diese

598 АкYÜN, Hatice (2015): »Mein kleines Dorf«. In: dies.: Ich küss dich, Kismet, Köln: Kiepenheuer \& Witsch, S. 184-202. Siehe auch: STERNBERG, Jan (2013): »Deutschland, du wirst mich nicht los«. In: Kultur im Norden, 04.09.2018. Siehe hierzu auch: AKYüN, Hatice (2013): Ich küss dich, Kismet. Eine Deutsche am Bosporus, Köln: Kiepenheuer \& Witsch.

599 KyмLickA, Will (1995): Multicultural Citizenship. A liberal theory of Minority Rights, Oxford: Oxford University Press, S. 105. 
Sehnsucht das Türkisch-Sein nicht tangierte. Denn wie ein Amerikaner konnte man auch im Istanbuler Stadtteil Bebek oder in Deutschland leben. Auch in Milton Gordons Assimilationstheorie von 1964 konnte man Amerikaner werden und sein und zugleich ethnisch einer anderen Gruppe angehören. In den 1980er Jahren gehörte man hingegen erst dann zum Westen, wenn man kein Teil des Ostens mehr war. Kymlickas Unterscheidung zwischen »eigen « und »fremd « aus den 1990er Jahren plädiert hingegen dafür, kulturelle Eigenarten und Kompatibilitäten aus einem geschützten Raum in eine kulturell anders gelagerte Mehrheitsgesellschaft hineinzutragen, also zu veröffentlichen. Die Kultur der Mehrheitsgesellschaft beschreibt er als die bestimmende »societal culture« im öffentlichen Raum, als Ort der Aushandlung und Begegnung, der sich durch ein alltägliches Vokabular des sozialen Lebens ergebe, welches über Praktiken im öffentlichen Raum alle Bereiche menschlicher Aktivitäten abdeckt. ${ }^{600}$ Jede Kultur wird in einer Gesellschaft, die nicht Teil dieser »societal culture« ist oder wird, immer stärker marginalisiert werden. So ist nach Kymlicka für gelingende Integrationsprozesse der Zugang der Minderheiten-Kultur zu dieser »societal culture» der Mehrheit zentral. Doch muss bei diesem Prozess, über den die Mitglieder der Mehrheit entscheiden, neben dem Zugang zur Mehrheit noch eine wesentliche Grundlage erfüllt sein. Denn die Basis für diesen auf Wechselseitigkeit gründenden Integrationsprozess zwischen Minderheiten und der Mehrheitsgesellschaft sei, ${ }^{601}$ dass das Leben der Mitglieder von innen (»from the inside«) mit Glaubensgrundsätzen und Werten geführt und gelebt wird. Aber auch für Andreas Wimmer ist Mitte der 2000er Jahre der »kulturelle Kompromiß« ein sich wechselseitig beeinflussendes Wechselspiel von innerer kultureller Prägung, öffentlichen Interpretamenten und Handlungen. ${ }^{602}$

Wie in diesem Kapitel gezeigt, bewegen sich die Akteure koordiniert oft von innen nach außen, aber auch von außen nach innen. Beide Bereiche sind zugänglich - anders, als in den 1990er Jahren, als der Fokus noch auf der Schwelle lag. Melek aus ZEIT DER WÜNSCHE (2005) geht z. B. gemeinsam mit ihren Kindern aus der Wohnung auf die Straße, Felix aus WUT (2006) steigt aus dem Schulbus, wird dort von Can ausgenommen, und der Film endet zuhause. In den behandelten Texten und Filmen haben aber auch die zentralen Elemente der »societal culture«, die Grundlagen eines »embodied social life« - nach Kymlicka: »schools, media, economy, government« -, ebenfalls eine herausragende Bedeutung. In Almanya, Wut, TÜRKISCH FÜR ANFÄNGER, Leyla, Die Tochter des Schmieds, in Murat Topals Kabarett Getürkte Fälle, in Kaya Yanars Made in Germany und im

600 Siehe hierzu: Ebd., S. 96.

601 Ebd., S. 96.

602 Siehe hierzu: Wimmer (2005): S. 34. 
Theaterstück Verrücktes Blut von 2010 werden die Schule, die Berufe der Protagonisten thematisiert bzw. in ALMANYA sogar die Bundeskanzlerin Angela Merkel selbst gezeigt. In EvET, ICH WILl!, Das Geheimnis meiner türkischen Großmutter, EInMal Hans Mit SCHARFER Sosse, Mein Name ist Revolution sind die Ausbildungen und Berufe der Protagonisten für die Erzählungen ebenfalls entscheidend; alle arbeiten in der Medienbranche der Mehrheitsgesellschaft. ${ }^{603}$

Doch selbst wenn die Zugänge und die Grundlagen der öffentlichen Gesellschaft einer Multikulturalismustheorie aus den 1990er Jahren mit den Filmen der 2000er Jahre übereinzustimmen scheinen, unterscheiden sich die filmischen und literarischen Erzählungen von der Theorie in einem wesentlichen Punkt. Denn im vielbeschworenen Verhältnis von innen und außen, der Privatheit und Öffentlichkeit in Kymlickas Theorie, muss die Kultur im Privaten auch die Angelegenheit ihrer Mitglieder sein und nicht die einer societal culture. Sie darf seiner Ansicht nach für ein Gelingen der Integration nicht ausgeleuchtet bzw. »veröffentlicht « oder herausgestülpt werden. Die Verhandlung der Migration und ihrer Folgen basiert in den 2000er Jahren aber genau auf der Ausleuchtung und Darstellung der privaten Ebene. In ZEIT DER WüNSCHE ist es das Bild vom Dorf in der Wohnung, das in den Akteuren steckt - und das uns in heller Belichtung übersetzt wird. Aber auch Zaimoǧlu, Şenocak, Kelek und viele andere leuchten diesen Innenraum aus, übersetzen ihn und verbinden ihn mit bestimmten Orten und öffentlichen Räumen. Als Gründe für seine Unterscheidung von innen und außen und ihrer Vermittlung über Zugänge gibt Kymlicka zwei Grundlagen seiner Migrations- und Integrationstheorie an: Als Gegner von Assimilationstheorien ist er davon überzeugt, dass jedes Mitglied einer Gesellschaft eng mit seiner kulturellen Herkunft verbunden ist. Sie kann gerade nicht, wie im klassischen assimilatorischen Modell, im Laufe der Zeit und über Generationen abgelegt werden. Aufgrund dieser Vorannahme und Vorentscheidung wird die Frage des Zugangs zum öffentlichen Raum, seinen Orten und Institutionen entscheidend für die Entwicklung eines gemeinsamen »everyday vocabulary of social life«. Denn die eingewanderten Menschen haben zwar ihre Sprache und ihre historischen Erzählungen mitgebracht, aber »they have left behind the set of institutionalized practices, conducted in their mother tongue «. ${ }^{604}$ Letztlich geht es für Kymlicka darum, Sprache und Geschichte als Teile der eigenen kulturellen Intimität dauerhaft mit der Praxis im öffentlichen Raum zu verbinden, ohne dabei die Intimität zu verletzen. Das klingt schön, ist aber nicht frei von Widersprüchen.

603 Siehe hierzu: AKYÜN (2005); GÜNGÖR (2007); AKKUŞ (2008); AYATA (2011). 604 Ebd., S. 77. 
Denn als Kymlicka seine Theorie zum Multicultural Citizenship in den 1990er Jahren entwickelt, sind sowohl Kanada als auch die Vereinigten Staaten von Amerika schon lange Einwanderungsgesellschaften. Er geht aber mit der Annahme, was Einwanderer mitgebracht und was sie verloren hätten, von einem Ankunftsnarrativ aus, das sehr an Wolfgang Schäubles oben zitierte Rede zum Abschluss der ersten Phase der Islam Konferenz erinnert. Auch die Bundesrepublik ist damals bereits seit über 50 Jahren von Einwanderung und Migration geprägt. Die Türken seien nun als Muslime angekommen. Der große Unterscheid zwischen den widersprüchlichen Annahmen von Schäuble und Kymlicka oder zwischen den 1990er und den 2000er Jahren ist, dass bei Kymlicka die Mitglieder der Minderheitenkultur von ihrem Zuhause aus an solchen Begegnungen teilnehmen. Bei Schäuble hingegen sind sie gerade aus dem Zug ausgestiegen und sofort Teil des öffentlichen Raums. ${ }^{605}$ Es geht umgehend darum, gemeinsam am Tisch zu bestimmen, was der deutsche Islam sein könnte, ja, was er sogar sein müsste. Bundeskanzler Gerhard Schröder konnte im Jahr 2000 noch als Voraussetzung für Integration bestimmen: »Verfassung achten, die Gesetze befolgen und die Landessprache beherrschen«. Diese integrationspolitische Ausrichtung, die die Privatheit von der Öffentlichkeit trennt, ist nach dem 11. September 2001 nicht mehr haltbar, denn die Terroristen haben in Deutschland studiert, sich dort an die gesellschaftliche Ordnung gehalten und zudem perfektes Deutsch gesprochen. ${ }^{606}$

So drückt sich in den politischen Initiativen für die Integration in den 2000er Jahren auch eine Verschiebung der Innen/Außen-Relation aus, denen wir ebenfalls in den filmischen, literarischen und theoretischen Erzählungen begegnen. Die Muslime sollten ihre Religion so organisieren oder praktizieren, dass sie zur öffentlichen Ordnung, zur deutschen Verfassung passt. Das war das Ziel der Deutschen Islam Konferenz - Stichwort: Minirock und Moschee. Das Ankommen in den Texten und Filmen ist interessanterweise meist auch ein Ankommen in der Mitte der Gesellschaft. Politische Ordnungsfragen des öffentlichen Raums sind auch in den Privaträumen präsent. Von Zaimoğlus Leyla wissen wir von Beginn an, dass sie gegen die Hausgesetze des Vaters ist, die aber auch den Regeln des öffentlichen Raums widersprechen. Daher ist ihre Ankunft in Deutschland zugleich die Ankunft in einer neuen und anderen gesellschaftlichen Ordnung. Der Humanist und Germanistikprofessor Nejat kann Ali nicht mehr als seinen Vater ansehen, weil er keinen Mörder zum Vater haben will. Züli Aladağ versteht die Wut seines Protagonisten Can, kann aber nicht auf seiner Seite stehen oder auch nur eine Zwischenposition einnehmen. Kader und seine Familie aus DIE

605 Siehe hierzu: ScHÄUBLE (2009).

606 Siehe hierzu: Tiвi (2002): S. 305. 
FREMDE können nur Teil der Gesellschaft sein und eine Zukunft darin haben, wenn sie sich gegen die Ordnung der türkisch-muslimischen Community, die ein freies Leben unterdrückt, und für ihre Tochter entscheiden. Aber auch in den besprochenen Komödien werden die Gesetze zu Hause für das Zusammenleben in der Gesellschaft gebrochen. Wie über die Integrationsinitiativen der 2000er Jahre mit Integrationsgipfeln, Islamkonferenzen, dem Zuwanderungsgesetz und dem Nationalen Integrationsfahrplan von 2007 geschehen, muss die Einwanderungsgesellschaft erst politisch, juristisch und ästhetisch gerahmt und sichtbar gemacht werden.

$\mathrm{Zu}$ diesem Prozess des Sichtbarmachens gehört eine besondere Produktion der kulturellen Marker, die entweder $\mathrm{zu}$ immer wieder entstehenden Beleidigungen und Konflikten wie in MEINE VERRÜCKTE TÜRKISCHE HOCHZEIT führen kann oder aber der Prozess der Vervielfältigung wird beispielsweise durch die Überführung der Religion in den Alltag zur Grundlage für ein gemeinsames Weitererzählen und Weitersprechen wie in AUF DER ANDEREN SEITE. Im ersten Film wird die Geschichte der türkischen Migration nach Deutschland und ihren Folgen als Aneinanderreihung wiedergegeben: Heiratsantrag auf Türkisch, deutscher Muslim werden, Einheitsbekenntnis sprechen, fasten, Beschneidung - und am Ende doch ein Macho sein. Dabei geht es nicht um die Darstellung von Stereotypen, sondern um die spezifischen Lebensweisen der Akteure, auch im öffentlichen Raum. Woher sie jeweils kommen und warum es sie immer noch gibt, wird nicht geklärt. Durch diesen Prozess der Aneinanderreihung von Abstrakta vergrößert sich gewissermaßen die Oberfläche der Identität, die verletzt und beleidigt werden kann. Der Film bietet folgenden Ausweg: Türkisches und Deutsches über das eigene Verhalten kompatibel zu machen, indem man sich z. B. mit einem vergangenen Ich berät oder mit türkischen Beobachtern. Kein Akteur in MEINE VERRÜCKTE TÜRKISCHE HoCHZEIT vermag individuell auf Beleidigungen zu reagieren, weil ein kulturell heterogener Alltag weder gezeigt noch dokumentiert wird. Abstrakta und Nomen wie Islam, Muslim, Türke, Deutscher bestimmen mit ihren materiellen Repräsentationen wie Moschee, Kopftuch, Beschneidung und Koran den Film. Man könnte auch sagen: Die Kultur, die auch Kymlicka innen verorten würde, ist längst zum Teil der Außenwelt, des öffentlichen Raums geworden.

Im Gegensatz dazu sind in AUf DER ANDEREN SEITE die unterschiedlichen kulturellen Marker wie Gebetsruf oder bestimmte Regeln für Interaktionsformen von Beginn an miteinander verwoben: Religiöse Begrüßungsformeln, bekannte tradierte Sätze sind Teil der Bedürfnisstruktur der Akteurinnen und Akteure. Im Finale des Films, dem Gespräch zwischen Susanne und Nejat, werden sie wiederholt. Zunächst wird auch hier eine sichtbare Struktur aufgebaut, die der Religion ihre Funktion, ihre Zeit und ihren Ort zuweist. Dadurch wird sie zu einem Bestandteil des Lebens, den die Akteure selbst gestalten können. Auch wenn 
Religion bei Süleyman aus MEINE VERÜCKTE TÜRKISCHE HocHZEIT und Kader aus DIE FREMDE eher im Weg steht, wird in allen genannten filmischen und literarischen Erzählungen die Entscheidung, die durch die informelle Geschichte der Migration in der Bundesrepublik entstandenen türkischen, muslimischen und deutschen kulturellen Marker in einen kompatiblen, d.h. auslebbaren Zusammenhang zu bringen, den Protagonisten selbst überlassen. Sie können sich dabei auf keine kulturellen Kodizes beziehen, wie sie in den Multikulturalismustheorien der 1990er Jahre noch zentral waren. Man ging damals davon aus, »daß alle menschlichen Kulturen, die ganze Gesellschaften über längere Zeiträume mit Leben erfüllt haben, allen Menschen etwas Wichtiges $\mathrm{zu}$ sagen haben «. ${ }^{607} \mathrm{Um}$ auf diese Ebene der Aufnahme kommen zu können, müsste man aber erst mal wieder hören, was Kulturen überhaupt sagen. Wenn Leylas Vater nach dem Koran greift und mit seiner Wutrede ansetzt, bringt er zwar einen mächtigen kulturellen Marker ins Spiel, setzt ihn aber dafür ein, das eigene Unbehagen und die eigene Wut zu artikulieren, ihr eine Form zu geben. Viel weniger geht es darum, tatsächlich zu ergründen, ob sein Verhalten mit den Lehren des Koran übereinstimmt oder nicht. Eine ähnliche Kluft zwischen Norm und Verhalten tut sich auch in DiE FREMDE auf. Hüseyin aus AlmANYA, der auf dem Türkischsein seiner Familie beharrt, obwohl die Familienmitglieder Deutsch miteinander sprechen, erklärt ebenfalls nicht, wodurch sich dieses Türkischsein genau auszeichnet. All das ist nicht zu vergleichen mit den Bemühungen, die in den 1980er Jahren angestellt wurden, um das Türkische zu verstehen. Herkunft ist in den 2000er Jahren im normativen Sinn etwas Fremdes geworden, auf das man nur noch im öffentlichen Raum korrektiv und angemessen reagieren kann, aber nicht mehr in den eigenen vier Wänden. Oder es gelingt einem, dem eigenen Ich aus alten Tagen zu begegnen. Genau durch diese Verwendung von kulturellen Markern und Inhalten unterscheidet sich das kulturelle Innenleben von dem der 1990er Jahre und insbesondere von der Theorie des Multikulturalismus. Dass die Herkunft fremd geworden ist, man aber nur über sie Orte, Plätze und die Gesellschaft finden kann, zu der man gehört, dokumentieren eindrücklich Der Mond ist unsere Sonne, Mein Name heißt Revolution, VERRüCKTES BLUT und LUKS GLÜCK. Im Unterschied zu AUF DER ANDEREN SEITE, Leyla, Wut, Die Tochter des Schmieds, Das Geheimnis meiner türkischen Großmutter und DIE FREMDE ist es in diesen Werken aus den Jahren 2010 und 2011 mitunter nicht mehr möglich, die richtige Entscheidung zu treffen.

Devrim, der Protagonist aus Mein Name ist Revolution, erzählt der »Kanakenlady« Rüya bei ihrer ersten Begegnung, dass er schon ewig nicht mehr in Dersim

607 TAYLOR, Charles (1993): Multikulturalismus und die Politik der Anerkennung, Frankfurt a. M.: Fischer, S. 63. 
gewesen sei, der Stadt, aus der auch Rüyas Eltern stammen. Er müsse auf jeden Fall wieder hin, meint Rüya, denn er werde dort das finden, was in ihm stecke, und diese Stadt verbinde sie beide. Der frisch verliebte Devrim hört sich Musik aus dieser Gegend an, aber er verreist nicht gerne und hat auch kein Fernweh - ganz wie die Protagonisten in Fatih Akıns Soul KITCHEN oder in Nuran David Calış' Der Mond ist unsere Sonne. In Calışs Roman möchte Alens deutsche Freundin weg, »umherziehen «, um die Welt zu entdecken. Alen hingegen ist bei seiner Arbeit als Türsteher in einer Bielefelder Diskothek »schon das ganze Rein und Raus an der Tür manchmal zu viel, all die Gesichter «. ${ }^{608}$ Allerdings überlegt er, mit seiner deutschen Freundin nach Genua zu ziehen und dort eine Espressobar zu eröffnen. ${ }^{609}$ Er sagt es ihr nicht, stellt aber weiter fest, dass sie »Fernweh« habe und er »Heimweh«. Seine deutsche Freundin Floh wusste schon alles über sich und wollte es vergessen. »Ich wollte wissen, wer ich bin. [...] Deshalb musste sie eine Reise nach draußen und ich eine nach drinnen machen. Ich lebte in einer fremden Welt und suchte nach einer vertrauten. « ${ }^{610}$ Alles, was Alen umgibt, gehört nicht ihm. Ihm gehört nur, was in ihm ist. ${ }^{611}$ Alen reist dann doch mit seinem Onkel in den Osten der Türkei, wobei diese Reise für ihn alles andere als eine Entdeckung ist. Der Onkel meinte, er sei »ein Stück Holz im Wasser« dieser deutschen Gesellschaft, das sich einfach treiben lässt, wenn er sich seiner Herkunft nicht bewusst werde. ${ }^{612}$ Doch wir wissen schon von Beginn der Erzählung an, dass die Herkunft seiner Familie, ihre Kultur für ihn keine Entdeckung einer Ressource oder von Freiheit mehr ist, wie es die neue Vielfalts- und Integrationspolitik in den 2000er Jahren sich vorstellte. Alen kann mit seiner Herkunft nichts anfangen und entscheidet sich, ein Teil der Gesellschaft zu werden, nach der er sich sehnt. Zurück in Bielefeld nimmt er sich vor, das »Migrationswunderkind [zu] spielen «, so gut er kann. ${ }^{613}$

Ich werde mich häuten. Ich werde mir die Haut abziehen, wenn sie sich nicht von alleine lösen will. Niemand wird wissen, wer ich wirklich bin. Noch nicht mal mehr ich selber. Meine Mutter wird mich nicht verstehen. Ich werde sie nicht mehr verstehen. Meine Freunde werden mich nicht mehr verstehen. Ich werde sie nicht mehr verstehen. Dafür werde ich ankommen. Dann werde ich endlich dabei sein und dazugehören. Nicht am Rand sein. Nicht mehr außen vor sein. Nicht wie der Typ neben mir. Der auf seiner Heimat-Scheiße

608 CALIŞ (2011): S. 132.

609 Ebd., S. 176.

610 Ebd., S. 185.

611 Ebd., S. 189.

612 Ebd., S. 179.

613 Ebd., S. 15. 
hängengeblieben ist. Der Typ neben mir ist meine eigene Spiegelung. In zwanzig Jahren hänge ich genauso wie er auf diesem Trip, wenn ich jetzt nicht die Kurve kratze. ${ }^{614}$

Auch Devrim aus Mein Name ist Revolution reist mit seinem Onkel in den Osten der Türkei - und will schon nach zwei Tagen wieder zurück. Zu seiner Begrüßung schlachtete der Bruder seines Vaters ein Tier. Devrim ist aber Vegetarier. Da sein Onkel ihm geraten hat, nicht wie ein Kulturimperialist aufzutreten, isst er das Fleisch, um nicht respektlos zu erscheinen. Doch bereuen Devrim und sein Onkel kurz darauf ihr Verhalten: "Du musstest vom Opferfleisch essen, weil wir nicht damit rausgerückt sind, dass du Vegetarier bist« ${ }^{615}$ Devrim findet allmählich zwar einen Umgang mit dem Herkunftsort seines Vaters und seinen Verwandten, doch ist und wird ihm dieser nicht zur Quelle einer Entdeckung, zur Ressource einer Identitätsfindung, die ihn in Deutschland besser ankommen lassen würde. Vielmehr wird ihm klar, dass er für Rüya, die sich so darüber freut, dass er ihrer beider Herkunftsort aufsucht, »jemanden spielt", der er nicht sein will. ${ }^{616}$ Auch seine deutsch-türkische Freundesclique ist nicht mehr das, was sie mal war bzw. das, was sie sich früher zu sein vorgestellt hatte. Früher wollten sie wie viele Akteure in den 1990er Jahren gemeinsam irgendwann ein »Haus am Meer« haben, an einem Strand im Süden, und jeden Tag per Münzwurf entscheiden, ob sie schwimmen gehen oder nicht. ${ }^{617}$ Doch Okan, der mittlerweile in Istanbul lebt und über den Berliner Kiez nur noch schlecht spricht, als Devrim ihn auf seiner Rückreise nach Berlin besucht, denkt nur noch an Geld und Ruhm. ${ }^{618}$ Devrim ist unendlich froh, als er zurück in Berlin ist. ${ }^{619}$ Ayatas Roman endet damit, dass Devrim wieder als Radiojournalist arbeitet.

Wie Güngörs Das Geheimnis meiner türkischen Großmutter endet auch Mein Name ist Revolution mit einer beruflichen Positionierung in der deutschen Gesellschaft. Allerdings hat die Protagonistin des ersten Romans die Herkunft ihrer Eltern und die kulturellen Folgen des Geheimnisses ihrer Großmutter gebraucht, um am Ende in Deutschland anzukommen; ein Narrativ, das in dieser Entschiedenheit weder in Calısss noch in Ayatas Roman eine Rolle spielt. Stattdessen stellt Devrim fest: »Meine Freunde, die mir eingeredet hatten, dass das Zusammensein mit einer Kanaklady anders, einfacher und besser sei, hatten sich getäuscht«. ${ }^{620}$

\footnotetext{
614 Ebd., S. 16.

615 AYATA (2011): S. 179.

616 Ebd., S. 176.

617 Ebd., S. 131.

618 Ebd., S. 228.

619 Ebd., S. 232.

620 Ebd., S. 303.
} 
Kultur ist keine bindende und verbindende Ressource mehr. Die Unterschiede gehen noch weiter: Am Ende des Romans besucht Devrim religiös-konservative Türken, die seinen Vater Ende der 1970er Jahre aufgrund seines Lottogewinns um eine Spende für ihre zu errichtende Moschee gebeten hatten. Sein Onkel und seine ganze Verwandtschaft sind immer linkspolitische Türken gewesen. Auch diese Suche führt in ein Unbehagen. Denn die Religiösen, die die Moschee auch ohne die finanzielle Hilfe seines Vaters bauten, erwecken bei Devrim den Eindruck, dass sie «zwielichtige Personen « seien, zu allem fähig. ${ }^{621}$ Am Ende des Romans beschreibt Devrim sich nicht als ein exkludiertes Individuum, sondern als ein »Alleiner«, der nicht mehr weiß, was er lebt. ${ }^{622}$

Am Ende des hoch gelobten Theaterstücks Verrücktes Blut von 2010 ruft der türkisch-kurdische Schüler Hasan mit einer Pistole in der Hand aus, dass die Rolle des deutsch-türkischen Tatort-Kommissars schon vergeben sei. ${ }^{623}$ Wohin solle man denn da noch aufsteigen. Als der Schüler dies ausspricht, haben die anderen schon abgewunken und erklärt, sie hätten nun keine Lust mehr auf dieses Theaterstück, darauf, `Kanaken`zu spielen bzw. das zu spielen, was die Deutschen in ihnen sehen wollen. Tatsächlich beginnt das Stück wie auch Selim Özdoğans Roman Die Tochter des Schmieds oder Holtz' Film MEINE VERRÜCKTE TÜRKISCHE HocHzEIT mit vielen Klischees. Im Unterschied zu Özdoğans Roman, Akıns oder Şamderelis Film ermöglichen diese Klischees aber kein gemeinsames Erzählen mehr. Zu Beginn des Stücks kommen sieben Heranwachsende, zwei Frauen und fünf Männer, auf die Bühne, d.h. in ihre Schulklasse. Sie stellen sich selbstbewusst auf und spucken mehrmals ins Publikum. Nur einer von ihnen hat keinen Migrationshintergrund. Danach beginnen alle laut und in Fäkalsprache mit ihren Handys zu telefonieren, man versteht kaum mehr als »Opfer« und »Fick Dich «. ${ }^{624}$

621 Ebd., S. 309.

622 Ebd., S. 315. In diese inhaltlich ausgerichtete Erzähllogik passt, dass Altan, ein anderer Freund Devrims, seine Dissertation zur Geschichte der Türken in Deutschland abbricht und seine »Kanakenlady« sich von ihm trennt. Tatsächlich baut Imran Ayata immer wieder Erinnerungen und Lebensumstände der Türken in der Bundesrepublik von den 1970ern bis heute ein. Sie folgen allerdings eher der Logik einer informellen Geschichte im Gegensatz zu einer Geschichte, auf der ein kollektives Gedächtnis im Sinne von Aleida Assmann basieren könnte. Berufe scheinen wichtiger zu sein als eine Aufarbeitung der Geschichte der Migration in der Bundesrepublik Deutschland.

623 Tatsächlich ermittelte Mehmet Kurtuluş, der Hauptdarsteller aus KURZ UND SCHMERZLOS, von 2008 bis 2012 als Hauptkommissar Cenk Batu im Hamburger Tatort. Dabei arbeitete er oft als verdeckter Ermittler, spielte auch gelegentlich einen Türkeistämmigen. Die ARD beschreibt Mehmet Kurtuluş als jemanden, für den sein Hintergrund keine Rolle spielte, nur die »die anderen waren es, die darauf reagierten«. Siehe hierzu: https://www.daserste.de/unterhaltung/krimi/ tatort/kommissare/mehmet-kurtulus-100.html (30.09.2018).

624 Siehe hierzu: ERPUlAT/HiLlJE (2012). 
Die Lehrerin, die eigentlich Kehlig heißt, nennen alle »Frau Kellesch $«{ }^{625}$ Sie tritt auf, bittet um Ruhe und kündigt an, dass es heute um Schillers Die Räuber und seine Ästhetische Erziehung gehe. Es bleibt aber so lange laut, bis eine Pistole bei einer Rauferei aus einer Tasche auf den Boden fällt. Frau Kehlig hebt sie auf und zwingt die Schüler damit zur Probe von Schillers Stück. Mit der Waffe in der Hand erläutert sie ihren Schülern, dass in der Ästhetischen Erziehung die Frage zentral sei, wie der Mensch dazu gebracht werden könne, verantwortlich mit seiner Freiheit umzugehen. „Durch das Spiel«, antwortet sie selbst, denn der Mensch sei nach Schiller nur da ganz Mensch, wo er spiele. ${ }^{626}$ Daraufhin verteilt sie die Rollen. Jeder Schüler bekommt ein gelbes Reclam-Heft und soll daraus die entsprechenden Passagen vorlesen. Am Anfang muss die Lehrerin fast jedes Wort korrigieren, weil Aussprache und alles andere bei den Schülern nicht stimmen. Dabei mutet sie - gerade auch wegen der Waffe in der Hand - in ihrem sprachlichen Purismus fundamentalistisch und kulturterroristisch zugleich an. Als die Schüler anfangen, ganze Sätze zu sprechen, ernten sie nur Demütigung: »Du kannst ja richtig Deutsch sprechen, Du Muschi«. ${ }^{627}$

Im Laufe des Stücks entwickeln sich die Schüler rhetorisch so weit, dass sie die Passagen aus Schillers Räuber auswendig und mit Inbrunst vortragen, sich mitunter sogar mit den gespielten Szenen identifizieren. Die Identifikation überrascht nicht so sehr wie der Umstand, dass sie beginnen, das Stück mit sprachlich überzeugender Performanz und Leben $\mathrm{zu}$ füllen. Unterbrochen wird dieses Schauspiel mehrmals durch den gemeinsamen Gesang von Lehrerin und Schülern, die ans Publikum gewandt deutsche Volkslieder wie Heimatland ade oder Ich habe mich ergeben mit Herz und Hand zum Besten geben. Am Ende erfahren die Schüler, dass Frau Kehlig/Kellesch tatsächlich aus der Türkei stammt, aber mit einem deutschen Mann verheiratet ist, dessen Nachnamen sie trägt. Hätten sie gewusst, dass sie »eine von ihnen« sei, beteuern die Schüler, hätten sie sich ihr gegenüber nie so verhalten, wie sie es getan haben. Als es darum geht, Musa zu verurteilen, weil er seinen Mitschüler Hasan, den kurdischstämmigen Deutschen, sexuell missbraucht hat, sind die Schüler gegen die von Kehlig empfohlene Todesstrafe. Wütend fragt sie: »Nerde sizin delikanlılığınız?« (»Wo ist euer feuriger jugendlicher Übereifer?«) ${ }^{628}$ Die Schüler sind durch die Gewaltandrohung

$\mathbf{6 2 5}$ Keleş (ausgesprochen: Kellesch) ist ein türkischer Nachname.

626 Ebd.

627 Ebd.

628 Damit nennt sie den Titel des Stückes, der - erneut - eine wörtliche Übersetzung aus dem Türkischen ist: »delikanli« heißt »verrücktes Blut«. Siehe hierzu: STEuERwALD, Karl (1993): Türkçe Almanca Sözlük, Istanbul: Novaprint Basım Evi, S. 210 u. S. 479. 
mit der Waffe zu überzeugten Aufklärern geworden. Im letzten Drittel des Stücks wird die freie Meinungsäußerung à la Voltaire zur politischen Diktion: »Ich bin nicht Deiner Meinung, aber ich würde mein Leben dafür geben, dass Du deine Meinung äußern kannst «. ${ }^{629}$ Als die Waffe in die Hände von Hasan gelangt, bittet er um Aufmerksamkeit. Doch seine Mitschüler haben »keinen Bock mehr auf dieses Spiel« und wollen jetzt lieber einen Döner essen. Hasan fragt dennoch, wie viele Erfolgskanaken dieses Land eigentlich noch vertrage, die Rolle des Tatort-Kommissars sei bereits vergeben. Auch die Lehrerin fragt nun, warum sie »diesen ganzen Scheiß hier « machen und zeigt dabei fragend auf das Publikum: »Für die hier?!« Hasan beendet das Stück mit den Worten »Herr muss ich sein, dass ich das mit Gewalt ertrotze, wozu mir die Liebeswürdigkeit gebricht «. ${ }^{630} \mathrm{Er}$ schießt in das Publikum und die ganze Gruppe auf der Bühne singt das Schlaflied Schlafe mein Kindlein, schlafe auch du. Für die Türken ergibt es keinen Sinn und macht auch keine Lust mehr, den Problemtürken oder den integrierten Türken zu spielen, denn die Möglichkeiten des Aufstiegs sind bereits vergeben.

Das Ende von VERRÜCKTES BLUT mag eine natürliche narrative Einheit suggerieren: Ein Tag beginnt morgens und endet mit dem Zubettgehen. Doch findet dieser Tag in einer Problemklasse in einer Brennpunktschule statt. Und tatsächlich waren die Regisseure nicht darauf aus, den Zuschauern die Realität aufzuzeigen, sondern wollten vielmehr ihre eigenen Vorstellungen von den Problemklassen in Brennpunktschulen vorführen. Das kämpferische Spiel im Spiel, das nicht erzieht, sollte den fiktionalen Charakter deutlich machen. Eine Transparenz von innen nach außen gibt es hier nicht. ${ }^{631}$ Sie wird auch gar nicht benötigt, da die Geschichte der türkischen Migration nach Deutschland und ihre Folgen als kulturelles und überall erkennbares Material so gängig geworden sind, dass man kein Türke mehr sein muss, um sich wie einer zu verhalten. Götz aus MEINE VERRÜCKTE TÜRKISCHE HOCHZEIT kann deshalb Aylin fragen, ob sie sich denn

\footnotetext{
629 ERpulat/Hillje (2012).

630 Siehe hierzu: ERPUlat/Hillje (2012).

631 Peter von Becker schreibt, dass statt »ideologischem Krampf ein spielerischer Kampf« das Stück von Erpulat auszeichne. Es werde ein Panorama der Stereotypen und Klischees mit einem Migrationsvordergrund geschaffen. "Doch im Laufe der folgenden Schulstunde werden dann alle Urteile und Vorurteile, alle vermeintlichen Sicherheiten oder als unvermeidlich geltende Unsicherheiten über den Haufen gestoßen. Das festgefügte Bild über Integration oder Desintegration in unserer Gesellschaft explodiert. Der Scherbenhaufen aber steckt voller Gedankensplitter, die in den Köpfen und Herzen der Beteiligten, auch der Zuschauer, hängen- und steckenbleiben.« Siehe hierzu: BECKER, Peter von (2012): „Verrücktes Blut. Ein spannungstoller Sieg im Schulklassenkampf«. In: Verrücktes Blut, von Nurkan Erpulat und Jen Hillje, Berlin: belvedere edition $\mathrm{GmbH}$.
} 
wie eine Türkin verhalten würde, wenn er den Türken spielt. Das Türkische wird für die Türken zu einer entscheidenden Kategorie, die nicht mehr innen liegt, sondern außen produziert wurde und verteidigt werden muss. Die Produktion der Vielfalt, wie sie in den 2000er Jahren einsetzt, kommt daher ohne Herkunft aus, leitet sich jedoch aus der Teilhabe im öffentlichen Raum ab. Diese Bedingungen haben ohne die Kultur der Multikulturalisten eine politische multikulturelle Gesellschaft geschaffen, die Zusammenhalt entweder nur durch ein Weitersprechen und Weitererzählen sichern kann oder aber sich in Spaltungen, Diskriminierungen und Selbstgesprächen verliert. Es macht sich eine binäre Logik breit, die nur noch die Zustände des Verknüpftseins oder des Getrenntwerdens kennt. Bei Letzterem ist der Konnex von Diskriminierung, Trennung und Selbstgespräch, wie ich ihn bereits für die Erzählung und Reflexionen in den 1980er Jahren beschrieben habe, in den ästhetischen Produktionen der letzten Jahre ebenfalls konstitutiv. Auch die Klasse in Verrücktes Blut bewegt sich in einem geschlossenen und sogar schalldichten Raum und wir sehen keinen der Schüler das Zimmer verlassen.

Dieser erzählerische Zusammenhang wiederholt sich in der Geschichte der Migration in der Bundesrepublik, nur dass er sich von den türkischen Wohnungen hin zu öffentlichen Orten verschoben hat - von Berliner und Hamburger Hinterhofwohnungen in die Schulklassen. Aktuell korreliert er mit einer Rückkehr nationaler Narrative. Im Unterschied zu den 1980ern hat sich jedoch die Bedeutung, Verwendung und der Gebrauch der Historie und der kulturellen Marker verändert. In den 1980er Jahren bestimmten Deutsche wie Türken die Türkei als einen Ort der Rückkehr oder als einen Ort des Ursprungs kultureller Probleme, von Gastfreundschaft und Sinnlichkeit. Die derartige Auslagerung von Orientierungen, Wünschen und Frustrationen ermöglichte auch ein Hinausgehen, von »drinnen « nach »draußen « zu gelangen. Diese Option gibt es heute nicht mehr. Als Folge können Interaktionen und Begegnungen zwischen Deutschen und Türken weitaus belasteter sein als noch in den 1980er Jahren. Allein weil es an Ausweichmöglichkeiten mangelt: »Man kann sich nicht mehr ausweichen, steht einander gegenüber, auf einmal nicht mehr auf dem Schlachtfeld, sondern in einem Klassenzimmer mitten im öffentlichen Raum einer offenen Gesellschaft», konstatiert Zafer Şenocak lapidar in Das Fremde, das in jedem wohnt. Wie Unterschiede unsere Gesellschaft zusammenhalten von 2018.632 Daher wird die Frage nach der Geschichte vor Ort und in der Bundesrepublik und nach den Schichten im Leben der Akteure zentral; die Frage danach, ob wir es in den unterschiedli-

632 ŞENOCAK, Zafer (2018): Das Fremde, das in jedem wohnt. Wie Unterschiede unsere Gesellschaft zusammenhalten, Hamburg: Körber Stiftung, S. 213f. 
chen Begegnungskonstellationen mit einer angestauten gemeinsamen Historie oder einer zusammengewachsenen zu tun haben? Erstere Konstellation vollzieht sich in einer Form der doppelten Schließung, wie sie sich bereits in den Werken VerrüCKtes Blut, Der Mond ist unsere Sonne und Mein Name ist Revolution andeutet. Letztere Konstellation steht für eine Perspektive, die über das Weitersprechen den Wandel der Geschichte der Migration und ihrer Folgen sichtbar macht, die aufzeigt, in welch komplexen Verhältnissen Deutsche und Türken von den 1960er Jahren bis heute zueinandergestanden haben.

Doch ob zusammengewachsene oder angestaute Geschichte, in jedem Fall ist die kulturpolitische Konstellation - ob im Selbstgespräch oder im Weitersprechen - prekär und von einer neuen Betroffenheit bestimmt. Dies zeigen auf der einen Seite eindrücklich neuere Texte und Filme wie Feridun Zaimoğlus Migrationsepos Siebentürmeviertel (2015), Ruhm und Ruin von Imran Ayata (2015), Wieso Heimat, ich wohne zur Miete von Selim Özdoğan (2016), Fatma Aydemirs Roman Ellbogen (2017) sowie 3 TÜRKEN UND EIN BABY von Sinan Akkuş (2015), PLÖTZLICH TÜRKE von Isabel Braak (2016), Züli Aladağs Dokudrama DIE OPFER. VERGESST MICH NICHT, der zweite Teil der ARD-Trilogie MitTen In Deutschland: NSU (2016), Fatih Akıns Aus DEM NicHTs (2017), Dilek Güngörs Roman Ich bin Özlem (2019) und die autobiografisch gefärbten Streitschriften und Studien Ihr Scheinheiligen (2018) von Tuba Sarica, Eure Heimat ist unser Albtraum (2019) von Hengameh Yaghoobifarah und Fatma Aydemir und Das ist auch unser Land (2020) von Ciğdem Toprak. Auf der anderen Seite reagieren die genannten Produktionen auf und verarbeiten eine politische Entwicklung, die sich von der Sarrazin-Debatte, der Aufdeckung der NSU-Morde im November 2011 über die Gezi-Proteste in der Türkei 2013, das Aufkommen der PEGIDA im November 2014 in Dresden, die Flüchtlingskrise von 2015, den versuchten Militärputsch in der Türkei 2016 bis zum Verfassungsreferendum im Jahr 2017, die Einrichtung einer Abteilung für Heimat im deutschen Innenministerium und ihrer Umbenennung zum Bundesministerium des Inneren, für Bau und Heimat im März 2018 bis zu den Anschlägen in Halle und Hanau vom Oktober 2019 und Februar 2020 erstreckt. Allein die Auflistung der politischen Themen, die verhandelt werden, deutet eher auf eine Politik der Zusammengehörigkeit hin als auf eine der getrennten Identitäten. Allerdings handelt es sich um eine Zusammengehörigkeit, deren bindende Narrative noch ausstehen. Denn alle bisherigen Medien der Migration und Integration von der Attraktivität, der Sogkraft des Westens in den 1960er Jahren über das Verorten und Verstehenwollen der anderen Kultur in den 1980er Jahren bis hin zum körperlichen Auftritt, den symbolischen und emanzipatorischen Aneignungen im öffentlichen Raum in den 1990er Jahren und den Praktiken im öffentlichen Raum in den 2000er Jahren, sind aktuell ins Stocken geraten. Das Themenspektrum von den NSU-Morden bis zum versuchten Militärputsch in der Türkei lässt ein neues 
»Zwischen den Kulturen«, zwischen den Ländern, zwischen den Gesellschaften vermuten, dessen Grundlagen, wie die vorliegende Kulturgeschichte gezeigt hat, nicht mehr verschiedene Kulturen sind und auch nicht sein können. Vielmehr hat das bisherige Fehlen einer formellen Kulturgeschichte der Migration in der Bundesrepublik dazu geführt, dass das soziale, aber auch kulturell zusammengewachsene deutsch-türkische Verhältnis ausgeblendet und getrennt wird. Aufgrund dieses nicht in der Kontinuität ihrer Geschichte wahrgenommenen Realitätsunterbaus schlägt die informelle Geschichte der Migration und Integration in der Bundesrepublik aktuell in Literatur, Film und in politischen Konflikten auf eine Art und Weise zurück, deren Medium nicht mehr ein sozialstruktureller Aufstieg oder ein in sich ruhendes Kulturbewusstsein ist. Es sind Affekte, die ein neues kulturelles Unbehagen ausdrücken. Sie treten an die Stelle der Emotionen, die für die 1980er Jahre bestimmend waren.

Nach klassischer psychoanalytischer Interpretation besteht eine enge Korrelation zwischen Affekten und Emotionen, die sich jedoch auch wesentlich unterscheiden: Affekte gehen den Emotionen voraus. Denn unter Affekt wird eine körperliche Reaktion »ohne bewusste Repräsentanz und Erleben des Affekts« verstanden. ${ }^{633}$ Bei Emotionen geht man umgekehrt von bewussten Wahrnehmungen und Erlebnissen aus. Weil eine klare Wahrnehmung und Positionierung des Selbst, der Situation und des Anderen bei Affekten fehle, stellten sie auch »kein psychologisches Ereignis « dar. ${ }^{634}$ Man könnte verkürzt auch sagen, Affekte sind im Unterschied zu Emotionen blind. Diesen besonderen Aspekt des Affekts hält auch der kanadische Philosoph Brian Massumi fest. Im Zentrum steht bei ihm wie bei Freud und Spinoza der Körper in »Bezug auf sein Vermögen, zu affizieren und affiziert zu werden «. ${ }^{635} \mathrm{Zu}$ den Primäraffekten werden Freude, Verzweiflung, Wut, Furcht, Ekel, Überraschung und Interesse gezählt; zu den Gefühlen Scham, Schuld und Verachtung, die aus einer Selbstreflexivität und Beobachtung resultieren. ${ }^{636}$ Dagegen sind Affekte nach klassischer Lesart »körperlich begründete Reaktionssysteme«. Ihre Grundlagen sind nach Freud körperlich-motorische, die sich aus zwei Abläufen zusammensetzen. »Ein Affekt umschließt erstens

633 LeXIKon DER Psychologie (2000): »Affekt«. In: Spektrum Akademischer Verlag, Heidelberg, https://www.spektrum.de/lexikon/psychologie/affekt/261 (27.03.2019).

634 DöLL-HenschKer, Susanne (2008): »Psychoanalytische Affektheorie(n) heute. Eine historische Annäherung«. In: Psychologie in Österreich 5. Themenschwerpunkt der Emotionen, Wien: Österreichische Akademie für Psychologie, S. 446-455, S. 451.

635 Massumi, Brian (2010): Ontomacht. Kunst, Affekt und das Ereignis des Politischen, Berlin: Merve, S. 27.

636 Siehe hierzu: DöLL-HENSCHKER (2008). 
bestimmte motorische Innervationen oder Abfuhren, zweitens gewisse Empfindungen [...] zweierlei Art«; erstens die Wahrnehmung der »motorischen Aktionen « und die »direkten Lust- und Unlustempfindungen, die dem Affekt [...] den Grundton geben «. ${ }^{637}$ Doch trotz dieser Körperlichkeit und Reaktionsbestimmtheit ist der Affekt im Kern nicht einfach eine körperliche Reaktion. Wenn wir tiefer blicken, erkennen wir nach Freud, »dass der Kern [des Affekts], welcher das genannte Ensemble zusammenhält, die Wiederholung eines bestimmten bedeutungsvollen Erlebnisses ist «. Im Unterschied zu den Trieben, die »als Kräfte des Es kontinuierlich und rhythmisch fließen, handelt es sich bei Affekten [...] um ererbte Antworten «. ${ }^{638}$ Freud konstatiert neben der äußerst körperlichen Dimension der Affekte, dass sie der »Niederschlag einer Reminiszenz« seien, die auf eine »Vorgeschichte« zurückgehe. ${ }^{639}$ In der Forschung werden sie zudem in drei Gruppen unterteilt: Information verarbeiten die Affekte »Interesse« und »Überraschung «. Als Bindungsaffekte gelten »Trauer« und »Freude«. Die letzte Gruppe unterbricht schließlich unerwünschte Aktivitäten, die auf den Affekten »Wut«, »Angst« und »Ekel« beruhen. Mehr als die Emotionen sind es in der aktuellen Literatur die Affekte, die darüber entscheiden, ob weiter oder nicht weitergesprochen wird, ob Interesse oder Überraschung (Information), Trauer oder Freude (Bindung) oder schließlich doch Wut, Angst und Ekel (Unterbrechung) überwiegen. ${ }^{640}$ Dilek Güngörs Reaktion im Bioladen im Jahr 2016 ist mehr eine affektive, denn eine emotionale Reaktion. Ihr fehlt die symbolische Repräsentation, das bewusste Erleben und die Bestimmung ihrer Gefühle. Ausführlicher geht sie auf diese Konstellation in ihrem Roman Ich bin Özlem ein. ${ }^{641}$ Die Begriffe »Ausländer « oder »Brennpunktschule« lösen dort den »Niederschlag einer Reminiszenz« aus und lassen die Reaktionen der Protagonistin wie eine geerbte Antwort wirken, denn sie begreift sich in einem historischen Zusammenhang - »hört es denn niemals auf « - als Teil eines Kollektivs. ${ }^{642}$ Bei Güngör ist es eine Wut, die aus den Untiefen der deutschen Migrationsgeschichte in den Alltag vordringt. Denn sie ist jetzt wieder eine Ausländerin, der ihr bisheriges Leben als Deutsche und deutsch-

637 FREUd, Sigmund (2009): »Die Angst«. In: ders.: Vorlesungen zur Einführung in die Psychoanalyse, Frankfurt a. M.: Fischer, S. 375-392, S. 378.

638 DöLL-HENSCHKER (2008): S. 447.

639 FREUd (2009): S. 378.

640 Auch in Massumis aktuellen Reflexionen sind Wut und Angst Affekte der Unterbrechung. Sie sind negativ, weil sie den in der Situation »stattfindenden Bedeutungsfluss [...] unterbrechen: die stattfindenden, normalisierten Wechselbeziehungen und Interaktionen und die zu erfüllenden Aufgaben«. MAssumi (2010): S. 32.

641 Siehe hierzu: GÜNGÖR (2019).

642 Ebd., S. $95 f$. 
sprachige Journalistin eigentlich widerspricht. Daher kann sie diesen Affekt weder mit ihrer sozialstrukturellen Aufstiegsgeschichte filtern noch durch die Tatsache, dass sie in Wirklichkeit gar nicht angesprochen wurde. Dieser Zustand verhindert Weitersprechen und Interaktion. Er setzt dagegen eine Dynamik der Schließung, die die Interaktion unterbricht und die erst im Selbstgespräch auf der Straße endet.

Auch aktuelle theoretische Reflexionen und publizistische Interventionen zu Postmigration, neuere Aufladungen und Bestimmungen des Begriffs »Integration « mit und nach der Flüchtlingskrise von 2015 schließen an die hier aufgezeigten Entwicklung vom Weitersprechen als Verknüpfung, Verbindung zu Selbstgesprächen als Trennung und Bruch an, ohne aber dabei ihre Spannung, ihre prekäre Konstellation, ohne letztlich ihre Herkunft zu reflektieren und damit auch zu kritisieren. Die politische Hauptdiktion der Postmigration lautet: die vielfältige von Diversität geprägte Gesellschaft anzuerkennen, sie Teil beruflicher und politischer Entscheidungen werden zu lassen und schließlich sie als Ausgangspunkt zukünftiger Politik zu begreifen. Auf die Fragen aber, wie sie genau $\mathrm{zu}$ dieser Gesellschaft geworden ist, die sie heute ist, was ihre Grundlagen, im Besonderen die Grundlagen der Affekte sind, werden wie in den großen historischen und politischen Arbeiten zur Geschichte der Bundesrepublik und auch in rezenten Publikationen zur Postmigration oder Migrationsgesellschaft keine befriedigenden Antworten gegeben. ${ }^{643}$ Mehr noch: das Gespräch wird mitunter verweigert oder nicht mehr weitergeführt, wenn Fragen nach der Herkunft gestellt werden. ${ }^{644}$ Beispielsweise leitet die Kulturwissenschaftlerin und Journalistin Mithu Sanyal ihren Beitrag Zuhause in Eure Heimat ist unser Albtraum mit den Worten ein, »inzwischen sollte auch dem Letzten klar sein, dass >Wo kommst du eigentlich her? « ein No-Go ist «. ${ }^{645}$ In einem vergleichbaren Sinne konstatierte der Gestalter unserer Ausstellung Das neue Deutschland. Von Migration und Vielfalt im Deutschen Hygiene Museum in Dresden bei deren Eröffnung am 8. März 2014, dass Deutschland ein Einwanderungsland geworden sei und dass man über dieses Faktum nicht mehr zu sprechen brauche. Wie naiv und unbedacht diese Aussagen waren und sind, und wie wichtig es doch ist, zu verstehen, dass die ersten Migranten der 1960er Jahre (wie Deutsche damals auch) Amerikaner werden oder sie zumindest spielen wollten, sich heute aber wieder, nachdem

643 Siehe hierzu: Wolfrum (2006); WeHLER (2008); SChILDT (2009); SCHMidT (2011); TREIBEL (2015); MÜNKLER/MÜNKLER (2016); ForoutAN (2019); PlAMPER (2019).

644 Siehe hierzu: Treibel, Annette (2015): Integriert euch! Plädoyer für ein selbstbewussteres Einwanderungsland, Frankfurt a. M.: Campus, S. 11-13.

645 SANYal, Mithu (2019): »Zuhause«. In: Eure Heimat ist unser Albtraum, Berlin: Ullstein, S. 101-121, S. 101. 
sie in den 2000er Jahren Deutsche wurden, wieder als Türken oder People of Color (PoC) begreifen, zeigen die aktuellen gesellschaftspolitischen Entwicklungen. Nur einen Monat nach dem Ausstellungsende im November 2014 setzten in Dresden die PEGIDA-Märsche ein. Seitdem erleben wir politische Entwicklungen, die erneut das verschieben, was gesehen und was nicht gesehen wird. 